Universidad de Lima

Facultad de Ingeniería Industrial

Carrera de Ingeniería Industrial

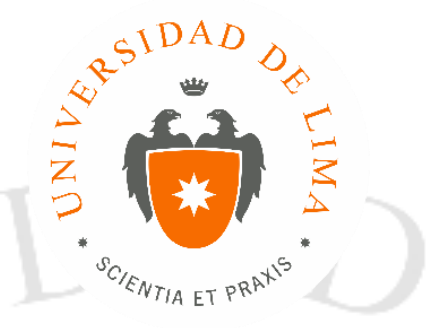

\title{
ESTUDIO DE PRE-FACTIBILIDAD PARA LA INSTALACIÓN DE UNA PLANTA PRODUCTORA DE HILOS DE CALIDAD ELABORADOS CON ALGODÓN NATIVO DE COLOR
}

Trabajo de investigación para optar el título profesional de Ingeniero Industrial

\author{
Ludwig Nick Declercq Pedraza
}

Código 20090327

\author{
Asesor \\ Ruth Vásquez Rivas Plata
}

Lima - Perú

Octubre del 2016 


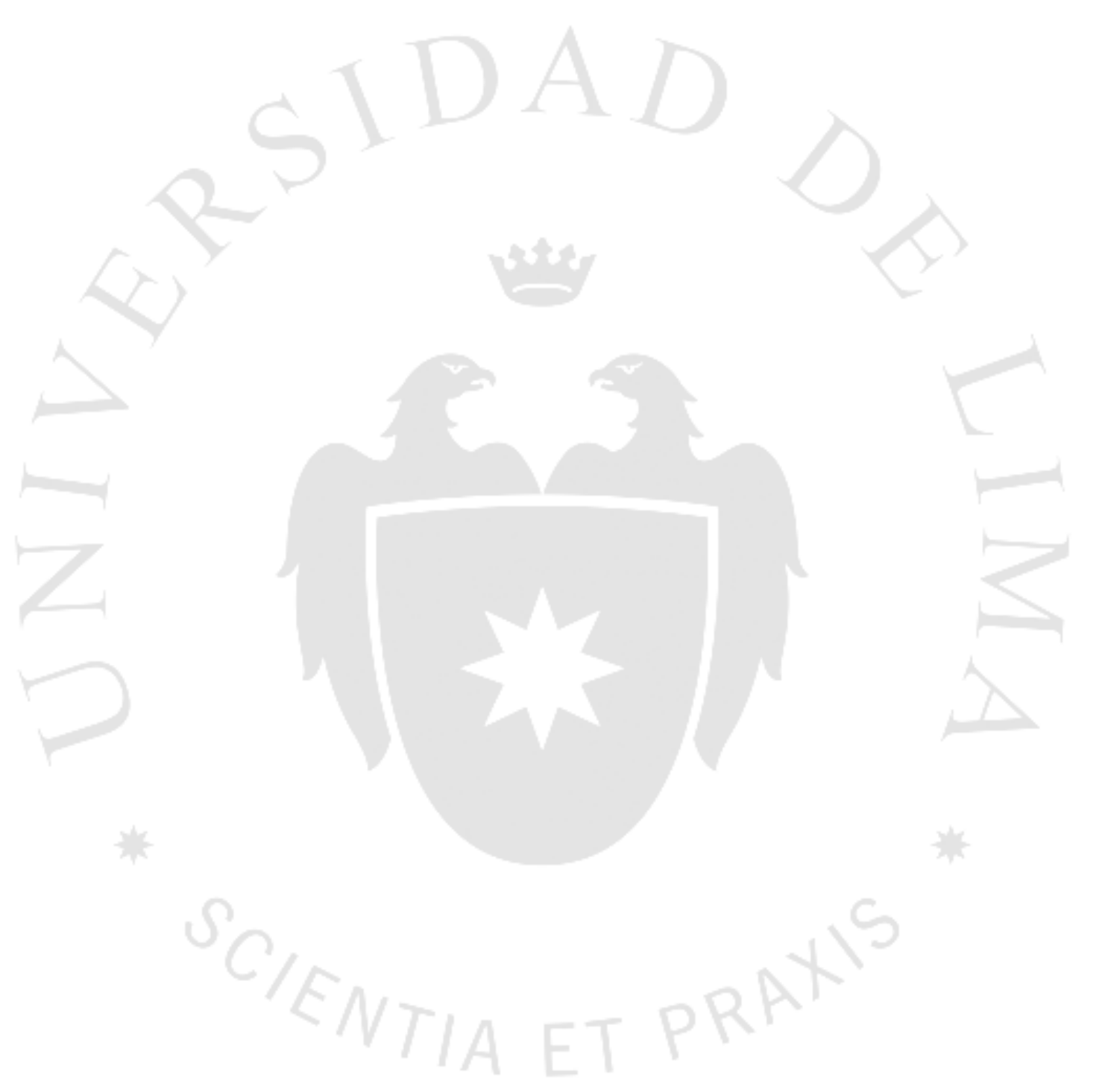




\section{ESTUDIO DE PRE-FACTIBILIDAD PARA LA}

INSTALACIÓN DE UNA PLANTA PRODUCTORA

DE HILOS DE CALIDAD ELABORADOS CON ALGODÓN NATIVO DE COLOR 


\section{TABLA DE CONTENIDO}

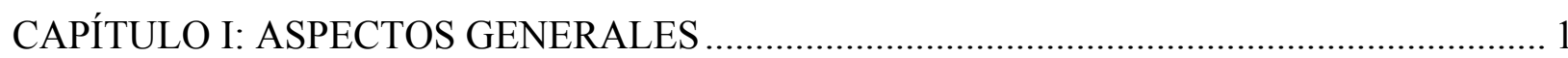

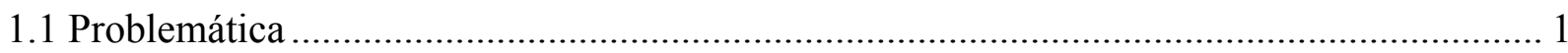

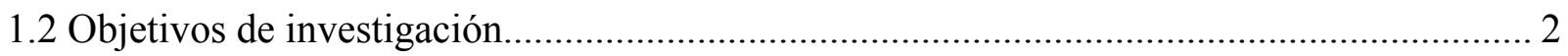

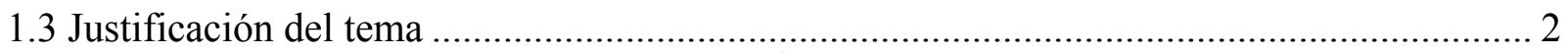

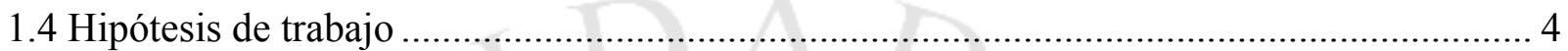

1.5 Marco referencial de la investigación........................................................................ 4

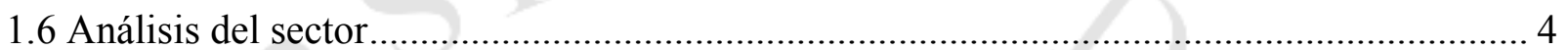

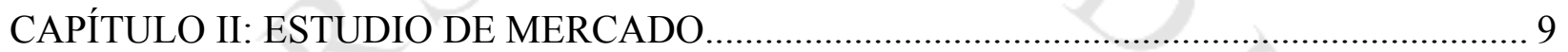

2.1 Aspectos generales del estudio de mercado ................................................................ 9

2.1.1 Definición comercial del producto …............................................................. 9

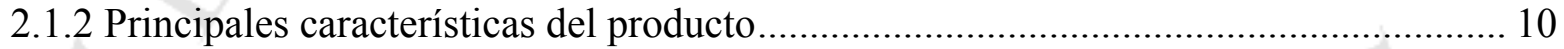

2.1.3 Determinación del área geográfica que abarcará el estudio .................................... 16

2.1.4 Determinación de la metodología que se empleará en la investigación de mercado ... 17

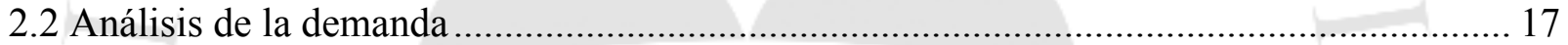

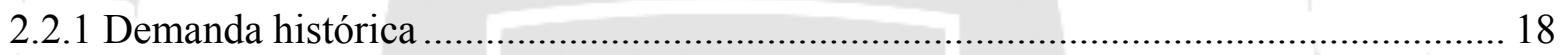

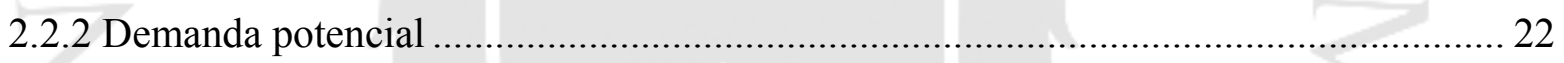

2.2.3 Proyección de la demanda y metodología de análisis ............................................ 27

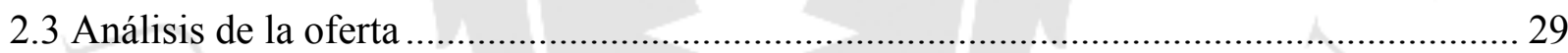

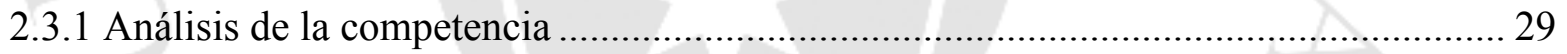

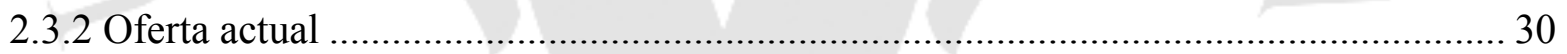

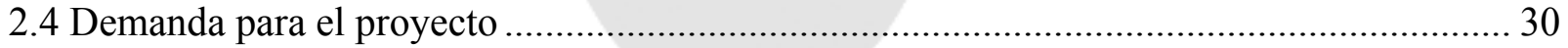

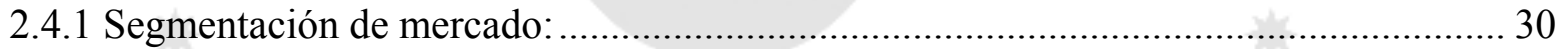

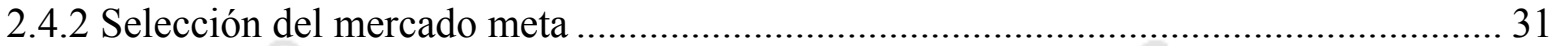

2.4.3 Determinación de la demanda para el proyecto................................................... 31

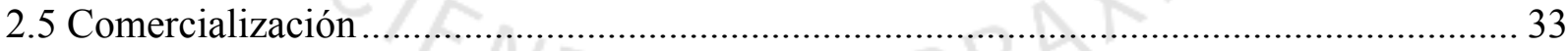

2.5.1 Políticas de comercialización y distribución ........................................................ 33

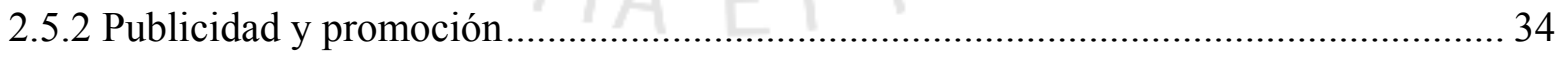

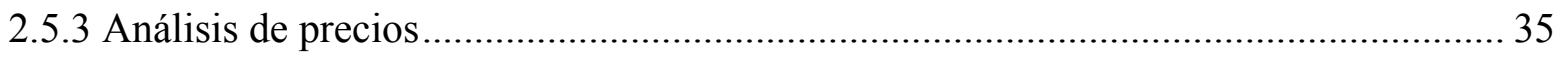

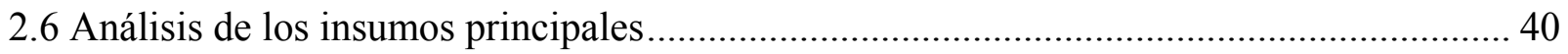

2.6.1 Características principales de la materia prima ................................................... 39

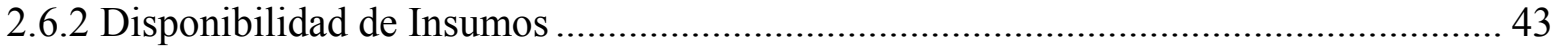

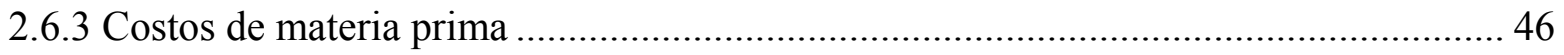

CAPÍTULO III: LOCALIZACIÓN DE PLANTA ................................................................ 48 
3.1 Identificación y análisis detallado de los factores de localización .................................. 48

3.2 Identificación y descripción de las alternativas de localización.................................... 50

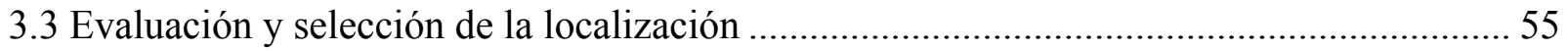

3.3.1 Evaluación y selección de la macro localización ................................................. 55

3.3.2 Evaluación y selección de micro localización......................................................... 57

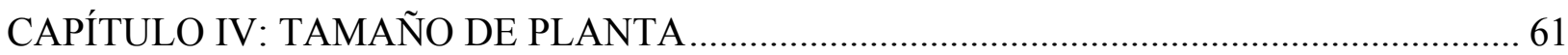

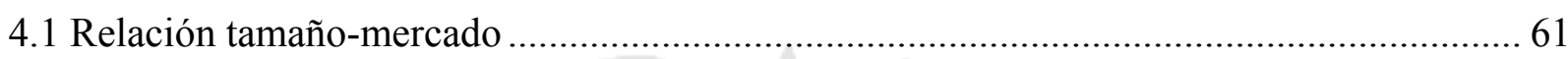

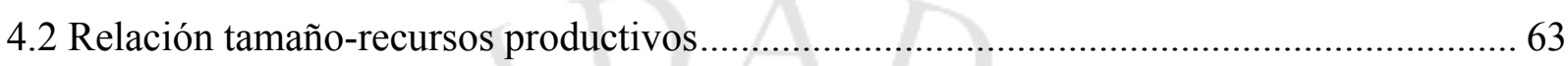

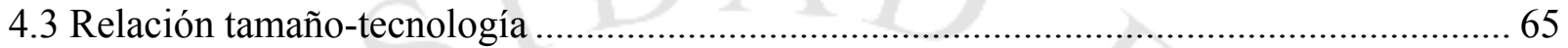

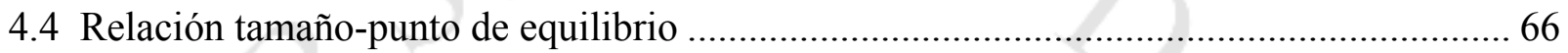

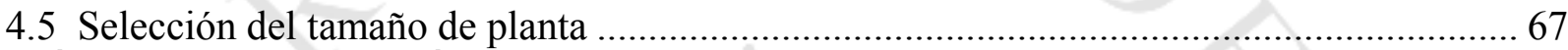

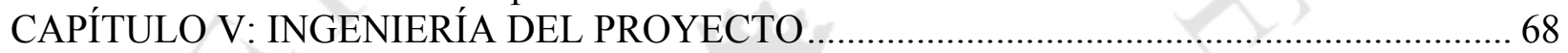

5.1 Definición del producto basada en sus características de fabricación ............................. 68

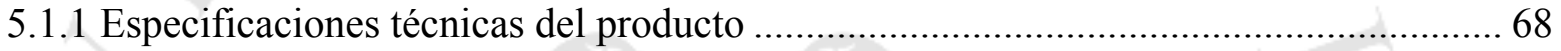

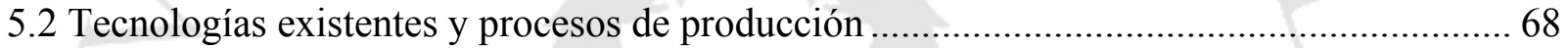

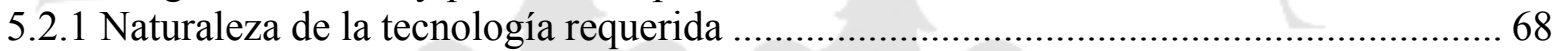

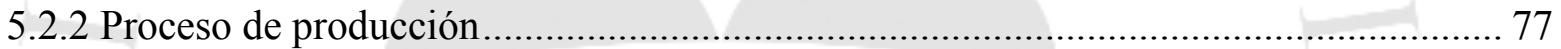

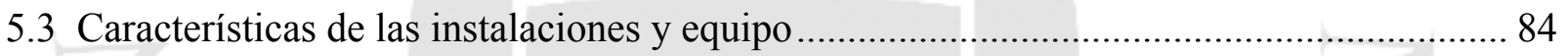

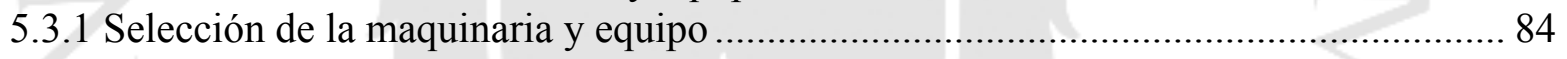

5.3.2 Especificaciones de la maquinaria................................................................... 85

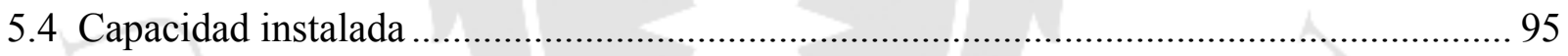

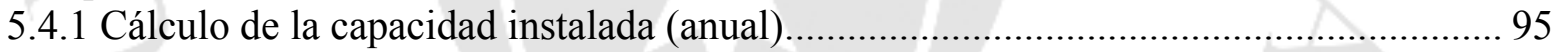

5.4.2 Cálculo detallado del número de máquinas requeridas ........................................... 98

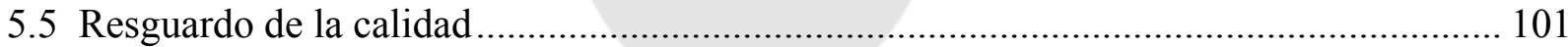

5.5.1 Calidad de la materia prima, de los insumos, del proceso y producto ...................... 101

5.5.2 Medida de resguardo de la calidad en la producción............................................... 106

5.6 Estudio de Impacto Ambiental ............................................................................... 108

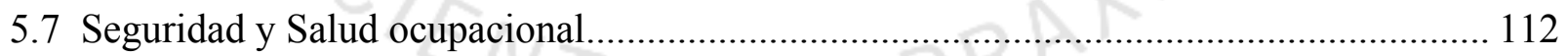

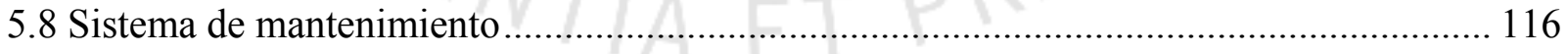

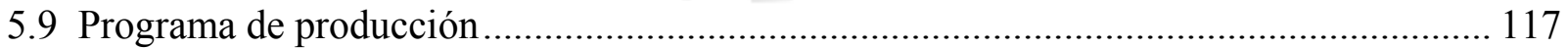

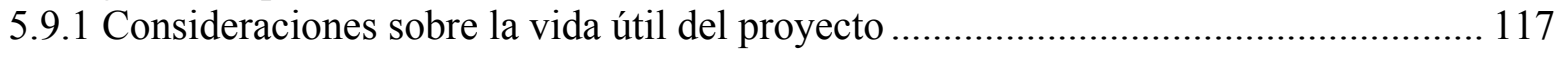

5.9.2 Programa de producción para la vida útil del proyecto ......................................... 118

5.10 Requerimiento de insumos, servicios y personal....................................................... 119

5.10 .1 Materia prima, insumos y otros materiales..................................................... 119

5.10.2 Servicios: energía eléctrica, agua, vapor, combustible..................................... 121

5.10.3 Determinación del número de operarios y trabajadores indirecto ........................... 123 


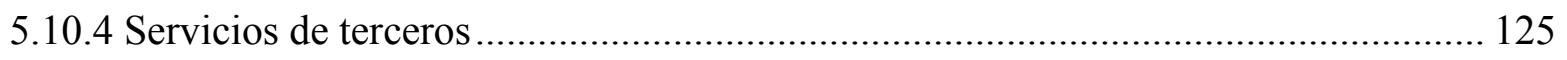

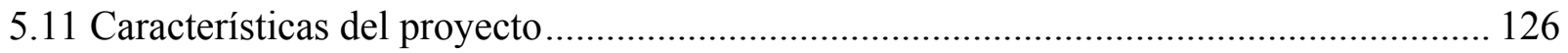

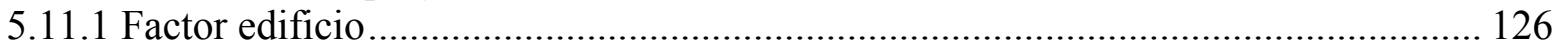

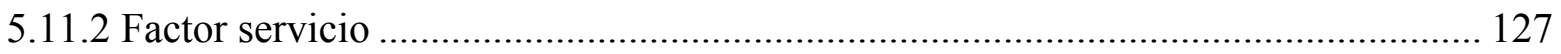

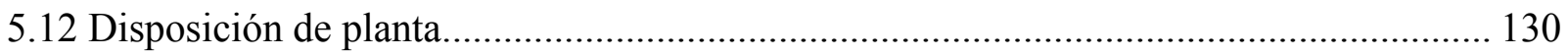

5.12.1 Determinación de las zonas físicas requeridas ................................................... 130

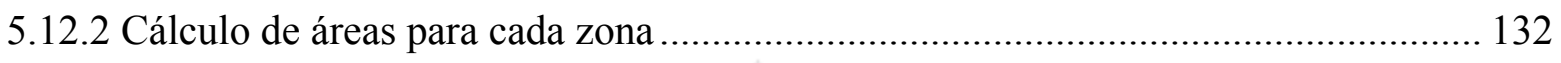

5.12.3 Dispositivos de seguridad industrial y señalización .............................................. 136

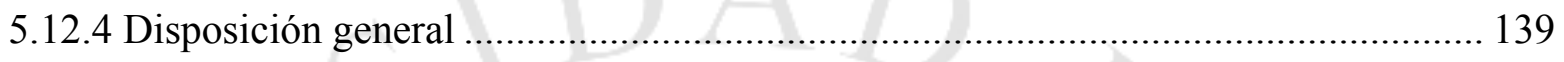

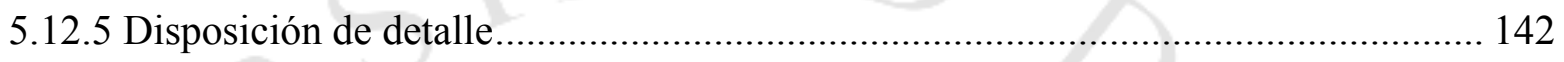

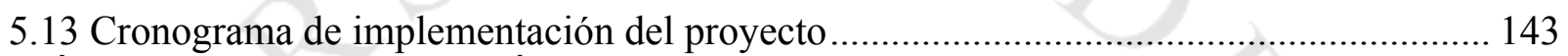

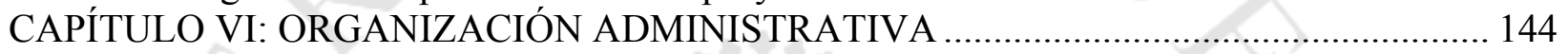

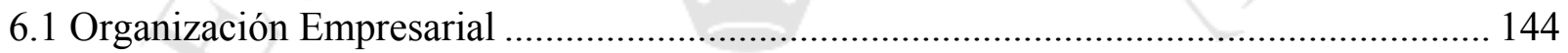

6.2 Requerimientos de personal directivo, administrativo y de servicios ............................. 144

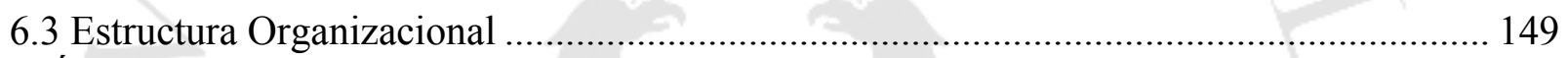

CAPÍTULO VII: ASPECTOS ECONOMICOS Y FINANCIEROS ........................................ 150

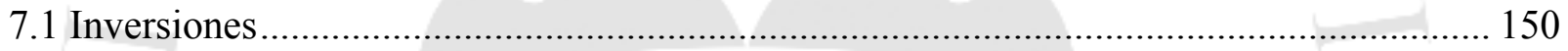

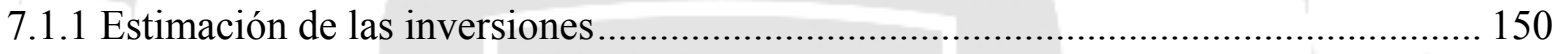

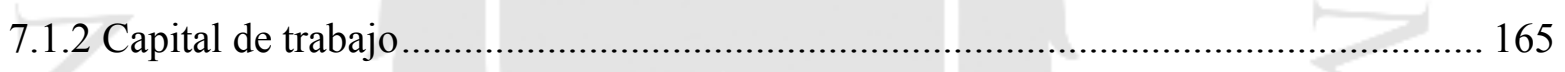

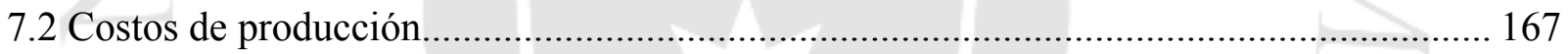

7.2.1 Costo de materias primas, insumos y otros materiales ................................................ 167

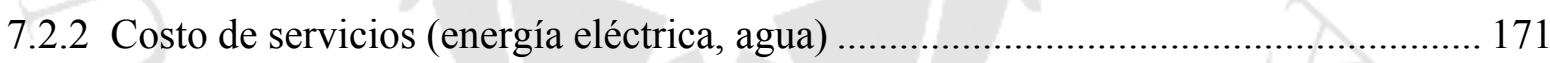

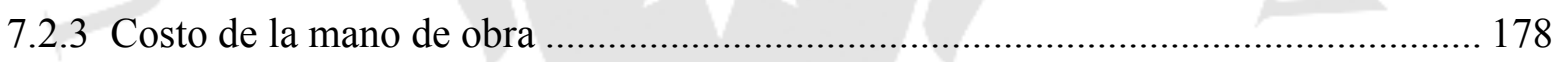

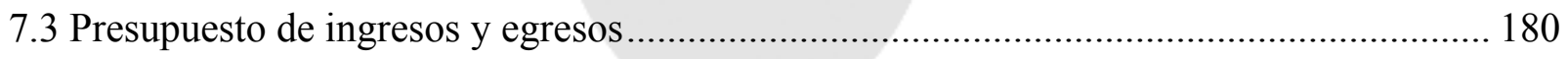

7.3.1 Presupuesto de ingresos por ventas .................................................................... 180

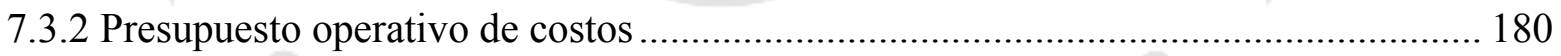

7.3.3 Presupuesto operativo de gastos administrativos ..................................................... 184

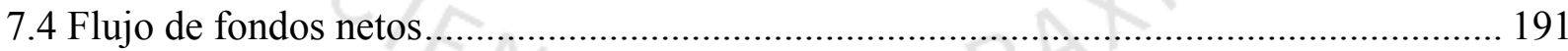

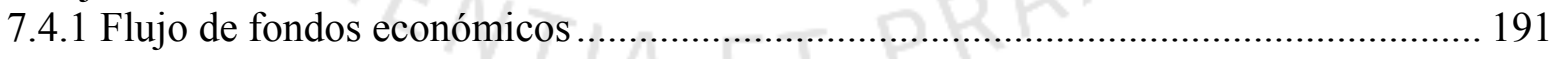

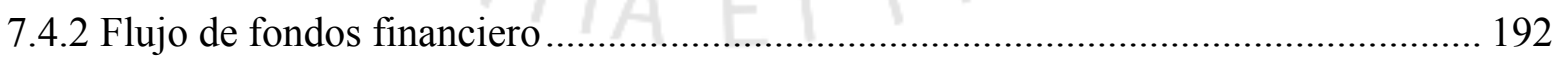

CAPÍTULO VIII: EVALUACIÓN ECONÓMICA Y FINANCIERA DEL PROYECTO ........ 199

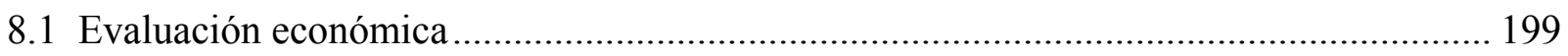

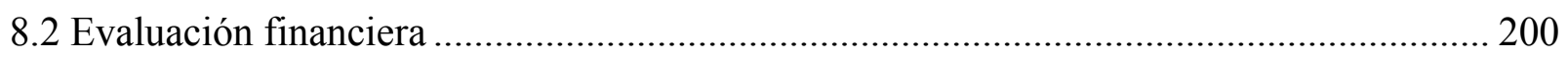

8.3 Análisis de los resultados económicos y financieros del proyecto ...................................... 201

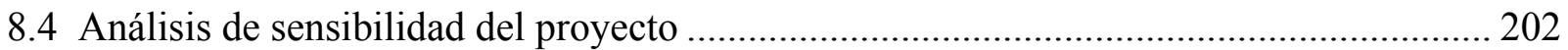

CAPÍTULO IX: EVALUACIÓN SOCIAL DEL PROYECTO ……………………................... 208 
9.1 Identificación de las zonas y comunidades de influencia del proyecto .......................... 208

9.2 Impacto en la zona de influencia del proyecto ........................................................... 209

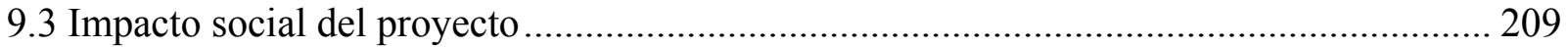

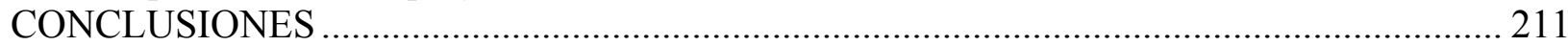

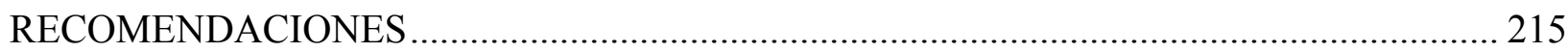

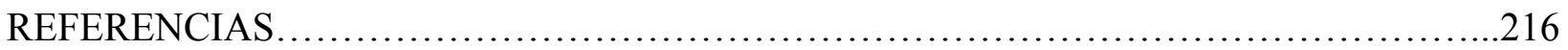

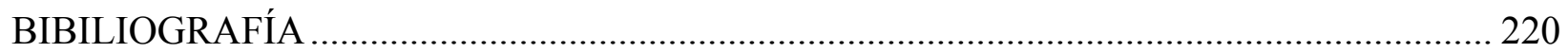

ANEXO: Estudio de mercado de la demanda de hilo de algodón nativo de color ................... 2221 


\section{ÍNDICE DE TABLAS}

Tabla 2.1. Rango de título para determinadas prendas de vestir .......................................... 11

Tabla 2.2. Análisis de las fibras de algodón nativo de color y Tangüis .................................. 12

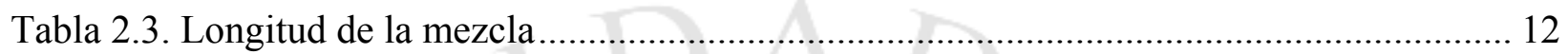

Tabla 2.4. Análisis de densidad lineal ........................................................................................... 13

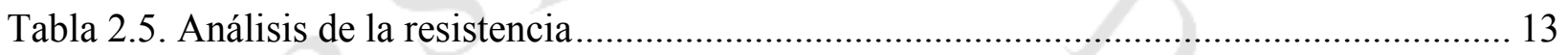

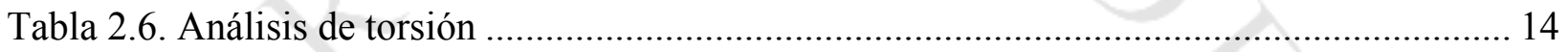

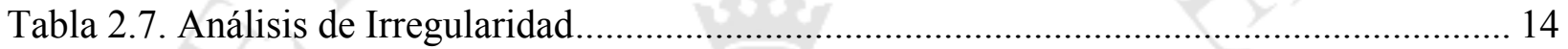

Tabla 2.8. Producción anual en TM de hilos de algodón nativo de color................................... 20

Tabla 2.9. Producción industrial de la mezcla entre algodón nativo de color y algodón Tangüis

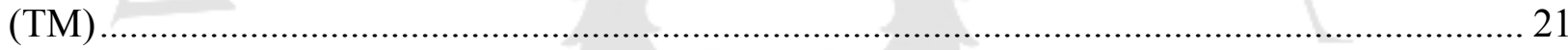

Tabla 2.10. Demanda interna aparente en TM de hilo de algodón nativo de color.................... 21

Tabla 2.11. Demanda interna aparente en TM de hilo de algodón nativo de color y algodón

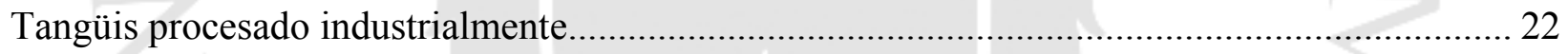

Tabla 2.12. Demanda interna aparente en TM de hilo de algodón ......................................... 22

Tabla 2.13. Población del segmento del adulto joven de Lima ............................................. 23

Tabla 2.14. Población de adultos jóvenes por segmento socioeconómico (miles de habitantes). 23

Tabla 2.15. Lugares donde se compran prendas de vestir por NSE ...................................... 24

Tabla 2.16. Frecuencia de compra de ropa de los jóvenes adultos (\%) ................................... 24

Tabla 2.17. Gasto promedio mensual en vestido y calzado por NSE ..................................... 25

Tabla 2.18. Fábricas textiles que elaboran tela Premium ........................................................ 27

Tabla 2.19. Demanda interna aparente de hilo de algodón nativo de color y algodón Tangüis ... 28

Tabla 2.20. Proyección de la demanda interna aparente........................................................ 29

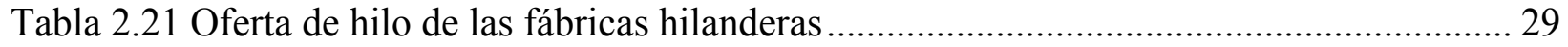

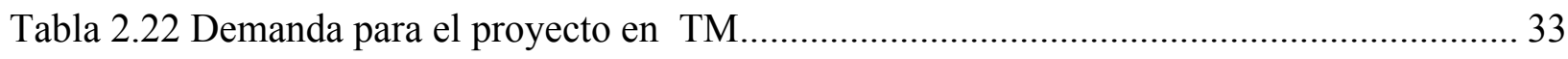

Tabla 2.23. Precio histórico de hilo de algodón Tangüis (en dólares)...................................... 35

Tabla 2.24. Precio histórico de hilo de algodón Pima (en dólares) .......................................... 36

Tabla 2.25. Costo variable unitario del hilo de algodón nativo de color ................................... 39 
Tabla 2.26. Análisis de las fibras de algodón nativo de color

Tabla 2.27. Análisis de longitud de fibra de algodón nativo de color ........................................... 42

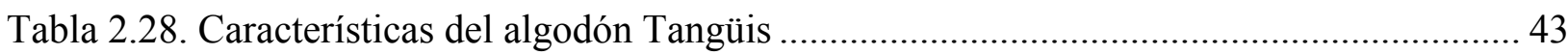

Tabla 2.29. Producción anual en TM de hilos de algodón nativo de color...................................... 45

Tabla 2.30. Producción de algodón Tangüis por región en toneladas ............................................ 46

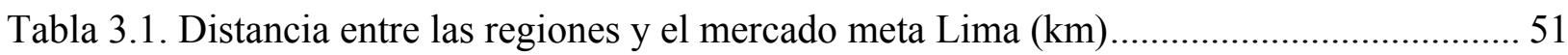

Tabla 3.2. Concentración geográfica de empresas operativas del subsector de fabricación de

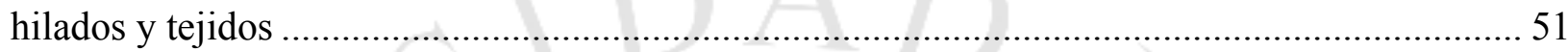

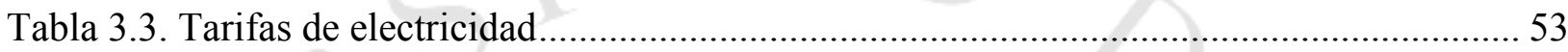

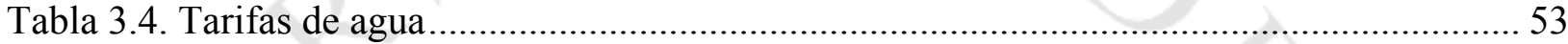

Tabla 3.5.Red vial por sistema de carreteras del 2012 ........................................................... 54

Tabla 3.6. Distancia desde cada alternativa de localización hacia el mercado meta (Lima) en Km

Tabla 3.7. Costo del flete de producto terminado desde cada alternativa de localización hacia el

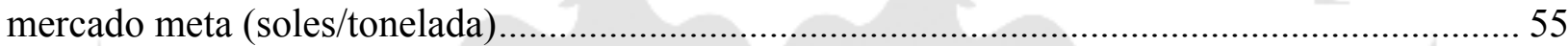

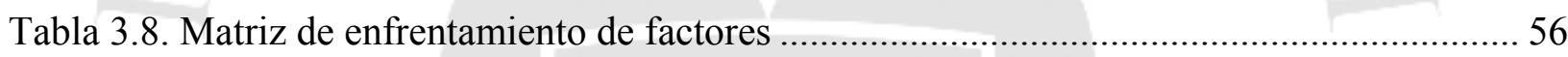

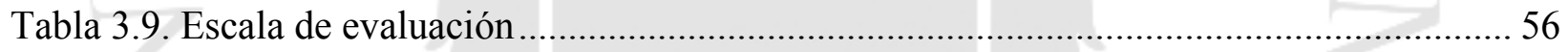

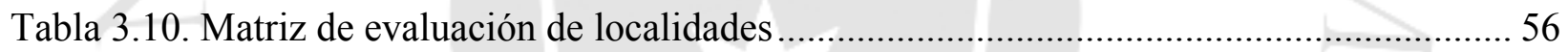

Tabla 3.11. Dirección de los clientes potenciales ........................................................................ 57

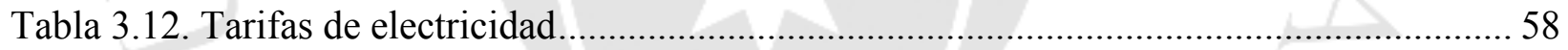

Tabla 3.13. Costo de alquiler mensual de un local industrial por distrito .................................... 58

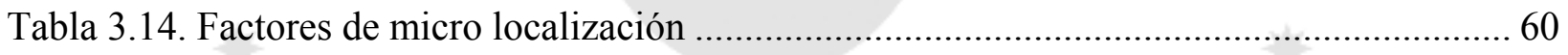

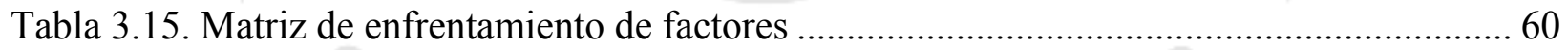

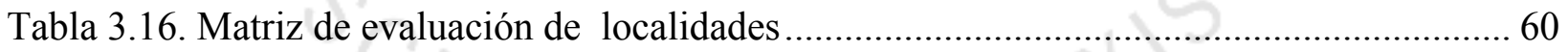

Tabla 4.1. Demanda interna aparente de hilo de la mezcla de algodón nativo de color y Tangüis

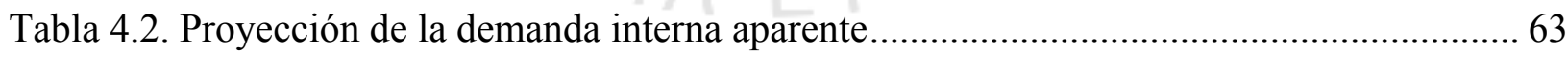

Tabla 4.3. Calculo de la relación tamaño-recurso productivo (TM)................................................. 65

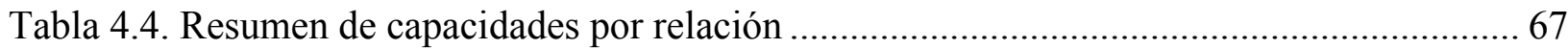

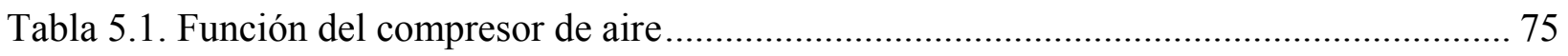

Tabla 5.2. Lista de máquinas/equipos requeridos ....................................................................... 77

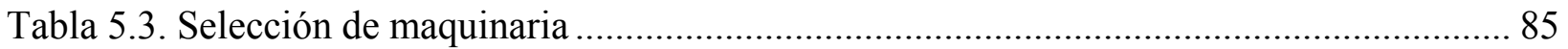




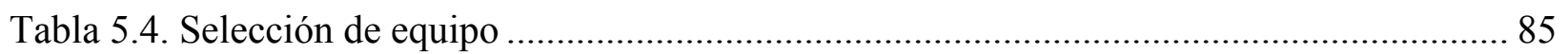

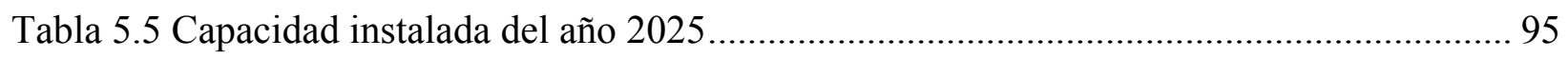

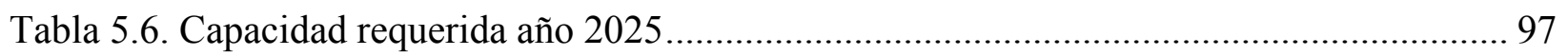

Tabla 5.7. Número de máquinas necesarias para alcanzar el nivel de producción...................... 100

Tabla 5.8. Detalle de adquisición de maquinaria ..................................................................... 100

Tabla 5.9. Clasificación de fibra según micronaire ……………………………………........... 101

Tabla 5.10. Clasificación de fibra según uniformidad .............................................................. 102

Tabla 5.11. Clasificación de fibra según longitud ................................................................ 102

Tabla 5.12. Clasificación de fibra según resistencia ............................................................. 103

Tabla 5.13. Clasificación de fibra según elongación ............................................................... 104

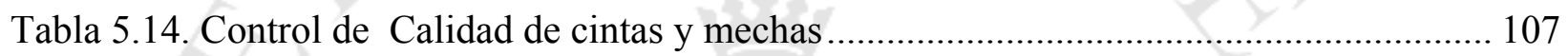

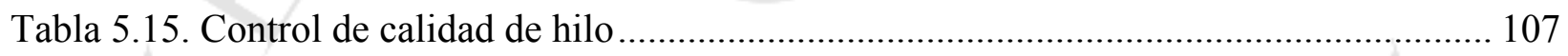

Tabla 5.16. Matriz de aspectos e impactos ambientales clasificados por actividad o proceso ... 110

Tabla 5.17. Matriz de Identificación de Peligros y evaluación de Riesgos (IPER) ...................... 114

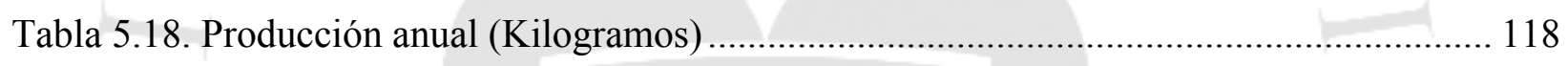

Tabla 5.19. Estimación del stock de seguridad (kilogramos) .................................................... 118

Tabla 5.20. Programa de producción anual (kilogramos) ........................................................ 119

Tabla 5.21. Determinación de la cantidad de materia prima $(\mathrm{kg})$............................................ 119

Tabla 5.22. Determinación de la cantidad de insumos por año (unidades) ................................. 120

Tabla 5.23. eterminación del número de bolsas y etiquetas ......................................................... 121

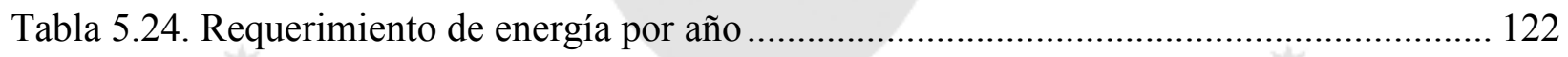

Tabla 5.25. Requerimiento de agua para la cámara de humidificación ....................................... 123

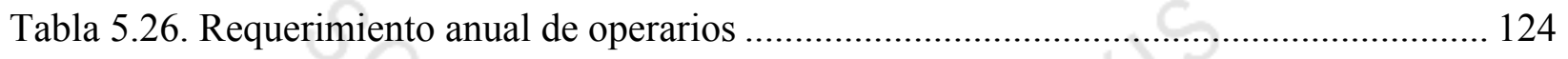

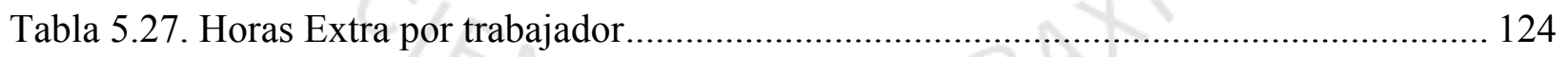

Tabla 5.28. Requerimiento de trabajadores indirectos........................................................... 125

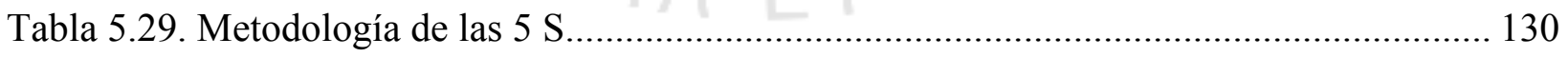

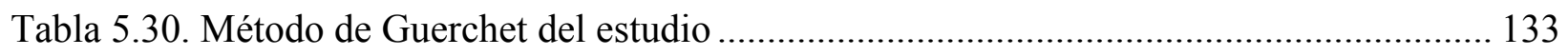

Tabla 5.31. Determinación del área que ocuparan los bloques de fardos .................................. 134

Tabla 5.32. Área de almacenamiento de producto terminado ………………………………... 135

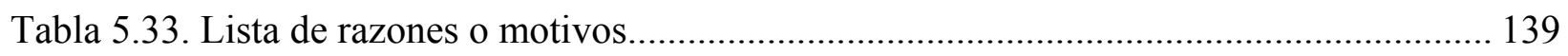

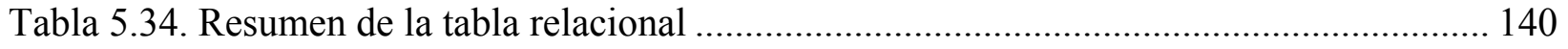


Tabla 6.1. Personal Área de Ventas y Comercialización 144

Tabla 6.2. Personal Área de Administración y Finanzas ................................................................ 145

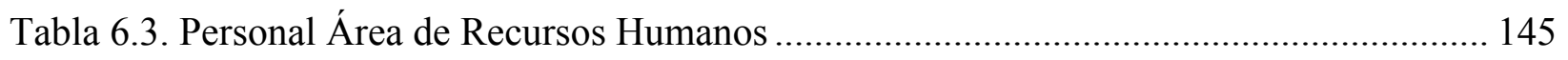

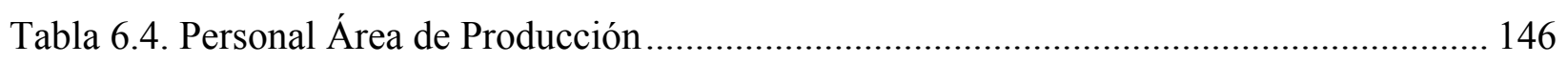

Tabla 6.5. Personal Área de Mantenimiento.................................................................................... 146

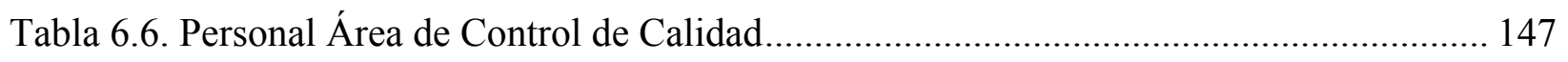

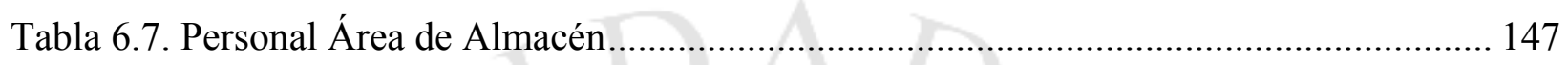

Tabla 6.8. Personal de seguridad, salud ocupacional y medio ambiente .................................... 147

Tabla 7.1. Cotización de máquinas para el proceso de hilatura................................................. 151

Tabla 7.2. Medidas impositivas para máquinas para hilar materia textil................................... 152

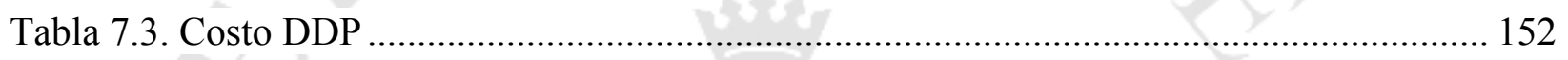

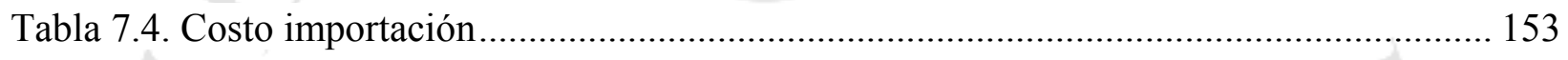

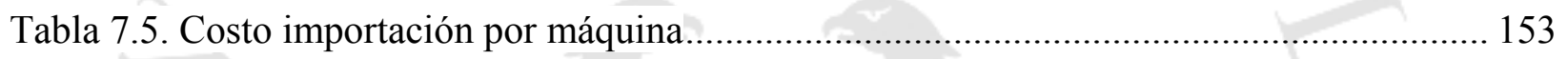

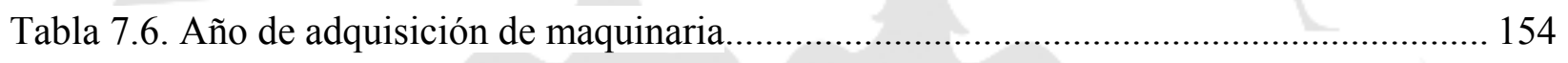

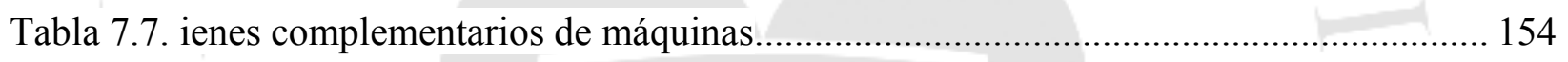

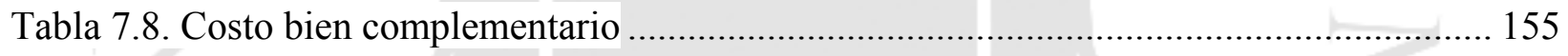

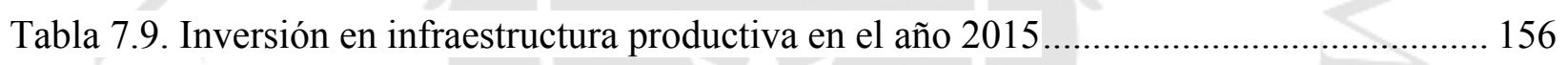

Tabla 7.10. Inversión en infraestructura productiva en el año 2019.......................................... 157

Tabla 7.11. Inversión en infraestructura productiva en el año 2022 ........................................ 157

Tabla 7.12. Conexiones básicas en media tensión (S/.) ......................................................... 158

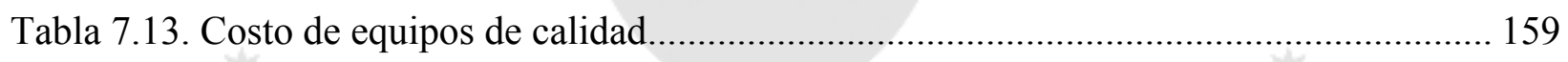

Tabla 7.14. Inversión en infraestructura productiva .............................................................. 161

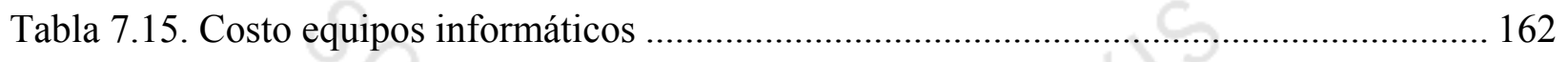

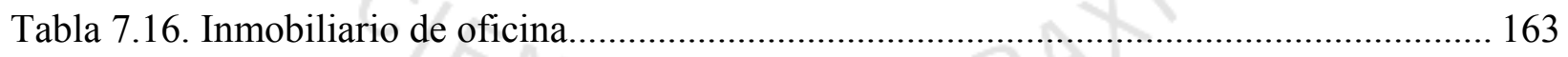

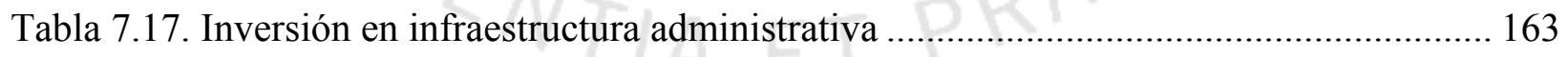

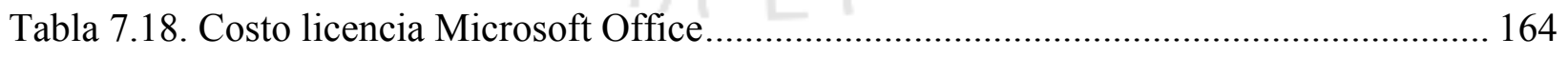

Tabla 7.19. Licencia municipal de Lurigancho para el funcionamiento (comercial, industrial y/o

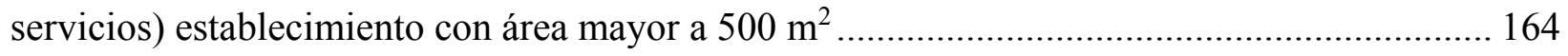

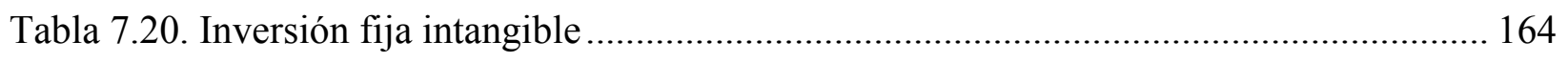

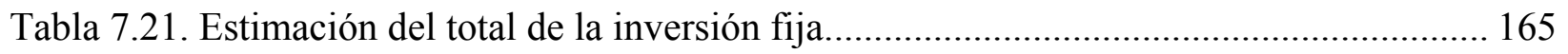

Tabla 7.22. Calculo del tiempo de producción de un fardo en el año 2016................................ 166 
Tabla 7.23. Costos y gastos del primer año del proyecto (S/.) ……………………………....... 166

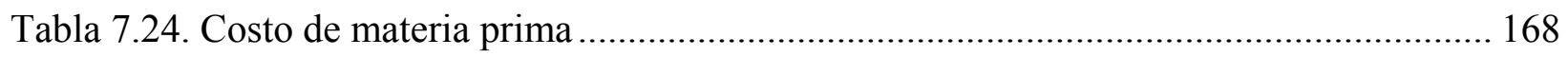

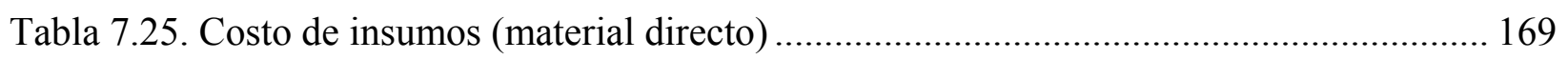

Tabla 7.26. Benchmarking de costos en fábricas hilanderas ..................................................... 170

Tabla 7.27. Costo de lubricantes y repuestos........................................................................... 171

Tabla 7.28. Tarifa de electricidad MT3 (Luz del Sur) ............................................................. 172

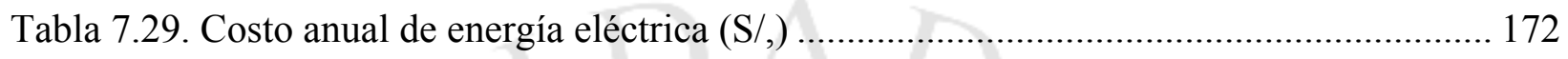

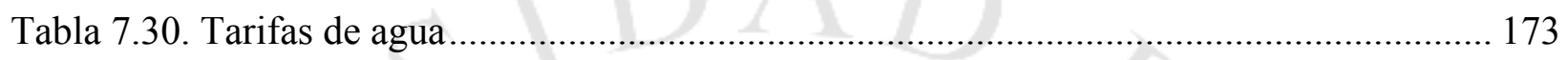

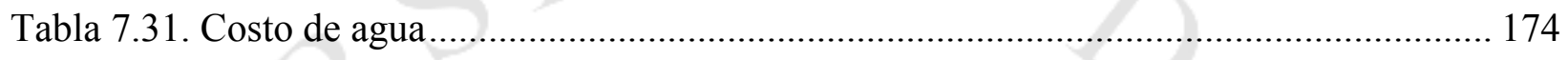

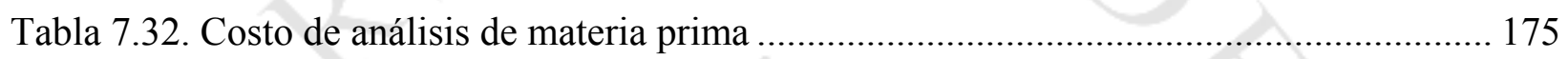

Tabla 7.33. Costo de anual de analizar la materia prima ............................................................ 176

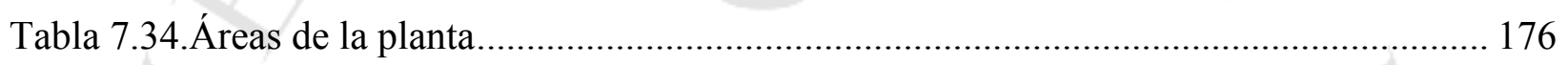

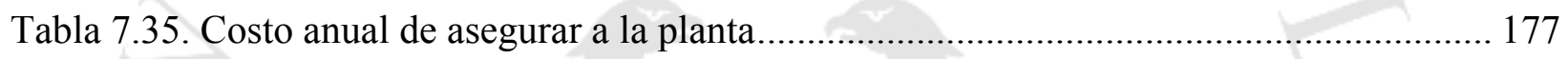

Tabla 7.36. Costo del traslado de algodón nativo desmotado desde Lambayeque hacia Lima .. 177

Tabla 7.37. Costo anual de mano de obra directa (S/.) .......................................................... 179

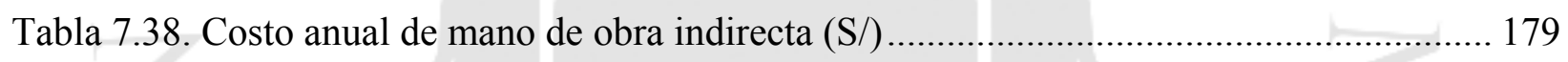

Tabla 7.39. Ingresos por ventas de hilo de algodón nativo de color (No incluye IGV) .............. 180

Tabla 7.40. Depreciación fabril de activos tangibles (S/.) ………………………………….... 181

Tabla 7.41. Presupuesto operativo de costos (S/.) ............................................................... 183

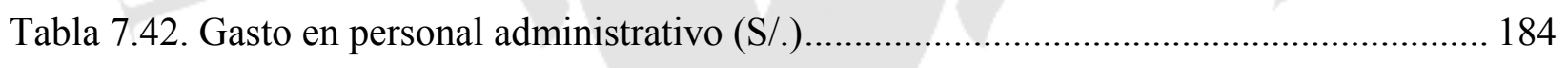

Tabla 7.43. Depreciación no fabril de activos tangibles (S/.) ................................................... 185

Tabla 7.44. Amortización de activos intangibles (S/.) ............................................................. 185

Tabla 7.45. Costo del transporte de producto terminado ......................................................... 188

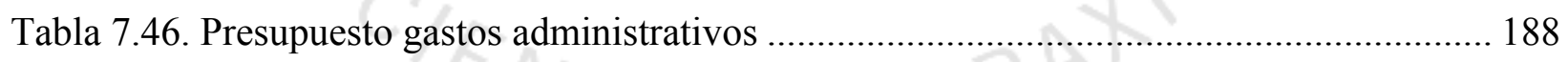

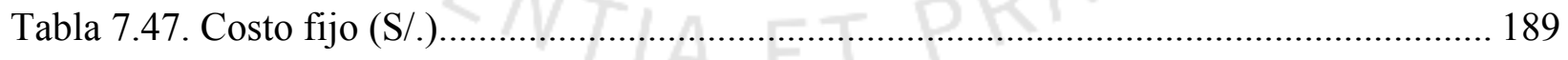

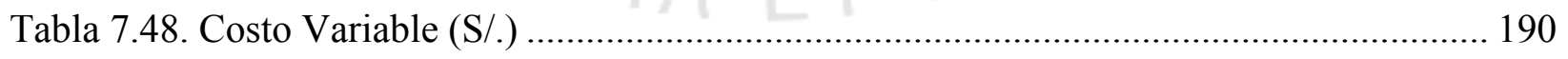

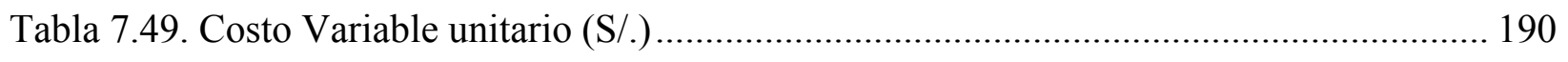

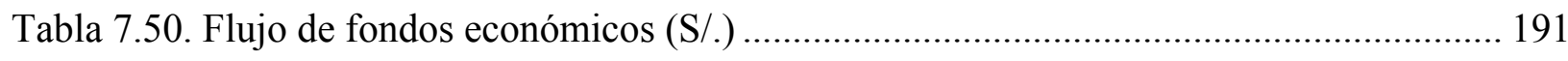

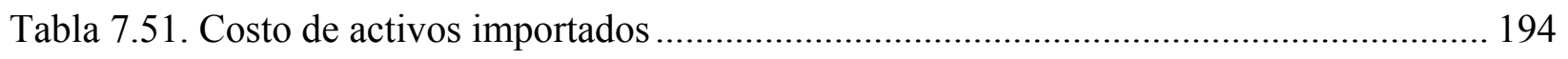

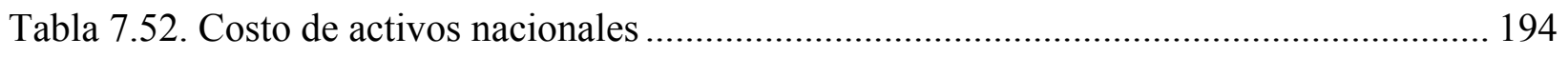


Tabla 7.53. Tasa de interés anual para préstamos a medianas empresas por periodos mayores a 360 días 195

Tabla 7.54. Servicio a la Deuda 195

Tabla 7.55. Compra del bien luego del Leasing 196

Tabla 7.56. Depreciación activos importados (S/.) 196

Tabla 7.57. Depreciación activos fabriles nacionales (S/.) 196

Tabla 7.58. Flujo de caja financiero 197

Tabla 8.1 Evaluación económica 199

Tabla 8.2. Periodo de recupero flujo de caja económico 199

Tabla 8.3. Interpolación para determinar el periodo de recupero del flujo de caja económico. 200

Tabla 8.4. Evaluación financiera 200

Tabla 8.5. Periodo de recupero flujo de caja financiero 201

Tabla 8.6. Interpolación para determinar el periodo de recupero del flujo de caja económico. 201 Tabla 8.7. Costo de materia prima considerando aumento del costo de algodón nativo a 20 soles $/ \mathrm{kg}$ 203

Tabla 8.8. Costo de mantenimiento considerando aumento del costo de algodón nativo a 20 soles $/ / \mathrm{kg}$ 204

Tabla 8.9. Presupuesto operativo de costos considerando aumento del costo de algodón nativo a 20 soles $/ \mathrm{kg}$ 205

Tabla 8.10. Calculo Flujo de fondos económico para el análisis de sensibilidad....................... 206 Tabla 8.11. Periodo de recupero del flujo económico de acuerdo al análisis de sensibilidad .... 207 


\section{ÍNDICE DE FIGURAS}

Figura 2.1. Promedio de kilos al año que comprarían del hilo elaborado con algodón nativo de color

Figura 2.2. Intención de compra de hilo de algodón nativo de color para usar en confecciones de calidad Premium y/o exportación 32

Figura 2.3. Resultado de la encuesta de intención de compra en escala de calificación 32

Figura 2.4. Precio promedio de hilo de algodón Pima entre 20 a 40 Ne al que compran las fábricas textiles de prendas Premium 37

Figura 2.5. Precio promedio de hilo de algodón Tangüis entre 20 a $40 \mathrm{Ne}$ al que compran las fábricas textiles de prendas Premium 37

Figura 2.6. Precio al que están dispuestos a pagar las fábricas que confeccionan prendas de vestir de calidad Premium. 38

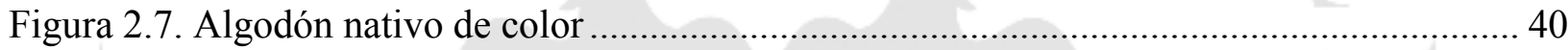

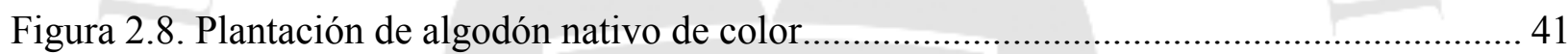

Figura 2.9. Área de producción, comercialización y artesanía del algodón nativo de color ......... 44

Figura 5.1. Cadena cinemática que brinda velocidad a los husos y al tren de estiraje ................. 70

Figura 5.2.. Cadena cinemática que brinda velocidad a los cilindros del tren de estiraje y al

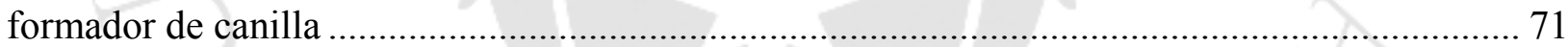

Figura 5.3. Tabla Relacional de la planta hilandera de algodón nativo de color ......................... 140

Figura 5.4. Diagrama relacional de la planta hilandera de algodón nativo de color.................... 141

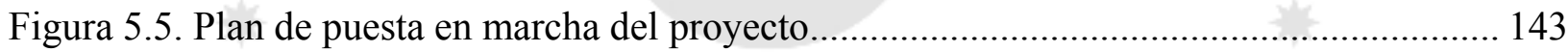

Figura 5.6. Estructura organizacional de la planta hilandera de algodón nativo de color .......... 149 


\section{RESUMEN EJECUTIVO}

El estudio realizado en el presente trabajo de investigación consiste en la evaluación de la implementación de una planta productora de hilo de algodón nativo de color el cual es de origen peruano y se caracteriza por tener variados colores como crema, marrón, verde, pardo, fifo, lila, blanco y beige y a su vez este algodón fue usado en Caral la primera civilización de América y otras culturas prehispánicas en Perú; sin embargo, posee características como fibra corta y baja resistencia a la torsión lo cual hace que sea imposible ser hilado por maquinaria convencional; por ello, se utilizará una máquina especialmente adaptada la cual tiene un rango de parámetros de velocidad específicos para no romper el hilo al momento de procesarlo. Cabe recalcar que para facilitar el proceso de hilatura se mezclará el algodón nativo de color con algodón Tangüis con lo cual también reducirá el costo de producción; ya que, este es más barato que el algodón nativo.

En primer lugar, se analizará la problemática y los objetivos de la investigación asi como la justificación tecnica, económica y social para implementar la planta de hilatura de algodón nativo de color. Además, se realiza un estudio de mercado a las fábricas textiles para poder determinar la demanda y el nivel de aceptación del hilo de algodón nativo. Posteriormente, se hará un estudio de localización para determinar el lugar idoneo para ubicar la fabrica teniendo en cuenta la ubicación de los potenciales clientes y la materia prima con la que se trabajará.

En el capítulo IV del estudio determinará el tamañode planta que permitirá tener un determinado nivel de producción optimo. En el capitulo V se hará un análisis técnico exhaustivo de la ingeniería del proyecto, incluyendo todo lo relacionado al proceso de producción conteniendo una explicación detallada de el sistema inventado y patentado con el cual se hilara el algodón nativo de color asi como aspectos de calidad, seguridad, medio ambiente, así como la disposición en detalle de la planta. Además, en el capítulo VI se determinará la estructura organizaciónal del proyecto, en el capitulo VII se determinara los aspectos economicos y financieros de implementar esta fabrica con el fin de poder realizar 
una evaluación ecnómica y financiera con la cual se pueda determinar la viabilidad del proyecto.

Por último se realizará una evaluación social del proyecto con el objetivo de poder tener un desarrollo sostenible y contribuir al desarrollo de las comunidades que se dedican a la siembra del algodón nativo de color.

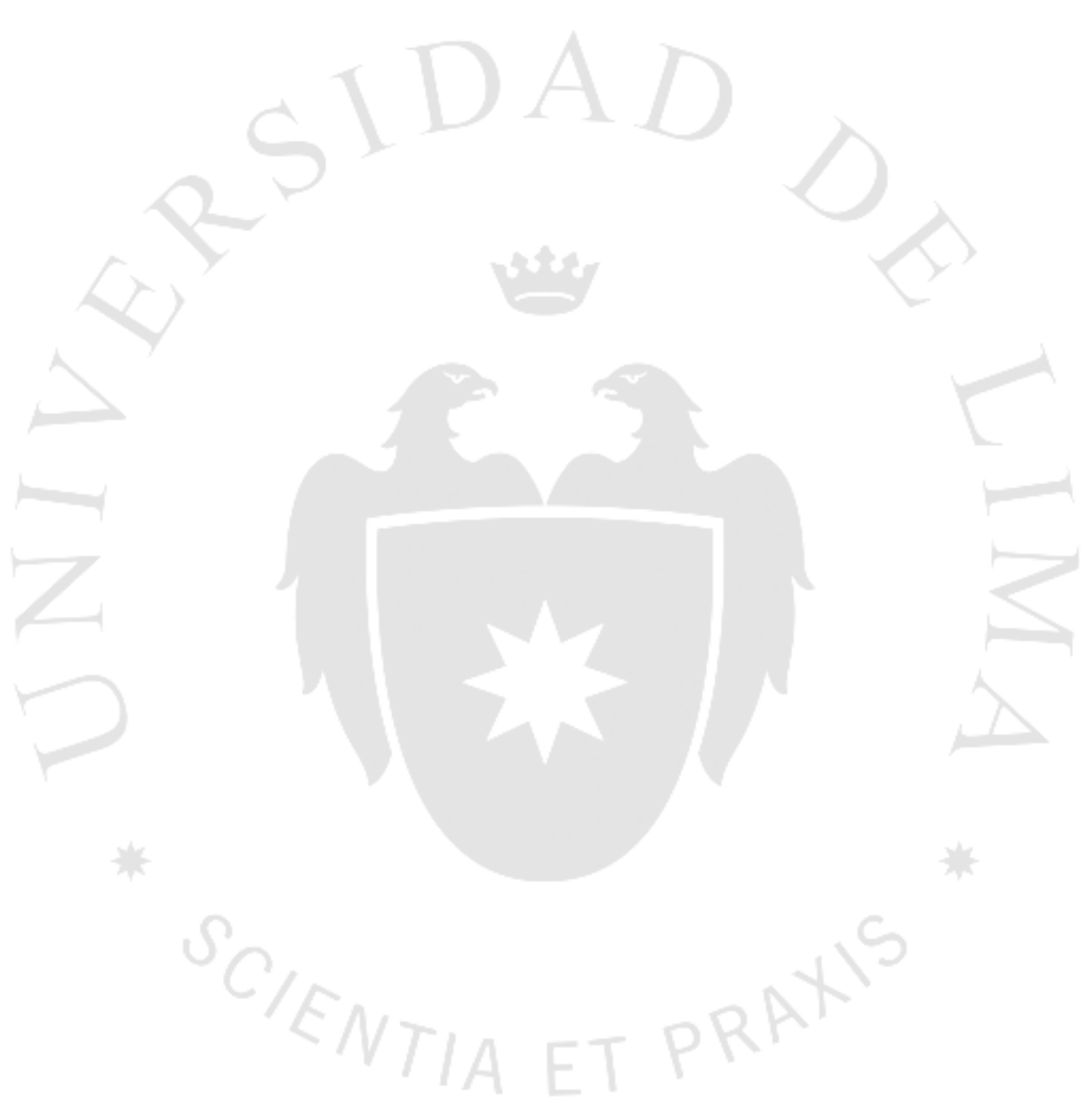




\section{EXECUTIVE SUMMARY}

The research consists in an assessment of the peruvian native cotton yarn factory implementation. This cotton is characterized by the diversity of their colors as cream, brown, green, brown, purple, white and beige. Furthermore, it was used in Caral the first civilitation of America and other pre-Hispanic cultures in Peru however this cotton has features such as short fiber and low torsional resistance which makes it impossible by conventional machinery be spun therefore a machine adapted will be used to spin this cotton. In the yarn process will be blended the peruvian native cotton with Tangüis to reduce the production cost due to Tangüis is cheaper than Peruvian native cotton.

Firstly, it will be analyzed the research objectives as well as the technical, economic and social justification to implement a peruvian Native cotton yarn factory. Furthermore a market research about the aceceptance level of native cotton yarn in the textil industry will be performed. Secondly, a location research will be conducted to determine the ideal place to locate the factory taking into account the location of the potential customers and the raw material.

In the chapter IV will be determinated the plant size in which it can be reached the optimum factory production. In the chapter $\mathrm{V}$ will be carried out a technical analysis of engineering project in which will be explained the production process to obtain native cotton yarn as well as the detailed information about the invented and patented system to spin the the native cotton yarn. Furthermore, it will be explained aspects related to the quality, safety, environmental and plant layout.

In the chapter VI will be determinated the organizational structure of the project. In the chapter VII will be analyzed the economic and financial aspects about this research in order to determinate the viability of this project.

Finally a social assessment of the project will be developed in order to get sustainable development and contribute to the development of communities related to native Cotton. 


\section{CAPÍTULO I: ASPECTOS GENERALES}

\subsection{Problemática}

El tema a tratar es un estudio de pre-factibilidad para la instalación de una planta productora de hilos en base a algodón nativo de color con el fin de ofrecer al mercado nacional hilos cuyo color es natural; ya que, este tipo de algodón se caracteriza por tener variados colores como crema, marrón, verde, pardo, fifo, lila, blanco y beige. Asimismo, las prendas de vestir que se elaborarán con este hilo tendrán la ventaja de que no requerirán ser teñidas lo cual reducirá una posible contaminación ambiental y propicia a que las personas alérgicas o de piel sensible a los tintes químicos puedan utilizar estas prendas de vestir así como las personas que apoyan el desarrollo sostenible.

Este tipo de algodón tiene fibra de corta longitud y baja resistencia a la torsión por tal motivo no se puede obtener hilo con las máquinas para hilar convencionales por lo cual para poder obtener un hilo en base a este algodón se utiliza una máquina para hilar especialmente acondicionada la cual tiene parámetros de velocidad específicos para no romper el hilo al momento de procesarlo.

La producción de hilo elaborado con algodón nativo de color se produce tanto de forma artesanal como industrial. El procesamiento artesanal se realiza en Lambayeque obteniendo un hilo muy grueso con el que solo se pueden confeccionar carteras, bolsos, billeteras y no prendas de vestir; y a su vez existe una empresa bien posicionada en el mercado (Perú Naturtex) la cual produce hilo industrial de este algodón, sin embargo, esta empresa exporta este hilo y no lo vende a las fábricas textiles locales.

La tesis que se propone contribuirá al desarrollo de las comunidades que se dedican a la siembra del algodón nativo de color como en la región Lambayeque, Piura y San Martin; ya que, se les comprará el algodón que cultivan para elaborar hilos de alta calidad que posteriormente se venderá a fábricas textiles para que elaboren prendas de vestir; por ello, esta fábrica incentivará el cultivo de algodón nativo de color. 


\subsection{Objetivos de investigación}

\subsubsection{Objetivos de la investigación}

El objetivo general es establecer la viabilidad de mercado, tecnológica, económica y financiera para la instalación de una planta productora de hilos elaborados con algodón nativo de color.

\subsubsection{Objetivos específicos}

- Realizar un estudio de mercado acerca de la aceptación del hilo elaborado con algodón nativo de color para posteriormente ser usado para confeccionar prendas de vestir.

- Identificar y analizar la tecnología con la cual se fabrica hilos elaborados en base a algodones convencionales para acondicionarlo al proceso de algodón nativo de color el cual tiene características especiales como baja resistencia a la torsión y fibra corta.

- Estudiar y analizar las propiedades físicas del algodón nativo de color y determinar el área geográfica en donde se presenta con mayor productividad.

- Determinar si el proyecto es económico y financieramente viable.

\subsection{Justificación del tema}

\section{Técnica:}

En esta investigación se estudiará acerca de la tecnología que convencionalmente se usa en la producción de hilo de algodón Pima y Tangüis con el fin de acondicionar las máquinas y utilizarlas en el procesamiento del algodón nativo de color debido a que tiene propiedades diferentes a los algodones convencionales como baja resistencia a la torsión y fibra corta. Asimismo, se propone mezclar el algodón nativo con el algodón Tangüis con el objetivo de obtener una fibra de mayor longitud que sea más fácil de ser procesada. La maquinaria que interviene en el proceso son las máquinas de apertura y limpieza, mezcladora, la carda, el manuar, la continua de anillos, la bobinadora y la cámara de humidificación. Para la adquisición de las máquinas se hará un estudio detallado acerca de las que son más fáciles de ser acondicionadas para procesar al algodón nativo de color que tiene características especiales que se mencionaron anteriormente. Por otro lado, se investigará acerca de la 
capacidad productiva de cada máquina a fin de que no se genere un cuello de botella que tarde demasiado la producción.

\section{Económica:}

El valor agregado que tiene el hilo producido a partir del algodón nativo tiene un gran potencial para la industria de la confección, con respecto a otros algodones comerciales como el Tangüis o el Pima; ya que, este tipo de algodón tiene variados colores como crema, marrón, verde, pardo, fifo, lila, blanco y beige; por ello, este hilo tiene naturalmente diversos colores sin ser teñido. Por otra parte, los potenciales clientes que serán empresas que elaboran tela y confeccionan ropa los cuales estarán muy interesados en comprar este hilo; ya que, podrán confeccionar prendas de vestir de diversos colores naturales lo cual les dará un mayor valor agregado a su producto; por ello, las personas interesadas en comprar ropa con colores naturales pueden ser potenciales compradores de su producto así como las personas alérgicas o de piel sensible a los tintes químicos. Se espera obtener un retorno de la inversión, un VAN positivo y una TIR que sea mayor al costo promedio de capital. El producto final es una bolsa de 12 conos de $2 \mathrm{~kg}$ de hilo el cual se vende a un valor de ventade 10 dólares $/ \mathrm{kg}$.

\section{Social:}

La investigación de producción de hilos a partir del algodón nativo de color espera contribuir al desarrollo de las comunidades que se dedican a la siembra de este tipo de algodón que se ubican principalmente en las regiones Lambayeque, Piura y San Martin; ya que, mediante la tecnología que se empleará para procesarlo se podrá obtener hilos de alta calidad con los cuales se pueda confeccionar prendas de vestir. Actualmente, las comunidades que siembran este tipo de algodón lo procesan de forma artesanal con lo cual obtienen un hilo que es muy grueso y con este sólo pueden elaborar carteras, bolsos y billeteras. La materia prima del presente estudio es el algodón nativo de color el cual se comprará a las comunidades mencionadas a un precio justo permitiéndoles mayores ingresos y por lo tanto una mejor calidad de vida. 


\subsection{Hipótesis de trabajo}

La instalación de una planta de hilos de calidad a partir del algodón nativo de color podría ser factible, debido a que existiría un mercado interesado en hilos cuyo color es natural y además, mediante innovaciones se podría procesar este hilo; por lo tanto, sería tecnológicamente viable. Asimismo, sería económicamente viable; ya que, al ser de color natural le da un valor agregado al hilo. Por último sería socialmente viable ya que contribuiría con el desarrollo de las comunidades que se dedican a la siembra de este tipo de algodón; y sería ambientalmente viable; ya que, las prendas de vestir que se elaboren con este hilo no requerirán ser teñidas lo cual evitaría la contaminación ambiental producida por el proceso de teñido

\subsection{Marco referencial de la investigación}

\section{Tabla 1.1}

Investigaciones previas sobre el tema propuesto.

\begin{tabular}{|c|c|}
\hline Título: & $\begin{array}{l}\text { Estudio preliminar para la implementación de un taller semi industrial para producir } \\
\text { vestidos para la exportación en base de algodón nativo de color. }\end{array}$ \\
\hline Autor: & Michue Huacache, Verónica y Puma Benedicto, Freddy \\
\hline Fecha: & Noviembre 2011 \\
\hline Semejanzas: & $\begin{array}{ll} & \text { Materia prima principal. } \\
\text { - } & \text { Ecológico } \\
\end{array}$ \\
\hline Diferencias: & $\begin{array}{ll}\text { - } & \text { Mercado objetivo distinto. } \\
\text { - } & \text { Se implementará una planta de hilado. }\end{array}$ \\
\hline
\end{tabular}

\begin{tabular}{|l|l|}
\hline Título: & $\begin{array}{l}\text { Estudio preliminar para producción de ropa de bebes en base al algodón nativo } \\
\text { peruano. }\end{array}$ \\
\hline Autor: & Huari Vera, Carlos y Álvarez Wong, Víctor. \\
\hline Fecha: & Julio 2011 \\
\hline Semejanzas: & $-\quad$ Realiza un estudio de algodón nativo de color. \\
& $-\quad$ Ecológico \\
\hline Diferencias: & $-\quad$ Producción de hilado. \\
& $-\quad$ Mercado objetivo distinto. \\
\hline
\end{tabular}

Elaboración propia. 


\subsection{Análisis del sector}

El análisis estructural del sector industrial se hace a través de las 5 fuerzas de Porter

\section{Amenaza de productos sustitutos}

El hilo puede estar compuesto por fibras1 naturales o químicas; por ello, las propiedades de un tipo de hilo dependen de las fibras por las que está compuesto. Los hilos elaborados con fibras naturales pueden ser de origen vegetal, animal o mineral.

Hilos elaborados con fibras naturales:

La fibra vegetal más importante proviene del algodón y los algodones que son más utilizados para elaborar hilos son el Tangüis y Pima los cuales usualmente se utilizan para elaborar hilos con los cuales se confeccionan prendas de vestir como polos, camisas, vestidos, medias; por lo tanto son los productos sustitutos de mayor amenaza con los que compite el hilo elaborado con algodón nativo de color.

Las fibras animales más importantes provienen de la lana de oveja, alpaca y vicuña con los cuales se puede obtener hilos que principalmente son usados para elaborar chompas y vestidos; por lo tanto, representan una amenaza intermedia.

Por último, las fibras minerales provienen principalmente de vidrio, amianto, fibras metálicas, turba fosilizada y caucho mineral; este tipo de fibras no es adecuado para obtener telas; ya que, son utilizadas como redes de resistencia de placas de cemento o de resinas como material aislante; por lo tanto, representan una amenaza baja.

Hilos elaborados con fibras químicas:

Las fibras químicas se dividen en artificiales y sintéticas. Las fibras artificiales se obtienen modificando las fibras naturales básicamente la celulosa para obtener mejores

\footnotetext{
${ }^{1}$ La fibra es un filamento plegable parecido a un cabello cuyo diámetro es muy pequeño en relación a su longitud.
} 
combinaciones con las cuales se puede obtener un hilo de mayor calidad; por lo tanto, se consideran una alta amenaza.

Las fibras sintéticas se elaboran combinando monómeros con el objetivo de obtener un polímero que es un compuesto químico complejo. Estas fibras son de tipo poliamidas, poliésteres, poliacrilicas, poliolefinas, poliuretano y polivinilo. Una poliamida conocida es el nylon el cual es usado para elaborar medias debido a su alta resistencia y durabilidad excelente. Los poliésteres tienen propiedades térmicas; por ello, se usan en la producción de fibras para el relleno de almohadas, colchas y alfombras. El poliacrilonitrilo es un tipo de fibra poliacrílica el cual se usa para elaborar telas semejantes a las elaboradas con lana; por lo tanto, representan una amenaza intermedia.

Mezclas:

La mezcla es la combinación íntima de fibras de diferente composición, longitud, diámetro o color que se hilan juntas para formar un hilo. La mezcla permite combinar las fibras de tal manera que las buenas cualidades se enfaticen y las deficientes disminuyan al mínimo. Las mezclas pueden ser entre fibras naturales con el objetivo de mejorar la uniformidad o entre algodón y lana; por lo tanto, se considera una alta amenaza.

También, la seda podría ser considerada como un producto sustituto que representa una baja amenaza; ya que, su precio es elevado debido a que sirve para elaborar telas lustrosas y suaves; y es un producto escaso.

En conclusión, se identificó que hay una alta amenaza de productos sustitutos; ya que, la mayoría de hilos son elaborados con fibras de algodón Pima, Tangüis, mezclas de diferentes tipos de fibras naturales y fibras artificiales con las cuales se puede elaborar un hilo de alta calidad.

\section{Poder de negociación de los proveedores}

El cultivo de algodón nativo de color se centra en el norte del país en las regiones de Piura, San Martín y Lambayeque. En este último, el cultivo de este tipo de algodón se concentra en los distritos de San José, Túcume, Mórrope y Ferreñafe. Lambayeque es la región donde mayormente se produce, considerando que la siembra en San Martin y Piura es escaza y se realiza de forma independiente por unos cuantos campesinos. 
El cultivo de algodón nativo de color es una actividad que tiene baja producción ya que, los cultivos de algodón más representativos son del algodón Pima y el algodón Tangüis.

La producción en rama del algodón nativo de color, es aproximadamente de $2500 \mathrm{~kg}$ por hectárea y su precio es de S/. 16 el kilo de algodón desmotado sin incluir IGV. El precio de algodón Tangüis y Pima procesado es de 4.4 soles $/ \mathrm{kg}$ y 5.2 soles $/ \mathrm{kg}$.

En conclusión, el precio del kilo de algodón nativo de color es elevado con respecto a los precios de otros tipos de algodón; sin embargo, hay muchos campesinos interesados en vender este algodón; ya que, les produce mayores ganancias que otros cultivos; por lo tanto los proveedores poseen un poder de negociación alto; ya que, si se les compra una mayor cantidad de algodón podrían empezar a cultivar en mayor medida este algodón; sin embargo, sería difícil negociar con ellos para rebajar el precio del algodón..

\section{Poder de negociación de los clientes}

Los principales clientes serían las fábricas textiles que dirigen su producto al sector socioeconómico A y B o que los exportan. Al ser este hilo un producto diferenciado con el valor agregado de tener colores naturales sin la necesidad de ser teñido y tener un proceso de fabricación más complejo debido a que tiene fibra corta y baja resistencia a la torsión tiene un precio de venta mayor que un hilo convencional2 (El valor de venta del algodón Tangüis es de $5.33 \$ / \mathrm{kg}$ y Pima es de $7.41 \$ / \mathrm{Kg}$ mientras que el valor de venta del algodón nativo de color es de $10 \$ / \mathrm{Kg}$ ). Al ser un producto innovador y tener poca competencia, el poder de negociación de los clientes es intermedio

\section{Rivalidad entre competidores}

La producción de hilo elaborado con algodón nativo de color se produce tanto de forma artesanal como industrial. Según los datos brindados por la Ing. Patricia Ocampo gerente regional de desarrollo productivo de la región Lambayeque, el algodón nativo de color es usado en un $80 \%$ para uso industrial y el resto para uso artesanal en Lambayeque Actualmente se procesa de forma artesanal en Lambayeque obteniendo un hilo muy grueso con el que solo se pueden confeccionar carteras, bolsos, billeteras y no prendas de vestir; y

\footnotetext{
${ }^{2}$ Ver el capítulo 2.5.3.2 (Precios sin IGV)
} 
a su vez existe una empresa bien posicionadas en el mercado (Perú Naturtex) la cual produce hilo industrial de este algodón, sin embargo, de acuerdo al estudio de mercado que se realizó Mercadeo y Opinión S.A (ver sección 2.1) se pudo evidenciar que el hilo que vende esta empresas se exporta ; ya que, este hilo no es comprado por las principales fábricas textiles. Asimismo, se podría considerar como competencia a las fábricas que producen hilos a partir de algodón Tangüis y Pima las cuales se podría considerar como un oligopolio; ya que, hay pocas fábricas y tienen presencia desde hace muchos años en este sector. Las principales fábricas son Industrias Textil Piura S.A, Ideas Textiles S.A.C, Textiles de Sudamérica S.A.C (ITESSA), Hilandería de Algodón Peruana S.A (Hialpesa), Sur Color Star S.A, Filasur S.A, La Colonial Fábrica de Hilos S.A. En conclusión, existe una alta rivalidad entre los competidores; ya que, las empresas están bien posicionadas.

\section{Amenazas de nuevos ingresos}

El algodón nativo de color al tener características como baja resistencia a la torsión y fibra corta los cuales hacen imposible hilarlo con maquinaria convencional; por tal motivo, para poder hilarlo se debe realizar adaptaciones en la maquinaria existente lo cual dificulta la entrada de inversionistas; ya que, hilarlo representa un alto costo en comparación con hilar otros tipos de algodón como el Pima y Tangüis

En el sector de la fabricación de hilos a partir de algodón Pima y Tangüis los cuales son los que tienen mayor nivel de producción en la actualidad, existen empresas bien posicionadas que cuentan con economías a escala; y por lo tanto, pueden vender sus hilos a precios bajos, asimismo, en el Perú se importa gran cantidad de hilos de la China e India a un precio muy bajo. Estas empresas podrían significar una dura competencia; por ello, si se desea invertir en una fábrica hilandera de algodón nativo de color se debería optar por una estrategia de diferenciación basada en la calidad.

En conclusión, debido a que es difícil procesar el algodón nativo de color para obtener hilo debido a las características de este algodón existe una baja amenaza de nuevos ingresos. 


\section{CAPÍTULO II: ESTUDIO DE MERCADO}

\subsection{Aspectos generales del estudio de mercado}

\subsubsection{Definición comercial del producto}

\section{Producto básico:}

El hilo elaborado con algodón nativo de color se caracteriza por tener variados colores como crema, marrón, verde, pardo, fifo, lila, blanco y beige sin la necesidad de ser teñido. Este hilo va a ser usado para la elaboración de telas que sirvan para la elaboración de prendas de vestir.

\section{Producto real:}

El algodón nativo de color al ser procesado para obtener hilo cardado ${ }^{3}$ adquiere ciertas particularidades como un título de menor grosor (entre 10 y $40 \mathrm{Ne}$ ), mayor estiraje y resistencia. Asimismo, la calidad de este hilo es óptima para elaborar prendas de vestir, las cuales tendrán el valor agregado de que no son teñidas lo cual reduce la contaminación ambiental producida por el proceso de teñido y propicia que las personas alérgicas o de piel sensible a los tintes químicos puedan utilizar estas prendas de vestir; ya que, en su proceso de fabricación se utilizará maquinaria especializada para hilar este tipo de algodón. El producto final es una bolsa con 12 conos de hilo de $2 \mathrm{Kg}$. Asimismo, se proporciona al mercado nacional un producto innovador y que resuelve la demanda de ropa ecológica. Cabe recalcar que con el objetivo de mejorar la calidad de la fibra y disminuir los costos se mezcla el algodón nativo de color con algodón Tangüis el cual es un algodón comercial. Debido a que el algodón Tangüis es color blanco al mezclarse sus algodón nativo de color las fibras resultantes de la mezcla tienen a aclararse (crema, marrón, verde, pardo, fifo, lila, blanco y beige).

\footnotetext{
${ }^{3}$ La hilatura de algodón cardado es la forma básica de producción del hilado de algodón, con el sistema de hilatura por anillos (ring spun). En forma muy simplificada el proceso comienza con la limpieza y apertura primaria de fibras, luego continúa con la apertura y paralelización en las cardas. Sigue con otro estiraje y doblado en manuar y luego con un nuevo doblado y estiraje en la mechera
} 


\section{Producto aumentado:}

Se refiere al tipo de servicio que se brinda durante la negociación, la venta y la post venta. Se cuenta con una excelente calidad de atención, puntualidad de suministro, asimismo las facilidades de pago. Para establecer la calidad del producto se establece un buen servicio post venta en el cual son atendidos los reclamos y quejas oportunamente.

\subsubsection{Principales características del producto}

\subsubsection{Posición arancelaria del producto NANDINA, CIIU}

\section{Código CIIU:}

El código CIIU (Revisión 4) al que pertenece el producto es C1311.Es decir sección C por ser industria manufacturera, la división 13 Fabricación de productos textiles. Dentro del cual, se encuentra el grupo 1 Preparación, hilatura, tejeduría y acabado de productos textiles y clase 1 Preparación e hilatura de fibras textiles.

\section{NANDINA}

La NANDINA constituye la Nomenclatura Arancelaria Común de la Comunidad Andina y está basada en el Sistema Armonizado de Designación y Codificación de Mercancías. Comprende las partidas, subpartidas correspondientes, Notas de Sección, de Capítulo y de Subpartidas, Notas Complementarias, así como las Reglas Generales para su interpretación

El código NANDINA para hilo superior al número métrico $14 \mathrm{Ne}$ pero inferior o igual al número métrico $43 \mathrm{Ne}$ para fibras cardadas es 5205.32.00.

\subsubsection{Usos y características del producto}

El hilo elaborado con algodón nativo de color a diferencia de los hilos elaborados con algodones convencionales como el Tangüis y Pima tiene la ventaja de que posee color natural sin haber pasado por algún proceso de teñido con lo que evita haber sido tratado con sustancias químicas; De tal forma que se deja de contaminar grandes cantidades de agua y disminuir las probabilidades de que las personas con piel sensible o que sostengan enfermedades dermatólogas se vean afectadas. Además, al presentar hilado de algodón nativo de color a las industrias textiles ofrece el ahorro del proceso de teñido lo que lo hace 
una alternativa atractiva. Este hilo tiene diversos colores como el crema, marrón, fifo, verde, pardo, blanco y beige

Este hilo será usado para la elaboración de telas para prendas de vestir como polos, poleras y chompas; es decir, telas que se hacen con tejido de punto; por ello, estos hilos tendrán un menor título entre 10 y $40 \mathrm{Ne}$. Cabe recalcar que para elaborar chompas se necesita hilos de 2 o 3 cabos y esta prenda será usada preferentemente en las estaciones de primavera y otoño; ya que, su tela es fresca y no abrigadora.

Asimismo, mediante el hilo de algodón nativo de color se elaborara vestidos, blusas y camisas; es decir, telas que se elaboran con tejido plano; por ello, estos hilos tendrán una mayor título entre 30 y $40 \mathrm{Ne}$.

Cabe recalcar que este hilo tiene un gran potencial en el mercado externo dado sus colores naturales que le dan un valor agregado.

Tabla 2.1

Rango de título para determinadas prendas de vestir

\begin{tabular}{|l|l|}
\hline \multicolumn{1}{|c|}{ uso } & \multicolumn{1}{c|}{ Rango del título (Ne) } \\
\hline Polos 1 & $30-50$ \\
\hline Chompas & $10-15 \mathrm{Ne}$ (2 a 3 cabos) \\
\hline Poleras & $10-20 \mathrm{Ne}$ \\
\hline Vestidos & $30-40$ \\
\hline Camisas & $40-50 \mathrm{Ne}$ \\
\hline
\end{tabular}

Fuente: Hialpesa, (2015)

Elaboración propia.

\section{Propiedades físicas}

El hilo que se va a utilizar es la mezcla entre algodón nativo de color y el algodón Tangüis debido a que al mezclarlos se obtiene una fibra de mayor longitud (ver tabla 2.2). Por ello, se analizará las propiedades de estos algodones como se puede apreciar en el cuadro 
Tabla 2.2

Análisis de las fibras de algodón nativo de color y Tangüis

\begin{tabular}{|c|c|c|}
\hline Análisis & Algodón nativo de color & Tangüis \\
\hline Longitud de fibra (mm) & 24,13 & 33,02 \\
\hline Resistencia (lbs / pulg $^{2}$ ) & 88,21 & 93,65 \\
\hline Finura (micronaire) & 6.2 & 4.7 \\
\hline
\end{tabular}

Fuente: Cortijo, D. ; Cancio, R. ,(2012).

Tabla 2.3

Longitud de la mezcla

\begin{tabular}{|l|c|c|c|}
\hline & Algodón nativo de & Algodón Tangüis & Mezcla \\
\hline Porcentaje (\%) & 63 & 37 & 100 \\
\hline Longitud de fibra (mm) & 24,13 & 33 & 27,42 \\
\hline
\end{tabular}

Fuente: Cortijo, D. ; Cancio R. (2012).

El motivo por el cual se mezclan estos algodones es para obtener una longitud de fibra de $27.42 \mathrm{~mm}$ la cual es adecuada para poder ser hilada y obtener un hilo cuyo título sea entre 10 y $40 \mathrm{Ne}$ el cual es apropiado para poder confeccionar prendas de vestir. Al aumentar la longitud de la fibra será más fácil conseguir un título del hilo de mayor valor; ya que, el título representa la relación entre la longitud y el peso del hilo.

El título es una propiedad del algodón que representa la finura de la mecha o el hilo

$$
\text { Título }(\mathrm{Ne})=\frac{0.59 \times \text { longitud }(\text { metros })}{\text { peso }(\text { gramos })}
$$

Asimismo, al predominar en la mezcla el algodón nativo de color se conservan sus propiedades como la pigmentación de diversos colores.

Cabe recalcar que el hilo es cardado; ya que, no necesita ser peinado debido a que tiene fibra corta. Los hilos peinados son de fibra larga como el Pima; ya que, la peinadora tiene como objetivo disgregar a las fibras cortas para obtener un hilo más fino y resistente.

Se analizó en el Laboratorio de Ensayos Textiles del Senati las características del hilo obtenido en el proceso productivo a fin de verificar la alta calidad de este Cabe recalcar, que todas las variables con las que se mide la calidad del hilo están descritos en la sección 5.5 Resguardo de la Calidad. 
Densidad lineal: La variable con la que se midió la densidad lineal es el título expresado Número Ingles $(\mathrm{Ne})$

Tabla 2.4

Análisis de densidad lineal

\begin{tabular}{|c|c|}
\hline Muestra $\mathrm{N}^{\circ}$ & Titulo (Ne) \\
\hline 1 & 15.73 \\
\hline 2 & 14.94 \\
\hline 3 & 14.74 \\
\hline 4 & 15.82 \\
\hline 5 & 14.47 \\
\hline Promedio Ne & 15.14 \\
\hline Desviación Estándar & 0.6 \\
\hline \%Coefic. Variac. & 3.99 \\
\hline
\end{tabular}

Fuente: Senati, (2016)

Resistencia: Se realizó 90 pruebas para poder determinar la resistencia del hilo. Las variables que se evaluó son fuerza máxima $(\mathrm{cN})$, tenacidad $(\mathrm{cN} / \mathrm{Tex})$, RKM, elongación máxima $(\mathrm{mm}), \%$ de elongación máximo $(\mathrm{mm})$

Tabla 2.5

Análisis de la resistencia

\begin{tabular}{|l|c|c|c|c|c|}
\hline & $\begin{array}{c}\text { Fuerza } \\
\text { máxima }(\mathrm{cN})\end{array}$ & $\begin{array}{c}\text { Tenacidad } \\
(\mathrm{cN} / \text { Tex })\end{array}$ & $\begin{array}{c}\text { RKM } \\
(10.1978)^{*}(\mathrm{Cn} / \mathrm{Tex})\end{array}$ & $\begin{array}{c}\text { Elongación } \\
\text { máxima }(\mathrm{mm})\end{array}$ & $\begin{array}{c}\text { \% Elongación } \\
\text { máximo }(\mathrm{mm})\end{array}$ \\
\hline Mínimo & 260.1 & 6.668 & 6.799 & 26.488 & 5.2976 \\
\hline Promedio & 351.5 & 9.011 & 9.189 & 31.047 & 6.2094 \\
\hline Máximo & 507.7 & 13.015 & 13.272 & 35.382 & 7.0785 \\
\hline Desviación & 52.94 & 1.357 & 1.384 & 2.23 & 0.446 \\
\hline Coeficiente & 15.06 & 15.06 & 15.06 & 7.18 & 7.18 \\
\hline
\end{tabular}

Fuente: Senati, (2016)

El coeficiente de variación es una medida de dispersión relativa de los datos y se expresa en porcentajes.

Coeficiente de variación $=$ Desviación estándar $/$ media aritmética

Torsión: Se realizó 25 ensayos en 5 canillas para poder determinar el nivel de torsión 
Tabla 2.6

Análisis de torsión

\begin{tabular}{|l|c|c|c|c|c|}
\hline & Canilla N$^{\circ} 1$ & Canilla N$^{\circ} 2$ & Canilla N$^{\circ} 3$ & Canilla N$^{\circ} 4$ & Canilla N$^{\circ} 5$ \\
\hline Promedio (T/i) & 13.79 & 14.04 & 13.99 & 13.89 & 14.03 \\
\hline Desviación & 0.48 & 0.68 & 0.59 & 0.54 & 0.65 \\
\hline CV (\%) & 3.45 & 4.84 & 4.25 & 3.86 & 4.64 \\
\hline Máximo (T/i) & 14.53 & 15.17 & 15.1 & 14.91 & 15.42 \\
\hline Mínimo (T/i) & 12.85 & 12.82 & 12.76 & 12.79 & 12.89 \\
\hline Alpha & 3.54 & 3.61 & 3.59 & 3.57 & 3.61 \\
\hline
\end{tabular}

Fuente: Senati, (2016)

\section{Irregularidad}

Tabla 2.7

Análisis de Irregularidad

\begin{tabular}{|l|c|c|}
\hline & $\mathrm{U} \%$ & CVM \% \\
\hline Muestra No1 & 13.83 & 17.62 \\
\hline Muestra N² & 13.41 & 17.54 \\
\hline Muestra N³ & 14.27 & 19.26 \\
\hline Muestra ${ }^{\circ} 4$ & 14.32 & 18.41 \\
\hline Muestra ${ }^{\circ} 5$ & 14.2 & 18.23 \\
\hline Medio & 14 & 18.21 \\
\hline CV & 2.7 & 3.8 \\
\hline Máximo & 14.32 & 19.26 \\
\hline Mínimo & 13.41 & 17.54 \\
\hline
\end{tabular}

Fuente: Senati, (2016)

Antecedentes históricos del algodón nativo de color

Hacia 1920 el cultivo del algodón nativo de color fue desplazado por el algodón Pima en los cultivos de la costa norte; ya que sus características eran las más adecuadas a las exigencias de la demanda de Inglaterra que era el principal destino al cual se exportaba algodón por lo que poco a poco fue desplazando el cultivo del algodón nativo de color.

La presencia de algodón nativo de color fue considerada como amenaza hacia las variedades hibridas introducidas debido a que atraía plagas (como especie silvestre era más resistente que las domesticadas), las disposiciones del ministerio de Agricultura llegaron a prohibir su cultivo a en el año 1940 y no fue considerado en la Ley de Aguas lo que implicaría 
que no recibiría agua del Estado y sus tallos, raíces y semillas serían quemadas después de cada cosecha.

A raíz de esto, el algodón nativo de color sólo se cultivó domésticamente en bajas cantidades en la zona norte del Perú, donde también creció en estado silvestre y forma parte de la tradición rural del norte. No obstante, investigadores como J. Vreeland entre otros destacaron sus propiedades en los años 80. En la primera década del siglo XXI el Gossypium barbadense L. fue declarado, en un marco general de puesta en valor de las tradiciones y biodiversidad nativas siendo declarado como "Patrimonio Natural de la Región Lambayeque", en el 2006 y como "Patrimonio Genético Étnico-cultural de la Nación” el 2008 dejando de esta manera sin efecto la prohibición de su cultivo. (Mincetur 2008).

A grandes rasgos, el algodón nativo de color no fue, después del período prehispánico, un cultivo de aceptación general en la medida en que su exportación fue minoritaria, fue remplazado por otras especies híbridas y hubo la intención de erradicarlo de su área de origen. Además, el algodón nativo de color nunca fue cultivado con mayores cuidados que el de la poda y pese a ello tuvo un buen rendimiento de producción. Esta variedad, legado genético y cultural de la nación, no ha demostrado aun toda su potencialidad.

\subsubsection{Bienes sustitutos y complementarios}

\section{Bienes sustitutos}

El hilo puede estar compuesto por fibras ${ }^{4}$ naturales o químicas; por ello, las propiedades de un tipo de hilo dependen de las fibras por las que está compuesto. Los hilos elaborados con fibras naturales pueden ser de origen vegetal, animal o mineral. . Los bienes sustitutos se describieron en la sección 1.6

\footnotetext{
${ }^{4}$ La fibra es un filamento plegable parecido a un cabello cuyo diámetro es muy pequeño en relación a su longitud.
} 


\section{Bienes complementarios}

En el caso de los hilos que se utilizarán para la elaboración de telas elaboradas con tejido de punto sólo es necesario como producto complementario el suavizante en cambio para los hilos que se utilizaran para elaborar telas elaboradas con tejido plano es necesario la goma de urdiembre, el encolante acrílico para urdiembre y el suavizante.

Goma para urdiembre:

Para poder elaborar telas planas se necesita hacer un baño de goma (encolante) para aumentar la resistencia y disminuir el porcentaje de fibras flotantes; por lo tanto se disminuye la fricción del hilo a hilo al tejer y se aumenta la eficiencia del telar. Debido a que en el hilo existen fibras sueltas o flotantes al momento de aplicarle una alta torsión influye negativamente en la elasticidad del hilo y es causante de roturas de hilo en el telar; por ello, es imprescindible el proceso de engomado.

Encolante acrílico para urdiembre:

Es un polímero acrílico soluble en agua recomendado en las formulaciones de engomado de urdimbres de algodón y sus mezclas con fibras sintéticas. Este está desarrollado para formar películas suaves y flexibles con buen anclaje en los sustratos ayudando así en el deslizamiento de los hilos durante la tejeduría. Asimismo, es un producto compatible con la gama de componentes utilizados en las recetas de engomado

Suavizante:

Se utiliza para conservar la suavidad de la tela y proporcionarle un agradable olor a las prendas cada vez que se lava una tela se le puede echar suavizante. Asimismo, el suavizante cubre la superficie del tejido con químicos lubricantes que reducen arrugas, incrementan la resistencia a las manchas.

\subsubsection{Determinación del área geográfica que abarcará el estudio}

Se decidió vender el hilo elaborado con algodón nativo de color a empresas que elaboran telas y confeccionan prendas de vestir principalmente en la ciudad de Lima y la ciudad de Chincha en la región Ica que dirigen sus productos a los sectores socioeconómicos A y B o que los exportan; ya que, al ser este hilo un producto diferenciado con el valor agregado de 
tener colores naturales sin la necesidad de ser teñido, su valor de venta tiene un costo mayor que un hilo convencional. Por ello, se planea vender este hilo a empresas textiles que elaboran prendas de vestir de alta calidad Asimismo, se podría vender este hilo a empresas que apoyen el desarrollo sostenible y por ende estén interesadas en vender prendas de vestir confeccionadas con un algodón de color natural.

\subsubsection{Determinación de la metodología que se empleará en la investigación de mercado}

- Se investigará cuáles son las fábricas textiles que puedan ser consideradas como potenciales clientes.

- Se hará uso de la estadística para determinar el número de muestra de las fábricas textiles a las cuales se les aplicará una encuesta para determinar el grado de aceptación de compra del hilo de algodón nativo de color.

- Se realizará una encuesta al cliente objetivo quienes son las industrias textiles, sobre todo al área de producción, con el fin de conocer la aceptación del producto y su posible consumo relativo (demanda).

- Con los resultados de la demanda interna aparente se empleará la técnica de la Regresión para proyectar la demanda los siguientes 10 años

- Luego de haber obtenido la demanda interna aparente, mediante el resultado de la encuesta se determinará el porcentaje de aceptación de compra y de acuerdo a ello se determinará la demanda del proyecto.

- Realizar un estudio de campo en donde se sitúan los principales proveedores de algodón nativo de color, con el objetivo de tener datos de primera mano relacionada a la materia prima.

\subsection{Análisis de la demanda}

Se realizó el análisis de la demanda en base al volumen de producción, exportación e importación de hilo de algodón nativo de color. Asimismo, se realizó un análisis de la demanda de hilo de algodón nativo de color considerando la producción de este de forma artesanal e industrial. Cabe recalcar que la siembra de este algodón fue prohibida desde 1934 hasta el 2008 cuando fue declarado Patrimonio Genético Étnico-cultural de la Nación” 
dejando de esta manera sin efecto la prohibición de su cultivo (Ley N ${ }^{\circ} 1401 / 2006$ CR; 1630/2007_CR).

\subsubsection{Demanda histórica}

\subsubsection{Importaciones y exportaciones}

El hilo elaborado con algodón nativo de color se produce mayormente en Lambayeque de forma artesanal. Se tiene conocimiento que la empresa Perú Naturtex Partners E.I.R.L. exporta el hilo elaborado de forma industrial de algodón nativo de color a Europa, Asia y Norte América dado a que la información de las exportaciones de esta empresa es confidencial no se tiene un histórico de sus exportaciones. Sin embargo, se puede calcular el total producido de hilo de este algodón en base a la producción de algodón lo cual incluiría producción y exportación de hilo de algodón nativo, esta información se detallará en la sección 2.1.2.2

Según la información brindada mediante una entrevista por la Ing. Patricia Ocampo, gerente regional de desarrollo productivo de la región Lambayeque, el algodón nativo de color se cultiva de forma artesanal en Ecuador y Brasil; por ello, la producción de este en dichos países se puede considerar escaza. Asimismo, en Perú se produce una cantidad de hilo de este algodón muy superior a la de otros países; por ello, no es necesario importarlo.

\subsubsection{Producción}

La producción de hilo elaborado con algodón nativo de color se produce tanto de forma artesanal como industrial. Según los datos brindados mediante una entrevista por la Ing. Patricia Ocampo gerente regional de desarrollo productivo de la región Lambayeque, el algodón nativo de color es usado en un $80 \%$ para uso industrial y el resto para uso artesanal en Lambayeque.

En base a la información proporcionada por la Ing. Patricia se puede estimar la producción anual de este algodón en rama en base a la producción por hectárea $\mathrm{kg} /$ hectárea y la cantidad de hectáreas sembradas por año. Cabe recalcar, que la información proporcionada es de la producción de este algodón en Lambayeque que es la región donde mayormente se produce, considerando que la siembra en San Martin y Piura es escaza y se 
realiza de forma independiente por unos cuantos campesinos; por ello, se puede considerar despreciable.

Se debe tener en cuenta que toda la producción de algodón nativo de color se destina para la elaboración de hilos lo cuales se pueden producir de forma industrial y artesanal siendo la merma en el primero de $13 \%$ mientras que en el segundo es de $66.67 \%$;ya que, según los datos brindados por Petronila Brenis Farfán, miembro del consejo local de fomento artesanal de la provincia de Ferreñafe, por cada $3 \mathrm{~kg}$ de algodón en rama se produce $1 \mathrm{~kg}$ de hilo de algodón nativo de color; por lo tanto, la merma es de $66,67 \%$.

Cabe recalcar que el algodón nativo de color se siembra (trasplanta) en los meses de mayo y noviembre; y se cosecha en los mismos meses; ya que, el tiempo para cosechar es de 6 meses desde la siembra. Según los datos brindados mediante una entrevista por el Ing. Percy Vásquez presidente de Aspromad (Asociación distrital de productores de maíz amarillo duro y otros cultivos de Mórrope) el algodón nativo de color se cosecha 2 veces al año en los meses de mayo y junio donde se tiene un rendimiento promedio de 1000 $\mathrm{kg} /$ hectárea; y en los meses de octubre y noviembre donde se tiene un rendimiento promedio de $2000 \mathrm{~kg} /$ hectárea; por lo tanto la producción anual es de $3000 \mathrm{~kg} / \mathrm{hectárea.}$

Por último, se debe considerar que en el año 2008 se promulgó una ley que dejo sin efecto la ley que prohibía la producción de algodón nativo de color; por ello, a partir de ese año la producción de este algodón se ha incrementado exponencialmente. 
Tabla 2.8

Producción anual en TM de hilos de algodón nativo de color

\begin{tabular}{|c|c|c|c|c|c|c|c|c|}
\hline Año & Hectáreas & Kg/hectárea & $\begin{array}{c}\text { Algodón } \\
\text { (TM) }\end{array}$ & $\begin{array}{c}\text { Algodón } \\
\text { industrial } \\
\text { (TM) }\end{array}$ & $\begin{array}{c}\text { Algodón } \\
\text { artesanal } \\
\text { (TM) }\end{array}$ & $\begin{array}{c}\text { Merma } \\
\text { Hilo } \\
\text { industrial } \\
\mathbf{1 3 \%}(\mathbf{T M})\end{array}$ & $\begin{array}{c}\text { Merma } \\
\text { hilo } \\
\text { artesanal } \\
\mathbf{6 6 . 6 \%} \\
\text { (TM) }\end{array}$ & $\begin{array}{c}\text { Hilo } \\
\text { industrial } \\
\text { (TM) }\end{array}$ \\
\hline 2010 & 5 & 3,000 & 15 & 12 & 3 & 1.56 & 1.98 & 10.44 \\
\hline 2011 & 25 & 3,000 & 75 & 60 & 15 & 7.8 & 9.99 & 52.2 \\
\hline 2012 & 30 & 3,000 & 90 & 72 & 18 & 9.36 & 11.99 & 62.64 \\
\hline 2013 & 50 & 3,000 & 150 & 120 & 30 & 15.6 & 19.98 & 104.4 \\
\hline
\end{tabular}

Fuente: Ocampo, P.; Vásquez P., (2015)

Elaboración propia.

\section{Mezcla industrial de algodón nativo de color y algodón Tanguiis}

Como se puede apreciar en la tabla 2.8 la merma del proceso artesanal es muy elevada; por ello, al procesarlo industrialmente como se propone en esta tesis se obtendría una mayor productividad debido a que la merma industrial es del $13 \%$. Por lo tanto se procederá a calcular la producción de hilo de algodón nativo de color de forma industrial considerando que el producto final consiste en una mezcla de $63 \%$ de algodón nativo de color y $37 \%$ de algodón Tangüis. Asimismo, la producción de algodón Tangüis es muy superior a la de algodón nativo de color por ello utilizaremos a este último como una restricción para la producción del producto final. Cabe recalcar, que en la tabla 2.9 se ha hecho un supuesto en un cuadro histórico de cuanto hilo obtenido con la mezcla de algodón nativo y algodón Tangüis se hubiese obtenido si hubieran utilizado esta mezcla. Este supuesto se ha hecho con la finalidad de que se obtenga una demanda del proyecto más precisa. 
Tabla 2.9

Producción industrial de la mezcla entre algodón nativo de color y algodón Tangüis (TM)

\begin{tabular}{|c|c|c|c|c|c|}
\hline Año & $\begin{array}{c}\text { Algodón } \\
\text { nativo de color } \\
\text { 63\% }\end{array}$ & $\begin{array}{c}\text { Algodón } \\
\text { Tangüis 37\% }\end{array}$ & $\begin{array}{c}\text { Algodón } \\
\text { total }\end{array}$ & $\begin{array}{c}\text { Merma } \\
\mathbf{( 1 3 \% )}\end{array}$ & Hilo \\
\hline 2010 & 15 & 8.8 & 23.8 & 3.09 & 20.7 \\
\hline 2011 & 75 & 44 & 119 & 15.47 & 103.53 \\
\hline 2012 & 90 & 52.86 & 142.86 & 18.57 & 124.29 \\
\hline 2013 & 150 & 88 & 238 & 30.94 & 207.06 \\
\hline
\end{tabular}

Fuente: Ocampo, P. ; Vásquez P., (2015)

Elaboración propia.

\subsubsection{Demanda interna aparente}

Considerando que la exportación y la importación del hilo elaborado con algodón nativo de color es despreciable según el análisis previamente hecho; por lo tanto, la producción de hilos de algodón nativo de color es igual a la demanda interna aparente (ver tabla 2.10)

Tabla 2.10

Demanda interna aparente en TM de hilo de algodón nativo de color

\begin{tabular}{|c|c|}
\hline Año & DIA (TM) \\
\hline 2010 & 10.44 \\
\hline 2011 & 52.2 \\
\hline 2012 & 62.64 \\
\hline 2013 & 104.4 \\
\hline
\end{tabular}

Fuente: Ocampo, P.; Vásquez P., (2015)

Elaboración propia.

\section{Mezcla industrial de algodón nativo de color y algodón Tangüis}

Como se mencionó anteriormente este caso es un supuesto de que hubiese pasado si se hubiera mezclado el algodón nativo con el algodón Tangüis. Se elaboró este supuesto con el fin de determinar una demanda del proyecto más precisa. En este caso la demanda interna aparente es igual a la producción debido a que la cantidad de hilo de algodón nativo de color que se exporta es despreciable y a que no se importa algodón nativo de color. 
Tabla 2.11

Demanda interna aparente en TM de hilo de algodón nativo de color y algodón Tangüis procesado industrialmente

\begin{tabular}{|c|c|}
\hline Año & DIA \\
\hline 2010 & 20.7 \\
\hline 2011 & 103.53 \\
\hline 2012 & 124.29 \\
\hline 2013 & 207.06 \\
\hline
\end{tabular}

Fuente: Ocampo, P.; Vásquez P., (2015)

Elaboración propia.

Para poder tener un mayor entendimiento de la producción total de hilos en el Perú se obtuvo datos tanto de importación, exportación y producción

Tabla 2.12

Demanda interna aparente en TM de hilo de algodón

\begin{tabular}{|c|c|c|c|c|}
\hline Año & Producción & Importación & Exportación & DIA (TM) \\
\hline 2010 & 41,316 & 7,586 & 694 & 48,207 \\
\hline 2011 & 37,689 & 5,244 & 1,063 & 41.870 \\
\hline 2012 & 35,551 & 8,461 & 1,315 & 42,696 \\
\hline 2013 & 35.986 & 7,628 & 1.265 & 42,348 \\
\hline 2014 & 31,276 & 8.237 & 813 & 38,701 \\
\hline
\end{tabular}

Fuente: Produce y Veritrade Elaboración propia

Como se observa en la tabla 2.12 la demanda interna aparente de hilos de algodón se ha mantenido estable a excepción del año 2010 en la que se tuvo una mayor producción de lo habitual y por ende la demanda interna aparente fue mayor. No obstante a partir del año 2011 se observa un crecimiento en la demanda debido al incremento de las importaciones de hilo que mayormente provienen de la India. 


\subsubsection{Demanda potencial}

\subsubsection{Patrones de Consumo}

El hilo de algodón nativo de color se va a vender a fábricas que confeccionen ropa para los sectores socioeconómicos A y B en Lima. Por ello, se evaluará los patrones de consumo de prendas de vestir en estos sectores. Los principales compradores de ropa son los adultos jóvenes cuya edad está entre los 21 y 35 años; por ello, se hará un estudio de sus hábitos de consumo. En la tabla 2.13 se muestra la relación entre la cantidad de adultos jóvenes y la población total de Lima en el año 2014.

Tabla 2.13

Población del segmento del adulto joven de Lima

\begin{tabular}{|l|c|}
\hline \multicolumn{1}{|c|}{ Población de Lima } & Habitantes \\
\hline Adulto joven (21-35 años) & $2,624,000$ \\
\hline Población total & $9.751,000$ \\
\hline Relación & $26.91 \%$ \\
\hline
\end{tabular}

Fuente: IPSOS APOYO

Elaboración propia

Asimismo, se evaluará la cantidad de población de adultos jóvenes en Lima por segmento socioeconómico como se puede apreciar en el cuadro 2.14.

Tabla 2.14

Población de adultos jóvenes por segmento socioeconómico (miles de habitantes)

\begin{tabular}{|c|c|c|c|c|}
\hline A & B & C & D & E \\
\hline 110 & 469 & 999 & 800 & 246 \\
\hline
\end{tabular}

Fuente: IPSOS APOYO

Elaboración propia

Por lo tanto, la cantidad de adultos jóvenes de los segmentos A y B es de 579,000 habitantes.

\section{Lugar de compra}

Ipsos Apoyo ha realizado una encuesta a adultos jóvenes en Lima, de diferentes NSE, acerca del lugar donde suelen comprar ropa como se puede apreciar en la tabla 2.15 , dando como resultado que la mayoría de personas de los segmentos A y B compran ropa en tiendas por departamento y tiendas de ropa en general, a diferencia de los demás NSE los cuales optan por comprar prendas de vestir en Gamarra. 
Tabla 2.15

Lugares donde se compran prendas de vestir por NSE

\begin{tabular}{|l|c|c|c|c|c|}
\hline & A & B & C & D & E \\
\hline Gamarra & 20 & 41 & 56 & 59 & 55 \\
\hline Galerías / mercado / puestos & 11 & 17 & 38 & 46 & 66 \\
\hline Tiendas de ropa en general & 44 & 39 & 31 & 14 & 13 \\
\hline Tiendas por departamento & 75 & 51 & 27 & 7 & 4 \\
\hline Amigos/ Conocidos & 6 & 4 & 4 & 4 & 2 \\
\hline Boutiques & 12 & 3 & 1 & 1 & 0 \\
\hline
\end{tabular}

Fuente: IPSOS APOYO

Elaboración: IPSOS APOYO

\section{Frecuencia de compra}

Según el estudio elaborado por Ipsos Apoyo en Lima en promedio un joven adulto compra ropa 3 veces al año. En la tabla 2.16 se muestra la frecuencia de compra de ropa de los jóvenes adultos, dando como resultado que la mayor frecuencia de compra es de 2 a 3 meses.

Tabla 2.16

Frecuencia de compra de ropa de los jóvenes adultos (\%)

\begin{tabular}{|l|c|}
\hline \multicolumn{1}{|c|}{ Frecuencia de compra } & Porcentaje \\
\hline Todas las semanas & $1 \%$ \\
\hline Quincenal & $3 \%$ \\
\hline Una vez al mes & $17 \%$ \\
\hline Cada 2-3 meses & $27 \%$ \\
\hline Cada 4-5 meses & $16 \%$ \\
\hline Cada 6-8 meses & $18 \%$ \\
\hline Cada 9-11 meses & $4 \%$ \\
\hline Una vez al año & $6 \%$ \\
\hline Menos de una vez al año & $2 \%$ \\
\hline
\end{tabular}

Fuente: IPSOS APOYO

Elaboración: IPSOS APOYO

\section{Gastos en ropa y calzado}

Según el estudio de nivel socioeconómico en Lima elaborado por Ipsos Apoyo elaborado el 2013, se determinó el gasto promedio mensual por un hogar constituido por 4 personas el cual se ha incrementado en 135 soles con respecto al 2012. En la tabla 2.17 se muestra el gasto promedio mensual por NSE en ropa y calzado, dando como resultado que el gasto en los sectores A y B es superior al de los demás nivel socioeconómicos. 
Tabla 2.17

Gasto promedio mensual en vestido y calzado por NSE

\begin{tabular}{|l|c|c|c|c|c|}
\hline & A & B & C & D & E \\
\hline Vestido y calzado & 262 & 140 & 95 & 67 & 56 \\
\hline
\end{tabular}

Fuente: IPSOS APOYO

Elaboración: IPSOS APOYO

\subsubsection{Determinación de la demanda potencial}

Considerando que el hilo elaborado con algodón nativo de color se produce mayormente en Perú y que en los otros países donde se cultiva como Brasil y Ecuador. En dichos países se cultiva de forma artesanal y se realiza de forma independiente por unos cuantos campesinos; por ello, no se podría comparar la producción de hilo de algodón nativo de color con la de otros países para poder determinar la demanda potencial. Por lo tanto, para poder determinar la demanda potencial se utilizará la siguiente fórmula:

Demanda potencial $=$ clientes $\mathrm{x}$ frecuencia de compra $\mathrm{x}$ cantidad de compra $(\mathrm{kg})$

En base a los resultados obtenidos por "El estudio de demanda de hilo de algodón nativo en la Gran Lima” elaborado por la empresa Mercadeo y Opinión S.A en el año 2015 elaborado por encargo de Ludwig Declercq Pedraza.se determinó la demanda potencial en base a la encuesta que se realizó a las 11 principales empresas textiles que usan hilado de algodón para la confección de prendas de calidad Premium (ver anexo). 
Figura 2.1

Promedio de kilos al año que comprarían del hilo elaborado con algodón nativo de color

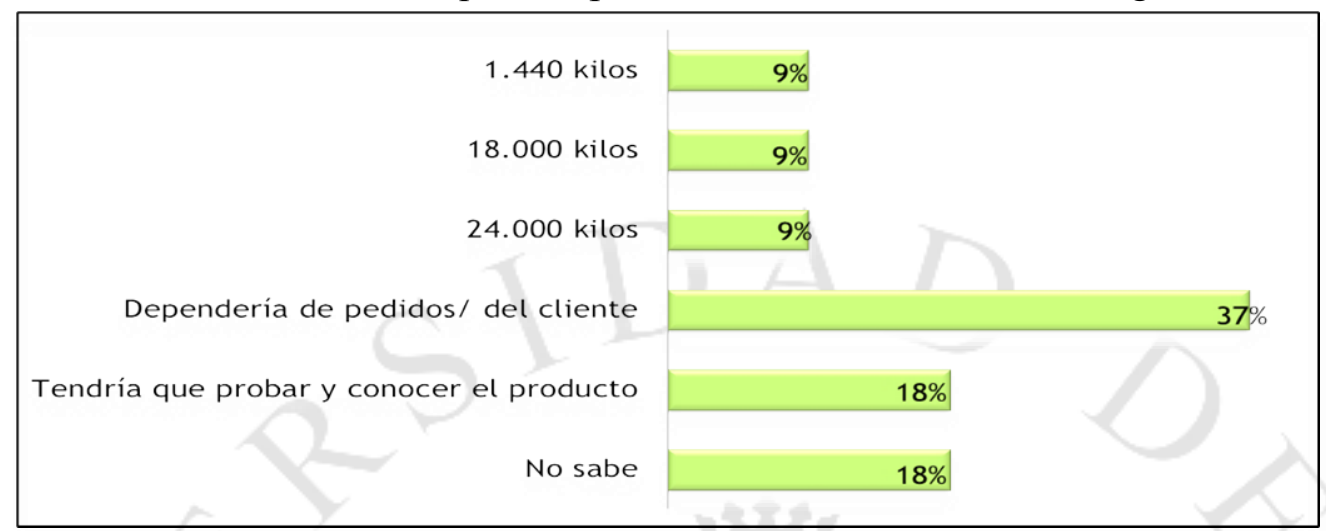

Fuente: Mercadeo \& Opinión S.A

Como se puede apreciar en el figura 2.1, la mayoría de empresas mencionan que dependería de los pedidos de sus clientes y asimismo, desean conocer el producto para poder determinar su demanda potencial pero sí ven con agrado al producto. Con el objetivo de determinar la demanda potencial se considerará que el promedio de compra anual es de 24,000 kilos anuales.

Debido a que la encuesta se realizó sólo 11 empresas estas representan sólo una muestra de la población de fábricas textiles que confeccionan prendas; por ello, para poder estimar la población total se debe definir el total de la población de las fábricas que elaboran telas Premium las cuales son los clientes potenciales del hilo de algodón nativo de color 
Tabla 2.18

Fábricas textiles que elaboran tela Premium

\begin{tabular}{|l|l|}
\hline \multicolumn{2}{|c|}{ Lista de Fábricas } \\
\hline Confecciones Textimax S.A & Peru Fashions S,A.C \\
\hline Corporación Fabril de confecciones S.A & Rhin Textil S.A.C \\
\hline Corporación textil Imperio del Sol S.A & Southern textile Network S.A.C \\
\hline Cotton Knit S.A.C & Textil Carmelita E.I.R.L \\
\hline Devanlay S.A (La Coste) & Textil del Valle \\
\hline Hilandera de Algodón Peruano S.A & Textil only Star S.A.C \\
\hline Inca Designs S.A.C & Textiles Camones S.A \\
\hline Industria textil del Pacifico & Topy top S.A \\
\hline Industrias Nettalco S.A & Textil Océano S.A.C \\
\hline Ideas Textiles S.A.C & Universal Textil S.A \\
\hline Textil del Valle S.A & Consorcio La Parcela S.A \\
\hline Total: 22 & \\
\hline
\end{tabular}

Elaboración propia.

Demanda potencial $=24,000 \times 22$

Demanda potencial $=528,000$ kilos

Por lo tanto, la demanda potencial en el año 2015 es de 528 toneladas de algodón nativo de color.

\subsubsection{Proyección de la demanda y metodología de análisis}

Para proyectar la demanda se realizó una regresión lineal en la cual se proyectó la demanda en base a la demanda interna aparente.

Como a partir del año 2008 se promulgo una ley en la cual dejó sin efecto la ley que prohibía la producción del algodón nativo de color; y por este hecho, a partir de esa fecha se empezó a producir en mayor escala, los primeros años que se tienen registro como el año 2009 y 2010 se sembraron muy poco en comparación a los siguientes años donde ya se tiene una producción más estable; por ello, se hará una proyección de la demanda a partir del año 2011 mediante una regresión lineal en la cual se proyecta la demanda en base a la demanda interna aparente de la mezcla industrial entre algodón nativo de color y algodón Tangüis (tabla 2.19). 
Tabla 2.19

Demanda interna aparente de hilo de algodón nativo de color y algodón Tangüis

\begin{tabular}{|c|c|}
\hline Año & Producción Hilo \\
\hline 2011 & 103.53 \\
\hline 2012 & 124.29 \\
\hline 2013 & 207.06 \\
\hline
\end{tabular}

Fuente: Ocampo, P.; Vásquez P., (2015)

Elaboración propia.

Aplicando regresión lineal

$\mathrm{Y}=\mathrm{A}+\mathrm{BX}$

$\mathrm{A}=41,43$

$\mathrm{B}=51,765$

Para $2014 \quad y=41,43+51,765 \times 4$

$$
\mathrm{Y}=248,49
$$

Para $2015 y=41,43+51,765 \times 5$

$$
\mathrm{Y}=300,26
$$

Para $2016 \quad y=41,43+51,765 \times 6$

$$
\mathrm{Y}=352,02
$$

Siguiendo la misma metodología se halló la demanda interna aparente del hilo de la mezcla entre algodón nativo de color y algodón Tangüis en TM desde el año 2015 hasta el año 2025 (ver tabla 2.20). 
Tabla 2.20

Proyección de la demanda interna aparente

\begin{tabular}{|c|c|}
\hline Año & DIA (TM) \\
\hline 2014 & 248.49 \\
\hline 2015 & 300.26 \\
\hline 2016 & 352.02 \\
\hline 2017 & 403.79 \\
\hline 2018 & 455.55 \\
\hline 2019 & 507.32 \\
\hline 2020 & 559.08 \\
\hline 2021 & 610.85 \\
\hline 2022 & 662.61 \\
\hline 2023 & 714.38 \\
\hline 2024 & 766.14 \\
\hline 2025 & 817.91 \\
\hline
\end{tabular}

Elaboración propia

\subsection{Análisis de la oferta}

\subsubsection{Análisis de la competencia}

\section{Fábricas hilandera de algodón Pima y Tangüis}

Tabla 2.21

Oferta de hilo de las fábricas hilanderas

\begin{tabular}{|c|c|c|c|}
\hline Fábrica & Materia prima & Producción & $\begin{array}{l}\text { Producción anual } \\
\text { (TM) }\end{array}$ \\
\hline Industria Textil Piura & Pima & $480 \mathrm{TM} / \mathrm{mes}$ & 5,760 \\
\hline Ideas textiles S.A.C & Tangüis & $30 \mathrm{TM} /$ día & 10,800 \\
\hline $\begin{array}{l}\text { Textiles de } \\
\text { Sudamérica S.A.C }\end{array}$ & $\begin{array}{l}\text { Lana de alpaca, algodón Pima } \\
\text { y Tangüis }\end{array}$ & No indica & No indica \\
\hline Hialpesa S.A & $\begin{array}{l}\text { algodón con polyster y lana de } \\
\text { alpaca }\end{array}$ & $250 \mathrm{TM} / \mathrm{mes}$ & 3,000 \\
\hline Sur Color Star S.A & No indica & $600 \mathrm{TM} / \mathrm{mes}$ & 7,200 \\
\hline $\begin{array}{l}\text { La colonial fábrica de } \\
\text { hilos S.A }\end{array}$ & $\begin{array}{l}\text { algodón Pima y Tangüis, } \\
\text { polipropileno }\end{array}$ & No indica & No indica \\
\hline Romosa S.A.C & Algodón Pima & $200 \mathrm{TM} / \mathrm{mes}$ & 2,400 \\
\hline \multicolumn{3}{|r|}{ Total } & 29,160 \\
\hline
\end{tabular}

Elaboración propia.

Como se puede apreciar en la tabla 2.21 la oferta actual es de 29,160 TM al año, la cual se aproxima a la producción anual que es de 31,276 TM al año. Cabe recalcar que la oferta debe ser igual a la demanda interna aparente que es de 38,701 TM en el año 2014, pero para ello 
se debe considerar también el total de hilos que importan las fábricas y restarlo con la exportación; por ello, como se puede apreciar la oferta se aproxima a la demanda interna aparente.

\subsubsection{Oferta actual}

\section{Fábricas hilanderas de algodón nativo de color}

\section{Perú Naturtex Partners E.I.R.L}

Es una organización de fabricación por contrato que procesa fibra orgánica de algodón como de algodón nativo de color y lana de alpaca para producir más de 125 productos textiles ecológicos incluyendo hilados peinados y cardados, tejidos y prendas de vestir de amplia variedad.

Los títulos de hilo de algodón que se producen son de $6 \mathrm{Ne}$ a $60 \mathrm{Ne}$ cuyos efectos se pueden lograr mediante la mezcla de colores naturalmente pigmentados con variedades finas blancas. Esta organización terceriza la producción de hilado, tejido y producción de prendas de vestir.

\subsection{Demanda para el proyecto}

\subsubsection{Segmentación de mercado:}

Mediante la herramienta estratégica de segmentación de mercado se dividirá a las fábricas textales en grupos que posean características y comportamientos similares, con el fin de conocer a qué clase de clientes específicos está orientado el producto.

\section{Segmentación geográfica}

Se considerará a todas las fábricas hilandera y productoras de telas que estén ubicadas en Lima e Ica (especialmente en Chincha)

\section{Segmentación sectorial}

Se considerara a las fábricas textiles que estén interesadas en adquirir un hilo de colores naturales sin la necesidad de ser teñidos; y por tal motivo apoyen el desarrollo sostenible. 


\section{Tamaño de empresa}

Empresas medianamente grandes que confeccionen prendas de vestir de alta calidad y de un precio elevado y por ende principalmente dirijan sus productos a los sectores socioeconómicos A y B.

\subsubsection{Selección del mercado meta}

El mercado meta para el hilo elaborado con algodón nativo de color son las empresas que elaboran telas principalmente en la ciudad de Lima y la ciudad de Chincha en la región Ica que dirigen sus productos a los sectores socioeconómicos A y B o que los exportan; ya que, al ser este hilo un producto diferenciado con el valor agregado de tener colores naturales sin la necesidad de ser teñido, su valor de venta tiene un costo mayor que un hilo convencional. Por ello, se planea vender este hilo a empresas que elaboran telas de alta calidad Asimismo, se podría vender este hilo a empresas que apoyen el desarrollo sostenible y por ende estén interesadas en vender prendas de vestir confeccionadas con un algodón de color natural.

\subsubsection{Determinación de la demanda para el proyecto}

Para determinar la demanda del proyecto primero se estableció la demanda que planea captar el proyecto para ello se realizó encuestas a fábricas textiles que elaboran prendas premium y según la siguiente metodología se determinó la demanda del proyecto.

En base a los resultados obtenidos por "El estudio de demanda de hilo de algodón nativo en la Gran Lima” elaborado por la empresa Mercadeo y Opinión S.A en el año 2015 se determinó el nivel de aceptación del hilo de algodón nativo de color en base a la encuesta que se realizó a las 11 principales empresas textiles que usan hilado de algodón para la confección de prendas de calidad Premium.

Primero se realizó la siguiente pregunta: ¿Compraría usted hilo elaborado con algodón nativo de color? 
Figura 2.2

Intención de compra de hilo de algodón nativo de color para usar en confecciones de calidad Premium y/o exportación

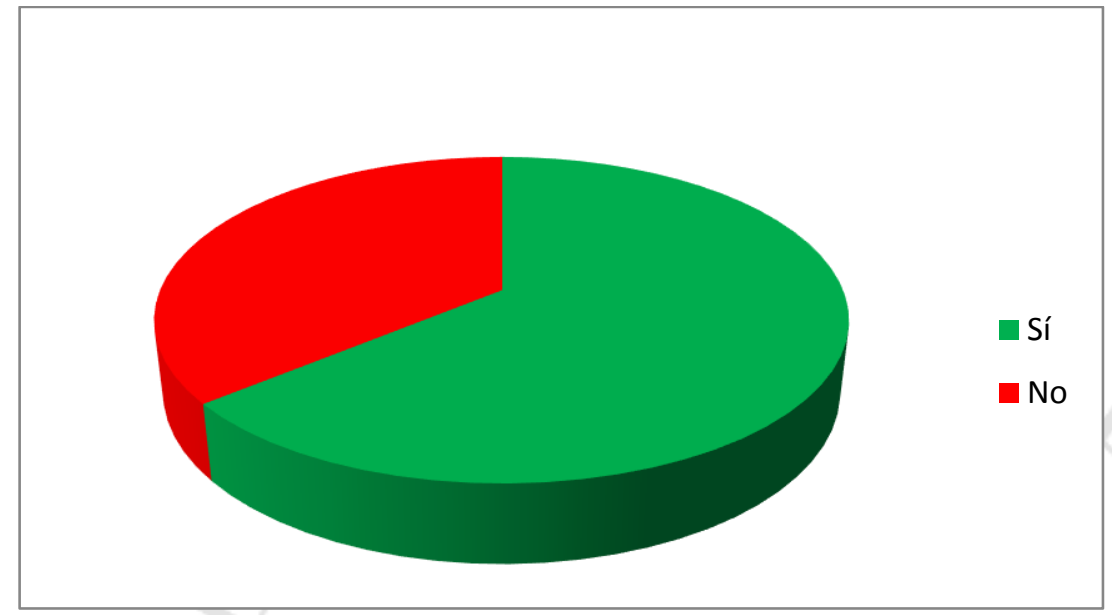

Fuente: Mercadeo \& Opinión S.A

Entonces la intención de compra es del 64\%. Luego se realizó la siguiente pregunta: Si la respuesta de la pregunta uno es afirmativa, en la siguiente escala del 1 al 10 favor señale el grado de intensidad de su probable compra, Siendo 1 probablemente y 10 de todas maneras.

Figura 2.3

Resultado de la encuesta de intención de compra en escala de calificación

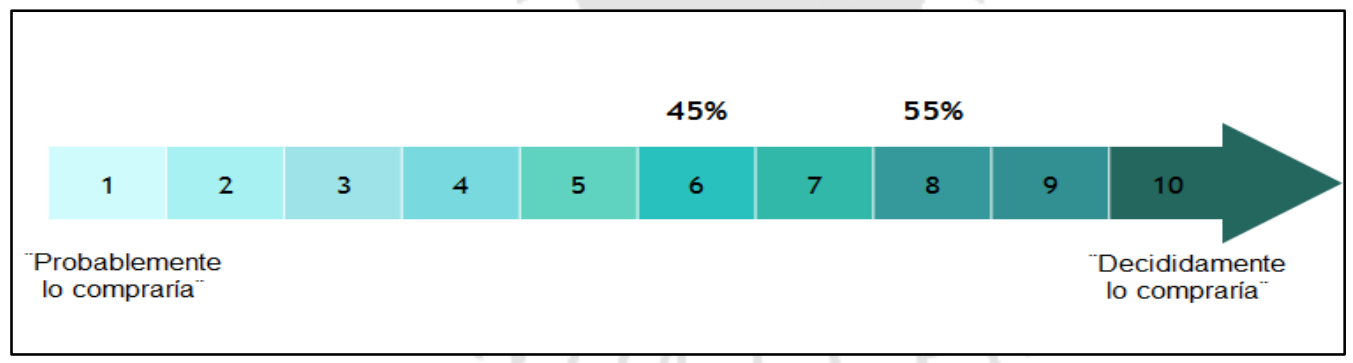

Fuente: Mercadeo \& Opinión S.A

Por lo tanto la intención de compra en el segmento comprador es de 7,1 puntos equivalente a $71 \%$

La corrección de intención de compra es de $64 \%$ x 71\% $=45,4 \%$

Entonces la demanda susceptible de ser captada por el proyecto es de $45,4 \%$ 
Tabla 2.22

Demanda para el proyecto en TM

\begin{tabular}{|c|c|c|}
\hline Año & DIA (TM) & Demanda para el proyecto \\
\hline 2014 & 248.49 & 112.81 \\
\hline 2015 & 300.26 & 136.32 \\
\hline 2016 & 352.02 & 159.82 \\
\hline 2017 & 403.79 & 183.32 \\
\hline 2018 & 455.55 & 206.82 \\
\hline 2019 & 507.32 & 230.32 \\
\hline 2020 & 559.08 & 253.82 \\
\hline 2021 & 610.85 & 277.33 \\
\hline 2022 & 662.61 & 300.82 \\
\hline 2023 & 714.38 & 324.33 \\
\hline 2024 & 766.14 & 347.83 \\
\hline 2025 & 817.91 & 371.33 \\
\hline
\end{tabular}

Elaboración propia

\subsection{Comercialización}

\subsubsection{Políticas de comercialización y distribución}

Para definir las políticas de comercialización se hará una distinción en base a las “4 P's” del Marketing Mix (o mezcla comercial) para implementar las estrategias de mercadeo.

\section{Plaza}

El contacto con los clientes, quienes están en la industria textil y confección, será directo debido a ello el canal de distribución no tendrá intermediarios. Sin embargo, se contará con un camión propio el cual estará asegurado con un seguro de desplazamiento. Este camión se encargará de llevar el producto a los clientes que se encuentran ubicados en la región Lima e Ica.

\section{Producto}

El producto a comercializar propiamente dicho es hilo de algodón nativo de color cuya presentación será en bolsas de 12 conos de hilo de $2 \mathrm{~kg}$.

\section{Precio}

El precio se establecerá de acuerdo a la respuesta del mercado y al precio establecido de los productos similares de la competencia. Además, se tomará en cuenta los costos tanto de producción como de distribución de tal manera que se genere una utilidad favorable. 


\section{Promoción}

Se brindará facilidad a los clientes para poder comprar al crédito y se ofrecerán descuentos por volumen de ventas para aquellas empresas que compren cantidades significativas del producto. Asimismo, se difundirá los beneficios ambientales de comprar hilo de algodón nativo como que posee colores naturales lo cual evita la contaminación ambiental del proceso de teñido

\subsubsection{Publicidad y promoción}

\section{Publicidad}

- Se realizará visitas a nuestros clientes potenciales con la finalidad de llegar a un acuerdo y ofrecer el producto.

- Participación en el comité textil de la sociedad nacional de industrias, cámara de comercio y en la asociación de exportadores ADEX. Para ingresar al comité textil como persona natural se debe hacer un pago de inscripción de 30 soles y el pago adelantado de 2 trimestres por 60 soles.

- Participar la feria "Expo Textil” que se realiza en octubre de cada año con el objetivo de establecer contacto con clientes potenciales.

- Publicidad vía internet: Se contará con una página web de la empresa en donde se hará publicidad al producto, se mostrará la visión y misión, así como también las políticas de la empresa, se responderán las dudas de los consumidores y se ofrecerá tanto un número telefónico como correo electrónico.

\section{Promoción}

Se brindará la facilidad a los clientes de poder comprar al crédito (30 días) como estrategia de expansión de mercado, así como descuentos por volumen para aquellas entidades que compren en cantidades significativas de producto. Además, en los descuentos se considerará el pago al contado (para evitar las cuentas por cobrar y obtener efectivo en caja en caso de necesitarlo) y si la entidad realiza recojo del producto desde la planta (compra directa). 


\subsubsection{Análisis de precios}

\subsubsection{Tendencia histórica de los precios}

Debido a que el hilo de algodón nativo de color recién se ha industrializado no se tiene datos históricos del hilo de este algodón; sin embargo, se tiene datos históricos del hilo de algodón Tangüis el cual se mezclará con el algodón nativo de color y también del algodón Pima el cual es uno de los más utilizados a nivel nacional.

A partir del precio del Kilogramo de algodón se utiliza la siguiente fórmula para poder determinar el precio del hilo de $30 \mathrm{Ne}$ de algodón cardado.

Precio hilo $=$ Precio fibra $(\mathrm{kg}) / 0.87$ (considerando una merma total de $13 \%)+$ costo fijo algodón + margen de ganancia por $\mathrm{Kg}+$ costo de bolsas y transporte

Costo fijo unitario algodón Tangüis $=1.35 \$$ por kilogramo procesado

Costo fijo unitario algodón Pima $=1.60 \$$ por kilogramo procesado

Margen de ganancia por $\mathrm{kg}=0.20 \$$ por kilogramo

Costo bolsas y transporte $=0.06 \$$

Tabla 2.23

Precio histórico de hilo de algodón Tangüis (en dólares)

\begin{tabular}{|c|c|c|c|}
\hline Año & Precio por Kg de & Precio quintales de algodón & Precio de hilo de 30 \\
\hline 2010 & $2-93$ & 134.68 & 4.98 \\
\hline 2011 & 4.52 & 207.96 & 6.81 \\
\hline 2012 & 2.49 & 114.54 & 4.47 \\
\hline 2013 & 1.94 & 89.35 & 3.84 \\
\hline 2014 & 1.62 & 74.50 & 3.47 \\
\hline
\end{tabular}

Fuente: Hialpesa , (2015) 
Tabla 2.24

Precio histórico de hilo de algodón Pima (en dólares)

\begin{tabular}{|c|c|c|c|}
\hline Año & Precio por Kg de & Precio quintales de & Precio de hilo de $30 \mathrm{Ne}$ \\
\hline 2009 & 3.00 & 138.00 & 5.31 \\
\hline 2010 & 3.75 & 172.50 & 6.17 \\
\hline 2011 & 6.33 & 291.07 & 9.13 \\
\hline 2012 & 5.82 & 267.50 & 8.54 \\
\hline 2013 & 4.24 & 195.00 & 6.73 \\
\hline 2014 & 4.33 & 199.00 & 6.83 \\
\hline
\end{tabular}

Fuente: Hialpesa , (2015)

En los cuadros 2.23 y 2.24 aparece el precio por $\mathrm{Kg}$ de fardo el cual es un algodón procesado; es decir, sin pepitas ni ramas por ello es un precio superior al precio de algodón en rama.

\subsubsection{Precios actuales}

En base a los resultados obtenidos por "El estudio de demanda de hilo de algodón nativo en la Gran Lima” elaborado por la empresa Mercadeo y Opinión S.A en el año 2015 (ver anexo), se determinó el precio promedio de algodón Tangüis, Pima y algodón nativo de color al cual están dispuestos a pagar las 11 principales empresas textiles que usan hilado de algodón para la confección de prendas de calidad Premium. 


\section{Hilo de algodón Pima}

Figura 2.4

Precio promedio de hilo de algodón Pima entre 20 a 40 Ne al que compran las fábricas textiles de prendas Premium

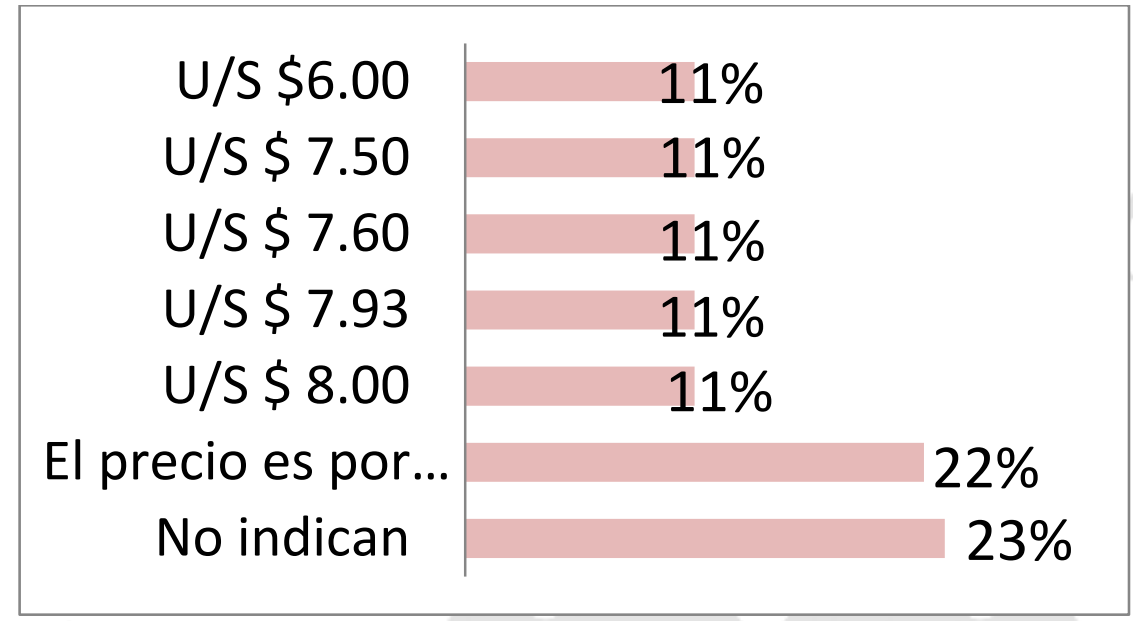

Fuente: Mercadeo \& Opinión S.A

Elaboración: Mercadeo \& Opinión S.A

Por lo tanto, el precio promedio que se paga por hilo de algodón Pima es de $\$ 7,41$

\section{Hilo de algodón Tangüis}

Figura 2.5

Precio promedio de hilo de algodón Tangüis entre 20 a 40 Ne al que compran las fábricas textiles de prendas Premium

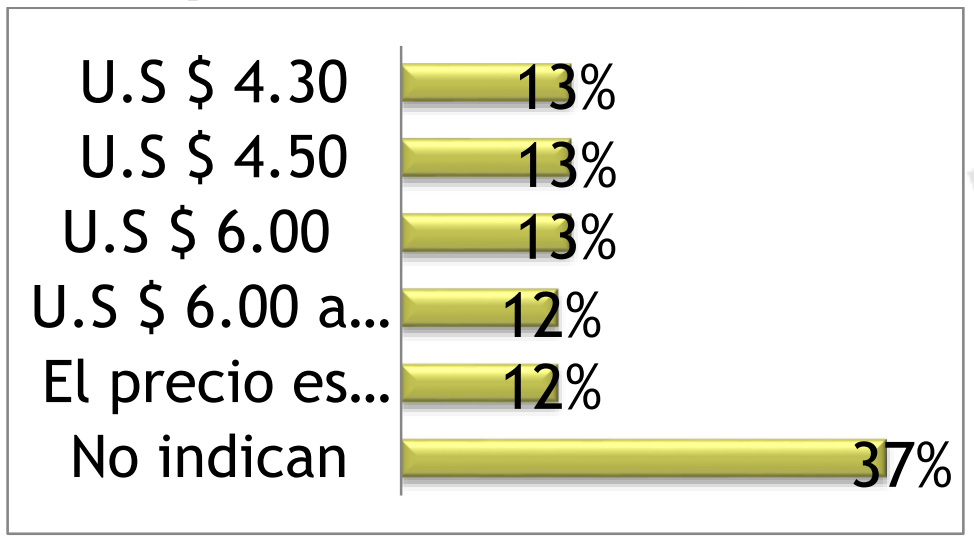

Fuente: Mercadeo \& Opinión S.A

Elaboración: Mercadeo \& Opinión S.A 
Por lo tanto, el precio promedio que se paga por hilo de algodón Tangüis es de $\$ 5,33$

Como dato adicional, se averiguo que el precio del hilo artesanal cuesta 120 soles por kilogramo.

\section{Hilo de algodón nativo de color}

Para poder determinar un precio adecuado para el hilo de algodón nativo de color se formuló la siguiente pregunta: ¿Hasta cuándo estaría dispuesto a pagar por un kilo de hilo de algodón nativo de color.

Figura 2.6

Precio al que están dispuestos a pagar las fábricas que confeccionan prendas de vestir de calidad Premium

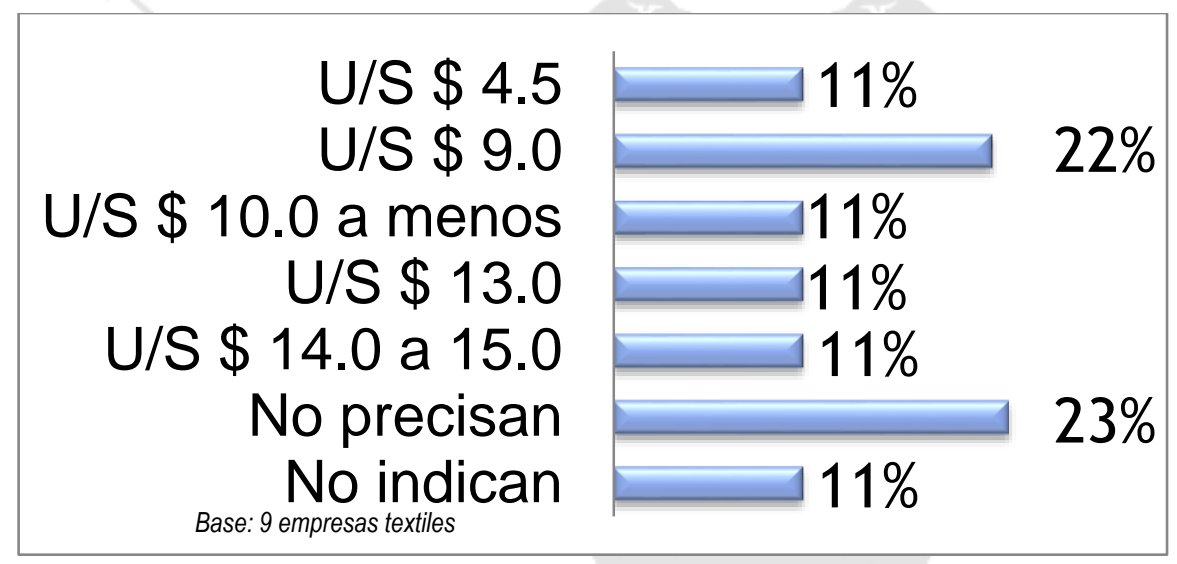

Fuente: Mercadeo \& Opinión S.A

Elaboración: Mercadeo \& Opinión S.A

Por lo tanto, el valor de venta promedio que se paga por hilo de algodón nativo de color es de $\$ 10$.

\section{Precio alternativo del hilo del algodón nativo de color}

Previamente se determinó el precio en base a lo que están dispuestos a pagar las fábricas que confeccionan prendas de vestir de calidad Premium; sin embargo, también se puee determinar un precio en función a los costos y un margen de ganancia. Para ello se empleará la siguiente fórmula 
Precio hilo $=$ Precio fibra $(\mathrm{kg}) / 0.87$ (considerando una merma total de $13 \%)+$ costo fijo algodón + margen de ganancia por $\mathrm{Kg}+$ costo de bolsas y transporte

Precio fibra algodón Tangüis: $1.94 \$ / \mathrm{kg}$

Precio fibra algodón nativo: $3 \$ / \mathrm{kg}$

Precio fibra de la mezcla: 3 x $0.63+1.94 \times 0.37=4.5 \$ / \mathrm{kg}$

Costo fijo unitario algodón Tangüis $=1.35 \$$ por kilogramo

Costo fijo algodón nativo de color $=2.2 \$ / \mathrm{kg}$

Costo fijo de la mezcla $=2.2 \times 0.63+1.35 \times 0.37=1.88 \$ / \mathrm{kg}$

Margen de ganancia por $\mathrm{kg}=0.20 \$$ por kilogramo

Costo bolsas y transporte $=0.06 \$$

Precio $=4.5 / 0.87+1.88+0.2+0.06=7.31 \$ / \mathrm{kg}$

En el capítulo 7 se determinó el costo variable unitario del hilo algodón nativo de color para todos los años de duración del proyecto como se puede apreciar en la tabla 2.25.

Tabla 2.25

Costo variable unitario del hilo de algodón nativo de color

\begin{tabular}{|l|c|c|c|c|c|c|c|c|c|c|}
\hline & 2016 & 2017 & 2018 & 2019 & 2020 & 2021 & 2022 & 2023 & 2024 & 2025 \\
\hline $\begin{array}{l}\text { Costo variable } \\
\text { unitario (S/./kg) }\end{array}$ & 19.7 & 21.0 & 21.0 & 20.7 & 20.9 & 20.7 & 20.4 & 20.7 & 20.7 & 22.0 \\
\hline $\begin{array}{l}\text { Costo variable } \\
\text { unitario }(\$ / \mathrm{kg})\end{array}$ & 5.71 & 6.09 & 6.10 & 6.00 & 6.05 & 5.99 & 5.91 & 5.99 & 5.99 & 6.39 \\
\hline
\end{tabular}

Elaboración propia.

Como se puede apreciar el costo variable unitario más alto corresponde al año 2025 y es de $6.39 \$ / \mathrm{kg}$. Por lo tanto, el precio de hilo de algodón nativo debe ser mayor a $6.39 \$ / \mathrm{kg}$ para generar ganancias. 


\subsection{Análisis de los insumos principales}

\subsubsection{Características principales de la materia prima}

\section{Algodón nativo de color}

El algodón nativo del Perú tiene fibras de distintos colores naturales como crema, marrón, verde, pardo, fifo, lila, blanco y beige. Este algodón se produce mayormente en la región Lambayeque y en menor medida en Piura y San Martin. Según las investigaciones taxonómicas de la Universidad Nacional de Trujillo indican que el centro de diversidad del algodón nativo de color se ubica en la costa norte peruana, desde el rio Moche, en la Libertad hasta el rio Tumbes.

Se caracteriza por ser una planta de desarrollo arbustivo de hasta $5 \mathrm{~m}$ de largo, perenne, muy tardío y de amplia distribución natural. Está adaptada al grado más amplio de altitud que cualquier otra especie algodonera, alcanzando así unos 1,900 $\mathrm{m}$ en los valles interandinos y aproximadamente 1,600 m en las cuencas costeñas; además, no solamente es el más resistente a docenas de plagas, enfermedades bacterianas, fungosas u otras, sino que es resistente a las altas concentraciones de salinidad de los suelos y a la sequía y capaz de sobrevivir en áreas arenosas hasta por cinco años consecutivos sin riego alguno.

Figura 2.7

Algodón nativo de color

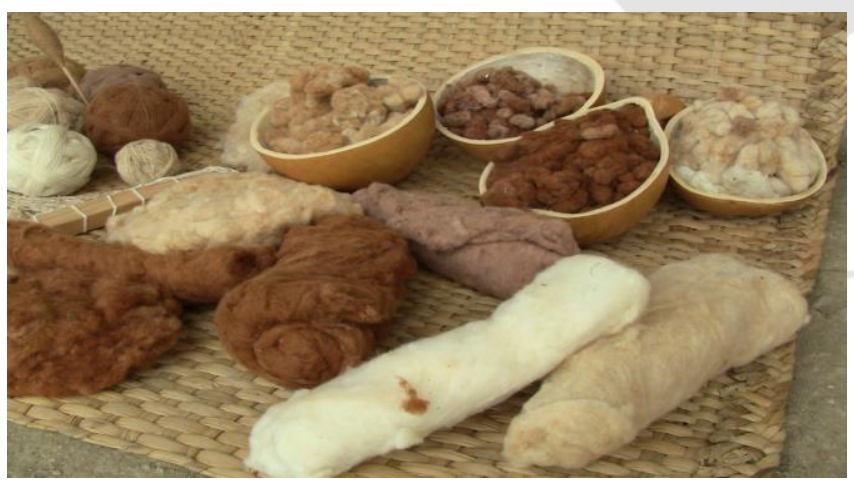

Fuente: Ocampo, P ,(2015) 
Figura 2.8

Plantación de algodón nativo de color

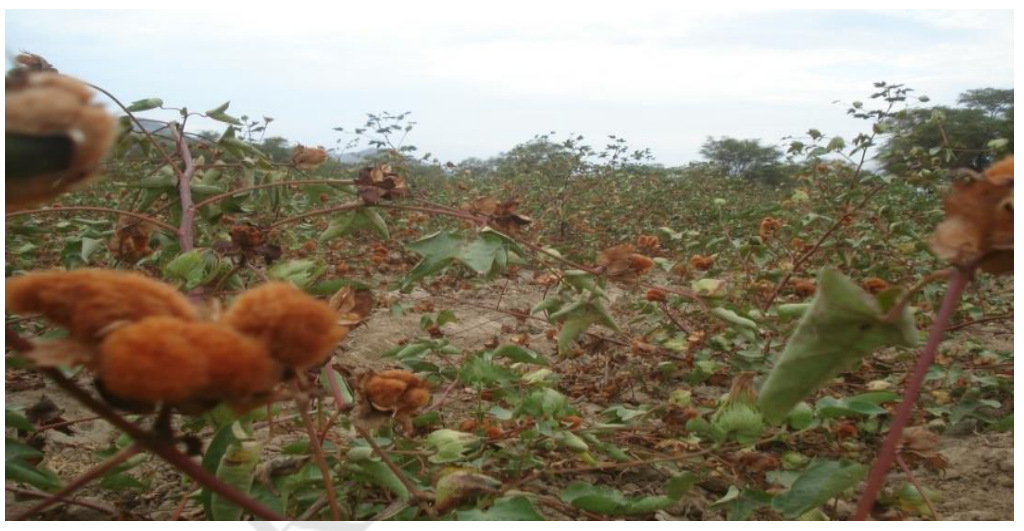

Fuente: Ocampo, $\mathrm{P},(2015)$

Por último, se debe considerar que en el año 2008 se promulgó una ley que dejo sin efecto la ley que prohibía la producción de algodón nativo de color; por ello, a partir de ese año la producción de este algodón se ha incrementado exponencialmente.

\section{Análisis de fibra del algodón nativo de color}

El análisis de la fibra se realiza para determinar los parámetros de calidad, es decir las características físicas, químicas y mecánicas de las fibras textiles que se toman como referencia para determinar los estándares de calidad.

Tabla 2.26

Análisis de las fibras de algodón nativo de color

\begin{tabular}{|l|c|c|c|c|c|}
\hline Color & Micronaire & $\begin{array}{c}\text { Longitud } \\
(\mathbf{m m})\end{array}$ & $\begin{array}{c}\text { Índice de } \\
\text { Uniformidad }\end{array}$ & Resistencia & Elongación \\
\hline Crema & 6.58 & 23.32 & 81.3 & 32.1 & 11.7 \\
\hline Pardo & 5.96 & 24.66 & 77.4 & 25.6 & 12 \\
\hline Verde & 2.89 & 22.22 & 74.5 & 23.9 & 9.4 \\
\hline Marrón & 4.22 & 23.55 & 77.7 & 25.6 & 15 \\
\hline Pardo & 5.63 & 20.73 & 70.3 & 21.5 & 18 \\
\hline
\end{tabular}

Fuente: Vásquez P. y Perez P. 2011 
Tabla 2.27

Análisis de longitud de fibra de algodón nativo de color

\begin{tabular}{|l|c|c|c|c|c|c|}
\hline Rango & $\begin{array}{c}\text { Crema } \\
\text { Oscuro }\end{array}$ & Fifo & $\begin{array}{c}\text { Pardo } \\
\text { claro }\end{array}$ & $\begin{array}{c}\text { Pardo } \\
\text { oscuro }\end{array}$ & Crema & Verde \\
\hline Mínimo & 20 & 11 & 20 & 11 & 20 & 22 \\
\hline Máximo & 25 & 16 & 25 & 15 & 27 & 25 \\
\hline Promedio & 23 & 15 & 23 & 13 & 25 & 25 \\
\hline
\end{tabular}

Fuente: Vásquez P. y Perez P. 2011

Como conclusión se obtuvo que las fibras de mayor longitud son el crema y el verde, con las cuales se pueden hacer hilos de gran calidad y finura; sin embargo, los colores fifo y pardo oscuro arrojaron una corta longitud de fibra que solo permite hacer hilos de grueso calibre

\section{Algodón Tangüis}

El Algodón Tangüis fue desarrollado por un ingeniero peruano cuyo apellido, Tangüis, dio el nombre a esta calidad de fibra. Este algodón crece en los valles irrigados de la costa central y sur del Perú. La combinación de la semilla, la tierra y el clima hace que el Algodón Tangüis tenga una fibra larga. Además, es una variedad de algodón muy fuerte y resistente haciendo las prendas más durables.

La fibra que se obtiene de esta variedad presenta características definidas que la convierten en única, especialmente deseable para mezclas con lana y otras fibras de carácter manufacturado. Se utiliza también en mezclas con otros algodones de inferior calidad. Por la buena calidad de su fibra, el Tangüis es muy apreciado en los mercados internacionales. Se utiliza para la industria textil, industria aceitera, manteca vegetal y margarinas. 
Tabla 2.28

Características del algodón Tangüis

\begin{tabular}{|l|l|}
\hline \multicolumn{1}{|c|}{ Características } & \multicolumn{1}{c|}{ Parámetros } \\
\hline Longitud de fibra & 29.36 a 32.54 \\
\hline Resistencia (lbs $/ \mathrm{pulg}^{2}$ ) & 86 a 88 \\
\hline Finura (micronaire) & 4.6 a 5.8 \\
\hline Color & Blanco \\
\hline
\end{tabular}

Fuente: Franky \& Ricky, (2015)

El hilo que se va a utilizar es la mezcla entre algodón nativo de color y el algodón Tangüis debido a que al mezclarlos se obtiene una fibra de mayor longitud. Las características del algodón que se obtiene como resultado de esta mezcla se puede apreciar en el cuadro 2.3 en el cual indica que la longitud de la fibra resultante es de $27.42 \mathrm{~mm}$ la cual es adecuada para poder ser hilada y obtener un hilo cuyo título sea entre 10 y $40 \mathrm{Ne}$ el cual es apropiado para poder confeccionar prendas de vestir. Asimismo, al predominar en la mezcla el algodón nativo de color se conservan las propiedades de este algodón como la pigmentación de diversos colores que tiene este algodón.

\subsubsection{Disponibilidad de Insumos}

Como se explicó anteriormente el hilo va a ser el resultado de la mezcla entre el algodón nativo de color y el Tangüis; por ello, estos algodones son los insumos principales para la elaboración del hilo.

\section{Algodón nativo de color}

El algodón nativo de color se siembra en las regiones de Piura, San Martin y Lambayeque siendo esta última dónde se produce en mayor cantidad principalmente en los distritos de San José, Túcume, Mórrope y la provincia de Ferreñafe mientras que en Piura y San Martin la producción de este algodón es relativamente poca y se realiza de forma artesanal e independiente por unos cuantos campesinos; por lo tanto, no existen registros certeros de la producción en estas regiones.

Según los estudios realizados por la ingeniera Patricia Ocampo, las zonas de la región Lambayeque, donde se produce, procesa artesanalmente y comercializa productos a base de algodón nativo son las siguientes: 
- Zona de producción: Mocupe y Mochumi

- Zona de producción, artesanía y comercialización: Morrope, Pacora, Túcume, Pitipo, Ferreñafe, Lambayeque y Monsefú.

- Zona de artesanía: San José, Ciudad Eten.

- Zona de comercialización: Chiclayo

La ciudad de Chiclayo se tiene en cuenta como área soporte, distribuidora y comercializadora de los productos terminado. Dicha área de estudio considera además del área de influencia, todo el ámbito de la cadena productiva (ver figura 2.9).

Figura 2.9

Área de producción, comercialización y artesanía del algodón nativo de color

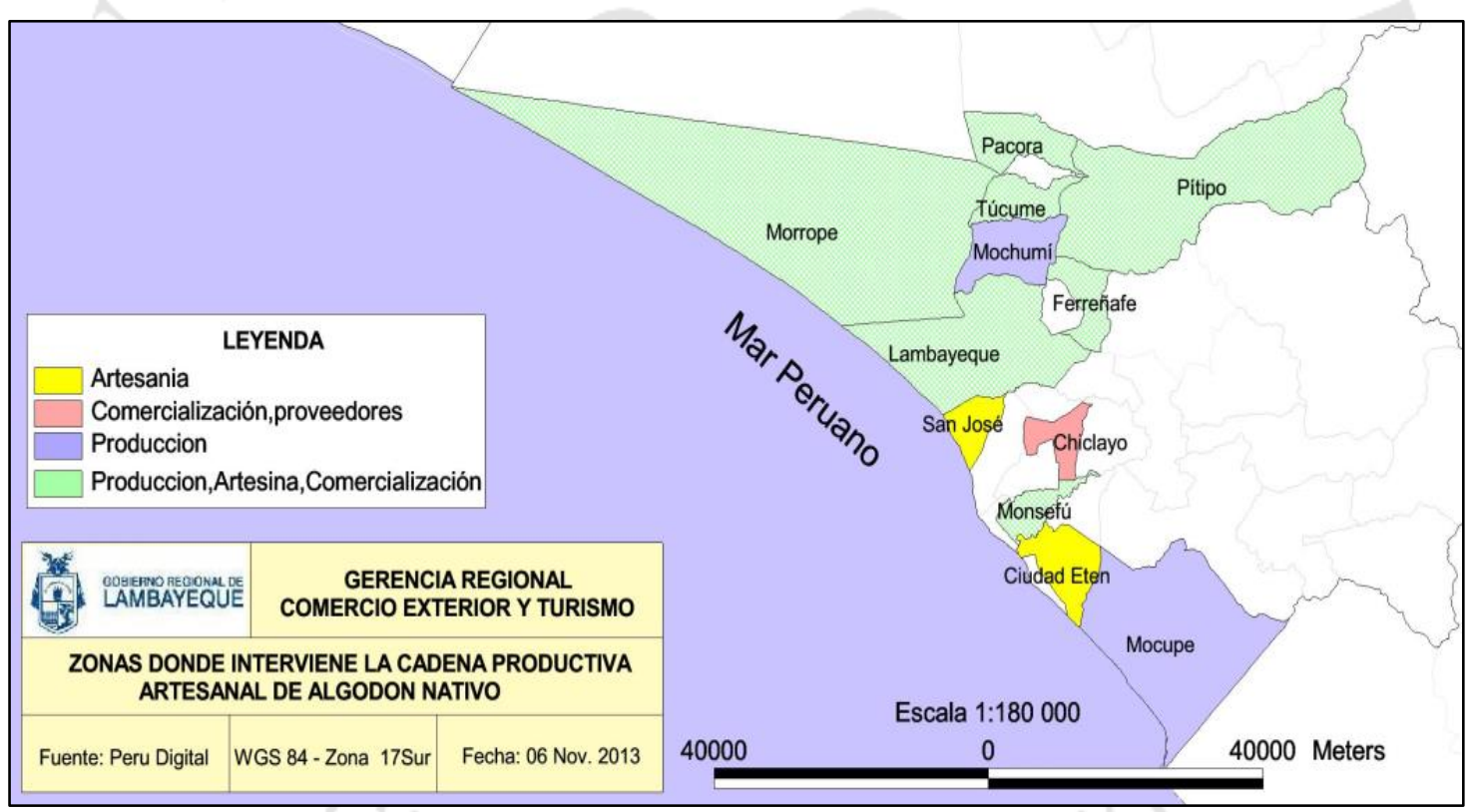

Fuente: Gobierno Regional de Lambayeque.

La producción del Algodón nativo peruano empieza entre los 7 y 12 meses de instalado en campo definitivo, cada color presenta una arquitectura de planta y una producción diferente. Los rendimientos promedios actuales a nivel de parcelas comerciales se encuentran en $1 \mathrm{~kg}$ por planta al año (existen datos de hasta $3 \mathrm{~kg} /$ planta-año). Teniendo en cuenta una densidad de siembra de 2500 plantas/ha se han obtenido rendimientos de 2500 kg de algodón rama,. Esta experiencia fue lograda por la Ing. Patricia Ocampo Escalante 
(Investigadora y formuladora del Proyecto PROPOMAC - Caritas - Fondo Italo Peruano) en donde manifestó que una de clave para el rendimiento de este cultivo es el manejo de densidades de siembra y obtención de semilla de calidad.

Con la información proporcionada por la ingeniera Patricia Ocampo, se puede obtener un histórico de la producción de algodón nativo de color de acuerdo a las hectáreas producidas y el rendimiento en $\mathrm{kg} /$ hectárea desde el año 2009. Asimismo, según el presidente de ASPROMAD (Asociación distrital de productores de maíz amarillo duro y otros cultivos de Mórrope) el Ing. Percy Vásquez Arca el algodón nativo de color se cosecha 2 veces al año en los meses de mayo y junio donde se tiene un rendimiento promedio de 1000 $\mathrm{kg} /$ hectárea; y en los meses de octubre y noviembre donde se tiene un rendimiento promedio de $2000 \mathrm{~kg} /$ hectárea. En el último periodo de producción anual se obtiene un mayor rendimiento de la cosecha debido a mejores condiciones climáticas como un clima más templado; ya que, la bellota abre con más facilidad en dichas condiciones climáticas.

Tabla 2.29

Producción anual en TM de hilos de algodón nativo de color

\begin{tabular}{|c|c|c|c|c|c|c|}
\hline Año & Hectáreas & $\begin{array}{c}\text { TM } \\
\text { /hectárea } \\
\text { (mayo - } \\
\text { junio) }\end{array}$ & $\begin{array}{c}\text { TM } \\
\text { /hectárea } \\
\text { (octubre - } \\
\text { noviembre) }\end{array}$ & $\begin{array}{c}\text { Algodón TM } \\
\text { (mayo - } \\
\text { junio) }\end{array}$ & $\begin{array}{c}\text { Algodón TM } \\
\text { (octubre- } \\
\text { noviembre) }\end{array}$ & $\begin{array}{c}\text { TM algodón } \\
\text { nativo }\end{array}$ \\
\hline 2010 & 5 & 1 & 2 & 5 & 10 & 15 \\
\hline 2011 & 25 & 1 & 2 & 25 & 50 & 75 \\
\hline 2012 & 30 & 1 & 2 & 30 & 60 & 90 \\
\hline 2013 & 50 & 1 & 2 & 50 & 100 & 150 \\
\hline
\end{tabular}

Fuente: Ocampo, P. ; Vásquez P ,(2015)

Cabe recalcar que el algodón nativo de color se siembra (trasplanta) en los meses de abril y noviembre; y se cosecha en los mismos meses. La producción en Kg / hectárea varía de acuerdo al color siendo el color pardo el que tiene mayor producción con 3,000 kg/ hectárea y el color fifo el de menor producción con 1,800 kg/ hectárea; en promedio, la producción es de 2,000 kg / hectárea en óptimas condiciones. Por último, se debe considerar que en el año 2008 se promulgó una ley que dejo sin efecto la ley que prohibía la producción de algodón nativo de color; por ello, a partir de ese año la producción de este algodón se ha incrementado exponencialmente. 


\section{Algodón Tangüis}

El algodón Tangüis se produce en las regiones de Arequipa, Ica, Lima y Ancash. Se tiene un registro histórico de la producción por región como se puede observar en la tabla 2.30

Tabla 2.30

Producción de algodón Tangüis por región en toneladas

\begin{tabular}{|c|c|c|c|c|c|}
\hline Año & Arequipa & Ica & Lima & Ancash & Total \\
\hline 2013 & 269 & 55,553 & 2,605 & 6,029 & 64,456 \\
\hline 2014 & 149 & 59,647 & 2,819 & 4,219 & 66,834 \\
\hline
\end{tabular}

Fuente: Ministerio de Agricultura y Riego

Los datos principales acerca del cultivo de algodón Tangüis son los siguientes:

- Tiempo de cultivo: 10 a 12 meses

- Rendimiento potencial: 80 a 120 quintales por hectárea (3,680 a 5,520 kg/ ha)

- Tiempo de cultivo 7.5 a 8 meses, luego de este tiempo se realizan 2 a 3 cosechas en la que se obtiene el 70 al $85 \%$ de la cosecha total y finalmente el remanente luego procediéndose a la matada o al corte de la parte aérea de la planta.

- Para sembrarlo se deja una distancia de 12 a $13 \mathrm{~cm}$ entre plantas.

\subsubsection{Costos de materia prima}

La materia prima con la cual está constituido el producto es algodón nativo de color y algodón Tianguis; por ello, se evaluará los precios de estos algodones.

En cuanto al algodón nativo de color se comprará algodón a asociación de agricultores de Morrope (Aspromad) los cuales lo venden en pacas de $50 \mathrm{~kg}$ a un precio de 8 soles el kilo. Según lo conversado con el presidente de Aspromad el señor Angel Damian actualmente en dicha asociación siembra 3 hectáreas de algodón nativo; pero si hay demanda en sus campos de cultivo tienen disponibilidad para sembrar hasta 1,500 hectáreas

Posteriormente, este algodón en rama será procesado en una desmotadora en Lambayeque. Recientemente mediante el apoyo del Fincyt se ha establecido una planta de desmote. El precio del algodón desmotado se estimará del siguiente modo:

Como se puede observar en el precio de algodón en rama es de 2.69 soles; mientras que el precio de algodón Tangüis desmotado es de 1.94 dólares (el tipo de cambio a 
diciembre del 2013 es de 2.795 dólares/ sol; por lo tanto, el precio de algodón desmotado es de 5.42 soles). En conclusión el precio de algodón Tangüis desmotado es 2.02 veces el precio de algodón en rama; por ello se puede concluir que el precio de algodón nativo de color es el doble del algodón en rama; por lo tanto, el precio de algodón nativo de color desmotado es de 16 soles $/ \mathrm{kg}$.

El algodón Tangüis tiene un costo de 1.62 dólares por $\mathrm{Kg}$ cabe recalcar que este algodón ha sido desmotado; por ello, tiene un precio mayor al algodón en rama mientras que el algodón nativo de color se compra a un precio de algodón rama debido a que no existe una fábrica desmotadora.

La materia prima se compra en fardos. El fardo de algodón Tangüis está constituido por 5,375 quintales los cuales equivalen a $250 \mathrm{Kg}$ de algodón.

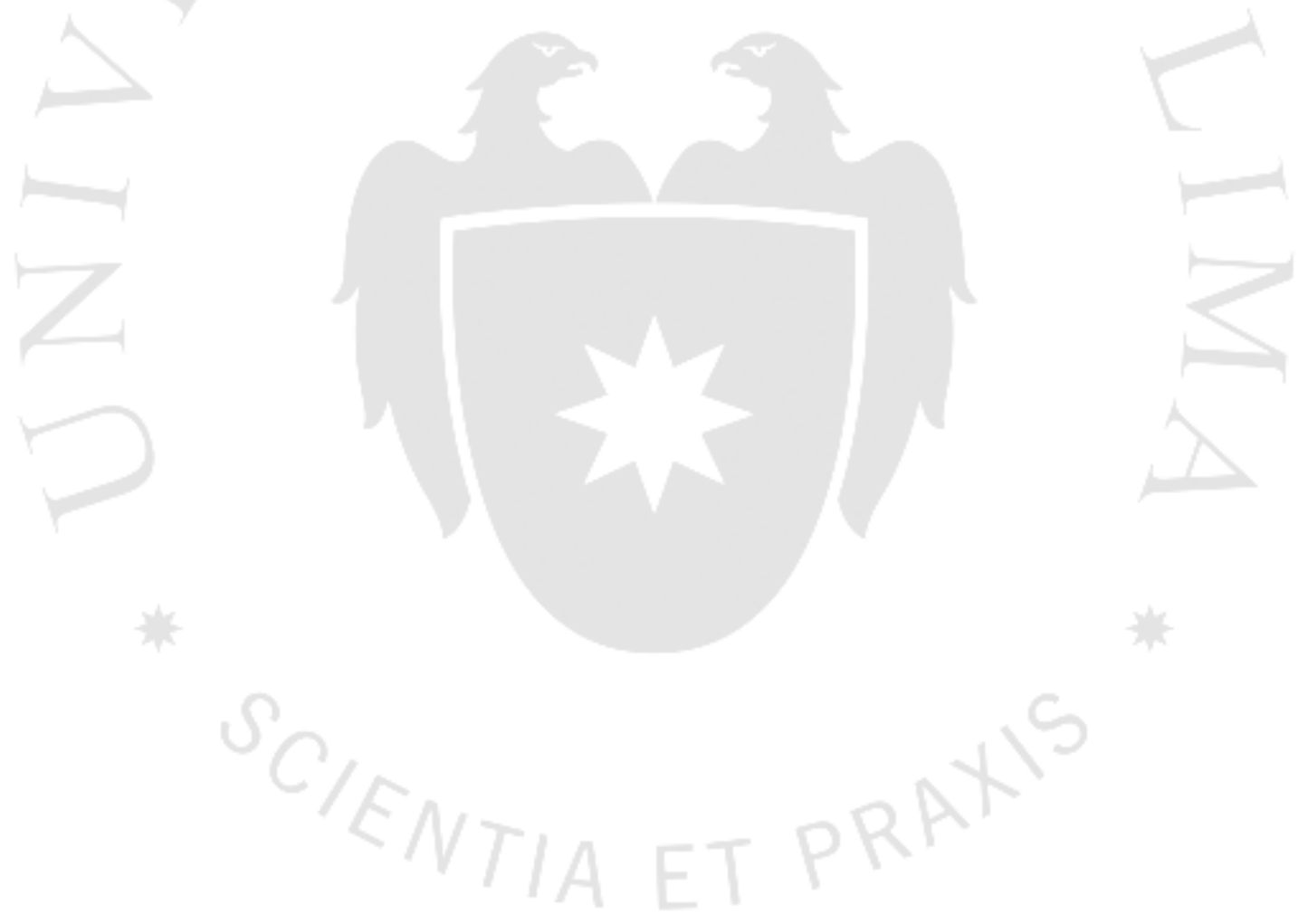




\section{CAPÍTULO III: LOCALIZACIÓN DE PLANTA}

\subsection{Identificación y análisis detallado de los factores de localización}

Se considera que los factores más importantes para la determinación de las posibles ubicaciones en base a factores preliminares son la cercanía de materias primas, cercanía al mercado, facilidades del transporte, disponibilidad de terrenos y mano de obra.

\subsubsection{Cercanía de materias primas}

La materia prima principal es el algodón nativo de color el cual se cultiva en las regiones de Piura, San Martin y Lambayeque siendo esta última dónde se produce en mayor cantidad principalmente en los distritos de San José, Túcume, Mórrope y la provincia de Ferreñafe, Mientras que el algodón Tangüis se cultiva en las regiones de Lima, Ica, Ancash y Arequipa. Cabe recalcar, que los insumos necesarios como el algodón nativo de color y el algodón Tangüis no se importarán; ya que, estos algodones son originarios de Perú.

\subsubsection{Cercanía al mercado}

Este factor es muy importante, pues minimiza el costo de distribución del producto al mercado. Resaltando que el mercado meta es Lima debido a la gran demanda potencial de hilos de algodón nativo de color sobre todo en los sectores de nivel socioeconómico alto. Cabe recalcar que no se piensa exportar hilo de algodón nativo de color debido a que se piensa vender este producto a fábricas peruanas que se encarguen de procesarlo para elaborar telas y prendas de vestir las cuales tendrán un alto valor y se venderán en el Perú y el extranjero.

\subsubsection{Disponibilidad de mano de obra}

La disponibilidad de mano de obra en nuestro país es un factor muy importante ya que se requiere de personas capacitadas en las distintas funciones dentro de la empresa. Se analizará con mayor énfasis la cantidad y calidad de personal capacitado en el trabajo industrial y de profesionales que puedan ocupar cargos importantes en la empresa. 


\subsubsection{Abastecimiento de energía eléctrica}

La futura planta de producción de hilos de algodón nativo de color tendrá una gran demanda de energía ya que el uso de máquinas y de distintas instalaciones será de forma continua. Por lo cual, es muy importante escoger la localidad que brinde mayor potencia y continuidad de este recurso. Además, es esencial evaluar los costos de este servicio por parte de la empresa que nos abastecerá.

\subsubsection{Abastecimiento de agua}

El servicio de agua potable en la localidad a escoger es necesario para ser utilizado en el ablandador de agua el cual proveerá de agua blanda a la cámara de humidificación y para la limpieza de las instalaciones de la planta y para el uso de los servicios higiénicos; ya que, los obreros al momento de terminar su jornada laboral se duchan. En verano el costo sube un poco ya que los obreros usan su hora de descanso para ducharse por el incesante calor que hay en la planta. Sin embargo, no se requiere de mucha agua para el proceso productivo por lo tanto, este factor no es tan importante como el abastecimiento de energía.

\subsubsection{Transporte}

Dentro de este factor, es muy importante mencionar el estado de las carreteras y el costo de transporte que brindan las empresas de este rubro. El transporte de productos terminados hacia el mercado y el transporte de las materias primas hacia la fábrica es un punto importante ya que se deberá escoger la región con fletes más baratos.

El medio de transporte sería terrestre se tiene en cuenta la facilidad de accesibilidad y estado de pistas o carreteras. Un punto a favor es que para transportar algodón no se requiere ningún trato especial, el algodón no sufre demasiado maltrato en su trayecto por lo que podría llevarse lejos de su lugar de origen, aunque por otro lado, significaría un incremento de los costos ligados al transporte 


\subsubsection{Disponibilidad de terrenos y sus costos}

Para la evaluación y posterior elección, se debe tomar en cuenta la región que disponga de mejores y adecuados espacios para la instalación de una planta industrial, sin dejar de lado el impacto ambiental generado en la zona. Por otro lado, se evaluará los costos del metro cuadrado en cada región y posteriormente en cada localidad.

\subsection{Identificación y descripción de las alternativas de localización}

La localización de la planta de producción es un punto importante en el desarrollo del proyecto, según lo desarrollado en los anteriores capítulos, se determinó que el origen de la materia prima es principalmente en el norte del país Piura, San Martin y principalmente en Lambayeque y el mercado meta es Lima Metropolitana. Por lo tanto, en el siguiente capítulo se analizan los diversos factores y su influencia dentro de la evaluación de localidades mediante métodos y técnica de ingeniería para concluir con la mejor ubicación. Por ello, se propone con lugares tentativos para la localización de planta a Lima, Lambayeque y San Martin.

\subsubsection{Proximidad a las Materias Primas}

El cultivo de algodón nativo de color se centra en el norte del país en las regiones de Piura, San Martín y Lambayeque. Cabe recalcar, que en una hectárea se produce $2500 \mathrm{~kg}$ de algodón nativo de color en rama cuyo precio es 8 soles por kilo. Mientras que el algodón Tangüis se cultiva en las regiones de Lima, Ica, Ancash y Arequipa y su precio es de 4,86 soles por kilogramo.

En conclusión, debido a que la materia prima principal es el algodón nativo de color y teniendo como referencia la distancia del mercado meta, Lima, hasta Moyobamba la capital de San Martin es de 1,378 km mientras que la distancia de Chiclayo en Lambayeque hasta Lima es de $775 \mathrm{~km}$ (ver cuadro 3.1). Asimismo, teniendo en consideración que el algodón Tangüis se cultiva en Lima y Ica, resulta más conveniente ubicar la planta en Lima y obtener el algodón nativo de color de Lambeyeque y el algodón Tangüis desde Lima. 
Tabla 3.1

Distancia entre las regiones y el mercado meta Lima $(\mathrm{km})$

\begin{tabular}{|c|c|c|c|}
\hline & Lima & Lambayeque (Chiclayo) & San Martin \\
\hline Lima & 0 & 775 & 1,378 \\
\hline
\end{tabular}

Fuente: Ministerio de transportes y comunicaciones Elaboración propia

\subsubsection{Cercanía al mercado}

La mayor parte de la demanda se encuentra en Lima; ya que, ahí se concentran la mayoría de fábricas textiles que se dedican a confeccionar prendas de vestir de alta calidad y orientadas al segmento socioeconómico A y B; por lo tanto, el mercado meta es Lima consecuentemente tener la planta de producción cerca de esta ciudad significaría minimizar los costos de transporte y agilizar la comunicación con los clientes. Sin embargo, también se propone vender el hilo del algodón nativo de color a fábricas textiles que se encuentran en el interior del país. En el cuadro 3.2 se puede apreciar la distribución geográfica de empresas operativas del subsector de fabricación de hilados y tejidos se analizó esta variable debido a que se deseaba saber en qué región del país se encuentra concentrada la industria textil.

Tabla 3.2

Concentración geográfica de empresas operativas del subsector de fabricación de hilados y tejidos

\begin{tabular}{|l|r|r|}
\hline \multicolumn{1}{|c|}{ Región } & empresas & \multicolumn{1}{c|}{$\%$} \\
\hline Lima & 472 & $64.8 \%$ \\
\hline Puno & 67 & $9.2 \%$ \\
\hline Arequipa & 42 & $5.8 \%$ \\
\hline Callao & 37 & $5.1 \%$ \\
\hline Junín & 28 & $3.8 \%$ \\
\hline Ica & 11 & $1.5 \%$ \\
\hline Otros & 71 & $9.8 \%$ \\
\hline Total & 728 & $100.0 \%$ \\
\hline
\end{tabular}

Fuente: Ministerio de la producción

Elaboración: Ministerio de la producción

En conclusión, según este factor sería más conveniente ubicar la planta en Lima que en Lambayeque y San Martin; ya que, el mercado meta son las fábricas textiles que orientan su producción al segmento socioeconómico A y B las cuales principalmente se ubican en Lima 


\subsubsection{Disponibilidad de mano de obra}

En una fábrica de hilar se necesita mano de obra calificada en la carrera técnica de mecánico textil en hilandería la cual se dicta en el SENATI de Lima; ya que, se requiere de operarios capaces de poder operar las máquinas que se utilizan en el proceso de hilado. Asimismo se requiere de Ingenieros textiles para que puedan dirigir las fábricas, esta carrera se dicta en la Universidad Nacional de ingeniería (UNI) y la Universidad tecnológica del Perú (UTP) las cuales se ubican en Lima.

En conclusión según este factor sería más conveniente ubicar la planta en Lima que en Lambayeque y San Martin debido que en Lima se encuentran la mayoría de operarios capacitados para poder operar las máquinas que intervienen en la hilatura así como profesionales calificados en el rubro textil.

\subsubsection{Abastecimiento de energía eléctrica}

En lo que respecta al factor de abastecimiento de energía eléctrica, se analizará básicamente el tema de los precios del proveedor de la zona geográfica. Debido a que se trata de una planta industrial, se analizará de acuerdo a la tarifa MT3; ya que, se requiere una potencia mayor a $90 \mathrm{~kW}$ por ello debe ser una tarifa de media tensión en vez de baja tensión (ver tabla $3.3)$.

La tarifa MT3 está dirigida para aquellos usuarios cuyos consumos de potencia se da durante todo el día; por lo tanto, es adecuada para la fábrica de hilar algodón nativo de color; ya que, esta operará desde las 6 am hasta las 11 pm. 
Tabla 3.3

Tarifas de electricidad

\begin{tabular}{|c|c|c|c|}
\hline Región & $\begin{array}{c}\text { Cargo } \\
\text { Fijo } \\
\text { Mensual }\end{array}$ & $\begin{array}{c}\text { Cargo por } \\
\text { Energía } \\
\text { Activa en } \\
\text { hora punta }\end{array}$ & $\begin{array}{c}\text { Cargo por } \\
\text { Energía Activa } \\
\text { en hora fuera de } \\
\text { punta }\end{array}$ \\
\cline { 2 - 4 } & $\mathrm{S} / . / \mathrm{mes}$ & Ctm. & Ctm. S/./kW.h \\
\hline Lima Norte & 3.02 & 17.60 & 14.60 \\
\hline Lima Sur & 3.02 & 17.64 & 14.62 \\
\hline Lambayeque & 6.25 & 18.64 & 15.62 \\
\hline San Martin & 6.43 & 24.61 & 20.22 \\
\hline
\end{tabular}

Fuente: OSINERGMIN

Elaboración propia

En conclusión, el precio de potencia y energía más económico es en Lima con respecto a Lambayeque y San Martin.

\subsubsection{Abastecimiento de agua}

Respecto al punto del abastecimiento de agua, el análisis se enfocará en el costo del servicio. Por lo tanto, se comparará las tarifas industriales mensuales de las tres empresas que brindan este servicio: SEDAPAL S.A., EPSEL S.A, EMAPA SAN MARTIN S.A.

Tabla 3.4

Tarifas de agua

\begin{tabular}{|c|c|c|c|c|c|}
\hline \multirow[t]{2}{*}{ Región } & \multirow[t]{2}{*}{$\begin{array}{c}\text { Empresa } \\
\text { Proveedora }\end{array}$} & \multirow[t]{2}{*}{$\begin{array}{c}\text { Rango } \\
\left(\mathbf{m}^{\mathbf{3}}\right)\end{array}$} & $\begin{array}{l}\text { Tarifa } \\
\mathrm{m}^{3}\end{array}$ & $\begin{array}{c}\text { Tarifa } \mathrm{m}^{3} \\
\text { alcantarillado }\end{array}$ & $\begin{array}{l}\text { Total agua }+ \\
\text { alcantarillado }\end{array}$ \\
\hline & & & $\mathrm{S} /$. & $\mathrm{S} /$. & $\left(\mathrm{S} / . / \mathrm{m}^{3}\right)$ \\
\hline Lima & SEDAPAL & $0-1000$ & 4,490 & 1,962 & 6.416 \\
\hline Lambayeque & EPSEL S.A & 0 a más & 7,052 & 3.116 & 10,168 \\
\hline San Martin & EMAPA & $100 \mathrm{a}$ & 4,549 & 1,244 & 5,793 \\
\hline
\end{tabular}

Fuente: SEDAPAL S.A., EPSEL S.A. EMAPA SAN MARTIN S.A.

Elaboración propia

En conclusión, la tarifa de agua más económica es en San Martin con respecto a Lima y Lambayeque, Asimismo, como se puede observar en el cuadro 3.4, la tarifa de Lambayeque es mucho más cara que las demás. 


\subsubsection{Transporte}

Con relación al transporte se tomará en cuenta la longitud total de carreteras que existen en cada región a evaluar, la distancia desde cada región hacia el mercado meta (Lima) y el costo del flete.

\section{Tabla 3.5}

Red vial por sistema de carreteras del 2012

\begin{tabular}{|c|c|c|c|c|c|c|c|c|c|c|}
\hline \multirow{3}{*}{ REGIÓN } & \multirow{3}{*}{$\begin{array}{l}\text { LONGITUD } \\
\text { TOTAL }\end{array}$} & \multicolumn{9}{|c|}{ SISTEMA DE CARRETERA (Kms.) } \\
\hline & & \multicolumn{3}{|c|}{ NACIONAL } & \multicolumn{3}{|c|}{ DEPARTAMENTAL } & \multicolumn{3}{|c|}{ VECINAL $(*)$} \\
\hline & & $\begin{array}{c}\text { SUB- } \\
\text { TOTAL }\end{array}$ & Pavimento & $\begin{array}{c}\text { No } \\
\text { Pavimento }\end{array}$ & $\begin{array}{l}\text { SUB- } \\
\text { TOTAL }\end{array}$ & Pavimento & $\begin{array}{c}\text { No } \\
\text { Pavimento }\end{array}$ & $\begin{array}{c}\text { SUB- } \\
\text { TOTAL }\end{array}$ & Pavimento & $\begin{array}{c}\text { No } \\
\text { Pavimento }\end{array}$ \\
\hline Lima & $7,378.2$ & $1,450.4$ & 1,454 & 396.4 & 1,687 & 158 & $1,528.9$ & $4,240.8$ & 180.5 & $4,060.2$ \\
\hline Lambayeque & $3,171.3$ & 467.6 & 410.5 & 57.2 & 642.5 & 213.8 & 428.8 & $2,061.2$ & 27.6 & $2,033.6$ \\
\hline San Martin & $\begin{array}{l}4,729.8 \\
\end{array}$ & 848.1 & 594.7 & 253.4 & 882 & 151 & 731 & $2,999.7$ & 14.8 & $2,984.8$ \\
\hline
\end{tabular}

Fuente: Grupo Técnico de Trabajo (DGCF, PVN, PVD y OGPP)

Elaboración: Ministerio de Transportes y Comunicaciones

Como se puede apreciar en el cuadro 3.5 en Lima tiene la mayor longitud de carreteras; es decir, tiene una mejor red vial que las otras regiones.

\section{Tabla 3.6}

Distancia desde cada alternativa de localización hacia el mercado meta (Lima) en Km

\begin{tabular}{|c|c|}
\hline Distancia desde / hacia & Lima \\
\hline Lima & 0 \\
\hline Lambayeque (Chiclayo) & 775 \\
\hline San Martin (Moyobamba) & 1,378 \\
\hline
\end{tabular}

Fuente: Ministerio de transportes y comunicaciones

Elaboración propia

Como se puede apreciar en el cuadro 3.6 resulta más conveniente localizar la planta en Lima ya que el mercado meta está en dicha región. Asimismo, la distancia de Lambayeque a Lima es de $775 \mathrm{~km}$ mientras que la distancia de San Martin a Lima es de 1,378 km.

Asimismo, considerando que el algodón en rama se comprará en sacos de $50 \mathrm{~kg}$ se elabora un cuadro con el precio por tonelada del transporte. 
Tabla 3.7

Costo del flete de producto terminado desde cada alternativa de localización hacia el mercado meta (soles/tonelada)

\begin{tabular}{|c|c|}
\hline & Lima \\
\hline Lima & 0 \\
\hline Lambayeque & 180 \\
\hline San Martin & 220 \\
\hline
\end{tabular}

Fuente: Trans Molina

Como se puede apreciar resulta más conveniente localizar la planta en lima; ya que, el costo del flete desde Lambayeque es de 180 soles por tonelada mientras que el costo del flete de San Martin a Lima es de 220 soles por tonelada.

\subsubsection{Disponibilidad de terrenos y costos}

La disponibilidad de terrenos es un punto muy importante y determinante para elegir la región más adecuada. Considerando que Lima cuenta con parques industriales en mejores condiciones y más grandes en comparación a lo que se puede encontrar en otras regiones del país, en este caso, enfocándose a Lambayeque y San Martin. Sin embargo, Lima está llegando a un tope de saturación en lo que respecta a terrenos industriales, lo que implica que el precio del metro cuadrado siga inflándose.

En conclusión, si bien es cierto el precio por metro cuadro en Lima es más caro que en otras regiones del país, al haber mejores parque industriales resulta un lugar atractivo para ubicar la fábrica.

\subsection{Evaluación y selección de la localización}

\subsubsection{Evaluación y selección de la macro localización}

La evaluación de la macro localización se realizó mediante el método de la matriz de enfrentamiento de factores 
Tabla 3.8

Matriz de enfrentamiento de factores

\begin{tabular}{|c|c|c|c|c|c|c|c|c|c|}
\cline { 2 - 11 } \multicolumn{1}{c|}{} & P.M.P & C.M & M.O & E.E & AGUA & T & D.T & Sumatoria & Ponderado \\
\hline P.M.P & & 0 & 1 & 1 & 1 & 1 & 1 & 5 & 0.22 \\
\hline C.M & 1 & & 1 & 1 & 1 & 1 & 1 & 6 & 0.26 \\
\hline M.O & 0 & 0 & & 0 & 1 & 1 & 1 & 3 & 0.13 \\
\hline E.E & 0 & 0 & 1 & & 1 & 1 & 1 & 4 & 0.17 \\
\hline AGUA & 0 & 0 & 0 & 0 & & 1 & 0 & 1 & 0.04 \\
\hline T & 0 & 0 & 0 & 0 & 1 & & 0 & 1 & 0.04 \\
\hline D.T & 0 & 0 & 1 & 0 & 1 & 1 & & 3 & 0.13 \\
\hline
\end{tabular}

Elaboración propia

Basándose en la siguiente tabla de calificación:

Tabla 3.9

Escala de evaluación

\begin{tabular}{|c|c|}
\hline Calificación & Puntaje \\
\hline Excelente & 10 \\
\hline Muy Bueno & 8 \\
\hline Bueno & 6 \\
\hline Regular & 4 \\
\hline Deficiente & 2 \\
\hline
\end{tabular}

Elaboración propia

Se obtuvo lo siguiente:

Tabla 3.10

Matriz de evaluación de localidades

\begin{tabular}{|c|c|c|c|c|c|c|c|}
\cline { 3 - 8 } \multicolumn{1}{c|}{} & \multicolumn{2}{c|}{ Lima } & \multicolumn{2}{c|}{ Lambayeque } & \multicolumn{2}{c|}{ San Martin } \\
\cline { 2 - 9 } \multicolumn{1}{c|}{} & Ponderación & Calificación & Puntaje & Calificación & Puntaje & Calificación & Puntaje \\
\hline P.M.P & 0.22 & 4 & $0 ., 88$ & 10 & 2.2 & 10 & 2.2 \\
\hline C.M & 0.26 & 10 & 2.6 & 4 & 1.04 & 2 & 0.52 \\
\hline M.O & 0.13 & 10 & 1.3 & 4 & 0.52 & 4 & 0.52 \\
\hline E.E & 0.17 & 10 & 1.7 & 6 & 1.02 & 4 & 0.68 \\
\hline AGUA & 0.04 & 8 & 0.32 & 10 & 0.4 & 4 & 0.16 \\
\hline T & 0.04 & 10 & 0.4 & 6 & 0.24 & 4 & 0.16 \\
\hline D.T & 0.13 & 8 & 1.04 & 6 & 0.78 & 4 & 0.52 \\
\hline
\end{tabular}

Elaboración propia

Como resultado de la aplicación de este método se elige la región Lima como el lugar donde se instalará la planta. 


\subsubsection{Evaluación y selección de micro localización}

Según el resultado del punto anterior, Lima fue escogida como la mejor opción en el ámbito regional. A continuación, se realizará un análisis con la misma metodología a partir del cual se escogerá el distrito en donde se ubicará la planta. Las opciones a examinar son: Independencia, Lurín y Lurigancho (Huachipa), debido a que son considerados distritos industriales que cuentan con locales legalmente certificados. Los factores considerados para la micro localización son cercanía de mercado, abastecimiento de energía eléctrica, costo de alquiler del local industrial y disponibilidad de local.

\section{Cercanía de mercado}

La cartera de potenciales clientes; es decir, fábricas textiles que fabrican tela y confeccionan prendas de vestir con sus respectivas ubicaciones se muestra en la tabla 3.11

\section{Tabla 3.11}

Dirección de los clientes potenciales

\begin{tabular}{|l|l|}
\hline \multicolumn{1}{|c|}{ Fábrica } & \multicolumn{1}{c|}{ Dirección } \\
\hline Devanlay S.A. & Av. Argentina Nro. 2743 Urb. Los Pinos, cercado de \\
\hline Confecciones Textimax S.A. & Av. Huarochirí 151, Santa Anita. \\
\hline Topy Top S.A. & Av. Alipio Ponce 1028, San Juan de Miraflores. \\
\hline Industrias Nettalco S.A. & Calle cinco, 115 Urb. Vulcano, Ate \\
\hline Corporación Fabril de Confecciones S.A. & Av. San Andrés 6299; Los Olivos \\
\hline Peru Fashions & Calle los hornos 251, Urb. Infantas. Los Olivos. \\
\hline Textil del Valle & Car. Panamericana Sur Km. 200 el Pedregal, Chincha \\
\hline Industria Textil del Pacífico & Av. Guillermo Dansey Nro. 1873, Cercado de Lima \\
\hline Cotton Knit S.A.C. & Jr. Santa Sofia Nro. 137, Ate \\
\hline Inka Designs SAC & Av. Lurigancho Nro. 1274, San Juan de Lurigancho \\
\hline Southern Textile Network SAC & Chincha - Ica \\
\hline Rhin Textil SAC & Los Talladores Mz.I-2, Lt 16 Urb. Industrial El \\
\hline Textil Carmelita E.I.R.L. & Mz C lote 6 y 19 zona industrial, Villa El Salvador \\
\hline Textil Only Star SAC & Av. Industrial Nro. 3248, Independencia \\
\hline Textiles Camones & Av. Santa Josefina 527 Puente Piedra \\
\hline
\end{tabular}

Elaboración propia.

Como se puede observar en el cuadro 3.11 la mayoría de fábricas se encuentra ubicada en el cono este y en menor medida en el cono norte de la ciudad mientras que solo 2 fábricas se encuentran el centro de Lima. 


\section{Abastecimiento de energía eléctrica}

En Lima existen 2 distribuidoras de energía eléctrica. Luz del Sur distribuye electricidad en Lurín y Lurigancho mientras que Edelnor suministra energía en Los Olivos (Ver tabla 3.12).

Tabla 3.12

Tarifas de electricidad

\begin{tabular}{|l|l|c|c|c|}
\hline \multirow{2}{*}{ Distrito } & Distribuidora & $\begin{array}{c}\text { Cargo Fijo } \\
\text { Mensual }\end{array}$ & $\begin{array}{c}\text { Cargo por Energía } \\
\text { Activa en hora } \\
\text { punta }\end{array}$ & $\begin{array}{c}\text { Cargo por Energía } \\
\text { Activa en hora } \\
\text { fuera de punta }\end{array}$ \\
\cline { 3 - 5 } & S/./mes & Ctm. S/./kW.h & Ctm. S/./kW.h \\
\hline Independencia & Edelnor & 3.02 & 17.60 & 14.60 \\
\hline Lurigancho & Luz del Sur & 3.02 & 17.60 & 14.62 \\
\hline Lurín & Luz del Sur & 3.02 & 17.64 & 14.62 \\
\hline
\end{tabular}

Fuente: OSINERGMIN

Elaboración propia

Costo de alquiler de Local industrial

Gracias a la información publicada por la consultora inmobiliaria Colliers Internacional se pudo estimar el costo de alquiler mensual por metro cuadrado de un local industrial en los distritos de Independencia, Lurín y Lurigancho como se puede apreciar en la tabla 3.13.

Tabla 3.13

Costo de alquiler mensual de un local industrial por distrito

\begin{tabular}{|l|c|c|c|}
\hline \$ $/ \mathrm{m}^{2}-\mathrm{mes}$ & Independencia & Lurín & Lurigancho \\
\hline Mínimo & 4 & 4 & 3 \\
\hline Máximo & 4.5 & 6 & 4 \\
\hline Promedio & 4.25 & 5 & 3.5 \\
\hline
\end{tabular}

Fuente: Consultora inmobiliaria Colliers Internacional Elaboración propia. 


\section{Disponibilidad de local}

La consultora inmobiliaria Colliers Internacional en el primer semestre del 2013 hizo un estudio acerca del estado de la disponibilidad de locales industriales en Lima metropolitana.

En la zona norte de Lima, entre los años 2012 y 2013 se generó una especulación sin sustento en los valores de los inmuebles lo cual generó una retracción de los potenciales interesados en adquirir terrenos o locales industriales. Por otra parte, las exigencias municipales para obtener licencias de funcionamiento en algunos sectores es bastante difícil por motivo de los requerimientos de las evaluaciones de impacto ambiental y vial, esto ha generado la posibilidad de cambios de uso por lo que hay interés de muchos inversionistas en adquirir inmuebles de zonificación industrial para destinarlos a otros usos como comerciales, educativos o residenciales. En la zona sur de Lima, se está consolidando Villa el Salvador como un clúster logístico. Asimismo, cabe destacar que obras viales de mejoramiento se vienen desarrollando sobre la antigua Panamericana Sur lo cual permitirá un óptimo desplazamiento hacia Lurín

En la zona este de Lima, a pesar del aumento de los precios de los inmuebles, sin tener sustentación válida, y que ha generado retracción en las operaciones comerciales se encuentra que sin embargo las empresas con necesidad de zonificación industrial liviana y operaciones logísticas tienen posibilidades de encontrar superficies aptas para sus actividades ;ya que, a pesar de que en Huachipa la mayor parte se encuentra con clasificación ZRE ( Zona de Reglamentación Especial) la Municipalidad otorga previa consulta la zonificación I-1 e I-2. A pesar del incremento de precios la zona de Huachipa y Cajamarquilla mantienen alternativas para inversiones industriales y logísticas, más aún si se analiza la disminución de inmuebles disponibles para la industria mediana, pesada o gran industria en otras zonas de Lima Metropolitana. 
Tabla 3.14

Factores de micro localización

\begin{tabular}{|l|c|c|c|}
\hline \multicolumn{1}{|c|}{ Factor } & Independencia & Lurín & Lurigancho \\
\hline Cercanía al mercado & Buena & Deficiente & Muy buena \\
\hline $\begin{array}{l}\text { Abastecimiento de energía } \\
\text { eléctrica }\end{array}$ & Buena & Regular & Buena \\
\hline Costo alquiler (\$/mes) & Buena & Regular & Excelente \\
\hline Disponibilidad de local & Regular & Buena & Muy buena \\
\hline
\end{tabular}

Elaboración propia

La evaluación de la macro localización se realizó mediante el método de la matriz de enfrentamiento de factores

Tabla 3.15

Matriz de enfrentamiento de factores

\begin{tabular}{|c|c|c|c|c|c|c|}
\cline { 3 - 7 } \multicolumn{1}{c|}{} & C.M & E.E & C.A & D.L & Sumatoria & Ponderado \\
\hline C.M & & 1 & 0 & 0 & 1 & 0,125 \\
\hline E.E & 1 & & 0 & 0 & 1 & 0,125 \\
\hline C.A & 1 & 1 & & 1 & 3 & 0,375 \\
\hline D.L & 1 & 1 & 1 & & 3 & 0,375 \\
\hline
\end{tabular}

Elaboración propia

Usando la misma escala del cuadro 3.9, se obtiene:

Tabla 3.16

Matriz de evaluación de localidades

\begin{tabular}{|c|c|c|c|c|c|c|c|}
\hline & & \multicolumn{2}{|c|}{ Independencia } & \multicolumn{2}{|c|}{ Lurín } & \multicolumn{2}{|c|}{ Lurigancho } \\
\hline & Ponderación & Calificación & Puntaje & Calificación & Puntaje & Calificación & Puntaje \\
\hline C.M & 0.125 & 6 & 0.75 & 2 & 0.25 & 8 & 1 \\
\hline $\mathrm{EE}$ & 0.125 & 6 & 0.75 & 4 & 0.5 & 6 & 0.75 \\
\hline C.A & 0.375 & 6 & 2.25 & 4 & 1.5 & 10 & 3.75 \\
\hline D.L & 0.375 & 4 & 1.5 & 6 & 2.25 & 8 & 3 \\
\hline & & & 5.25 & & 4.5 & & $8-5$ \\
\hline
\end{tabular}

Elaboración propia.

Como resultado de la elaboración de la matriz de evaluación de localidades el distrito elegido es Lurigancho (Huachipa); ya que, obtiene el mayor puntaje. 


\section{CAPÍTULO IV: TAMAÑO DE PLANTA}

En esta sección del estudio se analizarán los distintos factores que limitarán la capacidad de producción que la planta debería tener, de esta manera evitará en la medida de lo posible un desperdicio de recursos en el caso de definir la capacidad máxima en la cual se operará, y además para determinar la capacidad mínima en que la planta debe ser capaz de trabajar para poder cubrir al menos los costos y gastos fijos con el llamado "punto de equilibrio".

Para ello, se analizará el factor mercado, el cual proporciona un panorama bastante claro de cuál debe ser la capacidad requerida que se debe cumplir; el factor recursos productivos, para ver si es posible producir lo que se pretende de acuerdo a la disponibilidad de las materias primas necesarias en el mercado; el factor tecnología, para ver si existe la tecnología necesaria para poder poner en marcha el proyecto y qué capacidad de diseño puede ofrecer; y el factor punto de equilibrio, el cual será importante para conocer el nivel mínimo de producción que se debe conseguir para no incurrir en pérdidas.

A continuación se procederá a analizar cada factor que influye en la decisión que se deberá tomar para decidir el tamaño de planta ideal para este proyecto.

Los factores a analizar serán: Mercado, recursos productivos, tecnología y financiamiento. Cabe recalcar, que dichos factores se analizarán de acuerdo al último año del proyecto (2025).

\subsection{Relación tamaño-mercado}

Uno de los factores más importantes a la hora de definir el tamaño de planta estará representado por la demanda del producto en el mercado. Es posible y muy probable que la capacidad de planta que puedan ofrecer las máquinas con su tasa de producción sea mayor a la demanda del mercado, por lo que este factor es determinante al momento de establecer cuál será la capacidad máxima en la cual operará la planta. Para ello, en el capítulo 2 se determinó cuál será la demanda para el proyecto, derivada de la Demanda Interna Aparente del Perú para el hilo elaborado con algodón nativo de color, proyectada al horizonte de vida del proyecto y con su respectiva segmentación de mercado. 
La demanda proyectada es el mejor indicador de este proyecto debido a que refleja la intención del mercado por adquirir este producto, el cual muestra una tendencia creciente en los últimos años debido a que en el año 2008 este algodón fue declarado Patrimonio Genético Étnico-cultural de la Nación" dejando de esta manera sin efecto la prohibición de su cultivo (Ley N¹401/2006_CR; 1630/2007_CR); por ello, la producción de este algodón se ha incrementado exponencialmente desde 0,5 hectáreas en el 2009 hasta 50 hectáreas en el 2013 con una tendencia a aumentar significativamente.

En base a información recolectada en la sección 2.2.1.3 se determina la demanda interna aparente

Tabla 4.1

Demanda interna aparente de hilo de la mezcla de algodón nativo de color y Tangüis

\begin{tabular}{|c|c|c|c|c|c|}
\hline Año & $\begin{array}{c}\text { Algodón nativo } \\
\text { de color 63\% }\end{array}$ & $\begin{array}{c}\text { Algodón } \\
\text { Tanguiis 37\% }\end{array}$ & Algodón total & $\begin{array}{c}\text { Merma } \\
\mathbf{( 1 3 \% )}\end{array}$ & Hilo \\
\hline 2009 & 1,5 & 0,88 & 2,38 & 0,31 & 2,07 \\
\hline 2010 & 15 & 8,8 & 23,8 & 3,09 & 20,7 \\
\hline 2011 & 75 & 44 & 119 & 15,47 & 103,53 \\
\hline 2012 & 90 & 52,86 & 142,86 & 18,57 & 124,29 \\
\hline 2013 & 150 & 88 & 238 & 30,94 & 207,06 \\
\hline
\end{tabular}

Fuente: Ocampo, P., (2015)

Elaboración propia.

Asimismo, con la información obtenida en la sección 2.2.3 "Proyección de la demanda y metodología de análisis”, se determinó la proyección de la demanda interna aparente. 
Tabla 4.2

Proyección de la demanda interna aparente

\begin{tabular}{|c|c|}
\hline Año & DIA (TM) \\
\hline 2014 & 248,49 \\
\hline 2015 & 300,26 \\
\hline 2016 & 352,02 \\
\hline 2017 & 403,79 \\
\hline 2018 & 455,55 \\
\hline 2019 & 507,32 \\
\hline 2020 & 559,08 \\
\hline 2021 & 610,85 \\
\hline 2022 & 662,61 \\
\hline 2023 & 714,38 \\
\hline 2024 & 766,14 \\
\hline 2025 & 817,91 \\
\hline
\end{tabular}

Elaboración propia

Por lo tanto, la relación tamaño mercado para el año 2025 es de 817,71 toneladas por año.

\subsection{Relación tamaño-recursos productivos}

Como se explicó en el punto 2.6.2, el algodón nativo de color se siembra en las regiones de Piura, San Martin y Lambayeque siendo esta última dónde se produce en mayor cantidad principalmente en los distritos de San José, Túcume, Mórrope y la provincia de Ferreñafe mientras que en Piura y San Martin la producción de este algodón es relativamente poca y se realiza de forma artesanal e independiente por unos cuantos campesinos; por lo tanto, no existen registros certeros de la producción en estas regiones.

Según los estudios realizados por la ingeniera Patricia Ocampo, las zonas de la región Lambayeque, donde se produce, procesa artesanalmente y comercializa productos a base de algodón nativo son las siguientes:

- Zona de producción: Mocupe y Mochumi

- Zona de producción, artesanía y comercialización: Morrope, Pacora, Túcume, Pitipo, Ferreñafe, Lambayeque y Monsefú.

- Zona de artesanía: San José, Ciudad Eten.

- Zona de comercialización: Chiclayo 
La ciudad de Chiclayo se tiene en cuenta como área soporte, distribuidora $\mathrm{y}$ comercializadora de los productos terminado. Dicha área de estudio considera además del área de influencia, todo el ámbito de la cadena productiva (ver figura 2.28).

Como se puede apreciar en Lambayeque hay varias provincias que tienen mucho potencial para sembrar algodón nativo de color y si es que hay demanda los agricultores podrían incrementar la siembra de este algodón. Con la información que se cuenta se puede determinar la relación tamaño - productivo de Morrope; sin embargo, esta relación se podría determinar considerando que en Lambayeque se produce este algodón en varias provincias.

Según lo conversado con el presidente de Aspromad el señor Angel Damian actualmente siembra 3 hectáreas de algodón nativo; pero si hay demanda en sus campos de cultivo tienen disponibilidad para sembrar hasta 1500 hectáreas. El rendimiento promedio es de 3000 $\mathrm{kg} / \mathrm{año}$. Por lo tanto, en base a estos datos se calculará la relación tamaño-recurso productivo Producción potencial de algodón en Lambayeque $=1500$ ha $\times 3000 \frac{\mathrm{kg}}{\mathrm{ha}}$

\section{Producción potencial de algodón en Lambayeque $=4.500$ toneladas}

Considerando que el producto está compuesto por la mezcla de algodón nativo de color y Tangüis en un 63 y 37 por ciento respectivamente y que la merma de producción es de $13 \%$ se procederá a calcular la relación tamaño - recursos productivos para el 2025 y considerando que el algodón Tangüis se produce en las regiones de Arequipa, Ica, Lima y Ancash. Como se indicó en el punto 2.6.2, la producción de algodón Tangüis es muy superior a la de algodón nativo de color; por ello, no se considera como un limitante la producción de este algodón. 
Tabla 4.3

Calculo de la relación tamaño-recurso productivo (TM)

\begin{tabular}{|c|c|c|c|c|c|}
\hline Año & $\begin{array}{c}\text { Algodón } \\
\text { nativo de color } \\
\mathbf{6 3 \%}\end{array}$ & $\begin{array}{c}\text { Algodón } \\
\text { Tangüis } \\
\mathbf{3 7 \%}\end{array}$ & $\begin{array}{c}\text { Algodón } \\
\text { total }\end{array}$ & $\begin{array}{c}\text { Merma } \\
\mathbf{( 1 3 \% )}\end{array}$ & Hilo \\
\hline 2025 & 4,500 & 2,643 & 7,143 & $928-59$ & $6,214.41$ \\
\hline
\end{tabular}

Elaboración propia

Por lo tanto, la relación tamaño- recursos productivos para el 2025 es de 6,214.41 toneladas de hilo por año.

Por otro lado, en lo que respecta a los servicios de agua y luz, estos tampoco representan un obstáculo ya que, como se vio en el capítulo anterior, la planta estará situada en Lima, donde el abastecimiento de estos recursos no es limitado y se tiene la infraestructura adecuada para poder adquirirlos

Finalmente, respecto a la disponibilidad de mano de obra para el trabajo, se prevé que habrá demanda de trabajo suficiente debido a que en Lima se concentra el mayor porcentaje de mano de obra calificada en la carrera técnica de mecánico textil en hilandería la cual se dicta en el SENATI de Lima; ya que, se requiere de operarios capaces de poder operar las máquinas que se utilizan en el proceso de hilado. Asimismo se requiere de Ingenieros textiles para que puedan dirigir las fábricas, esta carrera se dicta en la Universidad Nacional de ingeniería (UNI) y la Universidad tecnológica del Perú (UTP) las cuales se ubican en Lima.

\subsection{Relación tamaño-tecnología}

Las máquinas y los equipos que se necesitarán para realizar las labores de producción proporcionarán un factor importante para definir la capacidad a la cual podrá trabajar la planta. Esta capacidad está dada por el diseño de la misma máquina o equipo en la cual hayan sido fabricados, que ofrece una tasa de producción fija (de diseño) pero que puede variar en mayor o menor medida dependiendo de la forma en que se empleen y/o el nivel de mantenimiento que reciban.

La capacidad de producción de las máquinas puede ser determinante, ya que de ser el caso que ésta permita producir una cantidad menor que la demanda del mercado, se 
convertirá en un limitante serio y evitará que la empresa pueda explotar toda la demanda que pretende cubrir. Para el proyecto se necesitarán las siguientes máquinas y equipos: Alimentador de mezcla, mezcladora, limpiador de mezcla, abridora, motor ventilador, carda, manuar, mechera, continua de hilar, conera, cámara de humidificación, compresor de aire y ablandador de agua

Para definir la capacidad determinada por los procesos de producción se tiene que considerar cuál de ellos es el que evita que el ritmo de producción a máxima capacidad de la planta (demanda instalada) sea el más alto posible, el llamado "cuello de botella" el cual según la sección 5.4 es el proceso de hilado y limita la producción en el año 2025 a 387,616 $\mathrm{kg} / \mathrm{año.}$

Sin embargo, cabe recalcar que la cantidad de continuas de hilar en la planta está en función a la demanda del proyecto; es decir, si se adquiere mayor número de estas máquinas la producción podría ser mucho mayor, por ello este factor no es un limitante.

\subsection{Relación tamaño-punto de equilibrio}

Para saber la capacidad mínima que debe tener la planta en la cual no se tenga ganancias ni pérdidas, se analiza el "punto de equilibrio" para el año 2025, el cual considera la totalidad de costos y gastos fijos, así como el precio y costo variable unitario. Para conocer los montos estimados de estos rubros, se utilizó la información recopilada en un capítulo posterior VII (Sección 7.3.2 y 7.3.3) donde se halló que será necesario alrededor de S/.1, 121,694 para cubrir los costos fijos. En cuanto a los costos variables, se determinó que el costo variable unitario por kilogramo será de 22 soles por kilogramo, lo cual estará representado principalmente por los costos incurridos en el abastecimiento de las materias primas, materiales e insumos.

Para la determinación del valor de venta, como se pudo apreciar en el capítulo 2, se investigó y el mercado ofrece un valor de venta promedio de 10 dólares por $\mathrm{kg}$ considerando que el hilo está constituido por una mezcla de $63 \%$ de algodón nativo de color y $37 \%$ de algodón Tangüis y de acuerdo el tipo de cambio estimado para el 2016 es de 34.5 soles. 
Entonces, aplicando el concepto de punto de equilibrio, se obtuvo el siguiente resultado:

Pto. de equilibrio $=1,342,494 /(34.5-22)$

Pto. de equilibrio $=107,673 \mathrm{~kg}$

Por lo tanto, se necesitará producir y vender por lo menos 89,964 kilogramos de hilo para no incurrir en pérdidas ni lograr utilidades.

\subsection{Selección del tamaño de planta}

Mediante los diversos tamaños de planta que se hallaron previamente se procederá a realizar la selección de tamaño de planta para el año 2025.

\section{Tabla 4.4}

Resumen de capacidades por relación

\begin{tabular}{|l|c|}
\hline \multicolumn{1}{|c|}{ Categoría } & Capacidad (toneladas) \\
\hline Relación Tamaño-Mercado & 817.70 \\
\hline Relación Tamaño-Recursos Productivos & $6,214.41$ \\
\hline Relación Tamaño-Tecnología & No es limitante \\
\hline Relación Tamaño-Punto de Equilibrio & 107.67 \\
\hline
\end{tabular}

Elaboración propia.

Por lo mostrado en el cuadro se determina que la capacidad máxima está limitada por el mercado, el cual requiere de la producción de 817,70 toneladas de hilo por año, ya que tanto la tecnología como los recursos productivos no restringen la capacidad a un menor nivel. Por otro lado, la cantidad mínima necesaria de producción para no incurrir en pérdidas será de 89.9 toneladas de hilo por año. 


\section{CAPÍTULO V: INGENIERÍA DEL PROYECTO}

\subsection{Definición del producto basada en sus características de fabricación}

\subsubsection{Especificaciones técnicas del producto}

El producto es una bolsa con 12 conos de $2 \mathrm{~kg}$ de hilo elaborado a partir de la mezcla del algodón nativo de color junto con algodón Tangüís en una proporción de 63\% Y 37\% respectivamente con la finalidad de aumentar la longitud de la mezcla (ver tabla 2.3) de tal forma que se pueda procesar para obtener un hilo cuyas características sean apropiadas para la confección de prendas de vestir (Como objetivo se busca obtener que el hilo presente un título entre 10 a $40 \mathrm{Ne}$ ) El hilo que se venderá conservará los colores naturales del algodón nativo de color como crema, marrón, verde, pardo, fifo, lila, blanco y beige lo cual da un valor agregado al producto; ya que, los colores son naturales sin la necesidad de teñirlos. Mediante este hilo se podrá elaborar telas con las cuales se podrá confeccionar de prendas de vestir como vestidos, polos, poleras, camisas y chompas.

\subsection{Tecnologías existentes y procesos de producción}

\subsubsection{Naturaleza de la tecnología requerida}

Para la producción del hilo de algodón nativo de color será necesario contar con la tecnología suficiente para una empresa de mediana envergadura y que satisfaga las necesidades de producción para cubrir la demanda. Además se debe considerar el nivel de adaptación de las máquinas a variaciones en los métodos de producción como por ejemplo si se desea obtener distintos tipos de títulos de hilos. Se piensa adquirir maquinaria de segunda en buen estado y que cuente con las características adecuadas para poder hilar el algodón nativo de color el cual tiene fibra corta y baja resistencia a la torsión de tal forma que se pueda obtener un producto de calidad. Las características adecuadas que se menciona anteriormente se refiere a la adaptación de la continua de hilar según la invención que se realizó asimismo el resto de maquinaria seleccionada se detalla en la sección 5.2.1.2 Selección de tecnología. 


\section{Invención máquina para hilar algodón nativo de color}

Para poder obtener hilo a partir de algodón nativo de color se modificará el sistema de transmisión de velocidades de la continua de hilar. En esta máquina se presentan dos procesos: el estiraje y la torsión los cuales deben ser adecuados para este tipo de hilo que presenta propiedades diferentes a los algodones convencionales como menor longitud de fibra y menor resistencia a la torsión

La máquina cuenta con un sistema de transmisión de velocidades cuyo objetivo es obtener una velocidad angular adecuada de los husos para obtener una torsión idónea para el algodón nativo de color; y obtener la velocidad adecuada del movimiento de los cilindros del tren de estiraje para poder estirar la fibra del algodón nativo Por tal motivo, la máquina cuenta con un sistema que le permite variar la velocidad de tal forma que se puede obtener una adecuada velocidad para los cilindros del tren de estiraje

Asimismo la máquina cuenta con un mecanismo de variación que varía la velocidad de los husos de tal forma que al variar la velocidad de ambos sistemas se pueda obtener varias torsiones debido a la sincronía existente en las partes móviles de la máquina. 


\section{Figura 5.1}

Cadena cinemática que brinda velocidad a los husos y al tren de estiraje

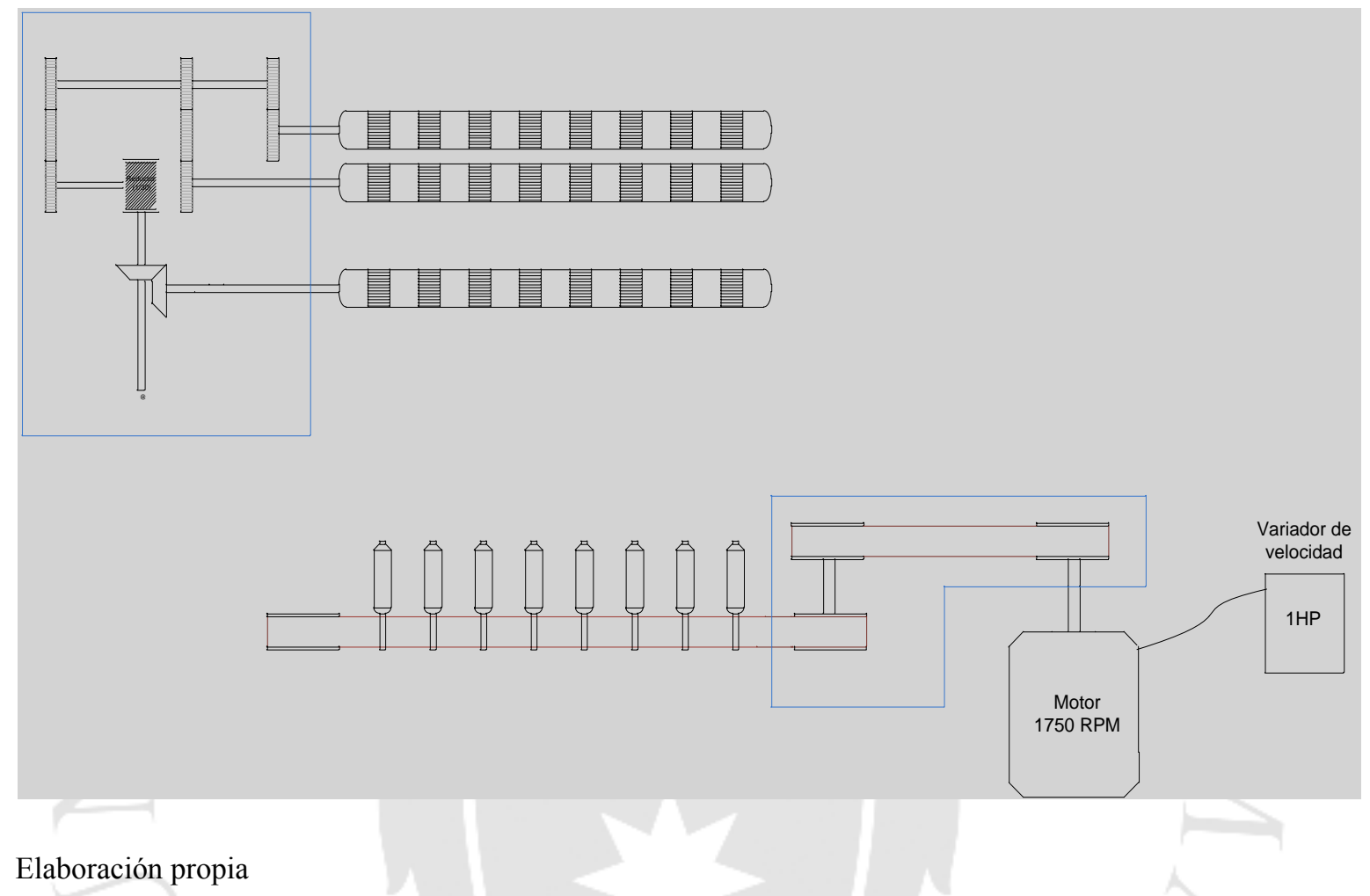

Por último, la máquina cuenta con un mecanismo formador de canilla el cual sirve para llenar el hilo a lo largo de los husos. 


\section{Figura 5.2}

Cadena cinemática que brinda velocidad a los cilindros del tren de estiraje y al formador de canilla

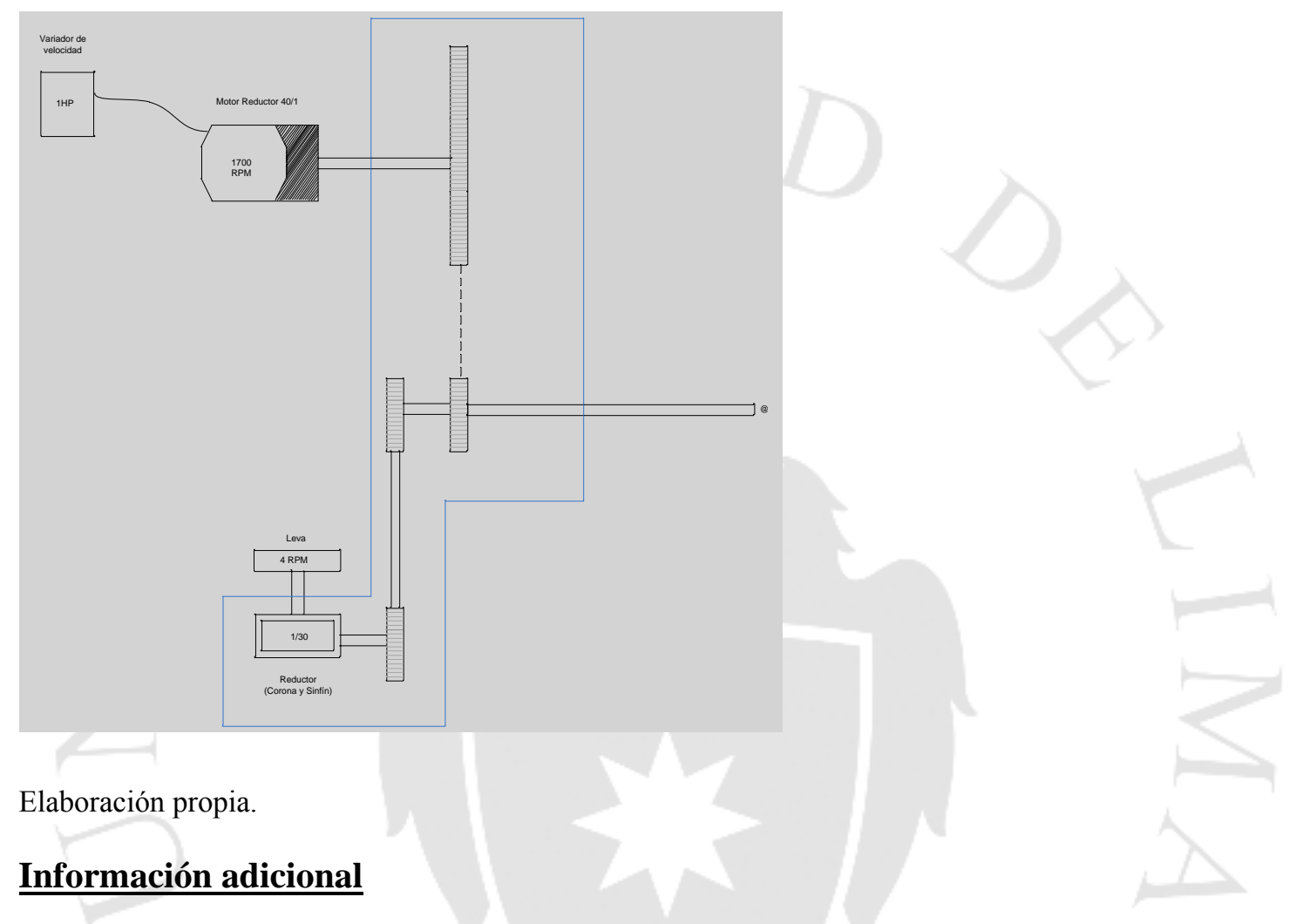

La patente se denomina "Máquina para hilar algodón nativo de color" y su número de expediente es 2015-002190. Esta patente pertenece a la Universidad de Lima y está en trámite.

Los inventores de la máquina para hilar algodón nativo de color son:

- Ludwig Nick Declercq Pedraza

- Jorge Luis García Silva

La máquina para hilar algodón nativo de color gano en el área temática Utilitarios y otros el Concurso Nacional de Patentes e Invenciones del 2015 organizado por Indecopi. 


\subsubsection{Descripción de las tecnologías existentes}

\section{Máquinas}

Para poder ejecutar el proyecto, se debe tener a la mano la tecnología necesaria para producir hilo a partir de la mezcla entre el algodón nativo de color y algodón Tangüis. Para eso mencionaremos las máquinas que intervienen en el proceso productivo del mismo.

- Alimentador de mezcla: Se encarga de realizar la alimentación de pequeños lotes de diferentes tipos de algodón.

- Mezcladora: Está máquina está conformada por un sistema de rodillos con púas cuya finalidad es de mezclar diferentes tipos de algodones y de tal manera que se obtenga una fibra y una tonalidad homogénea del color de la mezcla de algodones.

- Limpiador de mezcla: Se encarga de abrir y disgregar el algodón. Asimismo se encarga de limpiar las impurezas como fibras cortas, cascarillas, semillas, hojas y tierra. Esta máquina está equipada con bandas compuestas de púas y dos batidores de gran diámetro que le otorgan una alta eficiencia en la recolección de basura en todos los diferentes tipos de material crudo.

- Abridora: Se encarga de abrir el algodón apelmazadado sin romper las fibras

- Motor ventilador: Asegura la constante alimentación desde el último abridor hacia la carda

- Batán: El material proveniente de la máquina mezcladora es sometido a diversas operaciones en el batán como abrir los pequeños mechones de fibras y dar mayor homogenización a la mezcla, separar las fibras cortas y finalmente forma un rollo llamado napa en el cual las fibras se encuentran entrelazadas entre sí; por ello, es necesario posteriormente paralelizar estas fibras con la operación del cardado

- Silo: Se utiliza para dosificar la entrada del algodón que va desde la mezcladora hacia la carda

- Carda: Se utiliza para disgregar el algodón hasta la paralelización de las fibras, eliminación parcial de las fibras cortas y las impurezas existentes; y elaboración de una cinta (conjunto de fibras paralelizadas que se unen) para el siguiente proceso; asimismo, se efectúa una mezcla homogénea. 
- Manuar: El manuar se utiliza para paralelizar las fibras de algodón y corregir tanto como sea posible cualquier irregularidad de la cinta. Estos objetivos se consiguen mediante el estirado que, al tirar de las fibras tienden a colocarlas en posición paralela y el doblado que consiste en juntar entre 6 a 8 cintas irregulares; es decir, a lo largo de su longitud presentan diferentes títulos. El objetivo del doblado obtener una cinta más uniforme. El estirado se lleva a cabo por medio de un conjunto de rodillos cada uno de los cuales gira a una mayor velocidad que el cilindro predecesor a este. No siendo suficiente un solo proceso para obtener la paralelización y la regularidad necesaria, se recurre, por lo general, a dos procesos sucesivos, con el fin de dar a las fibras que constituyen la cinta de la carda el paralelismo necesario para facilitar el adelgazamiento.

- Reunidora de cinta: Su principal tarea es la de reunir varias cintas para formar un rollo y alimentar a la peinadora. Esta máquina esta provista de un tren de estiraje en el que las cintas reunidas sufren un pequeño estiraje.

- Peinadora: Esta máquina tiene como objetivo seleccionar las fibras, eliminando las que no alcancen una longitud determinada, terminar el proceso de limpieza y continuar con la paralelizando las fibras.

- Mechera: Esta máquina se utiliza para estirar y afinar la cinta proveniente del manuar mediante un tren de cilindros de estiraje que permiten obtener una mecha de título varias veces más fino que el original. Para lograr afinar la mecha se lleva a cabo un proceso de torsión que le otorga la resistencia necesaria para soportar el devanado en la siguiente etapa del proceso de hilatura.

- Open end: Es una máquina de hilatura donde su material de alimentación es la cinta de manuar con un promedio de título de $0.12 \mathrm{Ne}$. Esta máquina sirve para hilar títulos gruesos de hasta $24 \mathrm{Ne}$. El producto final de esta máquina es un hilo enrollado en un cilindro achatado.

- Hiladora continua de anillos

Esta máquina transforma la mecha proveniente de la mechera en hilos que se utilizan en la fabricación de tejidos planos, tejidos de punto y confecciones. 
Para producir un hilo adecuado para elaborar prendas de vestir a partir del algodón nativo de color se deben establecer ciertos parámetros en la operación de hilado. En primer, lugar se explicará cuál es el procedimiento de la operación de hilado.

Estirado (Tren de estiraje):

El objetivo de esta operación es estirar la mecha que ingresa con un título de $0.80 \mathrm{Ne}$ hasta obtener una hebra cuyo título entre 10 a $40 \mathrm{Ne}$.

Torsión:

Luego que la hebra sale del tren de estiraje empieza a torcerse; ya que, está entre el tren de estiraje y los husos cuya velocidad es de 8,000 RPM debido a que la hebra es jalada por los husos que giran a alta velocidad se va ir torciendo hasta obtener hilo.

Recolección del hilo

El hilo es recolectado en la canilla que está puesta sobre los husos los cuales giran a 8,000 RPM; y a su vez suben y bajan para que el hilo se acumule a lo largo de toda la canilla.

- Conera: Tiene por finalidad reunir varias husadas de la continua en un cono cuyo tamaño es muy superior al del huso para facilitar las operaciones posteriores de urdido y tisaje; ya que, el cono tiene mayor rendimiento que el huso. Se aprovecha este trasvase de hilo para depurarlo de los defectos de masa no deseados

- Cámara de humidificación: Sirve para mejorar la calidad de torsión del hilo; ya que, acondiciona el hilo de algodón a los niveles de humedad que acepta el mercado y las leyes de comercio sobre este producto. Los procesos de hilatura eliminan agua del hilo por lo que es necesario llevarlo a su nivel de mercado que es por lo general $8 \%$ de humedad. 


\section{Equipos}

1) Compresor de aire: Debido a que hay máquinas que necesitan de un sistema neumático para mover y hacer funcionar sus mecanismos. En la tabla 5.1 se muestra las máquinas que necesitan de aire suministrado por un compresor de aire.

\section{Tabla 5.1}

Función del compresor de aire

\begin{tabular}{|l|l|}
\hline \multicolumn{1}{|c|}{ Máquina } & \multicolumn{1}{c|}{ Función del compresor } \\
\hline Continua de hilar & Cambiar canillas llenas por canillas \\
\hline Manuar & Cambiar tachos llenos por tachos vacíos \\
\hline Mechera & Activar las guardas \\
\hline Conera & Cambio de canillas \\
\hline
\end{tabular}

Elaboración propia.

2) Ablandador de agua: Mediante el ablandador se busca eliminar la presencia de sales en el agua. Los iones presentes en agua dura son Calcio (Ca2+) y Magnesio $(\mathrm{Mg} 2+)$; ya que, estos son los causantes de la formación de depósitos o incrustamiento en las tuberías o en la cámara de humidificación. Mediante el intercambio de iones con una resina se logra remover los cationes de calcio y magnesio.

3) Transformador de media a baja tensión: Debido a que la energía eléctrica se compra mediante la tarifa MT3 con el objetivo de reducir los costos. Es necesaria la presencia de un transformador que reduzca el voltaje de media a baja tensión.

4) Equipos de medición de calidad

4.1 Uster Tensorapid III: Sirve para el análisis de resistencia, elongación y parámetros de tenacidad del hilado. Permite diagnosticar posibles fallas que pudieran suceder en la tejeduría

4.2 Uster Tester IV con expert system: permite controlar las pequeñas variaciones en la masa (regularimetría) de cintas, mechas e hilos para que el laboratorista pueda diagnosticar fallas mecánicas o de control en las maquinarias.

4.3. Uster Autosorter III: para el análisis de titulación (uniformidad de peso y longitud) de cintas, mechas e hilo. 
4.4. Uster AFIS L-N-T: sirve para detectar la calidad del algodón semi-elaborado en cuanto a la longitud de las fibras, la cantidad y tamaño de neps que contiene, las partículas, el micropolvo y madurez, evitando de esta manera anomalías en la materia prima que puedan transferirse posteriormente al producto terminado.

4.5. Lawson-Hemphill (CTT-BU): se utiliza para medir el coeficiente de fricción y de abrasión del hilo en las agujas.

\subsubsection{Selección de la tecnología}

Debido a que se piensa hacer una fábrica hilandera relativamente pequeña no será necesario usar máquinas que funcionen para grandes volúmenes de fabricación como la pinzadora. Asimismo, el batán al ser una tecnología relativamente antigua no será empleado; ya que con una mezcladora bastaría para realizar un mezclado adecuado entre el algodón nativo de color y el algodón Tangüis; y para homogenizar el tamaño de las fibras. Por otra parte, como el algodón nativo de color tiene fibra corta no será necesario usar a la peinadora; ya que esta máquina tiene como objetivo disgregar a las fibras cortas para obtener un hilo fino y resistente.

Además, no se usará la Open End; ya que, esta máquina sirve para hilar títulos gruesos de hasta $24 \mathrm{Ne}$ y en el proyecto se desea obtener desde hilos gruesos hasta hilos finos de hasta 40 Ne lo cual se consigue con una adaptación de la Continua de anillos.

Por último, como el algodón nativo de color se vende en bolsas las cuales contienen impurezas como fibras cortas, cascarillas, semillas, hojas y tierra será necesario el uso de máquinas especializadas para el proceso de apertura y limpieza para extraer estas impurezas. Por ello, la tecnología que se empleará en el proceso de hilatura es la siguiente: 
Tabla 5.2

Lista de máquinas/equipos requeridos

\begin{tabular}{|l|l|}
\hline \multicolumn{1}{|c|}{ Máquina } & \multicolumn{1}{c|}{ Equipo } \\
\hline Alimentador de mezcla & Compresor de aire \\
\hline Mezcladora & Ablandador de agua \\
\hline Limpiador & Transformador de mediana a baja tensión \\
\hline Motor de ventilador & \\
\hline Abridor & \\
\hline Silo & \\
\hline Carda & \\
\hline Manuar & \\
\hline Mechera & \\
\hline Continua de anillos & \\
\hline Conera & \\
\hline Cámara de humidificación & \\
\hline
\end{tabular}

Elaboración propia

\subsubsection{Proceso de producción}

\subsubsection{Descripción del proceso}

El proceso para producir hilo a partir del algodón nativo de color y el algodón Tangüis consta de varias etapas las cuales son: pre-mezclado, apertura, mezcla, limpieza, cardado, regularizado de cinta, estirado, hilado y enconado.

En primer lugar, cabe recalcar que la materia prima a utilizar son sacos de $50 \mathrm{~kg}$ de algodón nativo de color; ya que, en la actualidad no existe una fábrica desmotadora de este algodón la cual produzca fardos de este algodón. El algodón nativo de color contiene impurezas como fibras cortas, cascarillas, semillas, hojas y tierras. Asimismo también se usará como materia prima fardos de $250 \mathrm{~kg}$ de algodón Tangüis procesado.

\section{Pre- mezclado}

El pre mezclado consiste en esparcir en un espacio de 5 metros de largo por 3 metros de ancho el algodón nativo de color en una proporción de 63\% y el algodón Tangüis en una proporción de $37 \%$ de tal forma que se pueda obtener una manta del mezclado preliminar de las fibras de ambos tipos de algodones. Este espacio está al costado de una faja que conducirá a este al alimentador de mezcla. 


\section{Apertura, mezcla y limpieza}

La mezcla de algodón nativo de color y algodón Tangüis se pondrá sobre una faja la cual conducirá al algodón al alimentador de mezcla el cual se encarga de desmenuzar el algodón luego mediante un ducto el material es llevado hacia la mezcladora la cual es una máquina conformada por un sistema de rodillos con púas cuya finalidad es de mezclar algodón nativo de color con algodón Tangüis de tal manera que se obtenga una fibra de mayor longitud y una tonalidad homogénea del color de la mezcla de algodones. Luego mediante un ducto el material es llevado hacia un limpiador y un abridor colocados de forma adyacente, el limpiador sirve para abrir y disgregar el algodón y se encarga de limpiar las impurezas como fibras cortas, cascarillas, semillas, hojas y tierra mientras que el abridor se encarga de desmenuzar el algodón. Este proceso se repite dos veces para luego mediante un ducto el material es llevado por última vez a un limpiador el cual está colocado de forma adyacente con un motor ventilador el cual impulsa el material hacia la carda.

Cabe recalcar que en el caso que se mezclen 2 tipos diferentes de algodones como el algodón nativo de color y el algodón Tangüis es recomendable que primero realice la mezcla de tal manera que se mezclen las fibras de ambos algodones de forma más perfecta (homogénea) y luego se realice el proceso de apertura y limpieza.

\section{Cardado}

El material entra al silo el cual se utiliza para dosificar la entrada de este hacia la carda. Luego, el material ingresa a la carda, la cual se encarga de disgregarlo hasta la paralelización de sus fibras. Asimismo, en la carda se eliminan las impurezas existentes y como producto final se obtiene la cinta (conjunto de fibras paralelizadas que se unen). Cabe recalcar en la carda se efectúa una mezcla homogénea de las fibras. La cintas que salen de la carda de aproximadamente una pulgada de diámetro se ponen en tachos de $70 \mathrm{~cm}$ de diámetro los cuales tienen rueditas que facilitan su traslado al manuar. 


\section{Regularizado de cinta}

Entre 6 a 8 cintas provenientes del cardado entran al manuar el cual se utiliza para paralelizar las fibras de algodón y corregir tanto como sea posible cualquier irregularidad de la cinta (doblado). En el manuar se estiran las cintas de tal forma que se colocan en posición paralela y se doblan juntando entre 6 a 8 cintas irregulares (las cintas a lo largo de su longitud presentan diferentes títulos) para poder obtener una cinta más uniforme. El proceso de estirado de cinta realizado en el manuar se lleva a cabo mediante un conjunto de rodillos cada uno de los cuales gira a una mayor velocidad que el cilindro predecesor a este. No siendo suficiente un solo proceso para obtener la paralelización y la regularidad necesaria, se recurre, por lo general, a dos procesos sucesivos, con el fin de dar a las fibras que constituyen la cinta de la carda el paralelismo necesario para facilitar el adelgazamiento. Las cintas que se obtienen en el manuar se ponen en tachos de $50 \mathrm{~cm}$ de diámetro para posteriormente llevarlos a la mechera.

\section{Estirado}

La cinta proveniente del manuar ingresa a la mechera la cual se utiliza para estirar y afinar la cinta mediante un tren de cilindros de estiraje que permiten obtener una mecha de título varias veces más fino que el original. Asimismo, en la mechera se lleva a cabo un proceso de torsión que le otorga a la mecha la resistencia necesaria para soportar el devanado que se realizará en la continua de hilar. El producto de la mechara son bobinas en las cuales se enrolla la mecha. Posteriormente las bobinas se trasladan a la máquina de hilar.

\section{Hilado}

Las bobinas enrolladas con mecha se colocan en un soporte en la parte superior de la máquina de hilar. Luego cada mecha pasa a través del tren de estiraje con el objetivo de estirar la mecha y convertirla en hebra debido a que se usa como materia prima el algodón nativo de color las velocidades de los cilindros del tren de estiraje son adecuadas para poder estirar este tipo de algodón que se caracteriza por tener fibra corta. Luego, la hebra que sale del tren de estiraje viaja hasta los husos en los cuales se enrolla el hilo en la canilla que está insertada en los husos los cuales tienen una velocidad de 8000 RPM; ya que, el algodón nativo de color tiene poca resistencia a la torsión. Cabe recalcar que la torsión se produce en el recorrido entre la salida del último cilindro del tren de estiraje y los husos. Asimismo para que el hilo 
sea enrollado a lo largo de las canillas que están en los husos se utiliza la bancada la cual se mueve verticalmente y en la cual está insertada los aros y el cursor por el cual pasa el hilo antes de ser enrollado en el huso.

\section{Enconado}

Las canillas son trasladadas a la conera la cual tiene por finalidad reunir varias husadas de la continua en un cono de $2 \mathrm{~kg}$ cuyo tamaño es muy superior al del huso para facilitar las operaciones posteriores de urdido y tisaje; ya que, el cono tiene mayor rendimiento que la canilla. Asimismo, se aprovecha este trasvase de hilo para depurarlo de los defectos de masa no deseados

\section{Humidificado}

Sirve para fijar la torsión; es decir, le brinda más resistencia al hilo lo cual sirve para que este no se enrosque. Los conos son puestos en la cámara de humidificación la cual tiene forma cilíndrica un lapso de 45 minutos donde se consigue fijar la torsión. El peso que aumenta el cono es despreciable. La máquina puede almacenar 200 conos/lote (400 kg)

\section{Ablandamiento de agua}

Para el proceso de humidificado se necesita agua blanda; por tal motivo, previamente se ablandará el agua dura con el objetivo de eliminar las sales que pudiesen incrustarse en la cámara de humidificado. En el proceso de ablandamiento se utilizan resinas catiónicas las cuales tienen la propiedad de intercambiar sus iones $\mathrm{Na}+\mathrm{o} \mathrm{K}+$ por los iones $\mathrm{Mg}+2$ y $\mathrm{Ca}+2$ del agua dura. Para el proceso de intercambio de cationes se utilizan torres rellenas de resinas y el agua dura fluye desde la parte superior a la inferior atravesando el relleno para obtener agua blanda. En la parte inferior de la torre hay una serie de láminas perforadas, que sostienen el relleno. Cuando se agota la capacidad de cambio de la resina se requiere la regeneración de la misma con un retrolavado con solución de $\mathrm{NaCl}$ al $10 \%$. El retrolavado permite descompactar la resina y retirar cualquier material retenido durante la operación normal. 


\section{Embolsado}

Manualmente un operario se encargará de poner 12 conos en una bolsa para así tener la presentación final del producto. En promedio un operario se demora 40 segundos en el embolsar una bolsa con 12 conos.

\section{Etiquetado}

Se procederá a etiquetar cada bolsa que contendrá los 12 conos de hilo. Cada etiqueta tendrá el rótulo de la empresa y también se rotulará el título del hilo.

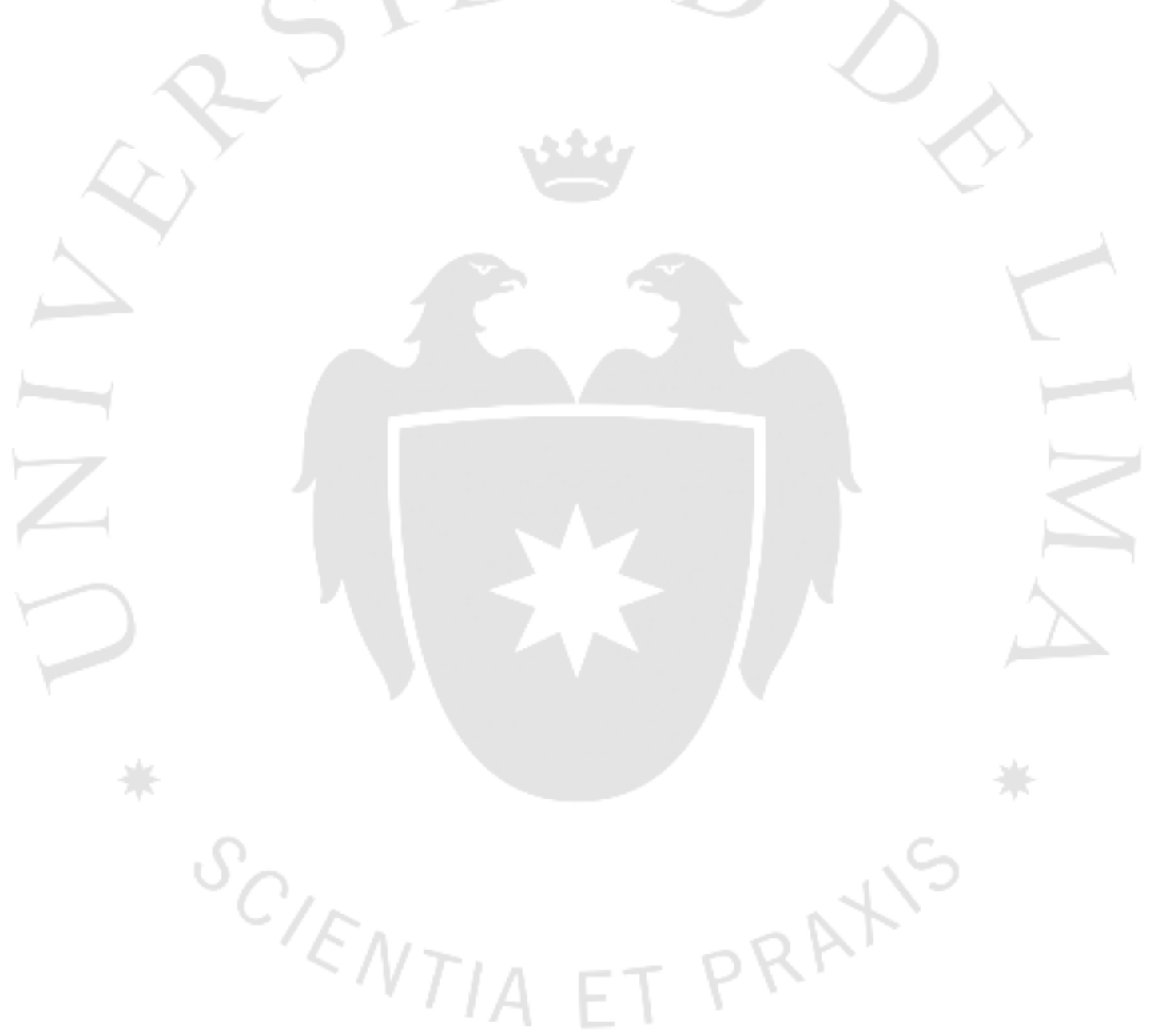




\subsubsection{Diagrama de proceso: DOP}

Diagrama de operaciones del proceso para la producción de hilos de algodón nativo de color

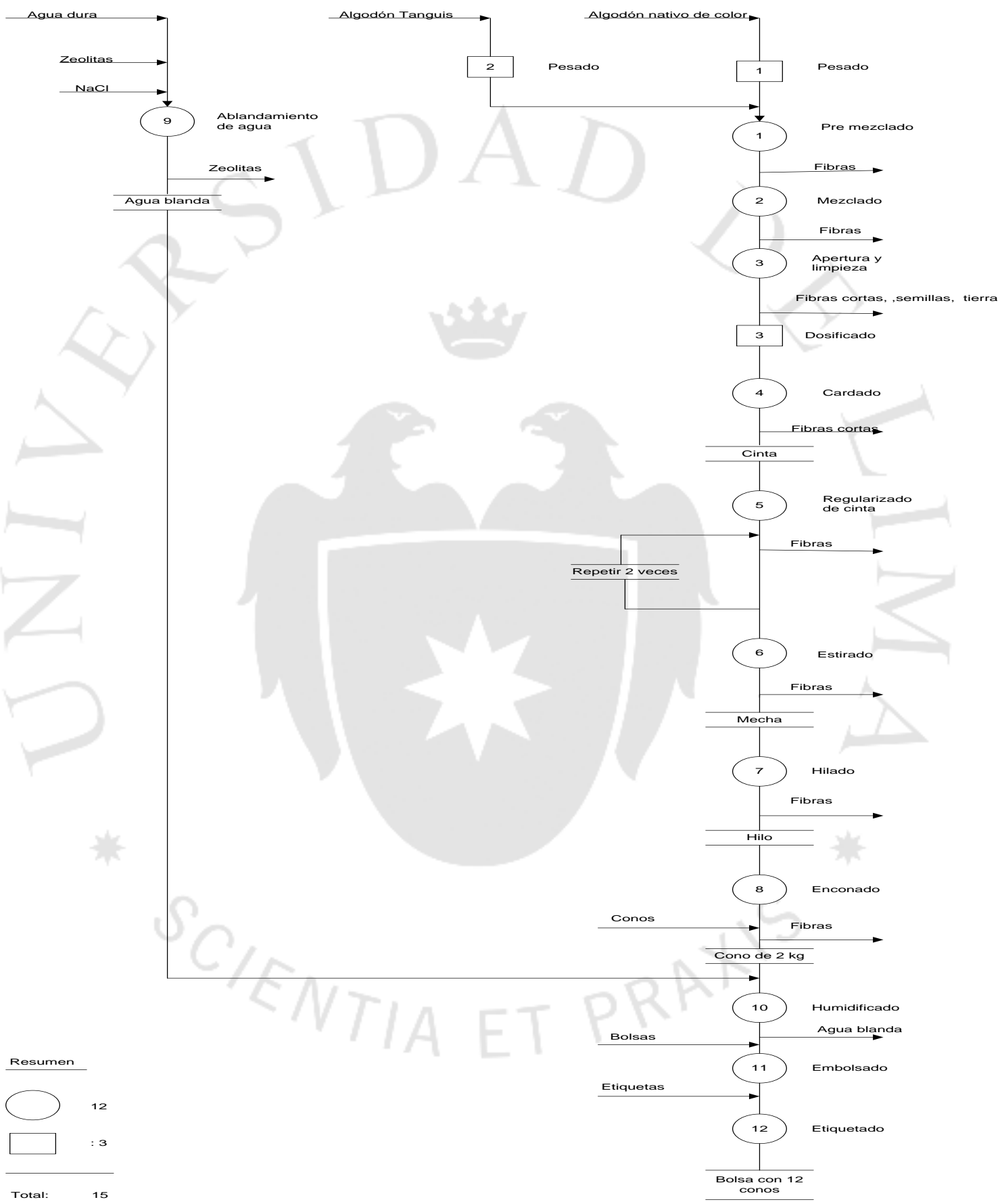

Elaboración propia. 


\subsubsection{Balance de materia:}

Diagrama de bloques del proceso para la producción de hilos de algodón nativo de color

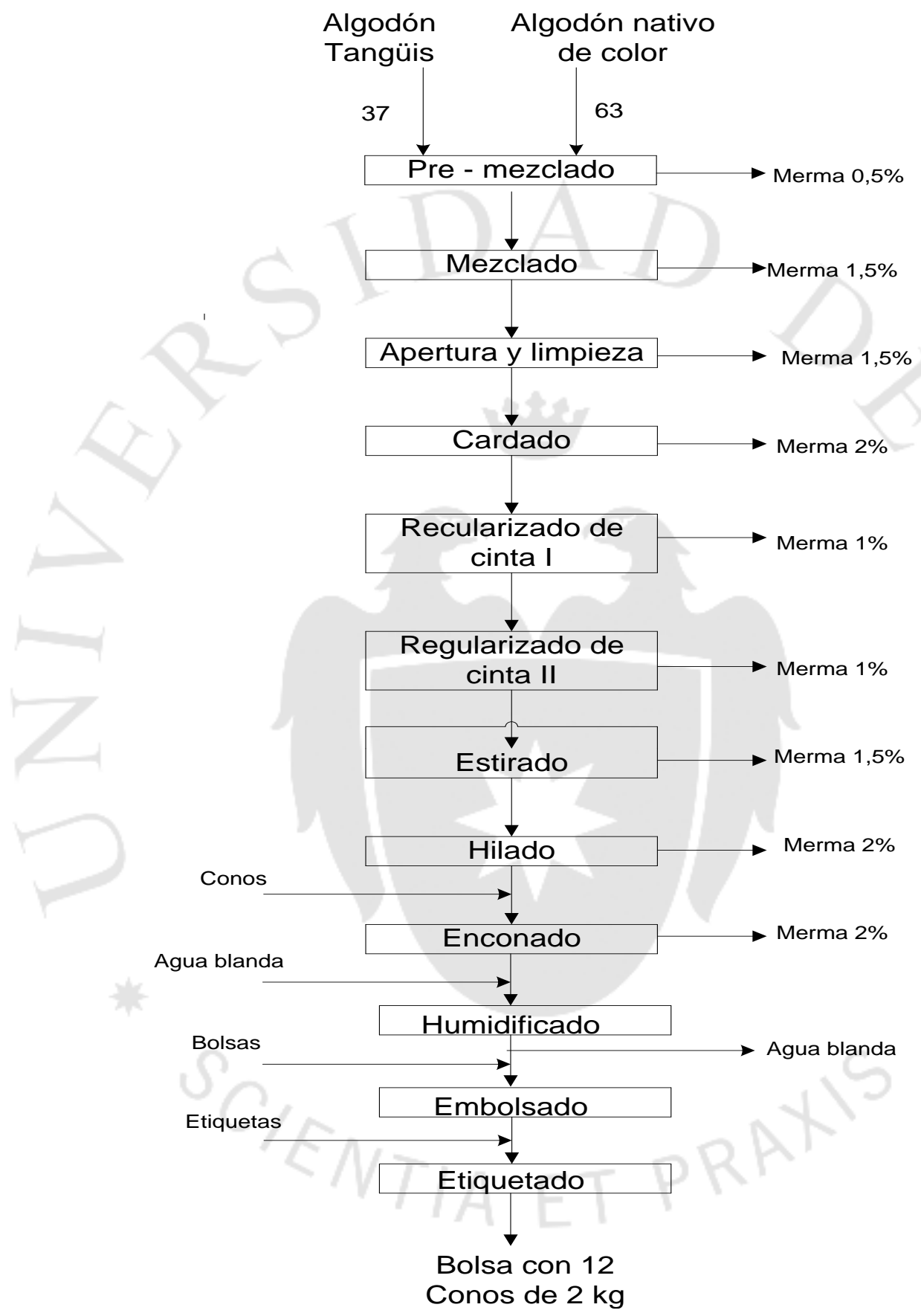

Elaboración propia. 


\subsection{Características de las instalaciones y equipo}

El proceso inicial de elaboración e implementación de una fábrica hilandera, necesita de una serie de equipos y máquinas los cuales tienen que ser instalados en los espacios correctos para un óptimo funcionamiento.

Por lo tanto, será de suma importancia alquilar un establecimiento que cumpla con los requerimientos resultantes de la suma de áreas de producción, además este establecimiento debe estar en una zona industrial ya que las mermas, desechos o los materiales usados pueden ser perjudiciales para las personas aledañas.

No se debe olvidar que algunas de las maquinarias necesarias para la producción del producto son relativamente grandes; por ello, requieren de un amplio espacio. Para poder llevar a cabo el proyecto se necesitará lo siguiente:

- Ubicación del terreno (Lurigancho).

- Conseguir los permisos de las autoridades tanto municipales como estatales.

- Definir las áreas de seguridad con las que debe cumplir la planta.

- Disposición de planta.

- Instalación de la maquinaria

La selección de la maquinaria se ha establecido de acuerdo a los requerimientos de producción dado por la demanda para nuestro proyecto, así como también se ha tenido en cuenta los costos generados por estos tales como de electricidad.

\subsubsection{Selección de la maquinaria y equipo}

\section{Maquinaria}

Debido a que previamente se describió al detalle el proceso y se diagramo este mediante un DOP resulta más sencillo seleccionar la maquinaria más adecuada para la producción de hilo de algodón nativo de color. En el cuadro 5.3 se detalla la maquinaria que se usara en cada proceso. 
Tabla 5.3

Selección de maquinaria

\begin{tabular}{|l|l|}
\hline \multicolumn{1}{|c|}{ Proceso } & \multicolumn{1}{c|}{ Máquina } \\
\hline \multirow{2}{*}{ Mezclado } & Alimentador de Mezcla -B10/1 Blending \\
\cline { 2 - 2 } & Mezcladora - B142 Automixer \\
\hline \multirow{2}{*}{ Apertura y Limpieza } & Limpiador de mezcla - B41 Cage Condenser \\
\cline { 2 - 2 } & Abridora - B34 Horizontal Opener \\
\cline { 2 - 2 } & Motor Ventilador - B151 Motorfan \\
\hline Cardado & Carda - CX300 \\
\hline Regularizado de Cinta I & Manuar -SH1-E One-delivery draw frame \\
\hline Regularizado de Cinta II & Manuar -SH1-E One-delivery draw frame \\
\hline Estirado & Mechera - BCX 16 Flyer Frame \\
\hline Hilado & Continua de hilar - NSF3 Ring spinning \\
\hline Enconado & Conera - Roccatrice Savio Espero \\
\hline Humedificado & Cámara de Humidificación - Xorella XO \\
\hline
\end{tabular}

Elaboración propia

\section{Equipo}

Tabla 5.4

Selección de equipo

\begin{tabular}{|l|l|}
\hline \multicolumn{1}{|c|}{ Equipo } & \multicolumn{1}{c|}{ Máquina } \\
\hline Ablandador de agua & Idotecnica BM5 \\
\hline Compresor & Atlas Copco GA5 \\
\hline Transformador de media a baja tensión & Triásico de media a baja tensión - \\
\hline
\end{tabular}

Elaboración propia.

\subsubsection{Especificaciones de la maquinaria}

\section{$\underline{\text { Maquinas }}$}

Para poder determinar la producción en $\mathrm{Kg}$ /hora de cada máquina se debe emplear la siguiente fórmula:

Producción en $\mathrm{Kg} /$ hora $=\frac{V s\left(\frac{\mathrm{m}}{\mathrm{min}}\right) \times 60\left(\frac{\mathrm{min}}{\text { hora }}\right) \times 0.59(\text { constante }) \times \text { husos }}{\text { Titulo }(\mathrm{Ne}) \times\left(1000 \frac{\mathrm{g}}{\mathrm{kg}}\right)}$ 
Vs $=$ Velocidad de salida

Constante $=0.59$

Husos o Cabezas $=$ Se utilizara en el caso de la mechera, la continua de anillos y la conera.

Titulo $(\mathrm{Ne})=\frac{\text { Longitud }(\text { metros })}{\text { Peso }(\text { gramos })} \times 0.59$

Velocidad de salida $=\frac{3.14 \times \text { diámero del cilindro }(\mathrm{mm}) \times \mathrm{RPM} \text { del cilindro }}{1000}$

Calculo de velocidad de salida en la continua de hilar para obtener título $30 \mathrm{Ne:}$

Velocidad de salida $=\frac{3.14 \times 27 \times 141.5}{1000}=12 \mathrm{~m} / \mathrm{min}$

\begin{tabular}{|l|l|l|}
\hline \multicolumn{3}{|c|}{ Alimentador de Mezcla -B10/1 Blending Feeder } \\
\hline Especificaciones: \\
Capacidad de producción: $200 \mathrm{~kg} / \mathrm{h}$ \\
Largo: $9,71 \mathrm{~m}$ \\
Ancho: $1,5 \mathrm{~m}$ \\
Altura : $2,10 \mathrm{~m}$ \\
Potencia: $3,7 \mathrm{~kW}$ \\
Año: 1995 \\
Marca: Marzoli \\
Modelo: Caricatrice B10/1 \\
Vida útil: 20 años \\
Precio Ex works (Italia): 15.000 euros \\
\hline
\end{tabular}




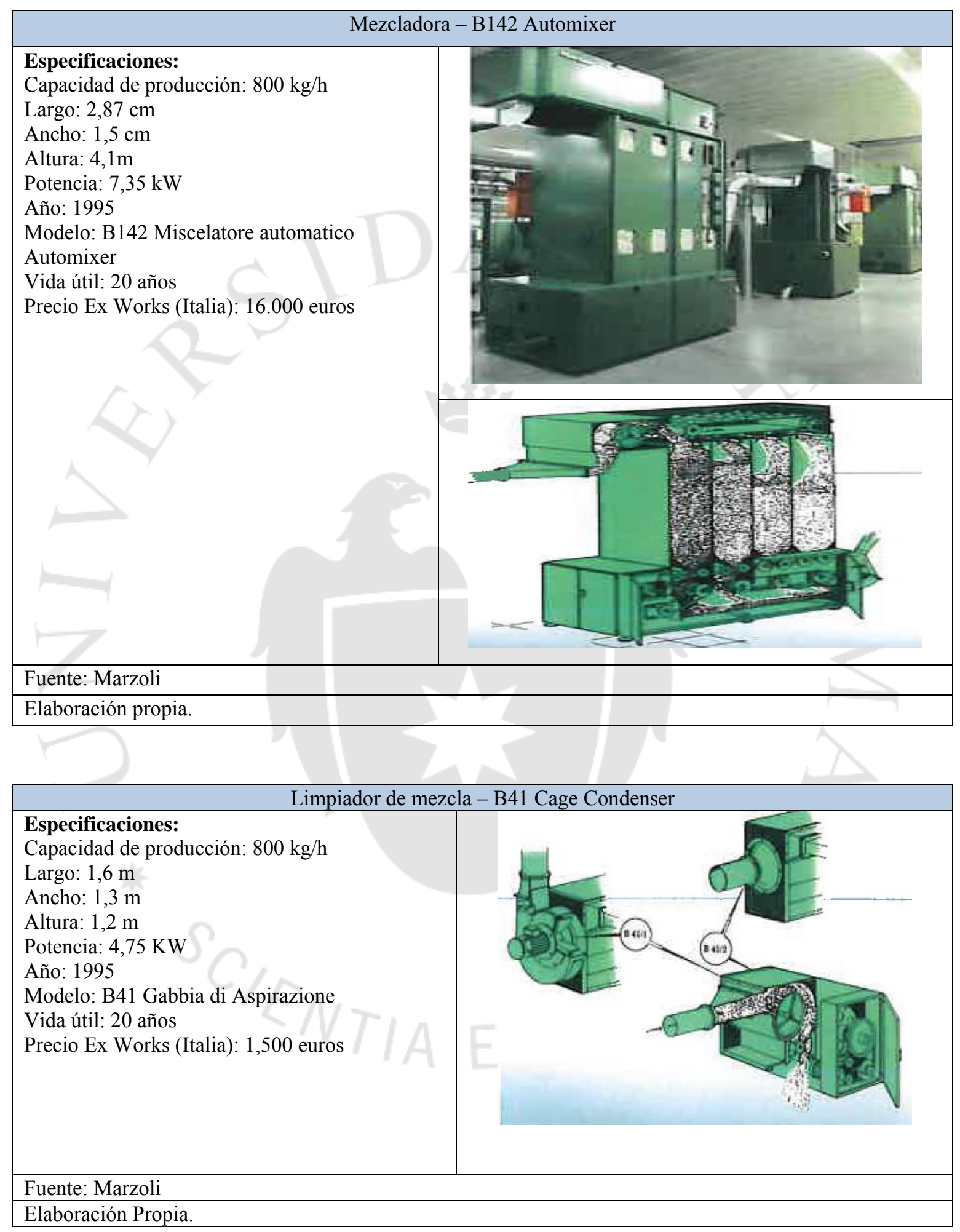




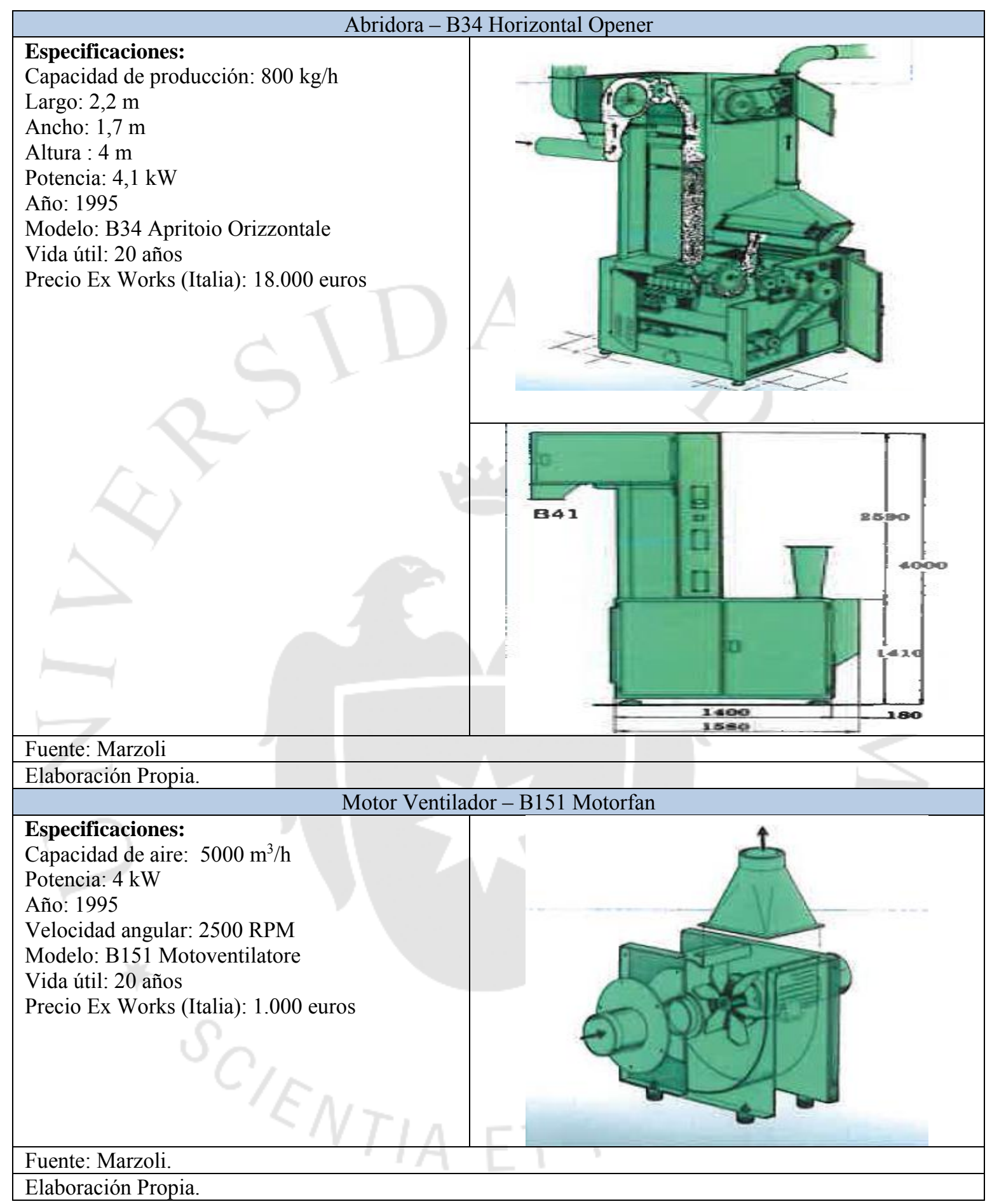




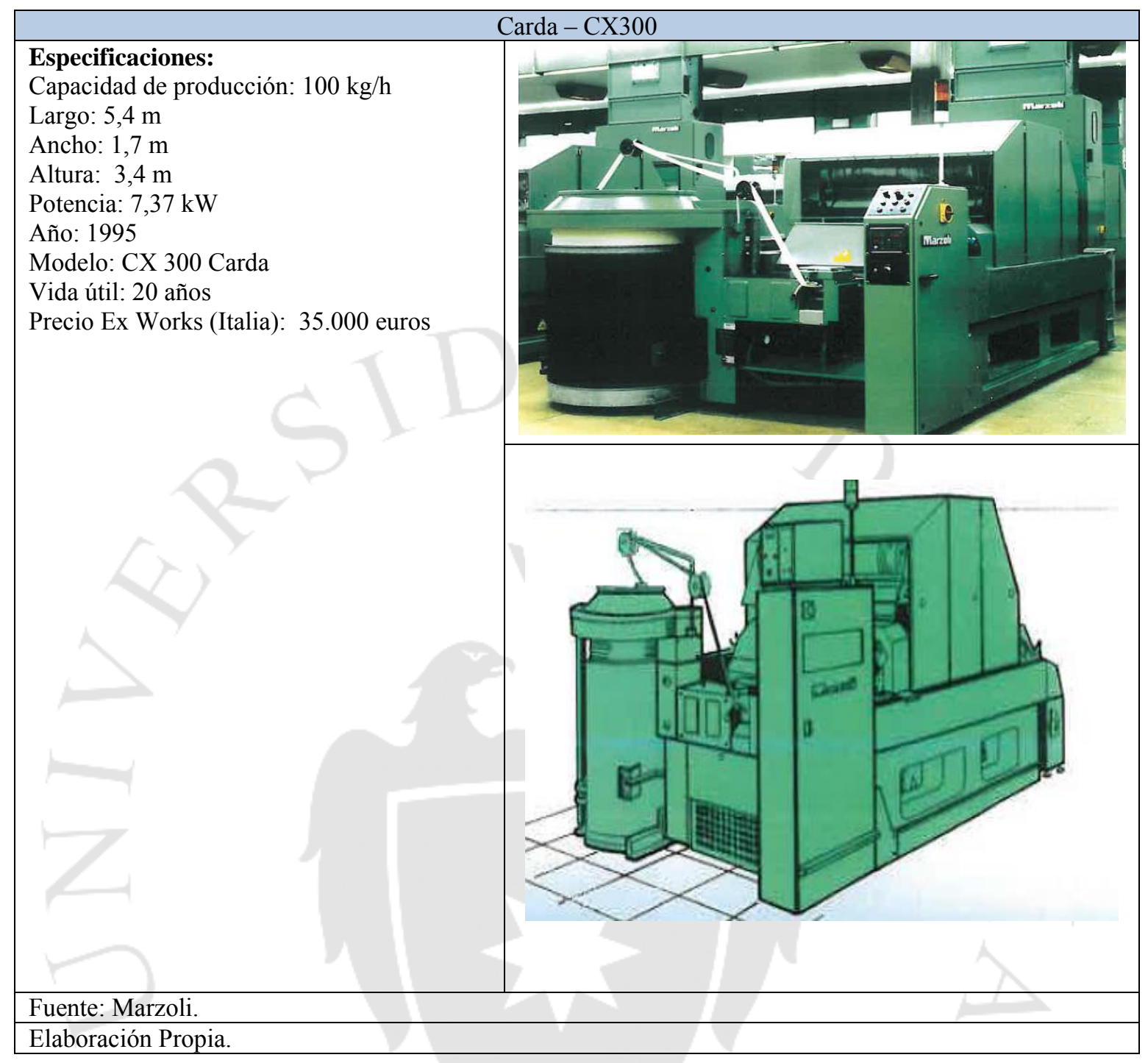




\section{Manuar -SH1-E One-delivery draw frame}

\section{Especificaciones:}

Velocidad de salida: $600 \mathrm{~m} / \mathrm{min}$

Titulo salida: $0,22 \mathrm{Ne}$

Estiraje: $4-10$ veces

Capacidad de producción: $96,55 \mathrm{~kg} / \mathrm{h}$

Largo: 7,1 m

Ancho: $3,7 \mathrm{~m}$

Altura: $1,9 \mathrm{~m}$

Potencia: $9,6 \mathrm{~kW}$

Año: 1995

Modelo: Stiratoio Unimax

Vida útil: 20 años

Precio Ex Works (Italia): 15.000 euros

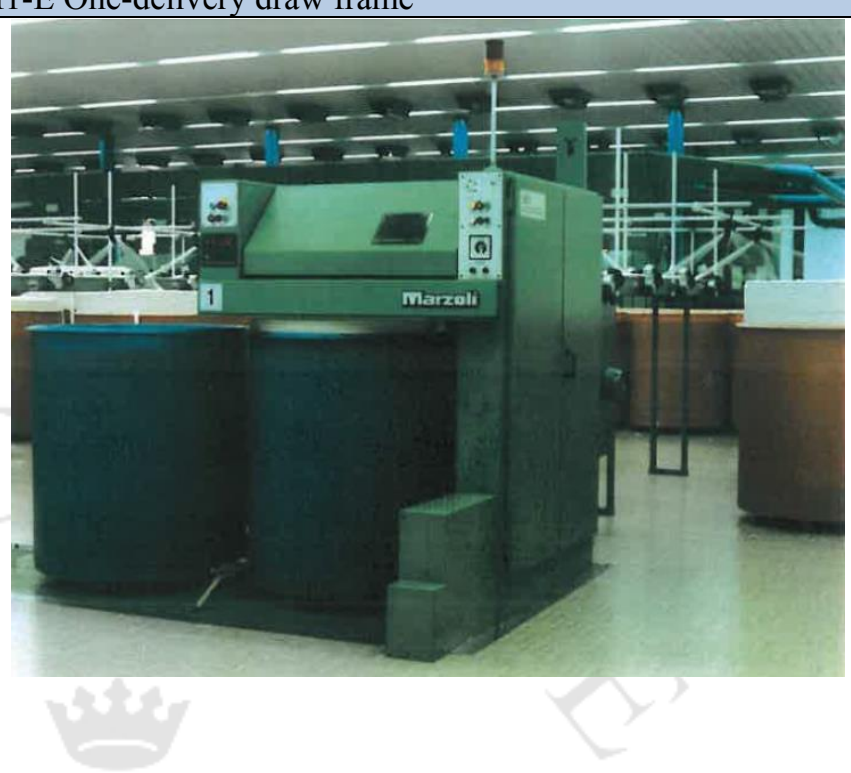

Fuente: Marzoli

Elaboración Propia.

\begin{tabular}{l}
\hline \multicolumn{2}{|c|}{ Mechera - BCX 16 Flyer Frame } \\
Especificaciones: \\
Velocidad de salida: $60 \mathrm{~m} / \mathrm{min}$ \\
Husos: 72 \\
Título: 0,4 -3,5 Ne \\
Titulo producción: $1 \mathrm{Ne}$ \\
Capacidad de producción: $152,93 \mathrm{~kg} / \mathrm{h}$ \\
Largo: $11,375 \mathrm{~m}$ \\
Ancho: $1,8 \mathrm{~m}$ \\
Altura: $3,6 \mathrm{~m}$ \\
Potencia: $11,5 \mathrm{~kW}$ \\
Año: 1995 \\
Modelo: BCX 16 Banco a Fusi \\
Vida útil: 20 años \\
Precio Ex Works (Italia): 35.000 euros
\end{tabular}




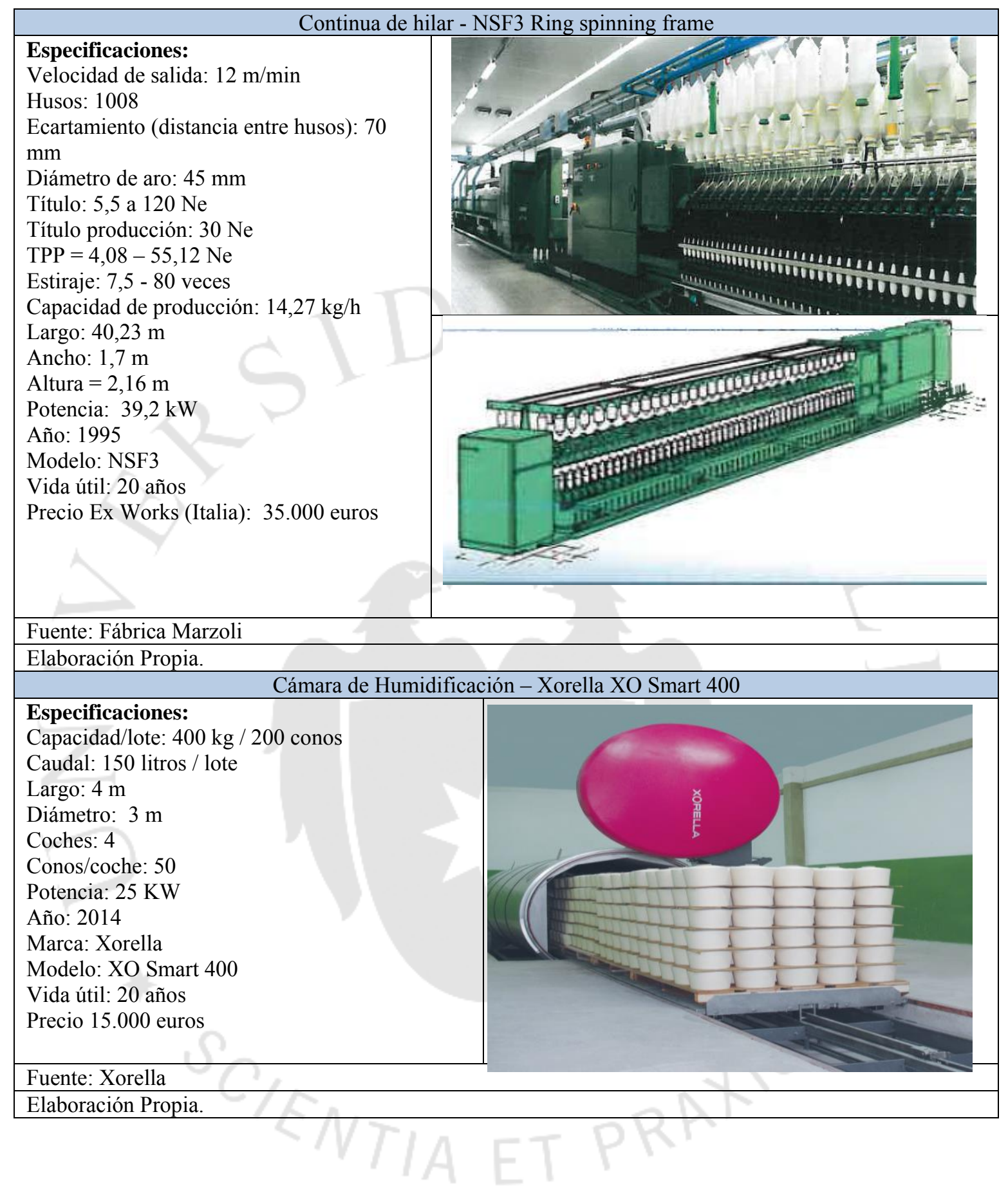




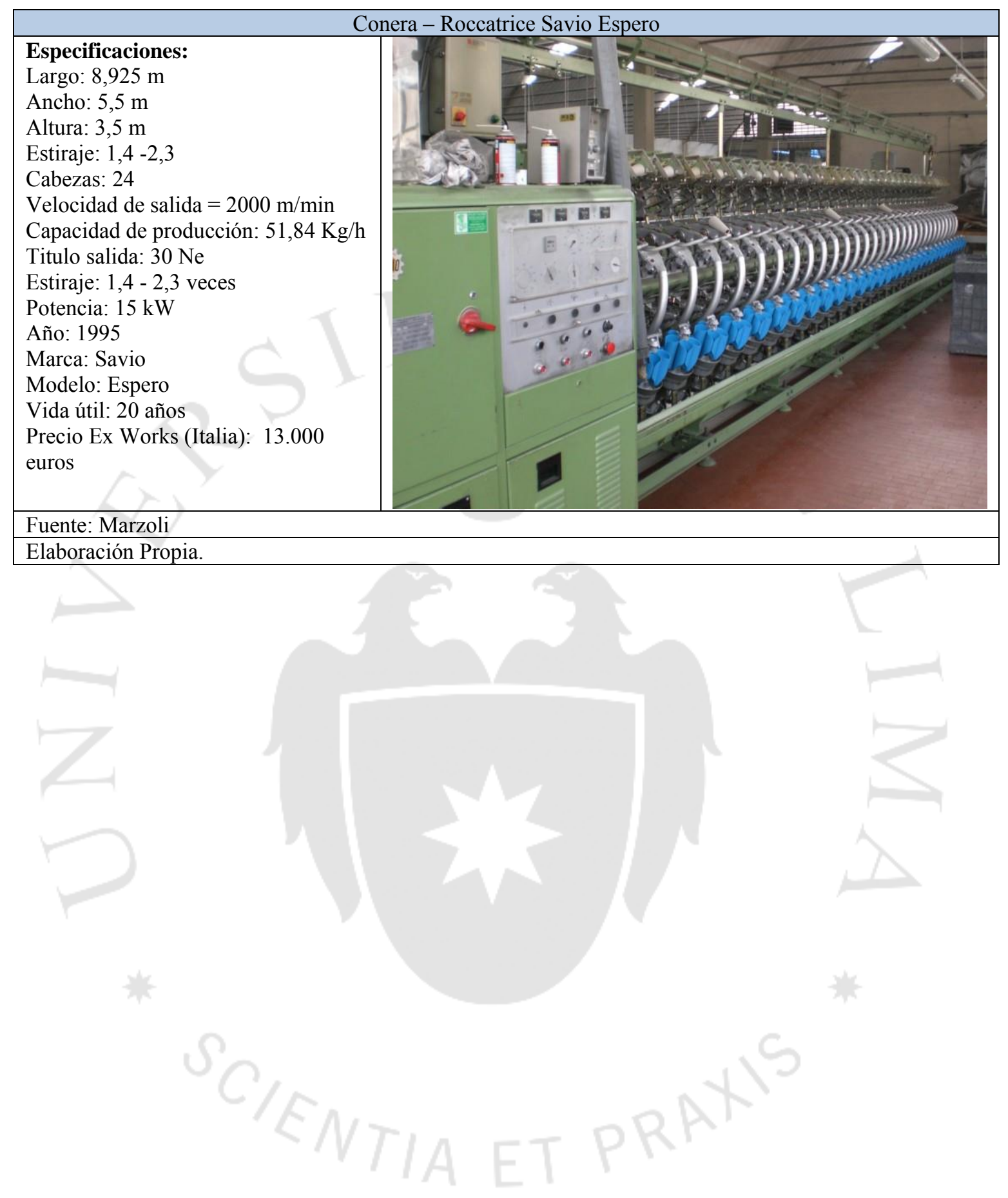




\section{Equipos}

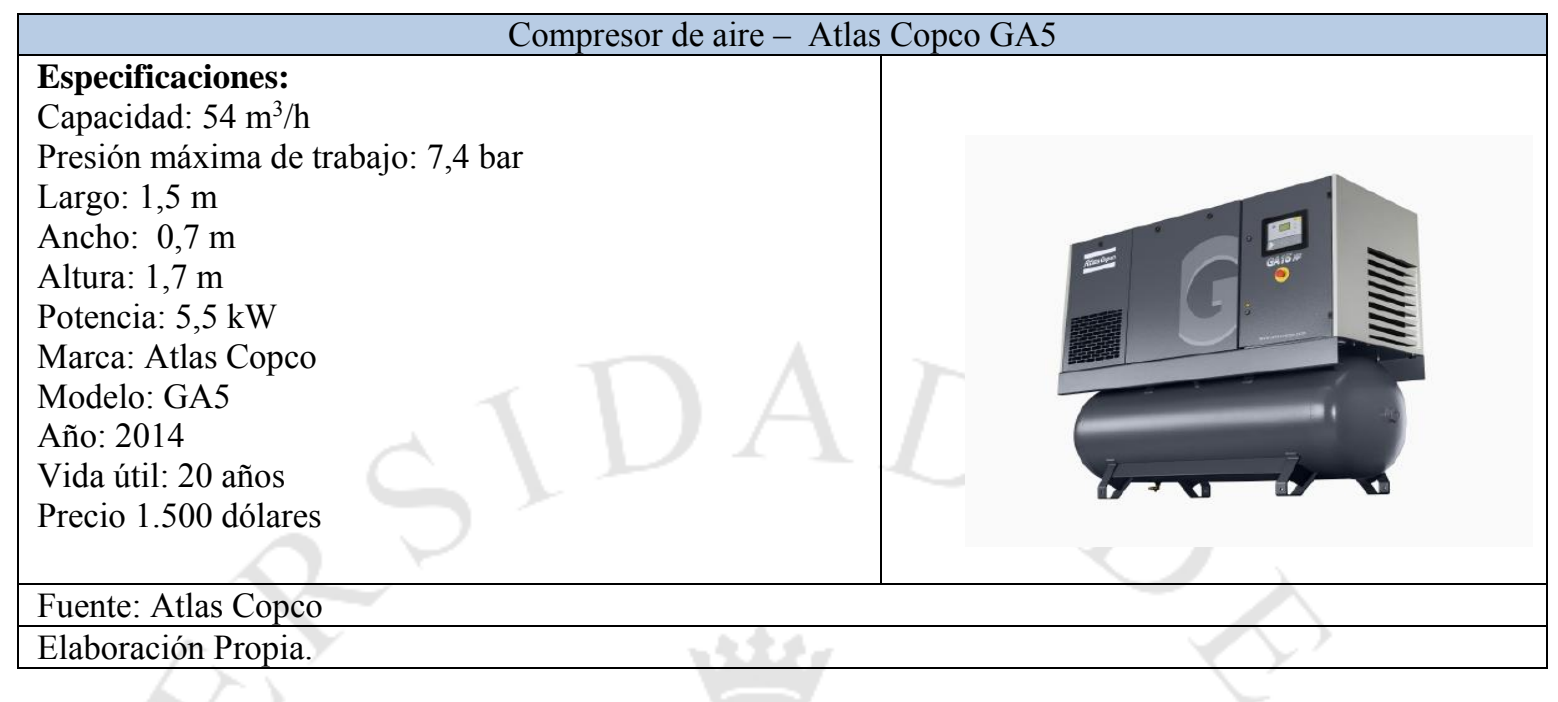

Ablandador de agua- Aquafil AFG/948G

\section{Especificaciones:}

Caudal: 1210 galones de agua por regeneración con 350 ppm de dureza total

Regenerado (retrolavado, regenerado y enjuague): 2 horas

Caudal: 2290 litros/hora

Diámetro Tanque reactor: $0.7 \mathrm{~m}$

Altura: $1.5 \mathrm{~m}$

Diámetro tanque: $0.7 \mathrm{~m}$

Altura $1.2 \mathrm{~m}$

Potencia: $1 \mathrm{~kW}$

Marca: Aquafill

Modelo: AFG/948G

Año: 2015

Vida útil: 20 años

Precio: 700 dólares

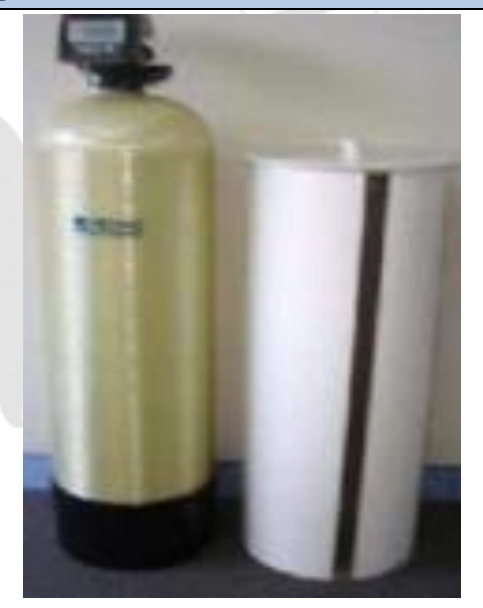

Fuente: Ecofil

Elaboración Propia. 


\section{Especificaciones:}

Lado de media tensión;

Tensión nominal: 4.16,7.62,10,13.2,22.9,9.33 kW

Conexión: Delta, estrella

Lado de baja tensión:

Tensión nominal: 220, $398,400,460,480,600 \mathrm{~V}$

Conexión: Delta, estrella

Frecuencia: $50,60 \mathrm{~Hz}$

Largo: 0,62 m

Ancho: $0,33 \mathrm{~m}$

Altura: 0,97 m

Potencia: $15 \mathrm{~kW}$

Año: 2014

Vida útil: 20 años

Marca: Promelsa

Precio: 1000 dólares

Fuente: OLX

Elaboración Propia. 


\subsection{Capacidad instalada}

\subsubsection{Cálculo de la capacidad instalada (anual)}

Para determinar la capacidad instalada se debe determinar en función al último año de la proyección del proyecto. Por definición la capacidad instalada o máxima se considera 3 turnos/día, 8 horas /turno, 7 días/Semana y 52 semanas/año, factor de utilización y factor de eficiencia. La demanda para el proyecto en el año 2025 es de 371.33 toneladas

Tabla 5.5

Capacidad instalada del año 2025

\begin{tabular}{|c|c|c|c|c|c|c|c|c|c|c|c|c|}
\hline Operación & $\begin{array}{c}\text { Cantidad entrante } \\
\text { según balance de } \\
\text { materia }(\mathrm{kg})\end{array}$ & $\begin{array}{c}\text { Capacidad de } \\
\text { procesamiento } \\
(\mathrm{kg} / \mathrm{h})\end{array}$ & $\begin{array}{l}\text { Número de } \\
\text { máquinas }\end{array}$ & $\begin{array}{l}\text { Horas } \\
\text { reales/ } \\
\text { turno }\end{array}$ & Turnos/día & días/sem & sem/año & $\begin{array}{l}\text { Factor de } \\
\text { utilización }\end{array}$ & $\begin{array}{l}\text { Factor de } \\
\text { eficiencia }\end{array}$ & $\begin{array}{l}\text { Cap. prod. En } \\
\text { kilogramos } \\
\text { por año }\end{array}$ & $\begin{array}{l}\text { Factor de } \\
\text { conversión }\end{array}$ & $\begin{array}{l}\text { Cap. prod. en } \\
\text { unid. de producto } \\
\text { terminado por } \\
\text { año }\end{array}$ \\
\hline Pre mezclado & 423,331 & & & & & & & & & & & \\
\hline Mezclado & 421,214 & 200 & 1 & 8 & 3 & 7 & 52 & 0.95 & 0.85 & $1,410,864$ & 0.882 & $1,243,777$ \\
\hline Apertura y limpieza & 414,896 & 800 & 1 & 8 & 3 & 7 & 52 & 0.95 & 0.85 & $5,643,456$ & 0.895 & $5,050,870$ \\
\hline Cardado & 408,672 & 100 & 1 & 8 & 3 & 7 & 52 & 0.95 & 0.85 & 705,432 & 0.909 & 640,973 \\
\hline Regularizado de cinta I & 400,499 & 96.55 & 1 & 8 & 3 & 7 & 52 & 0.95 & 0.85 & 681,095 & 0.927 & 631,490 \\
\hline Regularizado de cinta II & 396,494 & 96.55 & 1 & 8 & 3 & 7 & 52 & 0.95 & 0.85 & 681,095 & 0.937 & 637,868 \\
\hline Estirado & 392,529 & 152.93 & 1 & 8 & 3 & 7 & 52 & 0.95 & 0.85 & $1,078,817$ & 0.946 & $1,020,555$ \\
\hline Hilado & 386,641 & 14.27 & 5 & 8 & 3 & 7 & 52 & 0.95 & 0.85 & 503,326 & 0.960 & 483,394 \\
\hline Enconado & 378,908 & 51.84 & 2 & 8 & 3 & 7 & 52 & 0.95 & 0.85 & 731,392 & 0.980 & 716,764 \\
\hline
\end{tabular}

Elaboración propia 
Datos:

- La eficiencia es 0.85 debido a que se pretende comprar máquinas relativamente antiguas de modo que se minimice el costo.

- El pre mezclado se elabora de forma manual y no es una restricción para la producción; ya que, se puede producir en gran cantidad $(\mathrm{kg} / \mathrm{h})$. Dos trabajadores realizan el pre mezclado en $200 \mathrm{~kg}$ / hora.

- Como el proceso de apertura y limpieza está constituido por varias máquinas que están conectadas por ductos se considerará la producción por hora del cuello de botella de dichas máquinas la cual es $800 \mathrm{~kg} / \mathrm{h}$.

- Como el proceso de mezcla está conformado por el alimentador de mezcla y el mezclador se tomará la producción por hora del cuello de botella que es el alimentador con $200 \mathrm{~kg} / \mathrm{h}$.

- Se considera 5 continuas de hilar de 1,008 husos

En conclusión, la capacidad instalada a máxima capacidad de la planta está determinada en función al cuello de botella que es el valor más pequeño de capacidad de producción de productor terminado por año; por ello, el cuello de botella es el proceso de hilado; y en consecuencia, la capacidad de planta es de $483.394 \mathrm{~kg} / \mathrm{año}$.

\section{Cálculo de la capacidad requerida para el 2025}

Para determinar el cuello de botella se debe determinar este en función a la capacidad requerida la cual indica la producción requerida para satisfacer la demanda. El cuello de botella se determinara en función al último año de la proyección del proyecto. En este caso las horas trabajadas de las máquinas están en función al requerimiento de la demanda. En la planta se trabajará como máximo 12 horas de 2 turnos (considerando 4 horas extra) por semana (lunes a sábado) durante 52 semanas al año. 
Tabla 5.6

Capacidad requerida año 2025

\begin{tabular}{|c|c|c|c|c|c|c|c|c|c|c|c|c|}
\hline Operación & $\begin{array}{l}\text { Cantidad entrante } \\
\text { según balance de } \\
\text { materia }(\mathrm{kg})\end{array}$ & $\begin{array}{c}\text { Capacidad de } \\
\text { procesamiento } \\
(\mathrm{kg} / \mathrm{h})\end{array}$ & $\begin{array}{l}\text { Número de } \\
\text { máquinas }\end{array}$ & $\begin{array}{l}\text { Horas } \\
\text { reales/ } \\
\text { turno }\end{array}$ & Turnos/día & dias/sem & sem/año & $\begin{array}{l}\text { Factor de } \\
\text { utilización }\end{array}$ & $\begin{array}{l}\text { Factor de } \\
\text { eficiencia }\end{array}$ & $\begin{array}{l}\text { Cap. prod. En } \\
\text { kilogramos } \\
\text { por año }\end{array}$ & $\begin{array}{l}\text { Factor de } \\
\text { conversión }\end{array}$ & $\begin{array}{l}\text { Cap. prod. en } \\
\text { unid. de producto } \\
\text { terminado por } \\
\text { año }\end{array}$ \\
\hline Pre mezclado & 423,331 & & & & & & & & & & & \\
\hline Mezclado & 421,214 & 200 & 1 & 8.4 & 1 & 6 & 52 & 0.95 & 0.85 & 423,259 & 0.882 & 373,133 \\
\hline Apertura y limpieza & 414,896 & 800 & 1 & 2.07 & 1 & 6 & 52 & 0.95 & 0.85 & 417,213 & 0.895 & 373,404 \\
\hline Cardado & 408,672 & 100 & 1 & 8.2 & 2 & 6 & 52 & 0.95 & 0.85 & 413,182 & 0.909 & 375,427 \\
\hline Regularizado de cinta I & 400,499 & 96.55 & 1 & 8.3 & 2 & 6 & 52 & 0.95 & 0.85 & 403,792 & 0.927 & 374,383 \\
\hline Regularizado de cinta II & 396,494 & 96.55 & 1 & 8.2 & 2 & 6 & 52 & 0.95 & 0.85 & 398,927 & 0.937 & 373,609 \\
\hline Estirado & 392,529 & 152.93 & 1 & 10.3 & 1 & 6 & 52 & 0.95 & 0.85 & 396,851 & 0.946 & 375,418 \\
\hline Hilado & 386,641 & 14.27 & 5 & 10.78 & 2 & 6 & 52 & 0.95 & 0.85 & 387,561 & 0.960 & 372,213 \\
\hline Enconado & 378,908 & 51.84 & 2 & 7.3 & 2 & 6 & 52 & 0.95 & 0.85 & 381,369 & 0.980 & 373,741 \\
\hline Producto final & 371,330 & & & & & & & & & & & \\
\hline
\end{tabular}

En conclusión, la capacidad requerida de la planta está determinada en función al cuello de botella que es el valor más pequeño de capacidad de producción de producto terminado por año; por ello, el cuello de botella es el proceso de hilado; y en consecuencia, la capacidad de planta es de $372,213 \mathrm{~kg} / \mathrm{año}$.

Utilizando la misma metodología en la tabla 5.6 se determinará la producción de todos los años del proyecto. 


\subsubsection{Cálculo detallado del número de máquinas requeridas}

Se determinará el número de máquinas para el último año de la proyección del proyecto con el objetivo de determinar la capacidad instalada de planta. Asimismo, se determinará la cantidad de máquinas tanto para el primer año del proyecto como para el último con el objetivo de determinar la capacidad requerida.

\section{$\underline{\text { Capacidad instalada para el último año de la proyección del proyecto }}$}

La demanda para el proyecto en el año 2025 es de 371.33 toneladas de hilo.

Se considera 3 turnos/día, 8 horas /turno, 365 días/año, factor de utilización igual a 0,95 y factor de eficiencia. 0,85

\section{Mezclador}

\# mezcladores $=\frac{\frac{1 \mathrm{HM}}{200 \mathrm{~kg}} \times 421,214 \frac{\mathrm{kg}}{\mathrm{año}}}{365 \frac{\text { dias }}{\text { año }} \times 3 \frac{\text { turnos }}{\text { dia }} \times 8 \frac{\text { horas }}{\text { turno }} \times 0.95 \times 0.85}$

\# Mezcladores $=0,297=1$ máquina

\section{Apertura y limpieza}

\# Abridor y limpiador $=\frac{\frac{1 \mathrm{HM}}{800 \mathrm{~kg}} \times 414,896 \frac{\mathrm{kg}}{\text { año }}}{365 \frac{\text { dias }}{\text { año }} \times 3 \frac{\text { turnos }}{\text { dia }} \times 8 \frac{\text { horas }}{\text { turno }} \times 0.95 \times 0.85}$

\# Abridor y limpiador $=0,073$ máquinas $=1$ máquina

\section{Carda}

\# Cardas $=\frac{\frac{1 \mathrm{HM}}{100 \mathrm{~kg}} \times 408,672 \frac{\mathrm{kg}}{\mathrm{año}}}{365 \frac{\text { dias }}{\text { año }} \times 3 \frac{\text { turnos }}{\text { dia }} \times 8 \frac{\text { horas }}{\text { turno }} \times 0.95 \times 0.85}$

\# Cardas $=0,578$ máquinas $=1$ máquina 
Manuar (Regularizado de cinta I)

\# Manuares $=\frac{\frac{1 \mathrm{HM}}{96,55 \mathrm{~kg}} \times 400,499 \frac{\mathrm{kg}}{\mathrm{año}}}{365 \frac{\text { dias }}{\text { año }} \times 3 \frac{\text { turnos }}{\text { dia }} \times 8 \frac{\text { horas }}{\text { turno }} \times 0.95 \times 0.85}$

\# Manuares $=0,586$ máquinas $=1$ máquina

\section{Manuar (Regularizado de cinta II)}

\# Manuares $=\frac{\frac{1 \mathrm{HM}}{96,55 \mathrm{~kg}} \times 396,494 \frac{\mathrm{kg}}{\mathrm{año}}}{365 \frac{\text { dias }}{\text { año }} \times 3 \frac{\text { turnos }}{\text { dia }} \times 8 \frac{\text { horas }}{\text { turno }} \times 0.95 \times 0.85}$

\# Manuares $=0,58$ máquinas $=1$ máquina

\section{Mechera}

\# Mecheras $=\frac{\frac{1 \mathrm{HM}}{152,93 \mathrm{~kg}} \times 392,529 \frac{\mathrm{kg}}{\mathrm{año}}}{365 \frac{\text { dias }}{\text { año }} \times 3 \frac{\text { turnos }}{\text { dia }} \times 8 \frac{\text { horas }}{\text { turno }} \times 0.95 \times 0.85}$

\# Mecheras $=0,37$ máquinas $=1$ máquina

\section{Continúa de hilar}

\# Continuas $=\frac{\frac{1 \mathrm{HM}}{14,27 \mathrm{~kg}} \times 386,641 \frac{\mathrm{kg}}{\mathrm{año}}}{365 \frac{\text { dias }}{\text { año }} \times 3 \frac{\text { turnos }}{\text { dia }} \times 8 \frac{\text { horas }}{\text { turno }} \times 0.95 \times 0.85}$

\# Continuas $=3,83$ máquinas $=4$ máquinas

\section{Conera}

\# Coneras $=\frac{\frac{1 \mathrm{HM}}{51,84 \mathrm{~kg}} \times 378,908 \frac{\mathrm{kg}}{\mathrm{año}}}{365 \frac{\text { dias }}{\text { año }} \times 3 \frac{\text { turnos }}{\text { dia }} \times 8 \frac{\text { horas }}{\text { turno }} \times 0.95 \times 0.85}$ 
\# Coneras = 1,03 máquinas $=2$ máquinas

\section{$\underline{\text { Determinación del número de máquinas requeridas para el proyecto }}$}

De acuerdo a la capacidad requerida anual que se calculó en la sección 5.4.1 se ha elaborado la tabla 5.8 en el cual detalla los años en los cuales se adquirirá la maquinaria. Se considerará como año cero al año 2015. En el caso de las máquinas adicionales que se compren en los años de funcionamiento del proyecto, se comprará el mismo año en la cual se necesiten. Asimismo, en la tabla 5.7 se detalla las máquinas necesarias por año para alcanzar el nivel de producción. Por último, se debe considerar que las maquinarias se adquirirán el año anterior a su operación; ya que, se debe considerar el tiempo del traslado y montaje de máquina.

\section{Tabla 5.7}

Número de máquinas necesarias para alcanzar el nivel de producción

\begin{tabular}{|l|c|c|c|c|c|c|c|c|c|c|}
\hline & 2016 & 2017 & 2018 & 2019 & 2020 & 2021 & 2022 & 2023 & 2024 & 2025 \\
\hline Mezcla & 1 & 1 & 1 & 1 & 1 & 1 & 1 & 1 & 1 & 1 \\
\hline Apertura y limpieza & 1 & 1 & 1 & 1 & 1 & 1 & 1 & 1 & 1 & 1 \\
\hline Cardado & 1 & 1 & 1 & 1 & 1 & 1 & 1 & 1 & 1 & 1 \\
\hline Regularizado de cinta I & 1 & 1 & 1 & 1 & 1 & 1 & 1 & 1 & 1 & 1 \\
\hline Regularizado de cinta II & 1 & 1 & 1 & 1 & 1 & 1 & 1 & 1 & 1 & 1 \\
\hline Estirado & 1 & 1 & 1 & 1 & 1 & 1 & 1 & 1 & 1 & 1 \\
\hline Hilado & 3 & 3 & 3 & 3 & 4 & 4 & 4 & 5 & 5 & 5 \\
\hline Enconado & 1 & 1 & 1 & 1 & 1 & 1 & 1 & 2 & 2 & 2 \\
\hline
\end{tabular}

Elaboración propia.

\section{Tabla 5.8}

Detalle de adquisición de maquinaria

\begin{tabular}{|l|c|c|c|}
\hline & 2015 & 2019 & 2022 \\
\hline Mezcla & 1 & & \\
\hline Apertura y limpieza & 1 & & \\
\hline Cardado & 1 & & \\
\hline Regularizado de cinta I & 1 & & \\
\hline Regularizado de cinta II & 1 & & \\
\hline Estirado & 1 & & \\
\hline Hilado & 3 & 1 & 1 \\
\hline Enconado & 1 & & 1 \\
\hline
\end{tabular}

Elaboración propia. 


\subsection{Resguardo de la calidad}

\subsubsection{Calidad de la materia prima, de los insumos, del proceso y producto}

\section{Materia prima}

En la siguiente información acerca de la calidad de la materia prima (algodón nativo de color) se usó texto bibliográfico de la investigación: Revalorando un cultivo ancestral: algodón nativo fibra de calidad para la industria (Percy Perez Saldaña, 2012). Para poder determinar la calidad del algodón se debe hacer un análisis de la calidad de fibra de acuerdo a las siguientes variables: micronaire, uniformidad de la longitud, longitud de fibra, resistencia de la fibra y elongación.

\section{$\underline{\text { Micronaire }}$}

Es la medida de la finura de la fibra del algodón que hacer relación al mayor o menor diámetro. Está asociado con el grado de engrosamiento y calidad de las capas de celulosa depositados en ella. La importancia en el proceso textil está diámetro de la fibra, pues es fundamental para el título o calibre de los hilos. Fibras finas (Micronaire bajos), se utilizan para elaborar hilos delgados. Fibras ásperas (Micronaires altos) se emplean para confeccionar hilos gruesos.

Tabla 5.9

Clasificación de fibra según micronaire

\begin{tabular}{|c|c|}
\hline Micronaire & Descripción \\
\hline Menor a 3 & Extra fina \\
\hline $3-3,6$ & Fina \\
\hline $3,7-4,7$ & Promedio \\
\hline $4,8-5,4$ & Áspera \\
\hline Mayor a 5,5 & Muy Áspera \\
\hline
\end{tabular}

Fuente: Vásquez, P.; Pérez, P., (2011) 


\section{$\underline{\text { Uniformidad de la longitud }}$}

Mide la proporción de fibras de una muestra con una longitud igual o superior al promedio. El índice de uniformidad es medido en un fibrograma de una muestra de fibras y expresa el cociente de la longitud promedio en relación a la longitud promedio de la mitad superior y se expresa en porcentaje. El algodón con índice de uniformidad bajo tiende a incluir un porcentaje alto de fibras cortas

Tabla 5.10

Clasificación de fibra según uniformidad

\begin{tabular}{|c|c|}
\hline Uniformidad (\%) & Descripción \\
\hline Menor a 77 & Muy baja \\
\hline $77-80$ & Baja \\
\hline $81-84$ & Promedio \\
\hline $85-87$ & Alta \\
\hline Mayor a 87 & Muy alta \\
\hline
\end{tabular}

Fuente: Vásquez, P.; Pérez, P., (2011)

$\underline{\text { Longitud de fibra }}$

Se refiere a la longitud promedio de una porción típica de fibras de una muestra de algodón. La longitud varía de acuerdo a la variedad y se ve afectada por las condiciones ambientales, especialmente por la temperatura, disponibilidad de humedad y nutrición potásica.

Tabla 5.11

Clasificación de fibra según longitud

\begin{tabular}{|c|c|}
\hline Longitud (mm) & Descripción \\
\hline Menor a 21,8 & Fibra extra corta \\
\hline $21,8-24,9$ & Fibra corta \\
\hline $25,1-28,7$ & Fibra media \\
\hline $29-30,5$ & Fibra larga \\
\hline Mayor a 30,6 & Fibra extra larga \\
\hline
\end{tabular}

Fuente: Vásquez, P.; Pérez, P., (2011) 


\section{$\underline{\text { Resistencia de la fibra }}$}

Se define como la resistencia que oponen las fibras al ser sometidas a una tensión y se expresa en miles de libras por pulgada o en gramos por tex. La resistencia está relacionada con la longitud de fibra.

\section{Tabla 5.12}

Clasificación de fibra según resistencia

\begin{tabular}{|c|c|}
\hline Resistencia (g/tex) & Descripción \\
\hline Menor a 21 & Muy débil \\
\hline $22-24$ & Débil \\
\hline $25-27$ & Promedio \\
\hline $28-30$ & Resistente \\
\hline Mayor a 31 & Muy resistente \\
\hline
\end{tabular}

Fuente: Vásquez, P.; Pérez, P., (2011)

En el proceso textil existe una correlación importante entre la resistencia de la fibra y la del hilado. El algodón con resistencia alta soportara mejor las tensiones a que es sometido en el proceso de hilatura.

\section{Elongación}

Es una medida del comportamiento elástico de las fibras durante la medición de la longitud y resistencia a la tracción. Es la distancia que las fibras se estiran antes de que se rompan, y ese expresa como porcentaje de alargamiento. La elongación está asociada con la resistencia de fibra. 
Tabla 5.13

Clasificación de fibra según elongación

\begin{tabular}{|c|c|}
\hline Elongación & Descripción \\
\hline Menor a 5 & Muy débil \\
\hline $5-5,8$ & Débil \\
\hline $5,9-6,7$ & Regular \\
\hline $6,8-7,6$ & Elevado \\
\hline Mayor a 7,7 & Muy elevado \\
\hline
\end{tabular}

Fuente: Vásquez, P.; Pérez, P., (2011)

En el proceso textil el algodón con buena elongación soporta las tensiones a que se somete durante el proceso de elaboración de los hilos y produce menos revientes.

\section{$\underline{\text { Nepabilidad }}$}

Es la medida del contenido de neps (pequeñas motas) que se forman en el algodón

\section{Proceso y producto}

Para poder determinar la calidad del material en proceso se debe hacer un análisis de la calidad de acuerdo a las siguientes variables: título, regularidad de cinta, el al largo y distribución de las fibras, contenido de impurezas, resistencia

\section{$\underline{\text { Titulo (Densidad lineal) }}$}

Mediante el titulo se puede determinar la finura de la cinta, mecha e hilo. Para poder determinar el valor de esta variable se divide la longitud entre el peso. Su unidad de medida convencional es el Número inglés $(\mathrm{Ne})$.

$$
\begin{aligned}
& \mathrm{Ne}=\frac{\mathrm{L}}{\mathrm{P}} 0,54 \\
& \mathrm{~L}=\text { Longitud en yardas } \\
& \mathrm{P}=\text { Peso en gramos }
\end{aligned}
$$


Para poder medir el titulo se necesitan 2 equipos: la devanadora la cual es un cilindro que recolecta 100 metros de hilo del cono o canilla y la balanza electrónica en la cual se pesan los 100 metros de tal forma que mediante el cálculo de estas dos variables se pueda obtener el título.

\section{$\underline{\text { Torsión }}$}

Es la cantidad de vueltas que da el hilo en una pulgada con el objetivo de mantener unidas las fibras que lo constituyen y brindarle una mayor resistencia. Se puede realizar diferentes sentidos de torsión conocidos como Z y S. La torsión se mide mediante el torsiómetro

\section{$\underline{\text { Resistencia }}$}

Mide la capacidad que resiste el hilo para resistir una determinada fuerza hasta romperse. Esta fuerza sobre el hilo se pueda aplicar de 3 maneras: a lo largo del eje (tracción), en forma perpendicular al eje (flexión), haciéndolo girar sobre su eje (torsión). La resistencia se mide mediante un dinamómetro y su unidad es RKM. El hilo debe tener una resistencia de 12 RKM, si es que tiene una resistencia menor a 12 entonces tiene baja resistencia y si tiene un valor mayor a 12 entonces el hilo tiene una torsión excesiva.

\section{$\underline{\text { Regularidad (U, CV\%) }}$}

La regularidad mide la variación del título a lo largo del hilo. Este es expresado en U y CV\% Esta variable es muy importante para medir la calidad del hilo; ya que, el titulo no debe variar significativamente en su extensión. La regularidad se mide mediante un equipo de regularmetria.

\section{Elongación}

Mide la longitud hasta cuanto se puede estirar el hilo antes de romperse cuando se le aplica un estiramiento (fuerza de tracción). 


\section{$\underline{\text { Pilosidad }}$}

Mide la cantidad de vellosidad que se forma en el hilo. La vellosidad que se forma principalmente debido al desgaste del aro de la continua de hilar.

\subsubsection{Medida de resguardo de la calidad en la producción}

En la hilandera se controlara la calidad del algodón que ingresa, del producto que se obtiene en cada etapa (cintas, mechas) y del producto final (hilado) con el objetivo de asegurar la óptima calidad del producto terminado.

Se controlará la calidad de la materia prima

Mediante el equipo denominado HVI (High Volume Instrument) se medirá la calidad de la materia prima; ya que, este instrumento se analizará los lotes de algodón de tal forma que se previene inconvenientes en un futuro para el producto final.

Las variables que se miden son las siguientes:

- Longitud de fibra

- Uniformidad de longitud de fibra

- Elongación

- Finura

- Indicé de madurez

- Finura (micronaire)
- Indicé de madurez

- Humedad

- Índice de contenido de fibras cortas

- Color de la fibra

- Impurezas

Se controlará la calidad de producto en proceso como las cintas provenientes de las cardas y manuares; así como la calidad de las mechas provenientes de la mechera. Las variables que se miden en este caso son el título, la regularidad de cinta, el largo y distribución de las fibras y contenido de impurezas. 


\section{Tabla 5.14}

Control de Calidad de cintas y mechas

\begin{tabular}{|l|l|}
\hline \multicolumn{1}{|c|}{ Ensayo } & \multicolumn{1}{c|}{ Equipo / aparato } \\
\hline Regularidad (u, cv\%) & Regularimetro -tester \\
\hline $\begin{array}{l}\text { Largo y distribución de } \\
\text { fibras \% de fibras cortas }\end{array}$ & HVI \\
\hline impurezas & HVI \\
\hline titulación & Rodillo + balanza \\
\hline $\begin{array}{l}\text { Torsión (solo de las } \\
\text { mechas) }\end{array}$ & torsiometro \\
\hline
\end{tabular}

Elaboración propia.

Se Controlará la calidad del hilado (continuas y coneras)

Las variables que se miden son regularidad, el título y la torsión del hilado, así como su resistencia y elongación. También se controla la vellosidad. En la conera se realiza el purgado del hilo, donde se descartan las partes gruesas o delgadas que pueda contener.

Finalmente, para tener una mayor eficiencia en los análisis de control de calidad es recomendable contar con un sistema de climatización del laboratorio (equipo de climatización) y con un higrómetro para controlar la humedad relativa.

\section{Tabla 5.15}

Control de calidad de hilo

\begin{tabular}{|l|l|}
\hline Ensayo & Equipo / aparato \\
\hline $\begin{array}{l}\text { Regularidad (v, } \\
\text { cv\%) }\end{array}$ & regularimetro \\
\hline titulación & Aspa + balanza \\
\hline torsión & torsiometro \\
\hline $\begin{array}{l}\text { Resistencia y } \\
\text { elongación }\end{array}$ & dinamometro \\
\hline vellosidad & $\begin{array}{l}\text { Regularimetro; } \\
\text { modulo H (hairness) }\end{array}$ \\
\hline
\end{tabular}

Elaboración propia. 


\subsection{Estudio de Impacto Ambiental}

El impacto generado por una planta de producción de hilos de algodón nativo de color como la requerida para el presente proyecto se prevé que no será tan significativo como el que se puede generar en la industria textil que requiere el proceso de teñido.

Al tener este algodón un color natural se evitará el proceso de teñido el cual es el más contaminante en la hilatura. El hilo del algodón si no es tratado químicamente no es completamente blanco, sino que queda de un color beige muy pálido; por ello, se blanquea el algodón utilizando cloro. Asimismo, en el proceso de teñido se utiliza productos químicos y colorantes lo cual genera efluentes tóxicos que contaminan negativamente la salud humana, fauna y medio ambiente. En el proceso de teñido, no sólo se utiliza colorantes, agua y químicos, sino varios productos especiales conocidos como auxiliares de teñido para mejorar la calidad del teñido, la suavidad, la firmeza, la textura, estabilidad dimensional, resistencia a la luz y al lavado. En los efluentes procedentes del proceso de teñido se pueden encontrar un gran número de contaminantes como fenoles, sulfuros, cromo y colorantes.

La mayoría de pigmentos utilizados para la elaboración de colorantes están hechos a base de metales pesados que son altamente dañinos para la salud humana. Los más peligrosos son el arsénico el cual tiene gran capacidad toxica, el mercurio que produce enfermedades neurológicas y lesiones renales; y el plomo el cual es el más peligroso; ya que, causa daños en el cerebro.

En el proceso productivo de hilo elaborado con algodón nativo de color no se utiliza ningún tipo de sustancia peligrosa, pero al ser una empresa hilandera, se debe realizar un cuidadoso control de la fibra volátil y pelusa que se encuentran suspendidas en el ambiente; ya que, podrían ser inhaladas por los trabajadores causándoles daños a las vías respiratorias y molestias estomacales

siendo el proceso en el que se presenta un mayor grado este problema el pre mezclado ;ya que, se realiza manualmente; por ello, la fábrica contará con un sistema de climatización el cual consiste en un conjunto de ductos que se encuentran por debajo de las máquinas los cuales absorberán las fibras volátiles junto con aire caliente; para luego, pasar por un filtro en forma cilíndrica el cual se encarga de retener las pelusas para luego depositarlo en sacos mientras que el aire caliente es aspirado y botado al exterior de la fábrica mediante un ducto de 7 metros de altura. Cuando se desea aumentar la temperatura se deja de absorber el aire caliente. Debido a que el filtro absorbe 
todo el material particulado sólo se bota al medio ambiente el aire caliente el cual no es un parámetro que se controla por el ECA (estado de calidad ambiental) aire. Asimismo, este sistema sirve para mantener a la fábrica en una temperatura idónea de 32 grados centígrados para que el algodón no se deshidrate. En lo referente a residuos sólidos, además de las mermas generadas en todo el proceso productivo como las fibras, también se generan otros residuos producto de la limpieza, mantenimiento, y el trabajo de oficina y laboratorio.

En lo referente a residuos líquidos, para hacer un correcto mantenimiento se utilizan lubricantes como grasas y aceites para que no haya fricción en las máquinas. En el manuar, se utiliza una sustancia llamada hidrolina que sirve para el correcto funcionamiento del sistema hidráulico del brazo pendular el cual sirve para sujetar los rodillos que estiran las fibras.

En la fábrica se genera ruido en todos los procesos; ya que, las máquinas cuentan con motores eléctricos, sistemas de poleas, ejes, chapones y rodajes que hacen que el ruido sea constante e intenso. Asimismo, la vibración que se genera en las máquinas puede afectar el sistema nervioso, órganos internos y tejidos del cuerpo de los trabajadores. La intensidad del ruido se puede medir por medio de un medidor de nivel de sonido o decibelímetro, que expresa la intensidad en decibeles (DB). Cuando la exposición, al ruido está por encima de estos niveles máximos permisibles se pueden presentar daños como perdida de la audición temporal, daños irreversibles en el oído medio e interno, además de esto baja la eficiencia del trabajador y no se logra una comunicación efectiva.

Antes de comenzar la instalación de la planta, es necesario realizar el estudio de impacto ambiental, en el cual se analizará si el terreno elegido está cerca a zonas urbanas donde existan viviendas que sean potencialmente afectadas debido a que la planta podría generar ruidos intensos, como resultado del uso de la maquinaria los cuales son dañinos para la salud y que causan graves problemas a la población. 
Tabla 5.16

Matriz de aspectos e impactos ambientales clasificados por actividad o proceso

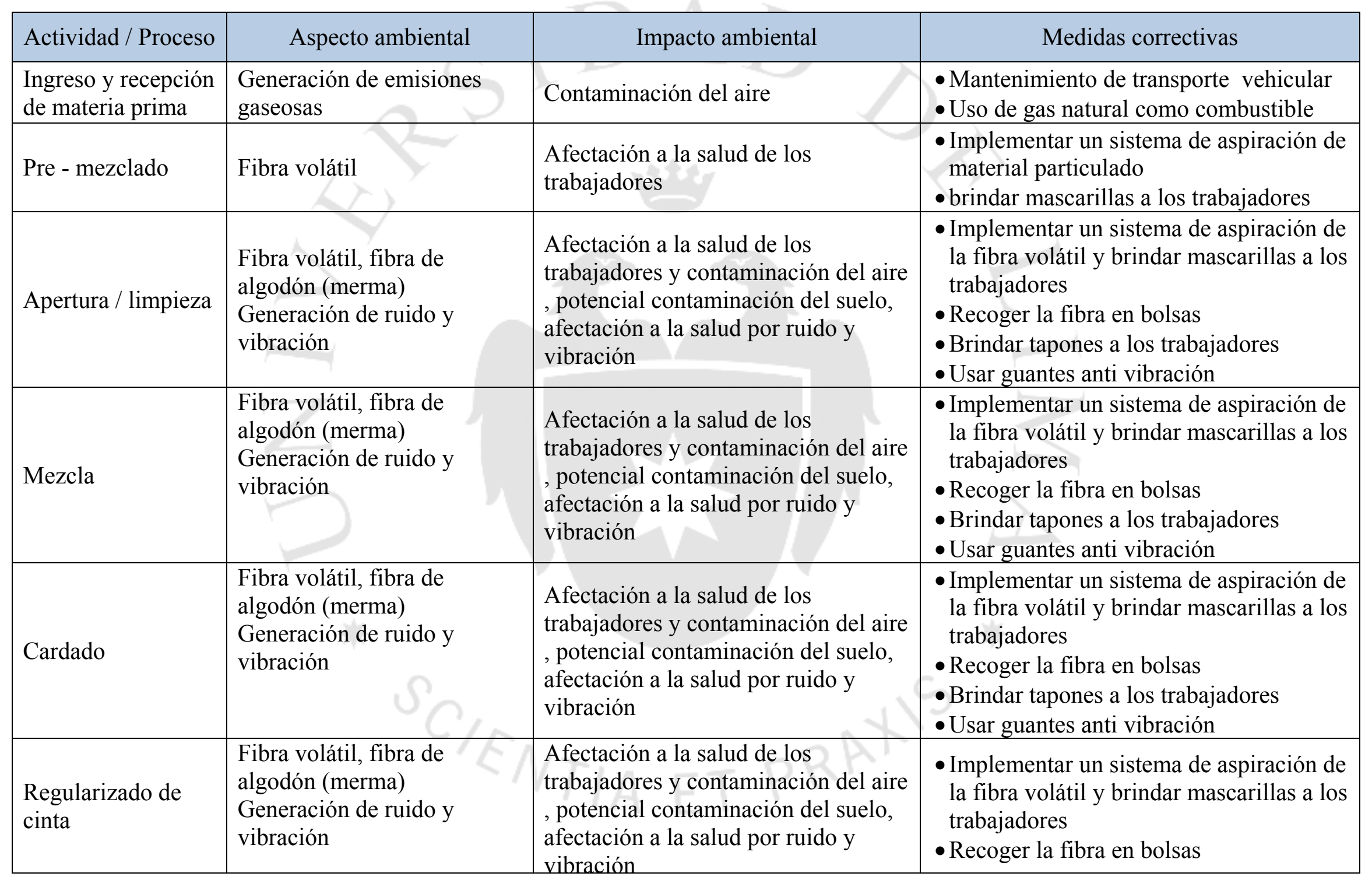




\begin{tabular}{|c|c|c|c|}
\hline Actividad / Proceso & Aspecto ambiental & Impacto ambiental & Medidas correctivas \\
\hline Estirado & $\begin{array}{l}\text { Fibra volátil, fibra de } \\
\text { algodón (merma) } \\
\text { Generación de ruido y } \\
\text { vibración }\end{array}$ & $\begin{array}{l}\text { Afectación a la salud de los } \\
\text { trabajadores y contaminación del aire } \\
\text {, potencial contaminación del suelo, } \\
\text { afectación a la salud por ruido y } \\
\text { vibración }\end{array}$ & $\begin{array}{l}\text { - Implementar un sistema de aspiración de } \\
\text { la fibra volátil y brindar mascarillas a los } \\
\text { trabajadores } \\
\text { - Recoger la fibra en bolsas } \\
\text { - Brindar tapones a los trabajadores } \\
\text { - Usar guantes anti vibración }\end{array}$ \\
\hline Enconado & $\begin{array}{l}\text { Fibra volátil, fibra de } \\
\text { algodón (merma) } \\
\text { Generación de ruido y } \\
\text { vibración }\end{array}$ & $\begin{array}{l}\text { Afectación a la salud de los } \\
\text { trabajadores y contaminación del aire } \\
\text {, potencial contaminación del suelo, } \\
\text { afectación a la salud por ruido y } \\
\text { vibración }\end{array}$ & $\begin{array}{l}\text { - Implementar un sistema de aspiración de } \\
\text { la fibra volátil y brindar mascarillas a los } \\
\text { trabajadores } \\
\text { - Recoger la fibra en bolsas } \\
\text { - Brindar tapones a los trabajadores } \\
\text { - Usar guantes anti vibración } \\
\end{array}$ \\
\hline Humidificado & Generación de efluentes & Potencial contaminación del agua & $\begin{array}{l}\text { - Se controlará que el efluente esté dentro } \\
\text { de los límites máximos permisibles. Las } \\
\text { variables que se controlarán son PH, } \\
\text { oxígeno disuelto, aceites y grasa; y } \\
\text { metales pesados. }\end{array}$ \\
\hline Embolsado & Fibra de algodón (merma) & Potencial contaminación del suelo & - Recoger la fibra en bolsas. \\
\hline $\begin{array}{l}\text { Distribución de } \\
\text { producto terminado }\end{array}$ & $\begin{array}{l}\text { Generación de emisiones } \\
\text { gaseosas }\end{array}$ & Contaminación del aire & $\begin{array}{l}\text { - Mantenimiento de transporte vehicular } \\
\text { - Uso de gas natural como combustible }\end{array}$ \\
\hline
\end{tabular}




\subsection{Seguridad y Salud ocupacional}

La fábrica hilandera de algodón nativo de color tiene como objetivo desarrollar un plan de seguridad y salud ocupacional, lo cual permitirá prevenir accidentes, incidentes, enfermedades ocupacionales y proteger la salud de los trabajadores, contratistas durante el desarrollo de sus operaciones.

Se toma medidas preventivas para evitar accidentes cómo inducciones de seguridad y salud ocupacional, brinda equipos de protección personal a los operarios y personal de la empresa que este en el área de operaciones, tiene un plan de contingencias ante posibles estados de emergencia, tener un listado de eventos críticos, su potencial daño y medidas preventivas, medir indicadores de desempeño en cuanto a seguridad de planta, elaborar reporte de incidentes y accidentes, asegura a todos los trabajadores; y por último establece todas las medidas preventivas en caso de incendio. La empresa tendrá un Reglamento de Seguridad y Salud Ocupacional, el cual será repartido a todos los trabajadores.

Se brinda inducciones de seguridad y salud ocupacional a los trabajadores constantemente para concientizarlos acerca del cuidado que deben de tener para prevenir posibles accidentes e identificar riesgos (por ley la empresa está obligada a brindar 4 capacitaciones al año).

Se brinda a los trabajadores los siguientes equipos de protección personal: cascos, botas punta de acero, mascarillas, lentes y tapones de oídos de tal forma que los trabajadores se encuentren en condiciones seguras para poder desempeñar su trabajo.

El Plan de Contingencias describe los procedimientos que serán usados para poder afrontar de manera oportuna, adecuada y efectiva, los eventuales estados de emergencia que podrían presentarse durante la Operación y Mantenimiento de la planta.

Se tiene un cuadro de eventos críticos en el cual se identifican los posibles riesgos y medidas preventivas.

Mensualmente se mide mediante indicadores de rendimiento el desempeño en cuanto a la seguridad de la planta. Los indicadores que se medirán serán los siguientes: número de accidentes que provocan incapacidad del trabajador para trabajar, número de incidentes, número de tratamientos médicos, número total de días totales dejados de trabajar por accidentes 
Si sucediese un accidente o incidente se hará un reporte detallando las causas de dicho evento y cómo prevenir que no vuelva a suceder.

Cabe recalcar, que todos los trabajadores contarán con EPS y los operarios con SCTR (Seguro complementario de trabajo de riesgo).

La fábrica tiene una disposición adecuada de extintores e hidrantes en zonas estratégicas que permitan combatir el fuego en el caso de que se genere un incendio, además de hacer una selección de los más adecuados extintores de acuerdo a los tipos de materiales inflamables presentes en la planta.

\section{Matriz IPER (Identificación de peligros y evaluación de riesgos)}

Se elaboró la matriz IPER con el fin de identificar los principales riesgos y peligros que se pudiesen suscitar en la planta así como las medidas preventivas.

Personas expuestas: Se toma como índice 1 porque en las áreas hay entre 1 o 2 operarios que están expuestos al peligro, en el caso este el mecánico o supervisor este llegaría a 3 trabajadores expuestos que aun así se mantiene en el índice 1. 
Tabla 5.17

Matriz de Identificación de Peligros y evaluación de Riesgos (IPER)

\begin{tabular}{|c|c|c|c|c|c|c|c|c|c|c|c|c|c|}
\hline Proceso & Sub proceso & Peligro & Riesgo & 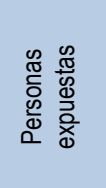 & 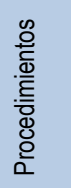 & 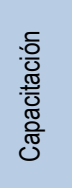 & 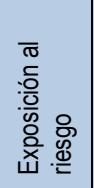 & 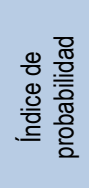 & 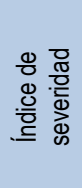 & 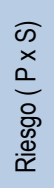 & 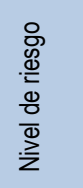 & 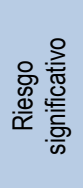 & Medidas de control \\
\hline \multirow[t]{3}{*}{$\begin{array}{l}\text { Ingreso y recepción } \\
\text { de materias primas }\end{array}$} & \multirow[t]{3}{*}{$\begin{array}{c}\text { Descarga y } \\
\text { almacenaje de } \\
\text { materia prima }\end{array}$} & $\begin{array}{l}\text { Emisión de gases por } \\
\text { el ingreso del vehículo }\end{array}$ & $\begin{array}{l}\text { Daños en las vías } \\
\text { respiratorias }\end{array}$ & 1 & 2 & 1 & 2 & 6 & 2 & 12 & $\mathrm{MO}$ & No & $\begin{array}{l}\text { Apagar el vehículo al estacionarse. Uso } \\
\text { de EPP (Mascarilla) por parte de los } \\
\text { trabajadores si es necesario }\end{array}$ \\
\hline & & Emisión de ruido & $\begin{array}{c}\text { Daño al sistema } \\
\text { auditivo }\end{array}$ & 1 & 2 & 1 & 2 & 6 & 2 & 12 & MO & No & $\begin{array}{l}\text { Uso de EPP (protector auditivo para } \\
\text { emisiones superiores a } 85 \mathrm{dBA} \text { ) }\end{array}$ \\
\hline & & $\begin{array}{c}\text { Descarga y recepción } \\
\text { de material }\end{array}$ & $\begin{array}{l}\text { Lesiones musculo- } \\
\text { esquelética }\end{array}$ & 1 & 1 & 1 & 2 & 5 & 2 & 10 & MO & No & $\begin{array}{c}\text { Realizar la descarga con un equipo } \\
\text { adecuado. El personal debe utilizar } \\
\text { fajas }\end{array}$ \\
\hline \multirow[t]{3}{*}{$\begin{array}{c}\text { Mezcladora, } \\
\text { apertura y limpieza }\end{array}$} & \multirow{3}{*}{$\begin{array}{l}\text { Preparación de } \\
\text { mezclas de } \\
\text { algodón, abridor y } \\
\text { limpiador }\end{array}$} & \multirow[t]{2}{*}{ Emisión de partículas } & $\begin{array}{l}\text { Daños en las vías } \\
\text { respiratorias }\end{array}$ & 1 & 1 & 1 & 3 & 6 & 2 & 12 & MO & No & Uso de EPP (Mascarillas) \\
\hline & & & $\begin{array}{l}\text { La acumulación de } \\
\text { partículas de } \\
\text { algodón en equipos } \\
\text { eléctricos produce } \\
\text { incendio }\end{array}$ & 1 & 1 & 1 & 3 & 6 & 2 & 12 & MO & No & $\begin{array}{l}\text { Limpieza y mantenimiento de } \\
\text { luminarias y cableado }\end{array}$ \\
\hline & & $\begin{array}{l}\text { Piso con residuos de } \\
\text { fibras es resbaloso }\end{array}$ & Caída al mismo nivel & 1 & 1 & 1 & 3 & 6 & 2 & 12 & MO & No & $\begin{array}{l}\text { Mantener la limpieza del área de } \\
\text { trabajo. }\end{array}$ \\
\hline \multirow[t]{3}{*}{ Cardado } & \multirow[t]{3}{*}{ Cardado } & $\begin{array}{l}\text { Emisión de partículas } \\
\text { de algodón }\end{array}$ & $\begin{array}{l}\text { Daños en las vías } \\
\text { respiratorias }\end{array}$ & 1 & 1 & 1 & 3 & 6 & 3 & 18 & IM & Sí & $\begin{array}{l}\text { Uso obligatorio de EPP (mascarillas } \\
\text { adecuadas) }\end{array}$ \\
\hline & & Emisión de ruido & $\begin{array}{c}\text { Daño a sistema } \\
\text { auditivo }\end{array}$ & 1 & 1 & 1 & 3 & 6 & 3 & 18 & $\mathrm{IM}$ & Sí & $\begin{array}{l}\text { Uso de EPP (protector auditivo para } \\
\text { emisiones superiores a } 85 \mathrm{dBA} \text { ) }\end{array}$ \\
\hline & & Partes en movimiento & $\begin{array}{c}\text { Atrapado de } \\
\text { miembros superiores }\end{array}$ & 1 & 1 & 1 & 3 & 6 & 3 & 18 & $\mathrm{IM}$ & Sí & Uso de guardas \\
\hline \multirow[t]{2}{*}{$\begin{array}{l}\text { Regularizado de } \\
\text { cinta }\end{array}$} & \multirow{2}{*}{$\begin{array}{c}\text { Estirado y } \\
\text { paralelizado de } \\
\text { cintas en } \\
\text { manuares }\end{array}$} & Partes en movimiento & $\begin{array}{c}\text { Atrapado de } \\
\text { miembros superiores }\end{array}$ & 1 & 1 & 1 & 3 & 6 & 3 & 18 & IM & Sí & Uso de guardas \\
\hline & & Emisión de ruido & $\begin{array}{l}\text { Daño a sistema } \\
\text { auditivo }\end{array}$ & 1 & 1 & 1 & 3 & 6 & 3 & 18 & IM & Sí & $\begin{array}{l}\text { Uso de EPP (protector auditivo para } \\
\text { emisiones superiores a } 85 \mathrm{dBA} \text { ) }\end{array}$ \\
\hline \multirow[t]{3}{*}{ Estirado } & \multirow{3}{*}{$\begin{array}{c}\text { Entrelazado y } \\
\text { estirado de la fibra } \\
\text { en la mechera }\end{array}$} & Alto Nivel de ruido & Hipoacusia & 1 & 1 & 1 & 3 & 6 & 3 & 18 & IM & sí & $\begin{array}{c}\text { Aislamiento del ruido si es posible - Uso } \\
\text { de EPP (protección auditiva) }\end{array}$ \\
\hline & & $\begin{array}{l}\text { Emisión de Partículas } \\
\text { de Algodón }\end{array}$ & $\begin{array}{c}\text { Daños de vías } \\
\text { respiratoria }\end{array}$ & 1 & 1 & 1 & 3 & 6 & 3 & 18 & $\mathrm{IM}$ & sí & $\begin{array}{l}\text { Uso obligatorio de EPP (mascarillas } \\
\text { adecuadas) }\end{array}$ \\
\hline & & Partes en movimiento & $\begin{array}{c}\text { Atrapado de } \\
\text { miembros superiores }\end{array}$ & 1 & 1 & 1 & 3 & 6 & 3 & 18 & $\mathrm{IM}$ & Sí & Uso de guardas \\
\hline
\end{tabular}




\begin{tabular}{|c|c|c|c|c|c|c|c|c|c|c|c|c|c|}
\hline Proceso & Sub proceso & Peligro & Riesgo & 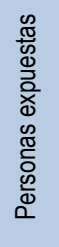 & 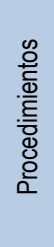 & 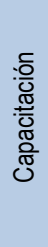 & 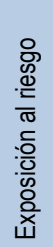 & 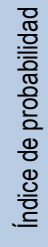 & 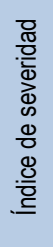 & 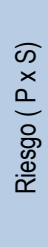 & 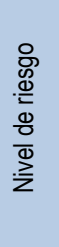 & 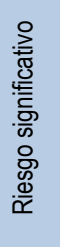 & Medidas de control \\
\hline \multirow[t]{4}{*}{ Hilado } & \multirow[t]{4}{*}{$\begin{array}{c}\text { Hilado en la } \\
\text { continua de anillos }\end{array}$} & $\begin{array}{l}\text { Partes de máquinas } \\
\text { en movimiento }\end{array}$ & Atrapamiento & 2 & 1 & 1 & 3 & 7 & 3 & 21 & IM & sí & $\begin{array}{l}\text { Colocar guardas de seguridad en } \\
\text { partes de equipo en movimiento }\end{array}$ \\
\hline & & Alto Nivel de ruido & Hipoacusia & 2 & 1 & 1 & 3 & 7 & 3 & 21 & IM & Sí & $\begin{array}{c}\text { Aislamiento del ruido si es posible - Uso } \\
\text { de EPP (protección auditiva) }\end{array}$ \\
\hline & & \multirow[t]{2}{*}{$\begin{array}{l}\text { Emisión de Partículas } \\
\text { de Algodón }\end{array}$} & $\begin{array}{l}\text { Daños a vías } \\
\text { respiratorias }\end{array}$ & 2 & 1 & 1 & 3 & 7 & 2 & 14 & MO & No & Uso de EPP (Mascarillas) \\
\hline & & & $\begin{array}{l}\text { La acumulación de } \\
\text { partículas de } \\
\text { algodón en equipos } \\
\text { eléctricos produce } \\
\text { incendio }\end{array}$ & 2 & 1 & 1 & 3 & 7 & 3 & 21 & $\mathrm{IM}$ & Sí & $\begin{array}{l}\text { Limpieza y mantenimiento de los } \\
\text { equipos eléctricos }\end{array}$ \\
\hline \multirow[t]{4}{*}{ Enconado } & \multirow{4}{*}{$\begin{array}{l}\text { Colocación de } \\
\text { Hilos en conos en } \\
\text { la conera }\end{array}$} & $\begin{array}{c}\text { Partes de máquinas } \\
\text { en movimiento }\end{array}$ & Atrapamiento & 1 & 1 & 1 & 3 & 6 & 3 & 18 & IM & Sí & $\begin{array}{l}\text { Colocar guardas de seguridad en } \\
\text { partes de equipo en movimiento }\end{array}$ \\
\hline & & Alto Nivel de ruido & Hipoacusia & 1 & 1 & 1 & 3 & $\overline{6}$ & 3 & 18 & IM & Sí & $\begin{array}{c}\text { Aislamiento del ruido si es posible - Uso } \\
\text { de EPP (protección auditiva) }\end{array}$ \\
\hline & & \multirow[t]{2}{*}{$\begin{array}{l}\text { Emisión de Partículas } \\
\text { de Algodón }\end{array}$} & $\begin{array}{l}\text { Daños de vías } \\
\text { respiratorias }\end{array}$ & 1 & 1 & 1 & 3 & 6 & 3 & 18 & IM & Sí & Uso de EPP (mascarillas) \\
\hline & & & $\begin{array}{l}\text { La acumulación de } \\
\text { partículas de } \\
\text { algodón en equipos } \\
\text { eléctricos produce } \\
\text { incendio }\end{array}$ & 1 & 1 & 1 & 3 & 6 & 3 & 18 & $\mathrm{IM}$ & Sí & $\begin{array}{l}\text { Limpieza y mantenimiento de equipos } \\
\text { eléctricos especialmente tableros }\end{array}$ \\
\hline $\begin{array}{c}\text { Almacenamiento y } \\
\text { despacho }\end{array}$ & $\begin{array}{c}\text { Almacenamiento y } \\
\text { despacho }\end{array}$ & $\begin{array}{c}\text { Disposición y } \\
\text { despacho }\end{array}$ & $\begin{array}{l}\text { Lesiones musculo - } \\
\text { esqueléticas }\end{array}$ & 1 & 1 & 1 & 3 & 6 & 2 & 12 & $\mathrm{MO}$ & No & $\begin{array}{l}\text { Realizar la descarga con equipo } \\
\text { adecuado. El personal debe utilizar } \\
\text { fajas para cargar el material. }\end{array}$ \\
\hline
\end{tabular}

Elaboración propia. 


\subsection{Sistema de mantenimiento}

La fábrica hilandera de algodón nativo de color tiene como objetivo desarrollar un plan de mantenimiento el cual este dirigido a conservar el estado deseado de conservación de las máquinas de la planta (disponibilidad) en beneficio de obtener una mayor utilidad en la empresa.

Las actividades de mantenimiento que realiza la planta son inspección, conservación y reparación. En la planta se realiza dos tipos de mantenimiento correctivo y preventivo.

a) Mantenimiento correctivo

|Es el mantenimiento en el cual no se realiza ningún tipo de planificación ni programación; es decir, reparación imprevista de fallas y que se practicará en aquellos componentes de naturaleza auxiliar de las máquinas que sean de bajo costo que no estén directamente relacionados a la producción. Si se realizaría en componentes de las máquinas que estén directamente relacionados a la producción el costo del mantenimiento sería sumamente elevado.

b) El mantenimiento preventivo

Es el mantenimiento planificado y programado que se lleva a cabo con el fin de que la administración de mantenimiento sea más eficiente; por lo tanto, el mantenimiento no debe corresponder únicamente al departamento de mantenimiento, sino también se debe asignar a todos las áreas de la empresa incluyendo la gerencia general y los operadores.

\section{b.1) Mantenimiento programado}

En el mantenimiento planificado se realiza inspecciones periódicas a las máquinas e equipos de tal forma que estos se conserven en buen estado. El intervalo de mantenimiento se determina mediante las horas de operación de la máquina. Aumenta la disponibilidad de los activos, evita grandes y costosas reparaciones antes de que se grave la situación. Este mantenimiento tiene una prioridad en la operación de la planta; ya que, si no se tiene un buen mantenimiento preventivo se puede originar una paralización de la planta por indisponibilidad de maquinarias; por lo tanto, pérdidas en la producción. 


\section{b.2) El mantenimiento predictivo}

Este mantenimiento sirve para el mismo propósito que el mantenimiento preventivo; es decir, prevenir fallas del equipo prediciendo cuando va a fallar un cierto componente, por ejemplo un rodamiento, una caja de engranajes o un motor. El mantenimiento predictivo incluye una serie de pruebas y análisis tales como:

- Análisis de las vibraciones

- Pruebas de asilamiento (Megger)

- Análisis espectografico del aceite

- Termografía

- Inspección infrarroja

- Ensayos no destructivos

- Análisis acústico

Este tipo de mantenimiento utiliza aparatos de prueba sofisticados para ayudar a predecir cuándo fallara algún componente de un equipo; por lo tanto, se puede identificar tendencias sobre desgaste de un equipo.

\subsection{Programa de producción}

\subsubsection{Consideraciones sobre la vida útil del proyecto}

Para determinar el volumen de producción se utilizará la proyección de la demanda para el proyecto con un horizonte de vida de 10 años. Para ello, se considerará además un inventario de seguridad de $10 \%$ o ligeramente mayor en cada año, el cual permitirá evitar rupturas de stock en caso de que exista algún retraso en la producción, debido a un retraso de los proveedores, una falla en alguna máquina, o si es que la demanda supera incluso el margen que se le aplicó en un inicio a la proyección hecha en el estudio de mercado. La producción anual se determinará en función al cuello de botella que es la continua de hilar. Para poder determinar la cantidad entrante al proceso de hilado se divide el producto final entre $96 \%$ debido a que la merma entre el producto final y la cantidad antes del proceso de hilatura es de $4 \%$. 


\subsubsection{Programa de producción para la vida útil del proyecto}

Se determina la producción anual de la planta en función al cuello de botella el cual es el proceso de hilado el cual se calculó en la sección 5.4.1. De acuerdo a dichos datos se elabora la tabla 5.18 el cual señala la producción anual.

Tabla 5.18

Producción anual (Kilogramos)

\begin{tabular}{|r|r|}
\hline Año & Producción \\
\hline 2016 & 179,546 \\
\hline 2017 & 186,452 \\
\hline 2018 & 207,169 \\
\hline 2019 & 233,065 \\
\hline 2020 & 255,508 \\
\hline 2021 & 277,606 \\
\hline 2022 & 306,610 \\
\hline 2023 & 327,327 \\
\hline 2024 & 348,044 \\
\hline 2025 & 372,213 \\
\hline
\end{tabular}

Elaboración propia

Asimismo, siguiendo el criterio de que el stock se seguridad es de $10 \%$, se calculará el valor del $10 \%$ de la demanda del proyecto para de esta forma al realizar el cálculo del inventario final de cada año este sea ligeramente mayor o igual al $10 \%$ de la demanda del proyecto

Tabla 5.19

Estimación del stock de seguridad (kilogramos)

\begin{tabular}{|c|c|c|}
\hline Año & Demanda para el proyecto & $\mathbf{1 0} \%$ de la demanda del \\
\hline 2016 & 159.820 & 15.982 \\
\hline 2017 & 183.320 & 18.332 \\
\hline 2018 & 206.820 & 20.682 \\
\hline 2019 & 230.320 & 23.032 \\
\hline 2020 & 253.820 & 25.882 \\
\hline 2021 & 277.330 & 27.733 \\
\hline 2022 & 300.820 & 30.082 \\
\hline 2023 & 324.330 & 32.433 \\
\hline 2024 & 347.830 & 34.783 \\
\hline 2025 & 371.330 & 37.133 \\
\hline
\end{tabular}

Elaboración propia 
Tabla 5.20

Programa de producción anual (kilogramos)

\begin{tabular}{|l|c|c|c|c|c|c|c|c|c|c|}
\hline & 2016 & 2017 & 2018 & 2019 & 2020 & 2021 & 2022 & 2023 & 2024 & 2025 \\
\hline $\begin{array}{l}\text { Inventario } \\
\text { inicial }\end{array}$ & 0 & 19,726 & 22,858 & 23,207 & 25,952 & 27,640 & 27,917 & 33,707 & 36,703 & 36,917 \\
\hline Producción & 179,546 & 186,452 & 207,169 & 233,065 & 255,508 & 277,606 & 306,610 & 327,327 & 348,044 & 372,213 \\
\hline Demanda & 159,820 & 183,320 & 206,820 & 230,320 & 253,820 & 277,330 & 300,820 & 324,330 & 347,830 & 371,330 \\
\hline $\begin{array}{l}\text { Inventario } \\
\text { final }\end{array}$ & 19,726 & 22,858 & 23,207 & 25,952 & 27,640 & 27,917 & 33,707 & 36,703 & 36,917 & 37,801 \\
\hline
\end{tabular}

Elaboración propia

\subsection{Requerimiento de insumos, servicios y personal}

\subsubsection{Materia prima, insumos y otros materiales}

De acuerdo a los valores de algodón entrante anual calculados en la sección 5.4.1, se elaborará la tabla 5.21. Asimismo, se obtendrá la cantidad de algodón nativo de color y algodón Tangüis considerando que sus porcentajes en la mezcla son 63 y 37 por ciento respectivamente.

\section{Tabla 5.21}

Determinación de la cantidad de materia prima $(\mathrm{kg})$

\begin{tabular}{|c|c|c|c|}
\hline Año & Algodón requerido & Algodón nativo de color & Algodón Tangüis \\
\hline 2016 & 200,419 & 126,264 & 74,155 \\
\hline 2017 & 208,992 & 131,665 & 77,327 \\
\hline 2018 & 235,783 & 148,543 & 87,240 \\
\hline 2019 & 262,574 & 165,421 & 97,152 \\
\hline 2020 & 289,365 & 182,300 & 107,065 \\
\hline 2021 & 316,167 & 199,185 & 116,982 \\
\hline 2022 & 342,946 & 216,056 & 126,890 \\
\hline 2023 & 369,749 & 232,942 & 136,807 \\
\hline 2024 & 396,540 & 249,820 & 146,720 \\
\hline 2025 & 423,331 & 266,698 & 156,632 \\
\hline
\end{tabular}

Elaboración propia 


\section{Insumos}

A lo largo de la producción desde el algodón hasta llegar al hilo. El material en proceso se tiene de los diferentes tipos de máquinas se deposita en diferentes tipos de envases.

- Tachos en los que se deposita el producto final de las cardas el cual es el producto entrante al primer regularizado de cinta en el manuar

- Tachos en los que se deposita el producto final del primer regularizado de cinta en el manuar

- Tachos en los que se deposita el producto final del segundo regularizado de cinta en el manuar

- Bobinas de mecha

- Canilla de hilo

- Conos

- Bolsa de conos

- Embolsado

Tabla 5.22

Determinación de la cantidad de insumos por año (unidades)

\begin{tabular}{|c|c|c|c|c|c|c|}
\hline $\begin{array}{c}\text { Año/ } \\
\text { Insumo }\end{array}$ & Tachos Cardas & $\begin{array}{c}\text { Tachos primer } \\
\text { regularizado }\end{array}$ & $\begin{array}{c}\text { Tacho segundo } \\
\text { regularizado }\end{array}$ & Bobina & Canilla & Cono \\
\hline 2016 & 24 & 24 & 24 & 2016 & 8.064 & 1.000 \\
\hline 2017 & 24 & 24 & 24 & 2016 & 8.064 & 1.000 \\
\hline 2018 & 24 & 24 & 24 & 2016 & 8.064 & 2.000 \\
\hline 2019 & 24 & 24 & 24 & 2016 & 10.080 & 2.000 \\
\hline 2020 & 24 & 24 & 24 & 2016 & 10.080 & 2.000 \\
\hline 2021 & 24 & 24 & 24 & 2016 & 12.096 & 2.000 \\
\hline 2022 & 24 & 24 & 24 & 2016 & 12.096 & 2.000 \\
\hline 2023 & 24 & 24 & 24 & 2016 & 12.096 & 2.000 \\
\hline 2024 & 24 & 24 & 24 & 2016 & 14.112 & 2.000 \\
\hline 2025 & 48 & 48 & 48 & 2016 & 14.112 & 2.000 \\
\hline
\end{tabular}

Elaboración propia.

Considerando que los conos pesan $2 \mathrm{~kg}$ y una bolsa contiene 12 conos, se procederá a calcular el número de bolsas y etiquetas. 
Tabla 5.23

Determinación del número de bolsas y etiquetas

\begin{tabular}{|c|c|c|c|}
\hline Año & Producción (kg) & Bolsas (unid) & Etiquetas (unid) \\
\hline 2016 & 179,546 & 7,481 & 7,481 \\
\hline 2017 & 186,452 & 7,769 & 7,769 \\
\hline 2018 & 207,169 & 8,632 & 8,632 \\
\hline 2019 & 233,065 & 9,711 & 9,711 \\
\hline 2020 & 255,508 & 10,646 & 10,646 \\
\hline 2021 & 277,606 & 11,567 & 11,567 \\
\hline 2022 & 306,610 & 12,775 & 12,775 \\
\hline 2023 & 327,327 & 13,639 & 13,639 \\
\hline 2024 & 348,044 & 14,502 & 14,502 \\
\hline 2025 & 372,213 & 15,509 & 15,509 \\
\hline
\end{tabular}

Elaboración propia.

\subsubsection{Servicios: energía eléctrica, agua, vapor, combustible}

\section{Energía}

La cantidad de energía consumida por el total de las maquinas en el año 2025 es de 412,885 kWh en hora punta y 1, 430,145 en hora fuera de punta como se puede apreciar en la tabla 5.23. Para poder ahorrar en costos de energía se operará en horas fuera de punta preferentemente. Asimismo, se considera que la planta trabajará 6 días/semana durante 52 semanas; es decir, 312 días por año. La planta operará como máximo en 2 turnos de 12 horas: (Primer turno: 7 am a 7 pm; y segundo turno de 7 pm a 7 am)

Hora punta: 18:00 horas - 23:00 horas: 5 horas/día

Hora fuera de punta: Resto del día $=19$ horas 
Tabla 5.24

Requerimiento de energía por año

\begin{tabular}{|c|r|r|r|r|}
\hline Año & kWh punta & kWh fuera de punta & $\begin{array}{c}\text { Max Potencia } \\
\text { consumida HP } \\
(\text { KW })\end{array}$ & $\begin{array}{c}\text { Max Potencia } \\
\text { consumida HFP } \\
(\mathrm{KW})\end{array}$ \\
\hline 2016 & 229,944 & 703,082 & 153.10 & 241.07 \\
\hline 2017 & 232,284 & 736,482 & 153.10 & 241.07 \\
\hline 2018 & 238,836 & 837,636 & 153.10 & 241 \\
\hline 2019 & 238,836 & 972,862 & 153.10 & 241 \\
\hline 2020 & 302,545 & 995,702 & 218.87 & 280 \\
\hline 2021 & 310,535 & $1,100,480$ & 218.87 & 280 \\
\hline 2022 & 320,782 & $1,236,353$ & 218.87 & 280 \\
\hline 2023 & 383,143 & $1,236,596$ & 273.07 & 334 \\
\hline 2024 & 398,321 & $1,324,194$ & 273.07 & 334 \\
\hline 2025 & 412,885 & $1,430,145$ & 273.07 & 334 \\
\hline
\end{tabular}

Elaboración propia

\section{Agua}

El mayor requerimiento de agua será del agua blanda necesaria para el uso de la cámara de humidificación el cual se indica en la tabla 5.25

Asimismo, el servicio de agua es necesario para limpieza de las instalaciones de la planta y para el uso de los servicios higiénicos; ya que, los obreros al momento de terminar su jornada laboral se duchan. En verano el costo sube un poco ya que los obreros usan su hora de descanso para ducharse por el incesante calor que hay en la planta. El consumo mensual para el uso de servicios higiénicos y para el uso de los servicios higiénicos en promedio es de $42 \mathrm{~m}^{3}$ al mes; por lo tanto, el consumo anual es de $504 \mathrm{~m}^{3}$ al año. 
Tabla 5.25

Requerimiento de agua para la cámara de humidificación

\begin{tabular}{|c|r|r|r|}
\hline Año & Kilogramos procesados & litros/kilogramos & Agua requerida (litros) \\
\hline 2016 & 175,800 & 0.375 & 65,925 \\
\hline 2017 & 183,320 & 0.375 & 68,745 \\
\hline 2018 & 206,820 & 0.375 & 77,558 \\
\hline 2019 & 230,320 & 0.375 & 86,370 \\
\hline 2020 & 253,820 & 0.375 & 95,183 \\
\hline 2021 & 277,330 & 0.375 & 103,999 \\
\hline 2022 & 300,820 & 0.375 & 112,808 \\
\hline 2023 & 324,330 & 0.375 & 121,624 \\
\hline 2024 & 347,830 & 0.375 & 130,436 \\
\hline 2025 & 371,330 & 0.375 & 139,249 \\
\hline
\end{tabular}

Elaboración propia.

\subsubsection{Determinación del número de operarios y trabajadores indirecto}

En la actualidad, el personal es uno de los activos más importantes de las empresas. Por ello, se buscará contratar una mano de obra y empleados en general eficientes, capaces de rendir lo necesario para lograr los objetivos de producción.

Cabe recalcar, que en la planta se trabajará como máximo 12 horas por turnos, 2 turnos al día durante 6 días a la semana y considerando 52 semanas al año; por lo tanto, si un trabajador excede las 8 horas diarias se le pagará horas extra.

\section{Determinación del número de operarios}

El número de operarios variara anualmente de acuerdo la producción calculada en la sección 5.4.1. Asimismo para economizar un operario podrá operar más de una máquina de acuerdo a las horas de funcionamiento de esta.

- En el proceso de apertura y Limpieza se usará el mismo operario que en el proceso de mezclado.

- En el proceso de ablandamiento de agua se usará el mismo operario que en la cámara de humidificación 
Tabla 5.26

Requerimiento anual de operarios

\begin{tabular}{|l|c|c|c|c|c|c|c|c|c|c|}
\hline & 2016 & 2017 & 2018 & 2019 & 2020 & 2021 & 2022 & 2023 & 2024 & 2025 \\
\hline Pre mezclado & 2 & 2 & 2 & 2 & 2 & 2 & 2 & 2 & 2 & 2 \\
\hline Apertura, limpieza y mezcla & 2 & 2 & 2 & 2 & 2 & 2 & 2 & 2 & 2 & 2 \\
\hline Cardado & 1 & 1 & 1 & 1 & 1 & 2 & 2 & 2 & 2 & 2 \\
\hline Regularizado de cinta I & 1 & 1 & 1 & 1 & 1 & 2 & 2 & 2 & 2 & 2 \\
\hline Regularizado de cinta II & 1 & 1 & 1 & 1 & 1 & 2 & 2 & 2 & 2 & 2 \\
\hline Estirado & 1 & 1 & 1 & 1 & 1 & 1 & 1 & 1 & 1 & 1 \\
\hline Hilado & 6 & 6 & 6 & 6 & 8 & 8 & 8 & 10 & 10 & 10 \\
\hline Enconado & 2 & 2 & 2 & 2 & 2 & 2 & 2 & 4 & 4 & 4 \\
\hline Humidificación y ablandamiento & 2 & 2 & 2 & 2 & 2 & 2 & 2 & 2 & 2 & 2 \\
\hline
\end{tabular}

Elaboración propia.

Tabla 5.27

Horas Extra por trabajador

\begin{tabular}{|l|c|c|c|c|c|c|c|c|c|c|}
\hline & 2016 & 2017 & 2018 & 2019 & 2020 & 2021 & 2022 & 2023 & 2024 & 2025 \\
\hline Pre mezclado & & & & & & & & & & 1 \\
\hline Apertura, limpieza y mezcla & & & & & & & & & & 1 \\
\hline Cardado & & 1 & 2 & 3 & 4 & & & & & 1 \\
\hline Regularizado de cinta I & & 1 & 2 & 3 & 4 & & & & & 1 \\
\hline Regularizado de cinta II & & 1 & 2 & 3 & 4 & & & & & 1 \\
\hline Estirado & & & & & & & 1 & 1 & 2 & 3 \\
\hline Hilado & 1 & 1 & 2 & 4 & 2 & 2 & 3 & 2 & 2 & 3 \\
\hline Enconado & & & 1 & 2 & 2 & 3 & 4 & & & \\
\hline
\end{tabular}

Elaboración propia.

\section{Trabajadores indirectos}

Los trabajadores indirectos son todos aquellos que no están involucrados directamente en la fabricación del producto. En la tabla 5.27 se indica el número de trabajadores indirectos en cada área. 
Tabla 5.28

Requerimiento de trabajadores indirectos

\begin{tabular}{|l|l|}
\hline \multicolumn{2}{|c|}{ Cargo } \\
\hline Jefe de planta & 2 Electricistas \\
\hline Jefe de planeamiento & Jefe de Control de Calidad \\
\hline 2 Supervisores & Encargado de laboratorio de calidad \\
\hline 2 Mecánicos de planta & Jefe de Almacén \\
\hline 2 Ayudantes de mecánico & 2 asistentes de almacén \\
\hline
\end{tabular}

Elaboración propia

\subsubsection{Servicios de terceros}

\section{Abastecimiento de algodón}

Se contratará a una empresa para que transporte el algodón nativo de color desde Lambayeque hacia las instalaciones de la fábrica en Lima; ya que, este se comprará a Aspromad en Lamabayeque. En cambio, el abastecimiento de algodón Tangüis lo procederá a hacer la empresa a la cual se le va a comprar este algodón.

\section{Contabilidad}

El servicio de contabilidad será entregado a una empresa externa, la cual estará a cargo de todos los aspectos referente a la contabilidad de la empresa. Las funciones principales serian: elaboración de estados financieros, declaración mensual de impuestos respectivos. Atender posibles contingencias que se puedan presentar con SUNAT.

\section{Seguridad}

El servicio de vigilancia externa se brindará en tres turnos de 01 persona por turno, cada uno debe realizar un trabajo de 8 horas al día, este trabajo específico va a ser tercerizado a una empresa especialista en este rubro. 


\section{Limpieza}

Se tercerizará los servicios de limpieza de la empresa; ya que dicha actividad no es parte del core business de la empresa. Se contratará a una empresa que se encargue de mantener limpia las instalaciones de la empresa.

\subsection{Características del proyecto}

Como se mencionó en el capítulo 3 el local donde funcionará la planta será alquilado; por ello, este local tiene que contar con ciertas características en su edificación para contribuir al aumento de la productividad y no generar interferencia a los procesos de producción.. Asimismo, la planta deberá contar con servicios que estarán conformados por elementos físicos y personal organizado destinados a satisfacer las necesidades de factores de producción

\subsubsection{Factor edificio}

1. Vías de circulación: Deben estar situadas y calculadas de tal manera que los trabajadores y medios de acarreo puedan utilizarlas fácilmente y con seguridad.

2. Áreas para almacenamiento: La planta debe tener un área separada y ambientada acorde con las necesidades de almacén tanto para materia prima como materiales en proceso y producto terminado. Debido a que el algodón tiene que tener una humedad del 8\%; por ello, se deberá considerar este factor al almacenar así como una buena iluminación y temperatura adecuada.

3. Puertas de acceso y salidas: Las puertas dan acceso a los espacios y permiten la evacuación en caso de incendios así como brindan protección contra el clima, regulan la visibilidad y el ruido. En el proceso de hilado hay riesgo de incendio debido a la alta velocidad en la que funcionan las máquinas así como la presencia de material inflamable; por ello, en la planta se deberá disponer como mínimo de 2 salidas hacia el exterior. Asimismo, las puertas situadas en las vías de urgencia deberán abrirse cuando sea necesario desde el interior. Por último, en las áreas de producción debe comprobarse que la puerta sea suficientemente ancha y alta para permitir el paso de los equipos.

4. Techos: El techo de la planta tiene que estar diseñado para que los elementos de producción no permanezcan a la intemperie y a su vez otorgue seguridad y mejores condiciones para trabajar. Este techo tiene que tener una altura mínima de 10 metros de alto y el cielo raso una altura de 6.5 
metros; ya que, la máquina de mayor altura (la abridora) tiene 4 metros de altura) y a asimismo la fábrica debe contar con un sistema de climatización.

\subsubsection{Factor servicio}

1. Servicios relativos al personal

Vías de acceso

La planta tendrá puertas de ingreso y salida de personal de tal forma que sean independientes de los lugares de recepción y despacho con el objetivo de evitar saturar determinados espacios. Asimismo la planta contará con salidas de emergencia.

Servicios de alimentación

En la planta se ubicará un comedor, el cual los trabajadores podrán hacer uso en el tiempo de su refrigerio.

Servicios médicos

La planta contará con botiquines, tanto en las oficinas administrativas como en la planta. Como la planta estará ubicada en la ciudad de Lima que cuenta con servicios hospitalarios y clínicas, se utilizará servicios de ambulancia y sólo se requerirá de servicios para atención ambulatoria o emergencia; por lo tanto, se tendrá una oficina que se podrá utilizar también para atenciones médicas.

\section{Iluminación}

Es un factor muy importante debido a que determina las condiciones de trabajo; ya que, mediante una iluminación correcta que llegue a las estaciones de trabajo proporcionará un medio circundante seguro el cual servirá para prevenir accidentes, haciendo posible el reconocimiento inmediato de los riesgos y evitarlos. Asimismo, con una iluminación adecuada, los errores y defectos se apreciaron con mayor rapidez, lo que conduce a una mayor calidad y cantidad de producción. Las paredes de la fábrica estarán pintadas con colores claros asimismo se deberá limpiar las fuentes de luz y cambiar bombillas deterioradas. 
Ventilación

La planta constará con un sistema de climatización el cual consiste en un conjunto de ductos que se encuentran por abajo y encima de las máquinas los cuales absorberán las fibras volátiles; para luego, depositarlos en sacos. Asimismo, este sistema sirve para mantener a la fábrica en una temperatura idónea de 32 grados centígrados para que el algodón no se deshidrate

\section{Servicios relativos al material}

Se deben realizar actividades sobre el material como control de calidad, análisis de laboratorio y cuidado del impacto ambiental

\subsection{Control de calidad}

Para poder producir hilos de calidad, se requiere del control de calidad, el control de producción y tratamiento adecuado de los desperdicios; los dos últimos son resultado de la operatividad del plan de producción y el control de inventarios.

\subsection{Consideraciones sobre el impacto ambiental}

En el proceso de producción se generarán residuos como fibra de algodón y fibra volátil que generarán contaminación al medio ambiente. Además existen otras formas de contaminación como vibraciones y ruido. Por ello, en la sección 5.6 se identificó, interpretó y previno todas las perturbaciones y contaminaciones que deriven del ejercicio de la actividad industrial mediante la "Matriz de aspectos e impactos ambientales clasificados por actividad o proceso".

3. Servicios relativos a la maquinaria

Instalación eléctrica

Se deberá proyectarse y realizarse de acuerdo a los requerimientos de planta de manera que no ofrezcan peligro de incendio o de explosión, y que las personas que manipulen los equipos se encuentren protegidas contra riesgos de accidentes causados por contacto directo o indirecto. Por tal motivo, es imprescindible realizar una revisión de los requerimientos técnicos de la maquinaria y equipos. 
Área de mantenimiento

Su tarea involucra el control constante de las instalaciones, así como supervisión de los trabajos de reparación y revisión de maquinaria y equipos para garantizar su funcionamiento continuo. Los tipos de mantenimiento que se realizarán serán preventivo, correctivo y predictivo. En el caso de mantenimiento preventivo, se programará mantenimientos de maquinaria de acuerdo a las horas de su funcionamiento mediante un plan de mantenimiento de planta.

Depósito de herramientas

En la planta se tendrá un área adecuada donde se guardaran todas las herramientas necesarias para el mantenimiento de las máquinas de la planta. Asimismo, se contará con un registro del stock de herramientas.

Protección contra incendios

Como medida para preservar los equipos y la vida de los operarios, se llevarán a cabo las siguientes medidas con el objetivo de minimizar los riesgos: se contará con extintores dentro de la planta de acuerdo a las características del edificio y de los equipos, todas las puertas se abrirán hacia fuera; se otorgará instrucciones al personal para evitar que cometan acciones riesgosas que puedan provocar un incendio; y se proporcionará el conocimiento necesario para la evacuación del área siniestrada.

4. Servicios relativos al edificio

Importancia de un ambiente de calidad en el trabajo: Será responsabilidad de la gerencia y de los trabajadores organizar, mantener, y mejorar permanentemente los lugares de trabajo, para lograr por este medio las mejoras en los índices de productividad y calidad. Por lo tanto en la planta se usará la política de las $5 \mathrm{~S}$ para desarrollar planes de mejoramiento en los ambientes de trabajo. 
Tabla 5.29

Metodología de las $5 \mathrm{~S}$

\begin{tabular}{|l|l|l|l|}
\hline & Japonés & \multicolumn{1}{|c|}{ Español } & \multicolumn{1}{|c|}{ En su estación de trabajo } \\
\hline \multirow{3}{*}{ Con las cosas } & Seiri & Clasificación & Mantenga todo lo necesario \\
\cline { 2 - 4 } & Seiton & Organización & Mantenga todo en orden \\
\cline { 2 - 4 } & Seiso & Limpieza & Mantenga todo limpio \\
\hline \multirow{2}{*}{ Con usted mismo } & Seiketsu & Bienestar social & Cuide su salud física y mental \\
\cline { 2 - 4 } & Shitsuke & Disciplina & Mantenga un comportamiento confiable \\
\hline
\end{tabular}

Fuente: Diaz, B. ; Jarufe, B. ; Noriega, M. (2007)

\subsection{Disposición de planta}

En esta parte del estudio, se realizará la disposición de la planta con el fin de conocer el área total que abarcará, así como las áreas en las que se dividirá para distribuirlas de la manera más eficiente, de tal forma que la planta presente las condiciones necesarias para la realización de sus actividades de forma óptima.

Las ventajas de una buena disposición de planta se traducen en una reducción del costo de fabricación, un aumento de la productividad y de calidad como resultado de los siguientes puntos:

Facilitar el proceso de manufactura

Uso más eficiente de la maquinaria, mano de obra y de los servicios

Uso más eficiente del espacio existente

Mejora de las condiciones de trabajo para el empleado

Incremento de la producción

$>$ Mantener flexibilidad de las operaciones

$>$ Reducción del tiempo total de producción

$>$ Reducción del costo de acarreo de material

$>$ Eliminación del desorden en la ubicación de los elementos de producción

Eliminación de recorridos excesivos

\subsubsection{Determinación de las zonas físicas requeridas}

La planta para hilar algodón nativo de color contará con zonas para el almacenamiento tanto de materia prima como producto terminado, zonas para el proceso de producción, zonas administrativas y una zona designada al laboratorio de calidad. 


\section{$\underline{\text { Almacén de materia prima }}$}

En esta zona se almacenará fardos de algodón nativo de color y algodón Tangüis los cuales entrarán al proceso de producción.

\section{$\underline{\text { Sala de producción }}$}

_En esta zona se ubicarán todos los procesos involucrados para obtener hilo a partir de algodón; por ello, se encentran los procesos de pre mezclado, mezclado, apertura y limpieza, cardado, regularizado de cinta, estirado, hilado, enconado, humidificado, ablandamiento de agua, embolsado y etiquetado.

\section{$\underline{\text { Almacén de producto terminado }}$}

En esta zona se almacenará las bolsas de 12 conos de $2 \mathrm{~kg}$ de hilo. las cuales se procederán a vender a los clientes.

\section{$\underline{\text { Área administrativa }}$}

En esta zona estarán ubicadas las oficinas de la alta gerencia, comercial, administración y finanzas, recursos humanos, las jefaturas de producción, mantenimiento y seguridad, salud y medio ambiente. Asimismo habrá un área designada a la atención de clientes y proveedores.

\section{$\underline{\text { Laboratorio de calidad }}$}

En este laboratorio se encuentran todos los equipos requeridos para analizar la materia prima, el material en proceso y el producto terminado que garantizarán que el producto final cumpla los estándares de calidad. Este laboratorio tendrá una dimensión de $30 \mathrm{~m}^{2}$ y estará ubicado cerca de las continuas de hilar.

\section{Zona de climatización}

Se debe mantener una temperatura de 32 grados centígrados en el ambiente del área de hilatura para que se pueda procesar el algodón en óptimas condiciones; ya que, si se presenta una temperatura mayor; el algodón se deshidrataría y se volvería más débil lo cual causaría rompimiento en cambio si se presenta una menor temperatura la mecha no se podría estirar y se deformaría. 


\subsubsection{Cálculo de áreas para cada zona}

Mediante el método de Guerchet se calcularán los espacios físicos que se requerirán para establecer la planta. Este método ha sido validado mediante su aplicación en numerosos estudios de disposición de planta. La utilización de esta técnica de cálculo de áreas dará como resultado un valor referencial del área total mínima requerida para producción, a la cual se le sumará otras áreas como áreas administrativas y almacenes.

Método de Guerchet

Para calcular los espacios físicos requeridos será necesario identificar el número total de máquinas y equipos requeridos (elementos estáticos), el número total de operarios por turno, y el número de equipos de carreo (elementos móviles), previamente calculados, con el fin de determinar el espacio que ocuparán en la planta.

La superficie total necesaria se calcula como la suma de tres superficies parciales:

$$
S T=n(S s+S g+S e)
$$

Se proyectará el tamaño de planta de acuerdo a los requerimientos del año 2025 el cual es el último año de proyección del proyecto 
Tabla 5.30

Método de Guerchet del estudio

\begin{tabular}{|c|c|c|c|c|c|c|c|c|c|c|c|c|}
\hline & Largo (L) & Ancho(A) & Alto $(h)$ & Diámetro (D) & $\mathrm{N}$ & $n$ & Ss & $\mathrm{Sg}$ & Ss $\times n$ & Ss $x \cap \times h$ & Se & St \\
\hline \multicolumn{13}{|l|}{ Elementos estáticos } \\
\hline Pre mezclado & 5 & 3 & 0.7 & 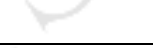 & & 1 & 15.00 & & 15.00 & 10.50 & 2.49 & 17.49 \\
\hline Alimentador de mezcla & 9.71 & 1.5 & 2.1 & & 1 & 1 & 14.57 & 14.57 & 14.57 & 30.59 & 4.83 & 33.96 \\
\hline Mezcladora & 2.87 & 1.5 & 4.1 & & 1 & 1 & 4.31 & 4.31 & 4.31 & 17.65 & 1.43 & 10.04 \\
\hline Limpiador de mezcla & 1.6 & 1.3 & 1.2 & & 1 & 1 & 2.08 & 2.08 & 2.08 & 2.50 & 0.69 & 4.85 \\
\hline Abridora & 2.2 & 1.7 & 4 & & 1 & 1 & 3.74 & 3.74 & 3.74 & 14.96 & 1.24 & 8.72 \\
\hline Carda & 5.4 & 1.7 & 3.4 & & 1 & 1 & 9.18 & 9.18 & 9.18 & 31.21 & 3.04 & 21.40 \\
\hline Manuar & 7.1 & 3.7 & 1.9 & & 1 & 2 & 26.27 & 26.27 & 52.54 & 99.83 & 8.71 & 122.50 \\
\hline Mechera & 11.375 & 1.8 & 3.6 & & 1 & 1 & 20.48 & 20.48 & 20.48 & 73.71 & 6.79 & 47.74 \\
\hline Continua de hilar & 40.23 & 1.7 & 2.16 & & 2 & 5 & 68.39 & 136.78 & 341.96 & 738.62 & 34.01 & 1195.90 \\
\hline Conera & 8.925 & 5.5 & 3.5 & & 1 & 2 & 49.09 & 49.09 & 98.18 & 343.61 & 16.27 & 228.89 \\
\hline Cámara de humidificación & 4 & 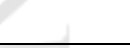 & 1.5 & 3 & 1 & 1 & 7.07 & 7.07 & 7.07 & 10.60 & 2.34 & 16.48 \\
\hline Compresor de aire & 1.5 & 0.7 & 1.7 & & 1 & 1 & 1.05 & 1.05 & 1.05 & 1.79 & 0.35 & 2.45 \\
\hline $\begin{array}{l}\text { Reactor Ablandador de } \\
\text { agua }\end{array}$ & E & & 1.5 & 0.7 & 1 & 1 & 0.38 & 0.38 & 0.38 & 0.58 & 0.13 & 0.90 \\
\hline $\begin{array}{l}\text { Tanque ablandador de } \\
\text { agua }\end{array}$ & & & 1.2 & 0.7 & 1 & 1 & 0.38 & 0.38 & 0.38 & 0.46 & 0.13 & 0.90 \\
\hline & & & & & & & & & 570.90 & 1376.60 & & 1712.21 \\
\hline \multicolumn{13}{|l|}{ Elementos móviles } \\
\hline Operarios & & +2 & 1.65 & & & 13 & 0.5 & & 6.5 & 10.725 & & 2 \\
\hline \multirow[t]{2}{*}{ Tachos con rueditas } & & & 0.5 & 0.7 & & 48 & 0.38 & & 18.5 & 9.24 & & \\
\hline & & & 14 & & & & & & 24.97 & 19.96 & 1 & ) \\
\hline
\end{tabular}


$\mathrm{K}=\frac{\text { hem }}{2 \text { hee }}$

$\mathrm{k}=\frac{19.96 / 24.97}{2 \times\left(\frac{1376.6}{570.9}\right)}$

$\mathrm{K}=0.17$

El área total de producción es de 1,712.21 m2

\section{Almacenamiento de materia prima}

Para el área de almacenamiento se tomará en cuenta el número de fardos de algodón que se necesitarán teniendo en cuenta que la dimensión de cada fardo es de $140 \mathrm{~cm}$ de largo, $81 \mathrm{~cm}$ de ancho y $55 \mathrm{~cm}$ de espesor; y su peso es de $250 \mathrm{~kg}$. Asimismo, se colocará hasta 6 fardos uno encima del otro y se apilara 3 fardos por nivel. Asimismo, se debe considerar un espacio para el movimiento del montacargas.

Al juntar los 18 fardos se obtiene que estos ocupan un área de $280 \mathrm{~cm}$ x $213 \mathrm{~cm}$ y cuyo peso es de 4,500 kg. Asimismo, considerando que todo el algodón requerido en el último año del proyecto (2025) es de 423,331 kg se dividirá esta cantidad entre el peso de cada bloque de 18 fardos obteniéndose que se requieren 95 bloques de fardos.

Tabla 5.31

Determinación del área que ocuparan los bloques de fardos

\begin{tabular}{|l|c|c|c|}
\hline & Bloques & $\mathrm{cm} /$ bloque & Total $(\mathrm{m})$ \\
\hline Largo & 45 & 280 & 12.6 \\
\hline Ancho & 50 & 243 & 12.2 \\
\hline
\end{tabular}

Elaboración propia.

Por lo tanto el área donde se almacenan los fardos es de $153.09 \mathrm{~m} 2$.

Por último, se debe considerar que el área donde se almacenará los fardos representa el 50\% del almacén de materia prima; ya que el resto del área servirá para el movimiento del montacargas y los trabajadores; por lo tanto, el área del almacén es de 306 m2. 


\section{Almacenamiento de producto terminado}

El tamaño del almacén de producto terminado se determina en un función a la cantidad de parihuelas de (1.2 metros de largo por 1 metro de ancho) que son necesarias para almacenar las bolsas de conos. Se debe considerar que en una parihuela se puede almacenar hasta 15 bolsas que contienen 12 conos de $2 \mathrm{~kg}$ por cono. Cabe recalcar que en este almacén también se almacenaran los conos y las bolsas. Por lo tanto, cada parihuela contendrá $360 \mathrm{~kg}$, y se considerará una rotación de 12 veces año; es decir, se venderán los productos mensualmente

\section{Tabla 5.32}

Área de almacenamiento de producto terminado

\begin{tabular}{|l|r|l|}
\hline Rotación & 12 & veces al año \\
\hline $\begin{array}{l}\text { Producto terminado año } \\
2025\end{array}$ & 371,330 & $\mathrm{~kg}$ \\
\hline almacenamiento mensual & 30,944 & $\mathrm{~kg}$ \\
\hline Total parihuelas & 86 & \\
\hline 1 parihuela & 1.2 & $\mathrm{~m}^{2}$ \\
\hline Área PT & 103.1 & $\mathrm{~m}^{2}$ \\
\hline
\end{tabular}

Elaboración propia.

Por lo tanto, el área donde se almacenara las parihuelas es de $103.1 \mathrm{~m} 2$

Por último, se debe considerar que el área donde se almacenará las bolsas conos representa el $60 \%$ del almacén de producto terminado; ya que el resto del área servirá para el movimiento del montacargas y los trabajadores; por lo tanto, el área del almacén es de 172 m2.

\section{Zona de climatización}

Para poder tener la temperatura del área de hilatura se mantenga en $32^{\circ} \mathrm{C}$ se cuenta con 2 sistemas. Mediante un sensor ubicado en la zona de hilatura se determinará si se necesitar aumentar o disminuir la temperatura con el fin de mantenerla a 32 grados centígrados.

El primer sistema tiene como objetivo absorber el aire caliente para disminuir la temperatura por ello, este sistema tiene un conjunto de ductos que pasan debajo y transversalmente por las continuas de hilar; estos ductos están conectados a un aspirador el cual se encarga de extraer el aire caliente y las fibras volátiles. Luego, estos pasan por un filtro en forma 
cilíndrica el cual se encarga de retener las pelusas para luego depositarlo en sacos mientras que el aire caliente es aspirado y botado al exterior de la fábrica mediante un ducto de 7 metros de altura. Cuando se desea aumentar la temperatura se deja de absorber el aire caliente.

El segundo sistema tiene por objetivo refrigerar la planta; por ello, este sistema cuenta con un ducto que extrae el aire del medio ambiente mediante un aspirador y a su vez humidifica este aire mediante ductos que cuentan con un sistema de aspersión. Luego este aire húmedo desemboca por unos ductos que se encuentran por encima de la zona de hilatura para de esta manera verter el aire húmedo y refrescar el ambiente.

\subsubsection{Dispositivos de seguridad industrial y señalización}

Dispositivos de seguridad industrial

\section{1) Guardas de seguridad}

Todas las máquinas contarán con guardas de seguridad con el objetivo de preservar la seguridad de los operarios. Las guardas tendrán los siguientes requisitos:

Prevenir contacto; es decir, prevenir que partes del cuerpo o la ropa del empleado sea atrapada por las partes peligrosas que se mueven, Segura; es decir, asegurada firmemente a la máquina de tal forma que no se despegue fácilmente, Protegida de objetos que puedan caer; es decir, asegurándose que no ingresen objetos a las partes móviles de la máquina, Que no creen nuevos peligros; es decir, que no tengan bordes cortantes o superficies sin terminar.

\section{2) Dispositivos contra incendios}

Se contará con los siguientes dispositivos: detectores de humo, alarma contra incendios y extintores de incendios los cuales se distribuirán por toda la planta. Se contará con el siguiente tipo de extintores:

- Extintores de dióxido de carbono los cuales se utilizarán en incendios donde estén presentes de agua y químico seco.

- Extintores de polvo químico seco los cuales utilizarán equipos eléctricos y energizados 
Señalización de seguridad

Se hará uso de señalizaciones de seguridad en toda la planta con el fin de alertar a los trabajadores de las zonas de riesgo, las salidas de emergencia así como los lugares seguros ante sismos. Se mostrará un mapa de riesgo en la oficina administrativa, en la entrada del personal, con el objetivo de que los trabajadores lo tengan presente.

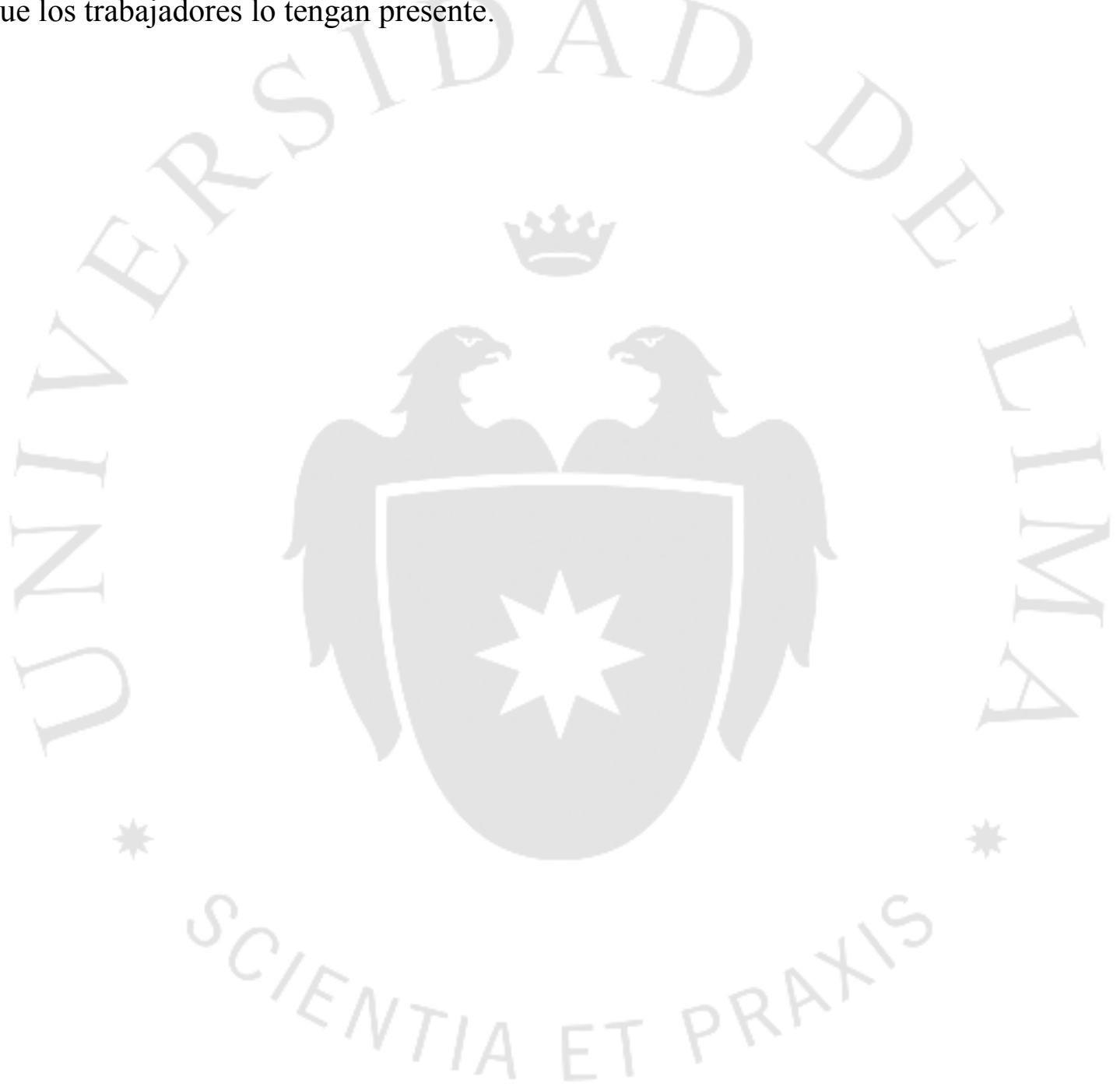




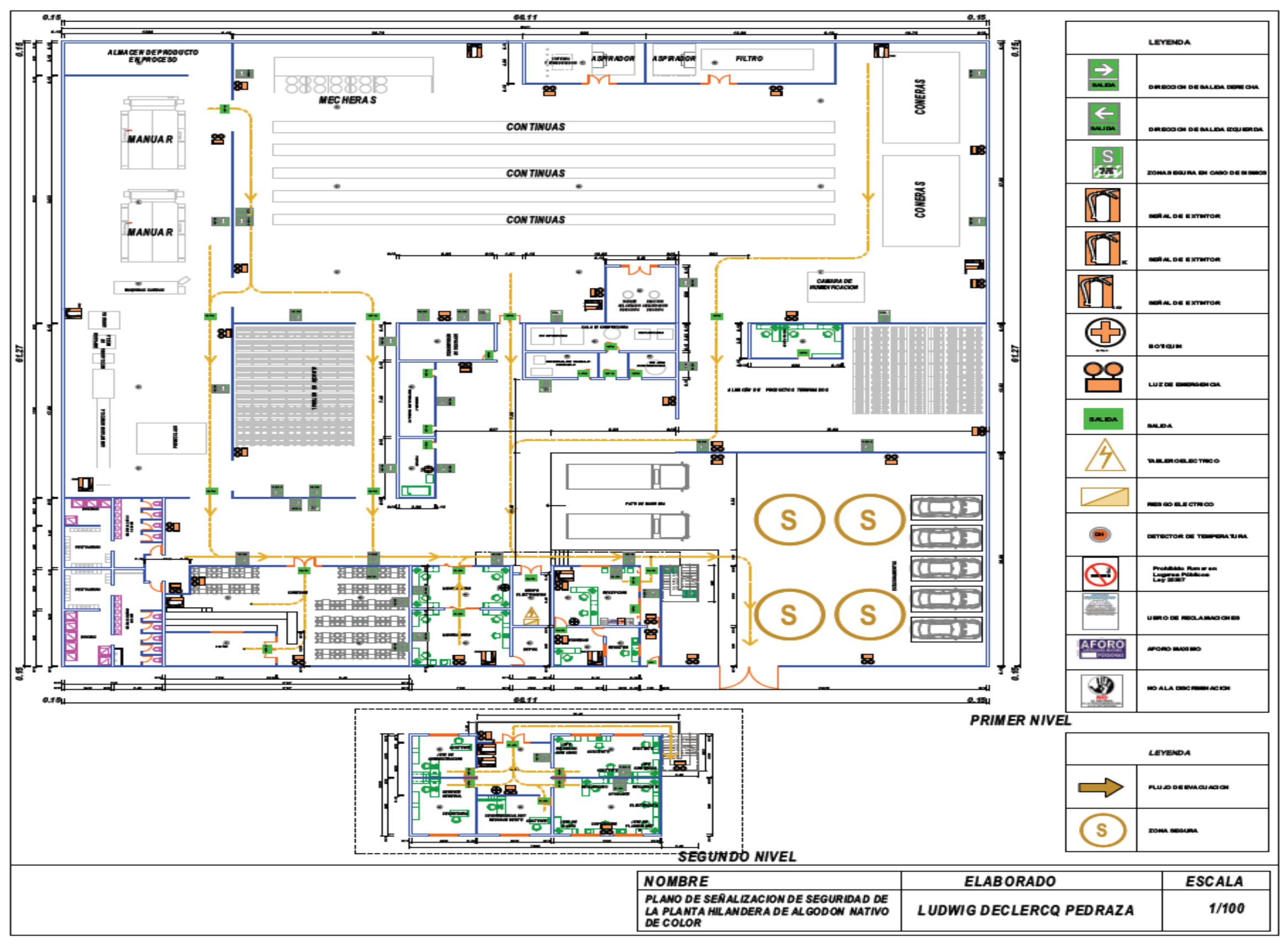




\subsubsection{Disposición general}

\section{Tabla Relacional}

Cabe recalcar que en la tabla relacional se señala las diversas áreas de las planta mas no procesos productivos o estaciones. Las áreas que se detallaran son las siguientes:

1. Almacén de materia prima

2. Producción de hilo

3. Área de climatización

4. Humidificado de hilo

5. Embolsado y etiquetado

6. Almacén de producto terminado
7. Patio de maniobras

8. Comedor

9. Baños

10. Oficinas administrativas

11. Control de calidad

Tabla 5.33

Lista de razones o motivos

\begin{tabular}{|c|l|}
\hline Número & \multicolumn{1}{|c|}{ Razón o motivo } \\
\hline 1 & Por secuencia de operaciones \\
\hline 2 & Requerimiento de almacenamiento \\
\hline 3 & Control de calidad \\
\hline 4 & Higiene y limpieza \\
\hline 5 & Complementación de áreas \\
\hline 6 & Por conveniencia \\
\hline
\end{tabular}

Elaboración propia. 
Figura 5.3

Tabla Relacional de la planta hilandera de algodón nativo de color

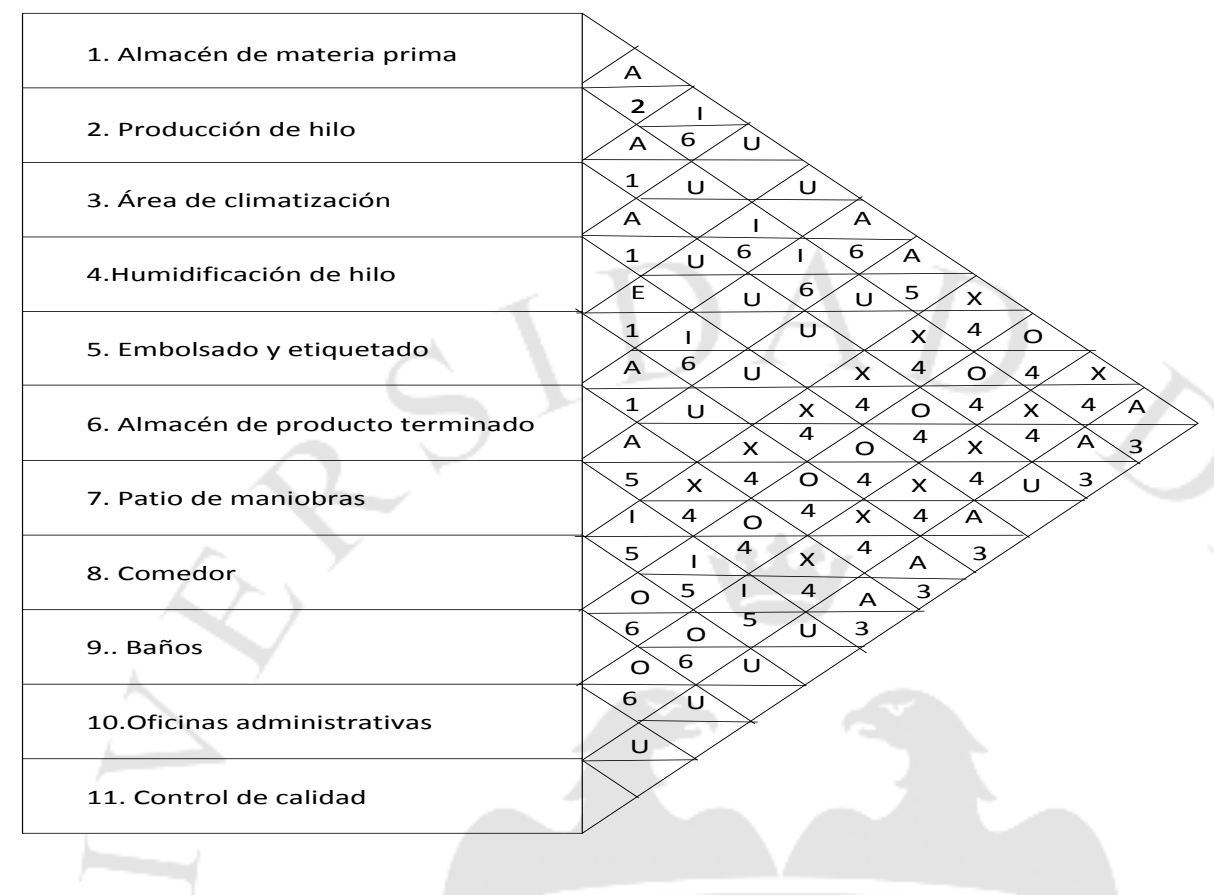

Elaboración propia.

Tabla 5.34

Resumen de la tabla relacional

\begin{tabular}{|cc|c|c|c|cc|}
\hline \multicolumn{2}{|c|}{$\mathrm{A}$} & $\mathrm{E}$ & $\mathrm{I}$ & $\mathrm{O}$ & \multicolumn{2}{c|}{$\mathrm{X}$} \\
\hline$(1,2)$ & $(5,6)$ & $(4,5)$ & $(1,3)$ & $(8,9)$ & $(1,8)$ & $(5,8)$ \\
$(1,6)$ & $(5,11)$ & & $(2,5)$ & $(8,10)$ & $(1,10)$ & $(5,10)$ \\
$(1,7)$ & $(6,7)$ & & $(2,6)$ & $(9,10)$ & $(2,8)$ & $(6,8)$ \\
$(1,11)$ & $(6,11)$ & & $(4,6)$ & $(1,9)$ & $(2,10)$ & $(2,9)$ \\
$(2,3)$ & & & $(7,8)$ & $(3,9)$ & $(3,8)$ & \\
$(2,11)$ & & & $(7,9)$ & $(4,9)$ & $(3,10)$ & \\
$(3,4)$ & & & $(7,10)$ & $(5,9)$ & $(4,8)$ \\
$(4,11)$ & & & & $(6,9)$ & $(4,10)$ \\
\hline
\end{tabular}

Elaboración propia. 
Diagrama relacional de recorrido o actividades

Figura 5.4

Diagrama relacional de la planta hilandera de algodón nativo de color

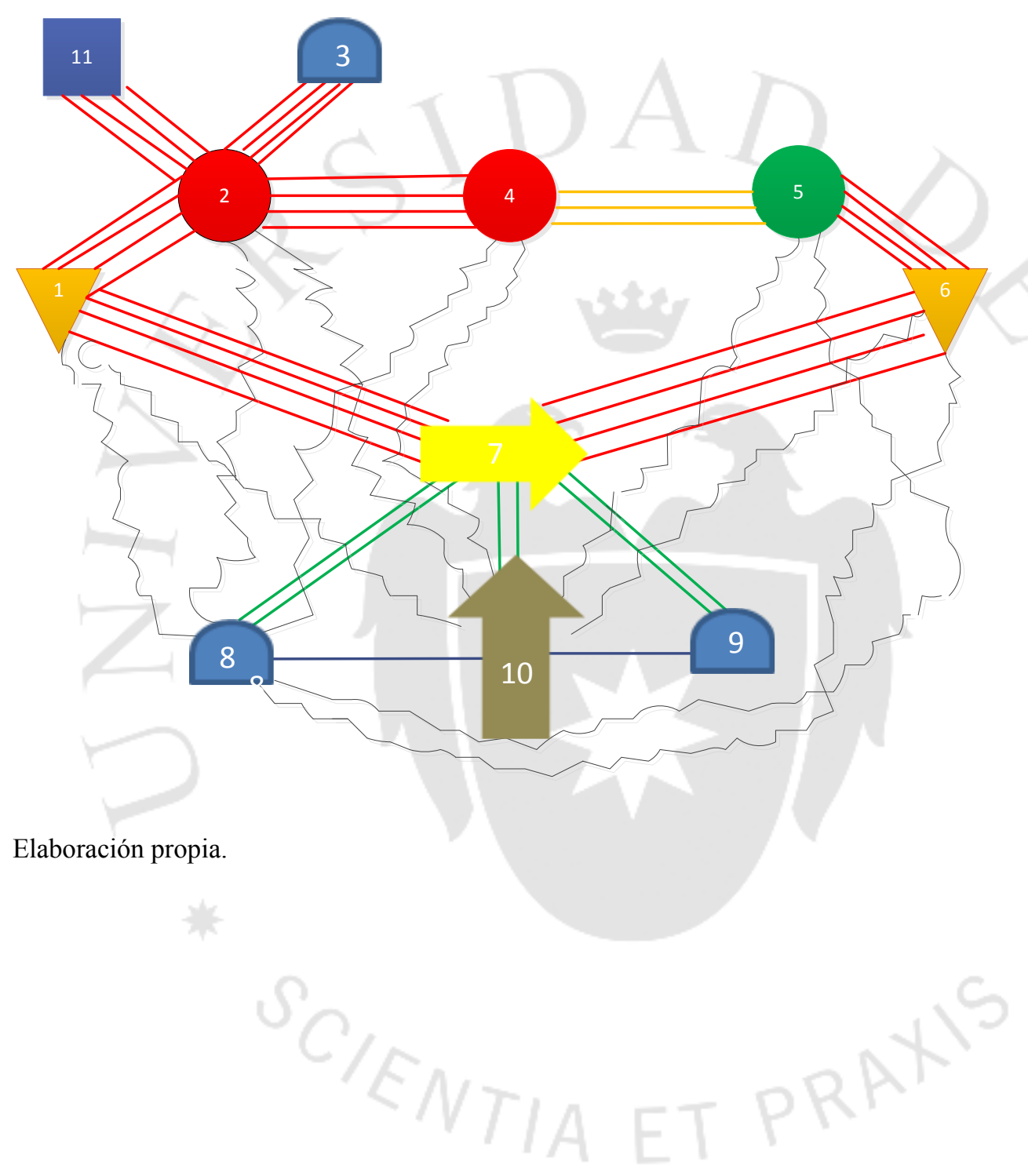


5.12.5 Disposición de detalle

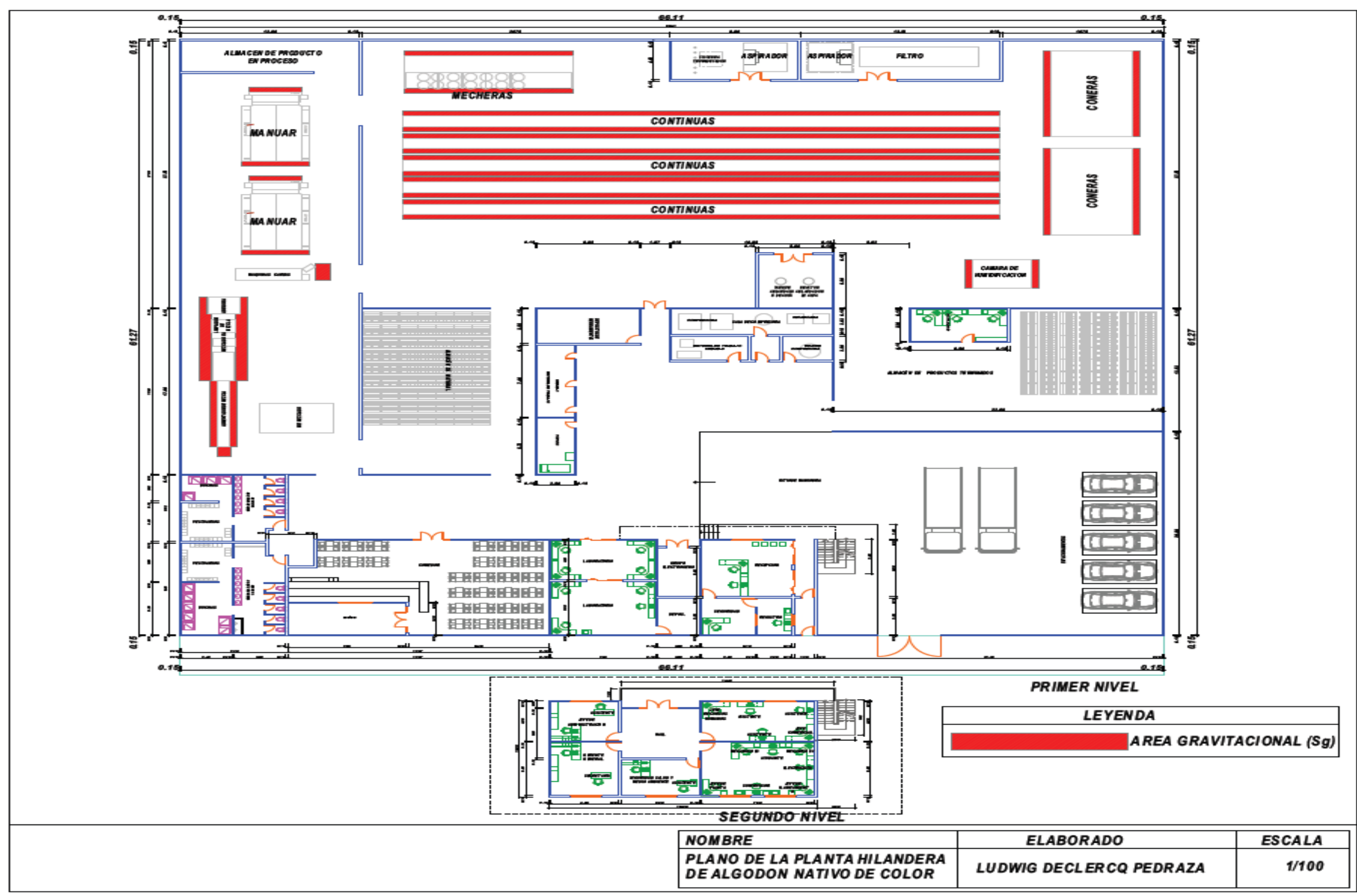




\subsection{Cronograma de implementación del proyecto}

Con el objetivo de realizar la ejecución del proyecto, será necesario programar las distintas actividades para su implementación, la cual terminará con la puesta en marcha de la planta del estudio. El método a utilizar para este fin es el Diagrama de Gantt, el cual permitirá realizar un cronograma que indica las actividades que se deben realizar y el tiempo de duración de cada una para poder dar inicio con la producción.

Figura 5.5

Plan de puesta en marcha del proyecto

\begin{tabular}{|c|c|c|c|c|c|c|c|c|c|c|c|c|c|c|c|c|c|c|c|c|c|}
\hline \multirow{2}{*}{ Nombre de la tarea } & \multirow{2}{*}{$\begin{array}{c}\text { Duración } \\
\text { (meses) }\end{array}$} & \multirow{2}{*}{ Comienzo } & \multirow{2}{*}{ Fin } & \multicolumn{8}{|c|}{2014} & \multicolumn{10}{|c|}{2015} \\
\hline & & & & 4 & 5 & 6 & 7 & 8 & 9 & 10 & \begin{tabular}{l|l}
1 & 12 \\
\end{tabular} & 1 & 2 & 3 & 4 & 5 & 6 & 7 & 8 & \begin{tabular}{l|l|}
9 & 10 \\
\end{tabular} & \begin{tabular}{l|l|}
11 & 12 \\
\end{tabular} \\
\hline Generación de ideas & 1 & $01 / 04 / 2014$ & $30 / 04 / 2014$ & & & & & & & & & & & & & & & & & & \\
\hline Etapa de estudio de Pre Factibilidad & 6 & $01 / 05 / 2014$ & $31 / 10 / 2014$ & & & & & & & & & & & & & & & & & & \\
\hline Cotización de financiamiento & 1 & $01 / 11 / 2014$ & $30 / 11 / 2014$ & & & & & & & & & & & & & & & & & & \\
\hline Solicitud y aprobación del financiamiento & 1 & $01 / 12 / 2014$ & $31 / 12 / 2014$ & & & & & & & & & & & & & & & & & & \\
\hline Alquiler de la planta & 2 & $01 / 01 / 2015$ & $28 / 02 / 2015$ & & & & & & & & & & & & & & & & & & \\
\hline Adquisición de maquinaria y equipo & 6 & $01 / 03 / 2015$ & $31 / 08 / 2015$ & & & & & & & & & & & & & & & & & & \\
\hline Contratación de personal & 4 & $01 / 05 / 2015$ & $31 / 08 / 2015$ & & & & & & & & & & & & & & & & & & \\
\hline Instalación de maquinaria y equipo & 3 & $01 / 09 / 2015$ & $30 / 11 / 2015$ & & & & & & & & & & & & & & & & & & \\
\hline Ensayos de producción & 1 & $01 / 12 / 2015$ & $31 / 12 / 2015$ & & & & & & & & & & & & & & & & & & \\
\hline
\end{tabular}

Elaboración propia 


\section{CAPÍTULO VI: ORGANIZACIÓN ADMINISTRATIVA}

\subsection{Organización Empresarial}

La organización empresarial es un tema importante para el estudio debido a que señala la manera en cómo se piensa distribuir los diferentes puestos de trabajo. Así como también, definir cuáles son las áreas vitales para este tipo de industria como por ejemplo el área de producción, el cual debe ser bien diseñada ya que una para en la producción por falla de alguna máquina perjudicaría todo el proceso. Se elaborará la organización para el año 2025.

\subsection{Requerimientos de personal directivo, administrativo y de servicios}

\section{Alta Gerencia}

Conformada por el Gerente General de la empresa, quien será designado como el Representante Legal de la empresa y estará encargado de la toma de decisiones, determinar las estrategias a seguir, administración de todas las áreas.

\section{Área comercial}

Área encargada de la búsqueda y negociaciones de los clientes, que en conjunto con el área de producción, evaluarán el abastecimiento de los clientes y establecerán las fechas de entrega. El gerente comercial contará con 2 analista, el primero se encargará de ayudar al gerente con las negociaciones con clientes de Lima y provincia mientras que el segundo apoyará en la coordinación con el área de producción y servicio al cliente.

Tabla 6.1

Personal Área de Ventas y Comercialización

\begin{tabular}{|l|c|}
\hline \multicolumn{1}{|c|}{ Cargo } & Cantidad \\
\hline Jefe comercial & 1 \\
\hline Analista comercial & 2 \\
\hline Total & 3 \\
\hline
\end{tabular}

Elaboración propia 


\section{Área de Administración y Finanzas}

Área encargada de consolidar ingresos y egresos de la empresa, gestión de las cuentas bancarias, seguimiento y control de los gastos realizados, evaluación y registro de los contratos.

\section{Tabla 6.2}

Personal Área de Administración y Finanzas

\begin{tabular}{|c|c|}
\hline \multicolumn{1}{|c|}{ Cargo } & Cantidad \\
\hline Jefe de Administración y Finanzas & 1 \\
\hline Asistente de Administración y & 1 \\
\hline Total & 2 \\
\hline
\end{tabular}

Elaboración propia

\section{Área de Recursos Humanos}

Área encargada del reclutamiento, programación de capacitación, control de las jornadas laborales, registro de planilla y manejo de los sueldos.

Tabla 6.3

Personal Área de Recursos Humanos

\begin{tabular}{|l|c|}
\hline \multicolumn{1}{|c|}{ Cargo } & Cantidad \\
\hline Jefe de Recursos Humanos & 1 \\
\hline Asistente & 1 \\
\hline Total & 1 \\
\hline
\end{tabular}

Elaboración propia

\section{Área de Producción}

Es el área encargada de la producción de las bolsas de conos de hilo, aquel que a partir de la planificación se va a abastecer a los clientes, debido a ello tendrá una comunicación permanente con el área de ventas y comercialización. 


\section{Tabla 6.4}

Personal Área de Producción

\begin{tabular}{|l|c|c|c|}
\hline \multicolumn{1}{|c|}{ Cargo } & $\begin{array}{c}\text { trabajadores por } \\
\text { Turno }\end{array}$ & Turnos & Cantidad \\
\hline Jefe de planta & & & 1 \\
\hline Jefe de planeamiento & 1 & 2 & 1 \\
\hline Supervisor & 2 & 2 & 4 \\
\hline Operario pre mezclado & 2 & 2 & 4 \\
\hline $\begin{array}{l}\text { Operario de apertura, } \\
\text { limpieza, mezcladora, }\end{array}$ & 1 & 2 & 2 \\
\hline Operario carda & 2 & 2 & 2 \\
\hline Operario manuar & 1 & 2 & 10 \\
\hline Operario mechera & 5 & 2 & 2 \\
\hline $\begin{array}{l}\text { Operario continua de } \\
\text { hilar }\end{array}$ & 2 & 1 & 36 \\
\hline Operario conera & 2 & & Total \\
\hline $\begin{array}{l}\text { Operario ablandamiento } \\
\text { de agua y humidificado }\end{array}$ & \multicolumn{2}{|l}{} \\
\hline \multicolumn{2}{|l|}{} & 2 & 4 \\
\hline
\end{tabular}

Elaboración propia.

\section{Área de Mantenimiento}

Área soporte de producción encargado de realizar el mantenimiento respectivo a cada máquina con la finalidad de evitar averías, paradas de proceso y extender la vida de las máquinas.

\section{Tabla 6.5}

Personal Área de Mantenimiento

\begin{tabular}{|l|l|c|}
\hline Cargo & Turno & Cantidad \\
\hline Mecánico de planta & 1 mecánico por turno & 2 \\
\hline Ayudante de mecánico & 1 ayudante por turno & 2 \\
\hline Electricista & 1 electricista por turno & 2 \\
\hline \multicolumn{2}{|r|}{ Total } & 6 \\
\hline
\end{tabular}

Elaboración propia.

\section{Área de Control de Calidad}

Área encargada del aseguramiento de la calidad tanto de las materias primas como de producto terminado, así como también supervisión durante el proceso. 
Tabla 6.6

Personal Área de Control de Calidad

\begin{tabular}{|l|c|}
\hline \multicolumn{1}{|c|}{ Cargo } & Cantidad \\
\hline Jefe de Control de Calidad & 1 \\
\hline Encargado de laboratorio & 2 \\
\hline Total & 3 \\
\hline
\end{tabular}

Elaboración propia.

\section{Área de Almacén}

Como su nombre lo indica, es el área encargada del almacenaje, recepción y despacho de materias primas y producto terminado. La empresa tercerizara los servicios de transporte de materia prima y de transporte de producto terminado hacia los clientes.

Tabla 6.7

Personal Área de Almacén

\begin{tabular}{|l|c|}
\hline \multicolumn{1}{|c|}{ Cargo } & Cantidad \\
\hline Jefe de Almacén & 1 \\
\hline Ayudante almacén & 2 \\
\hline Total & 3 \\
\hline
\end{tabular}

Elaboración propia

\section{Área de seguridad, salud ocupacional y medio ambiente}

Es el área encargada de proteger la salud de los trabajadores, controlando los factores de riesgo a los que están expuestos, tomando en cuenta aspectos técnico científicos de la ingeniería de higiene y seguridad ocupacional, en relación con la medicina ocupacional y del medio ambiente y la psicología organizacional. Asimismo, es el área encargada de prevenir, disminuir y mitigar los impactos ambientales en el proceso de fabricación y propiciar el desarrollo sostenible,

\section{Tabla 6.8}

Personal de seguridad, salud ocupacional y medio ambiente

\begin{tabular}{|l|c|}
\hline \multicolumn{1}{|c|}{ Cargo } & Cantidad \\
\hline Jefe de seguridad, salud y medio ambiente & 1 \\
\hline Asistente & 1 \\
\hline Total & 2 \\
\hline
\end{tabular}

Elaboración propia. 
Adicionalmente se contará con una secretaria la cual se encargará de atender a los clientes en la recepción de la empresa; así como recepcionar, registrar y distribuir correspondencia a las distintas áreas; atención de las agendas de la gerencia, atención a entrevistas personales y recepción de mensajes telefónicos.

\section{$\underline{\text { Tercerización }}$}

\section{Contabilidad}

Se contratará a una empresa la cual estará encargada de registrar todas las facturas y gasto efectuados por la empresa a la base de datos y llevar un control de toda la documentación contable

\section{Servicios de limpieza}

Se contratará a una empresa la cual se encargará de la limpieza de las instalaciones de la fábrica.

\section{Seguridad}

Se contratará a una empresa la cual brindará el servicio de vigilancia de la fábrica.

\section{Legal}

Se contratará a una empresa la cual se encargará de los asuntos legales de la empresa Esta se encargará de todo lo referente a la normatividad interna de la empresa; asimismo, será representante legal de la empresa ante los juzgados y tribunales en todo juicio que este inmerso la empresa. Asimismo, asesor

\section{Transporte materia prima y producto terminado}

Se contratará el servicio de terceros para el transporte tanto de la materia prima (fardos de algodón) hacia la planta, como para el traslado del producto terminado (bolsas de 12 conos de $2 \mathrm{~kg} /$ cono) hacia la planta de los clientes. 


\subsection{Estructura Organizacional}

Figura 6.1

Estructura organizacional de la planta hilandera de algodón nativo de color

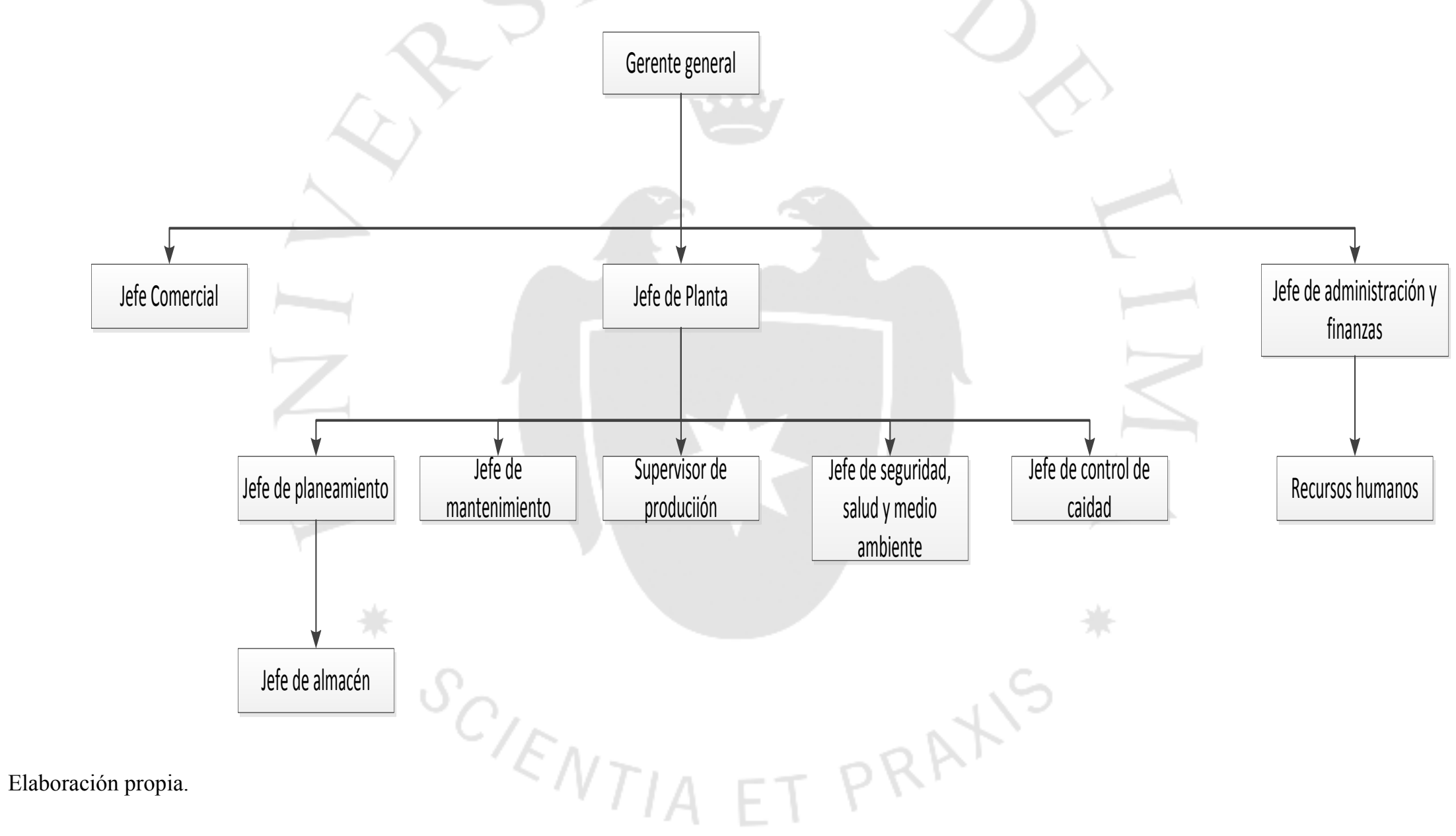




\section{CAPÍTULO VII: ASPECTOS ECONOMICOS Y FINANCIEROS}

\subsection{Inversiones}

Este capítulo tiene por objetivo analizar la información del estudio de mercado, requerimiento de maquinaria, alquiler de local, equipos y personal para poder establecer la inversión necesaria que se requerirá para poner en marcha el proyecto, este presupuesto incluye el monto necesario para garantizar la operación normal durante un ciclo productivo. Asimismo, se deberá considerar la inversión necesaria como capital de trabajo.

\subsubsection{Estimación de las inversiones}

La inversión está constituida por inversión fija tangible e inversión fija intangible los cuales se usarán para la compra de activos que sirven para la operación de la empresa. Asimismo, se debe determinar la vida útil de los activos; ya que, estos irán perdiendo valor hacia el final de la vida útil.

\section{Inversión fija tangible}

Las inversiones en activos son todas aquellas que se realizan en los bienes tangibles que se utilizarán en el proceso de producción en la transformación de insumos o que sirvan de apoyo a la operación normal del proyecto. A continuación se detalla las inversiones estimadas en lo que respecta a infraestructura productiva y el reforzamiento administrativo.

La inversión correspondiente a la infraestructura productiva (maquinaria y equipo); gastos administrativos es del orden de S/.2, 465,625.. En el cuadro 7.14 se muestra la inversión en infraestructura productiva,

De acuerdo a la proyección del tipo de cambio para el 2016 se establece que el tipo de cambio es 3.45 soles/dólar el cual se usará en todo el estudio de pre factibilidad

De acuerdo a la proyección del tipo de cambio para el 2016 se establece que el tipo de cambio es 1.10 dólares/euro el cual se usará en todo el estudio de pre factibilidad 


\section{$\underline{\text { Infraestructura productiva }}$}

Los costos en infraestructura productiva están referidos a la compra de maquinaria, equipos auxiliares, equipos de calidad e instalación de energía eléctrica. Las maquinarias de hilatura se importarán desde Pazzolo (Italia) hasta Huachipa (Lima); por ello se calculará el costo de importación en base a la cotización que aparece en la tabla 7.1. Esta cotización esta sobre la base de 7 contenedores de 40 pies.

Tabla 7.1

Cotización de máquinas para el proceso de hilatura

\begin{tabular}{|l|c|}
\hline \multicolumn{1}{|c|}{ Descripción } & Valor (euros) \\
\hline $\mathrm{N}^{\circ} 1$ Caricatrice B10/1 & 15,000 \\
\hline $\mathrm{N}^{\circ}$ 1 Mixer B 142N & 16.000 \\
\hline $\mathrm{N}^{\circ}$ Opener B34 (uno con aspa a punte/aghí e uno con aspa briseur) & 36,000 \\
\hline $\mathrm{N}^{\circ}$ 3 Gabbie B 41/1 & 4,500 \\
\hline $\mathrm{N}^{\circ}$ 1 Motorfan B151 & 1,000 \\
\hline $\begin{array}{l}\mathrm{N}^{\circ} 1 \text { Carda CX 300 con silos B136 e casa filtro, autoregolata, con } \\
\text { Guarnizioni per cotone nuove Graf e scelta del Cliente }\end{array}$ & 35,000 \\
\hline $\mathrm{N}^{\circ}$ 1 Stiratoi Unimax di primo passagio & 13,000 \\
\hline $\mathrm{N}^{\circ}$ 1 Stiratoi Unimax di 2 ${ }^{\circ}$ passagio auregolato & 17,000 \\
\hline $\mathrm{N}^{\circ}$ Banco mod BCX 16 e da 72 fusi con alette 6x16 & 35,000 \\
\hline $\begin{array}{l}\mathrm{N}^{\circ} 1 \text { Filatolio NSF3 da 1008 fusi anello diam 45, tubetto H 220 con leva } \\
\text { automática con rocatrice Savio Espero }\end{array}$ & 48.000 \\
\hline Total Costo Maquinario & $\mathbf{2 2 0 , 5 0 0}$ \\
\hline Ex - Fabrica (Palazzolo - Italia) & \\
\hline Montaje incluido & \\
\hline Embalaje: Pallets x contenedor (7 x 40') & \\
\hline Maquinas REVISIONADAS CON GARANTIA de 6 meses \\
\hline
\end{tabular}

Fuente: Marzolli, (2015)

Cabe recalcar que el AD-Valorem es el derecho arancelario que grava la importación de las mercancías y cuya base imponible es el valor CIF aduanero determinado según el Acuerdo del Valor de la O.M.C y cuya tasa impositiva tiene cuatro niveles según partida nacional los cuales son $0 \%, 4 \%, 6 \%$ y $11 \%$. El AD-Valorem en el caso de máquinas hilanderas es el $0 \%$ (ver la tabla 7.2) 


\section{Tabla 7.2}

Medidas impositivas para máquinas para hilar materia textil

\begin{tabular}{|l|c|}
\hline \multicolumn{1}{|c|}{ Gravámenes vigentes } & Valor \\
\hline Ad / Valorem & $0 \%$ \\
\hline Impuesto selectivo al consumo & $0 \%$ \\
\hline Impuesto general a las ventas & $16 \%$ \\
\hline Impuesto de promoción municipal & $2 \%$ \\
\hline & \\
Derecho especificos & N.A \\
\hline Derechos antidumping & N.A \\
\hline Seguro & $1 \%$ \\
\hline Sobretasa & $0 \%$ \\
\hline
\end{tabular}

Fuente: SUNAT (2016)

\section{Tabla 7.3}

\section{Costo DDP}

\begin{tabular}{|l|c|}
\hline \multicolumn{1}{|c|}{ Concepto } & Costo (\$) \\
\hline EXW & $\mathbf{2 4 2 , 5 5 0}$ \\
\hline Traslado desde Pazzolo al puerto de Genova Italia & 7,700 \\
\hline Gastos de consolidación aduanera Italiana & 1,100 \\
\hline FOB & 251,350 \\
\hline Flete & 23,366 \\
\hline Seguro DHL $(0.38 \%)$ & 1,044 \\
\hline & \\
CIF & 275,760 \\
\hline Ad- Valorem (0\% CIF) & 0 \\
\hline IPM 2 \% (CIF + Ad Valorem) & 5,515 \\
\hline IGB 16\% (CIF + Ad Valorem) & 44,122 \\
\hline Tasa de despacho & 27 \\
\hline Percepción 10\% & 32,540 \\
\hline Transporte x contenedor $(850$ \$) 7 contenedores & 5,950 \\
\hline Comisión de agencia & 1,224 \\
\hline Gastos operativos & 30 \\
\hline Total gastos locales & 7,204 \\
\hline IGV 18\% & 1,297 \\
\hline DDP & $\mathbf{3 6 6 , 4 6 4}$ \\
\hline
\end{tabular}

Fuente: DHL, (2016) 
Tabla 7.4

Costo importación

\begin{tabular}{|l|c|}
\hline \multicolumn{1}{|c|}{ Concepto } & Costo (\$) \\
\hline Traslado desde Pazzolo al puerto de Genova Italia & 7,700 \\
\hline Gastos de consolidación aduanera Italiana & 1,100 \\
\hline Flete & 23,366 \\
\hline Seguro DHL $(0.38 \%)$ & 1,044 \\
\hline Ad- Valorem (0\% CIF) & 0 \\
\hline IPM 2 \% (CIF + Ad Valorem) & 5,515 \\
\hline IGB 16\% ( CIF + Ad Valorem) & 44,122 \\
\hline Tasa de despacho & 27 \\
\hline Percepción 10\% & 32,540 \\
\hline Transporte x contenedor $(850$ \$) 7 contenedores & 5,950 \\
\hline Comisión de agencia & 1,224 \\
\hline Gastos operativos & 30 \\
\hline IGV 18\% & 1,297 \\
\hline Costo importación & $\mathbf{1 2 3 , 9 1 4}$ \\
\hline
\end{tabular}

Fuente: DHL, (2016)

Debido a que el valor de las maquinarias varía se calculará un costo de importación proporcional a su valor. Se añadirá el costo de importación al costo EXW por maquinaria.

\section{Tabla 7.5}

Costo importación por máquina

\begin{tabular}{|l|c|c|c|c|}
\hline \multicolumn{1}{|c|}{ Máquina } & Cantidad & $\begin{array}{c}\text { Costo EXW } \\
\text { (euros) }\end{array}$ & $\begin{array}{c}\text { Porcentaje del } \\
\text { costo total }\end{array}$ & $\begin{array}{c}\text { Costo de importación por } \\
\text { máquina (\$) }\end{array}$ \\
\hline Alimentador de mezcla & 1 & 15,000 & $6.80 \%$ & 8,430 \\
\hline Mezcladora & 1 & 16,000 & $7.26 \%$ & 8,991 \\
\hline Abridora & 2 & 36,000 & $16.33 \%$ & 20,231 \\
\hline Limpiador de mezcla & 3 & 4,500 & $2.04 \%$ & 2,529 \\
\hline Motor ventilador & 1 & 1,000 & $0.45 \%$ & 562 \\
\hline Carda & 1 & 35,000 & $15.87 \%$ & 19,669 \\
\hline Manuar & 2 & 30,000 & $13.61 \%$ & 16,859 \\
\hline Mechera & 1 & 35,000 & $15.87 \%$ & 19,669 \\
\hline Continua de hilar & 1 & 35,000 & $15.87 \%$ & 19,669 \\
\hline Conera & 1 & 13,000 & $5.90 \%$ & 7,306 \\
\hline & & 220,500 & & 123,914 \\
\hline
\end{tabular}

Elaboración propia. 
Las máquinas se adquirían en base a los cálculos establecidos en el capítulo 5; por ello, se calculará el costo anual por compra de maquinaria. La maquinaria se comprará meses antes de su uso debido a que se deben instalar; por, ello la compra de la maquinaria se hará un año previo a su uso.

Tabla 7.6

Año de adquisición de maquinaria

\begin{tabular}{|l|c|c|c|}
\hline & 2015 & 2020 & 2023 \\
\hline Mezcla & 1 & & \\
\hline Apertura y limpieza & 1 & & \\
\hline Cardado & 1 & & \\
\hline Regularizado de cinta I & 1 & & \\
\hline Regularizado de cinta II & 1 & & \\
\hline Estirado & 1 & & \\
\hline Hilado & 3 & 1 & 1 \\
\hline Enconado & 1 & & 1 \\
\hline
\end{tabular}

Elaboración propia.

Asimismo, se activarán los siguientes bienes complementarios en cada máquina; ya que, son imprescindibles para su funcionamiento

\section{Tabla 7.7}

Bienes complementarios de máquinas

\begin{tabular}{|c|c|}
\hline Máquina & Bien Comentario \\
\hline Carda & Tacho de Carda \\
\hline Manuar & Tacho manuar \\
\hline Mechera & Bobina \\
\hline Continua hilar & Canilla \\
\hline
\end{tabular}

Elaboración propia. 


\section{Tabla 7.8}

Costo bien complementario

\begin{tabular}{|l|l|l|l|}
\hline Concepto & Unidades & $\begin{array}{l}\text { Costo unid } \\
(\mathrm{S} / .)\end{array}$ & Costo (S/.) \\
\hline Tachos de cardas & 24 & 138 & 3,312 \\
\hline $\begin{array}{l}\text { Tachos regularizado de } \\
\text { cinta }\end{array}$ & 48 & 34.5 & 1,656 \\
\hline Bobinas & 2016 & 1.7 & 3,427 \\
\hline Canillas & 8064 & 0.69 & 5,564 \\
\hline
\end{tabular}

Fuente Sercomatex., (2015)

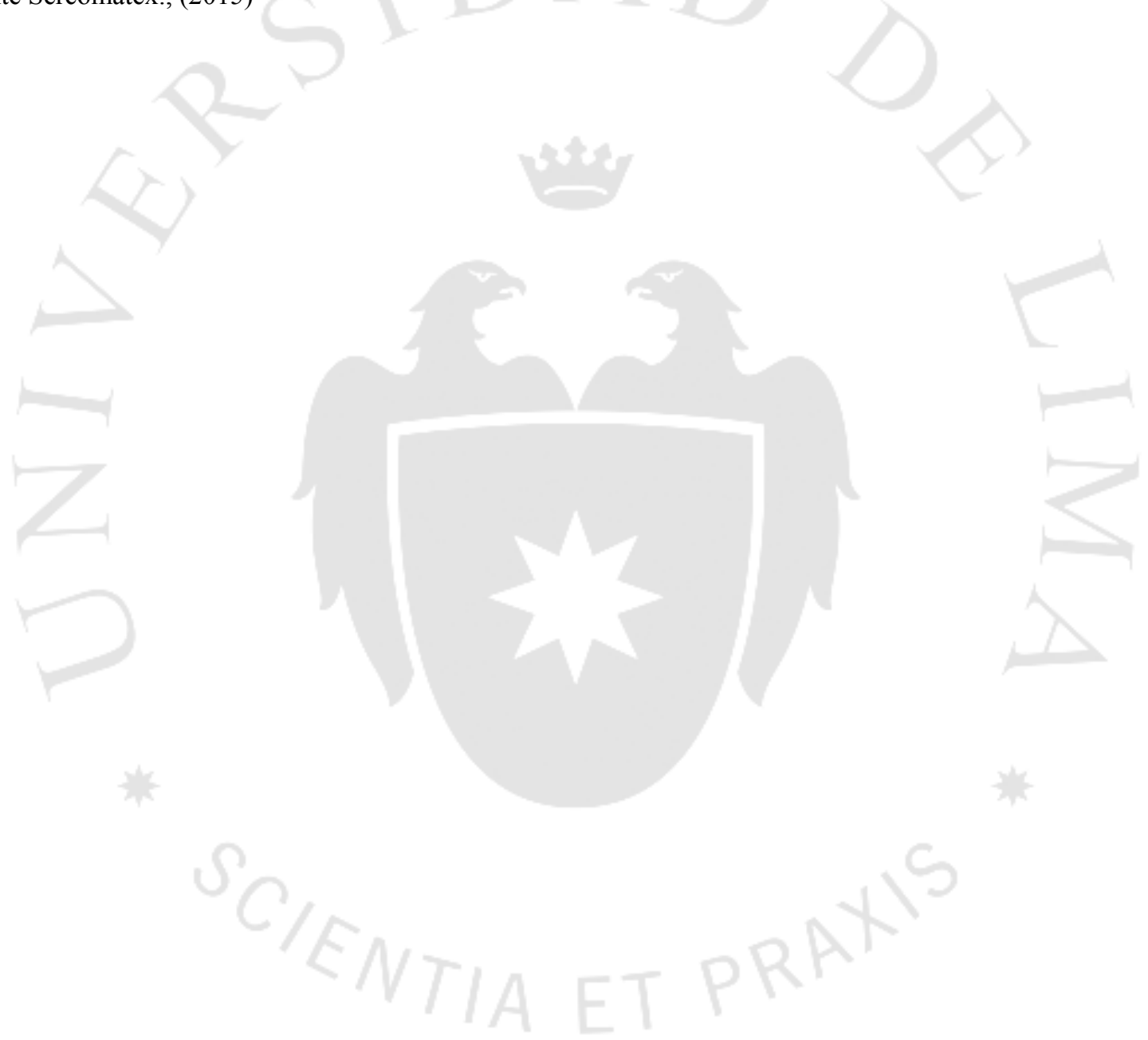




\section{Tabla 7.9}

Inversión en infraestructura productiva en el año 2015

\begin{tabular}{|c|c|c|c|c|c|c|c|}
\hline Máquina & Cantidad & $\begin{array}{c}\text { Costo } \\
\text { unitario } \\
\text { EXW } \\
\text { (Euros) }\end{array}$ & $\begin{array}{c}\text { Costo } \\
\text { unitario } \\
\text { EXW } \\
(\mathrm{S} / .)\end{array}$ & $\begin{array}{c}\text { Costo } \\
\text { importación } \\
(\mathrm{S} / .)\end{array}$ & $\begin{array}{l}\text { Costo } \\
\text { en } \\
\text { planta } \\
(\mathrm{S} /)\end{array}$ & $\begin{array}{c}\text { Activación } \\
\text { bienes } \\
\text { complementarios } \\
(\mathrm{S} / .)\end{array}$ & $\begin{array}{l}\text { Total } \\
(\mathrm{S} / .)\end{array}$ \\
\hline \multicolumn{8}{|l|}{ Máquinas } \\
\hline $\begin{array}{l}\text { Alimentador } \\
\text { de mezcla }\end{array}$ & 1 & 15,000 & 56,925 & 29,082 & 86,007 & & 86,007 \\
\hline Mezcladora & 1 & 16,000 & 60,720 & 31,021 & 91,741 & & 91,741 \\
\hline $\begin{array}{l}\text { Limpiador de } \\
\text { mezcla }\end{array}$ & 3 & 500 & 1,898 & 8,725 & 14,417 & & 14,417 \\
\hline Abridora & 2 & 18,000 & 68,310 & 69,797 & 206,417 & & 206,417 \\
\hline $\begin{array}{l}\text { Motor } \\
\text { ventilador }\end{array}$ & 1 & 1,000 & 3,795 & 1,939 & 3,795 & & 3,795 \\
\hline Carda & 1 & 35,000 & 132,825 & 67,858 & 200,683 & 3,312 & 203,995 \\
\hline Manuar & 2 & 15,000 & 56,925 & 58,164 & 172,014 & 1,656 & 173,670 \\
\hline Mechera & 1 & 35,000 & 132,825 & 67,858 & 200,683 & 3,478 & 204,160 \\
\hline Continua & 3 & 35,000 & 132,825 & 67,858 & 602,048 & 5,564 & 607,612 \\
\hline $\begin{array}{l}\text { Adaptación } \\
\text { continua }\end{array}$ & 3 & & & & 12,000 & & 36,000 \\
\hline Conera & 1 & 13,000 & 49,335 & 25,204 & 74,539 & & 74,539 \\
\hline $\begin{array}{l}\text { Cámara } \\
\text { humidificación }\end{array}$ & 1 & 15,000 & 56,925 & $x^{2}$ & 56,925 & & 56,925 \\
\hline \multicolumn{6}{|l|}{ Costo máquinas } & & $1,759,278$ \\
\hline \multicolumn{8}{|c|}{ Equipos } \\
\hline Compresor & & & & & 5,175 & & 5,175 \\
\hline $\begin{array}{l}\text { Ablandador de } \\
\text { agua }\end{array}$ & 6 & & & & 2,415 & & 2,415 \\
\hline $\begin{array}{l}\text { Transformador } \\
\text { de media a } \\
\text { baja tensión }\end{array}$ & & & & & 3,450 & & 3,450 \\
\hline \multicolumn{6}{|l|}{ Costo equipos } & & 11,040 \\
\hline Costo total & & & & & & & $1,770,318$ \\
\hline
\end{tabular}

Elaboración propia. 
Tabla 7.10

Inversión en infraestructura productiva en el año 2019

\begin{tabular}{|l|c|c|c|c|c|c|c|}
\hline Máquina & Cantidad & $\begin{array}{c}\text { Costo } \\
\text { unitario } \\
\text { EXW } \\
(\text { Euros) }\end{array}$ & $\begin{array}{c}\text { Costo } \\
\text { unitario } \\
\text { EXW } \\
(\mathrm{S} / .)\end{array}$ & $\begin{array}{c}\text { Costo } \\
\text { importación } \\
(\mathrm{S} / .)\end{array}$ & $\begin{array}{c}\text { Costo en } \\
\text { planta (S/) }\end{array}$ & $\begin{array}{c}\text { Activación } \\
\text { bienes } \\
\text { complementarios } \\
(\mathrm{S} / .)\end{array}$ & Total (S/.) \\
\hline Continua & 1 & 35,000 & 132,825 & 67,858 & 200,683 & 5,564 & 206,247 \\
\hline Adaptación & 1 & & & & 12,000 & & 12,000 \\
\hline Costo total & & & & & 218,247 \\
\hline
\end{tabular}

Elaboración propia.

Tabla 7.11

Inversión en infraestructura productiva en el año 2022

\begin{tabular}{|l|c|c|c|c|c|c|c|}
\hline \multicolumn{1}{|c|}{ Máquina } & Cantidad & $\begin{array}{c}\text { Costo } \\
\text { unitario } \\
\text { EXW } \\
(\text { Euros) }\end{array}$ & $\begin{array}{c}\text { Costo } \\
\text { unitario } \\
\text { EXW (S/.) }\end{array}$ & $\begin{array}{c}\text { Costo } \\
\text { importación } \\
(\mathrm{S} / .)\end{array}$ & $\begin{array}{c}\text { Activación } \\
\text { Costo en } \\
\text { planta (S/) }\end{array}$ & $\begin{array}{c}\text { bienes } \\
\text { complementarios } \\
(\mathrm{S} / .)\end{array}$ & Total (S/.) \\
\hline Continua & 1 & 35,000 & 132,825 & 67,858 & 200,683 & 5,564 & 206,247 \\
\hline Adaptación & 1 & & & & 12,000 & & 12,000 \\
\hline Conera & 1 & 13,000 & 49,335 & 25,204 & 74,539 & & 74,539 \\
\hline Costo total
\end{tabular}

Elaboración propia, 


\section{Costo de instalación de energía eléctrica}

Se debe considerar también el costo de instalación de energía eléctrica el cual se realizará en el año cero del proyecto; es decir, en el 2015. Para poder establecer el costo de conexión se debe determinar si la conexión es área o subterránea, y considerar la potencia instalada que para el caso del proyecto será la potencia del año 2025 la cual es $412.87 \mathrm{~kW}$.

Tabla 7.12

Conexiones básicas en media tensión (S/.)

\begin{tabular}{|c|c|c|c|c|c|c|c|c|c|c|}
\hline \multirow{2}{*}{ Fases } & \multirow{2}{*}{ Tipo } & \multirow{2}{*}{ Subtipo } & \multirow{2}{*}{$\begin{array}{l}\text { Potencia conectada } \\
\qquad(\mathrm{Pc})\end{array}$} & \multirow{2}{*}{$\begin{array}{l}\text { Opción } \\
\text { tarifaria }\end{array}$} & \multicolumn{2}{|c|}{$10 \mathrm{kV}$} & \multicolumn{2}{|c|}{$13.2 / 7.62 \mathrm{Kw}$} & \multicolumn{2}{|c|}{$20 \mathrm{Kv}-22.9 / 13.2 \mathrm{kV}$} \\
\hline & & & & & PMI & Celda & PMI & Celda & PMI & Celda \\
\hline \multirow{5}{*}{ Trifásica } & \multirow{5}{*}{$\mathrm{C} 5$} & C5 1 & $\mathrm{Pc}<=100 \mathrm{~kW}$ & $\begin{array}{c}\text { MT2 /MT3 } \\
\text { /MT4 }\end{array}$ & 9,841 & 16,019 & 10,797 & 20,801 & 12,023 & 20,831 \\
\hline & & C5 2 & $\begin{array}{c}100 \mathrm{~kW}<\mathrm{Pc}<400 \\
\mathrm{~kW}\end{array}$ & $\begin{array}{c}\text { MT2 /MT3 } \\
\text { /MT4 }\end{array}$ & 10,666 & 14,452 & 10,856 & 18,719 & 12,023 & 20,831 \\
\hline & & C5 3 & $\begin{array}{c}400 \mathrm{~kW}<\mathrm{Pc}<700 \\
\mathrm{~kW}\end{array}$ & $\begin{array}{c}\text { MT2 /MT3 } \\
\text { /MT4 }\end{array}$ & 10,576 & 13,835 & 11,131 & 17,898 & 12,565 & 23,266 \\
\hline & & C5 4 & $\begin{array}{c}700 \mathrm{~kW}<\mathrm{Pc} \\
<1000 \mathrm{~kW}\end{array}$ & $\begin{array}{c}\text { MT2 /MT3 } \\
\text { /MT4 }\end{array}$ & 10,892 & 13,162 & 11,131 & 17,898 & 12,822 & 22,707 \\
\hline & & $\mathrm{C} 55$ & $\begin{array}{c}1000 \mathrm{~kW}<\mathrm{Pc} \\
<2500 \mathrm{~kW}\end{array}$ & $\begin{array}{c}\text { MT2 /MT3 } \\
\text { /MT4 }\end{array}$ & 13,093 & 13,746 & 12,052 & 17,626 & 13,973 & 21,156 \\
\hline
\end{tabular}

Fuente: Osinergmin, (2015)

De acuerdo a los parámetros del proyecto la tarifa correspondiente es C5; ya que, en el año 2025 la potencia estará entre $400 \mathrm{~kW}$ y 700 kW. Asimismo, se piensa conectar con una línea de $10 \mathrm{kV}$ y por vía área (PMI); por lo tanto, el costo de instalación es de 10,576 soles 


\section{Equipos de medición de Calidad}

La fábrica contará con equipos para medir la calidad de material en proceso y el producto de hilar; es decir, la cinta de carda, cinta de manuar, mecha e hilo; sin embargo, el análisis de la materia prima (algodón) se tercerizará. El costo y función de los equipos necesarios para medir la calidad son los siguientes:

\section{Tabla 7.13}

Costo de equipos de calidad

\begin{tabular}{|c|c|c|c|c|}
\hline Equipo & Modelo & Función & Precio (\$) & $\begin{array}{l}\text { Precio } \\
(\mathrm{S} / .)\end{array}$ \\
\hline Nep Tester Uster & $\begin{array}{l}\text { Modelo } 720 \text { año } \\
1997\end{array}$ & $\begin{array}{l}\text { Medir los neps en algodón } \\
\text { desmotado }\end{array}$ & 3,500 & 12,075 \\
\hline $\begin{array}{l}\text { Equipo de regularmetria } \\
\text { Uster }\end{array}$ & $\begin{array}{l}\text { Tester } 4 \text { upgrade } x \\
5.5 \text { Suiza año } 2009\end{array}$ & $\begin{array}{l}\text { Medir la regularidad de hilos } \\
\text { mediante el coeficiente de } \\
\text { variación del titulo }\end{array}$ & 33,600 & 115,920 \\
\hline $\begin{array}{l}\text { Torsiometro eléctrico } \\
\text { Zweigle }\end{array}$ & Modelo DG14/1 & $\begin{array}{l}\text { Medir la cantidad de torsiones en } \\
\text { una pulgada }\end{array}$ & 1,500 & 5,175 \\
\hline Aspa eléctrico Mesdan & $\begin{array}{l}\text { Serie } 1463 \text { año } \\
2001\end{array}$ & $\begin{array}{l}\text { Es una devanadora que mide } 100 \\
\text { metros de hilo de un cono }\end{array}$ & 800 & 2,760 \\
\hline $\begin{array}{l}\text { Balanza electrónica } \\
\text { ohaus }\end{array}$ & $\begin{array}{l}\text { Gold Series } \\
\text { PAJ21M2N }\end{array}$ & $\begin{array}{l}\text { Medir el peso con precisión de los } \\
\text { hilos }\end{array}$ & 500 & 1,725 \\
\hline Dinamómetro Uster & Tensojet año 1997 & $\begin{array}{l}\text { Mide la resistencia del hilo } \\
\text { expresado en porcentaje de } \\
\text { elongación }\end{array}$ & 5,000 & 17,250 \\
\hline Costo total & & $x^{2}$ & & 142,830 \\
\hline
\end{tabular}

Fuente: Hialpesa, (2015)

Por último se comprará un montacargas con capacidad de carga de 2.5 toneladas a un precio de 6,300 dólares.

\section{Cálculo del costo de oportunidad de capital}

La tasa bajo el cual el dinero varía en el tiempo es en este caso el costo de capital o costo de oportunidad del inversionista.

$\mathrm{KC}=\mathrm{Rf}+\beta(\mathrm{Rm}-\mathrm{Rf})$ 
Se calculará este valor en base los datos de Estados Unidos y luego mediante el riesgo país se obtendrá el costo de capital en el Perú. Estos valores son basados en información a 10 años.

$\mathrm{Rf}=2.29 \%$

$\operatorname{Rm}-\operatorname{Rf}($ usa) $=6 \%$.

Se usará el Beta textil de prendas de vestir; ya que, no hay un Beta textil específicamente para el sector de hilandería

$\beta=1.06 \%$

$\mathrm{KC}(\mathrm{USA})=2.29 \%+1.06 \% \times 6 \%$

$\mathrm{KC}(\mathrm{USA})=8.65 \%$

Luego de obtener el valor del costo de capital en Estados Unidos, a este valor se le adicionara el riego país del Perú para finalmente obtener el costo de capital en Perú.

El riesgo país en Perú es de 2.91\%

$\mathrm{KC}($ Perú $)=2.91 \%+8.65 \%$

$\mathrm{KC}($ Perú $)=11.56 \%$

\section{Valor presente de activos tangibles}

Debido a que hay máquinas que se adquirirán en el transcurso del proyecto se traerá al valor presente el valor de dichas máquinas de tal forma que se pueda determinar el valor de infraestructura productiva para el 2015. El costo de capital a usar es de $11.56 \%$ que se calculó previamente. 
Inversión en infraestructura productiva

\begin{tabular}{|l|c|c|c|c|c|c|c|c|}
\hline & 2015 & 2016 & 2017 & 2018 & 2019 & 2020 & 2021 & 2022 \\
\hline Máquinas & $1,770,318$ & & & & 218,247 & & & 292,786 \\
\hline Equipos calidad & 142,830 & & & & & & & \\
\hline Montacargas & 21,735 & & & & & & & \\
\hline $\begin{array}{l}\text { Costo de instalación } \\
\text { eléctrica }\end{array}$ & 10,576 & & & & & & & \\
\hline Valor presente & $\mathbf{2 , 3 7 6 , 3 4 3}$ & & & & & & & \\
\hline
\end{tabular}

Elaboración propia.

Por lo tanto, la inversión correspondiente a la infraestructura productiva asciende a S/.2, 376,343 soles.

\section{$\underline{\text { Infraestructura administrativa }}$}

Los costos en infraestructura administrativa están referidos a los equipos de informática e inmobiliario de oficina.

i) Equipos de informática: Se considerará que todo el personal que requiera gestionar información contara con una laptop HP con pantalla de 14 pulgadas y procesador AMD Quad-Core A8-6410 cuyo precio es de 1,399 soles en Saga Falabella. Asimismo, la planta contara con 2 impresoras industriales HP cuyo valor unitario es de 599 soles 
Tabla 7.15

Costo equipos informáticos

\begin{tabular}{|l|c|c|c|}
\hline \multicolumn{1}{|c|}{ Puesto } & cantidad & Costo laptop (S/.) & Costo (S/.) \\
\hline Gerente general & 1 & 1,399 & 1,399 \\
\hline Jefe comercial & 1 & 1,399 & 1,399 \\
\hline Analista comercial & 2 & 1,399 & 2,798 \\
\hline $\begin{array}{l}\text { Jefe administración y } \\
\text { finanzas }\end{array}$ & 1 & 1,399 & 1,399 \\
\hline $\begin{array}{l}\text { Asistente administración y } \\
\text { finanzas }\end{array}$ & 1 & 1,399 & 1,399 \\
\hline Jefe de recursos humanos & 1 & 1,399 & 1,399 \\
\hline $\begin{array}{l}\text { Asistente de recursos } \\
\text { humanos }\end{array}$ & 1 & 1,399 & 1,399 \\
\hline Jefe de planta & 1 & 1,399 & 1,399 \\
\hline Jefe de planeamiento & 1 & 1,399 & 1,399 \\
\hline Supervisor & 2 & 1,399 & 2,798 \\
\hline Jefe de control de calidad & 1 & 1,399 & 1,399 \\
\hline Encargado de laboratorio & 2 & 1,399 & 2,798 \\
\hline Jefe de almacén & 1 & 1,399 & 1,399 \\
\hline Ayudante de almacén & 2 & 1,399 & 2,798 \\
\hline Costo Total & & $\mathbf{2 5 , 1 8 2}$ \\
\hline
\end{tabular}

Fuente: Saga Falabella, (2016)

Elaboración propia.

ii) Inmobiliario de Oficina: Se considerará que tanto el personal que requiera hacer funciones de índole administrativo requerirá un escritorio y una silla. 
Tabla 7.16

Inmobiliario de oficina

\begin{tabular}{|l|c|c|c|c|}
\hline \multicolumn{1}{|c|}{ Puesto } & Cantidad & $\begin{array}{c}\text { Costo } \\
\text { escritorio }\end{array}$ & Costo Silla & Costo (S/.) \\
\hline Gerente general & 1 & 649 & 329 & 978 \\
\hline Jefe comercial & 1 & 649 & 329 & 978 \\
\hline Analista comercial & 2 & 380 & 100 & 960 \\
\hline Jefe administración y finanzas & 1 & 649 & 329 & 978 \\
\hline Asistente administración y finanzas & 1 & 380 & 100 & 480 \\
\hline Jefe de recursos humanos & 1 & 649 & 329 & 978 \\
\hline Asistente de recursos humanos & 1 & 380 & 100 & 480 \\
\hline Jefe de planta & 1 & 649 & 329 & 978 \\
\hline Jefe de planeamiento & 1 & 649 & 329 & 978 \\
\hline Supervisor & 2 & 380 & 100 & 960 \\
\hline Jefe de control de calidad & 1 & 649 & 329 & 978 \\
\hline Encargado de laboratorio & 2 & 380 & 100 & 960 \\
\hline Jefe de almacén & 1 & 649 & 329 & 978 \\
\hline Ayudante de almacén & 2 & 380 & 100 & 960 \\
\hline Costo Total & & & & $\mathbf{1 2 , 6 2 4}$ \\
\hline
\end{tabular}

Fuente: Sodimac, (2016)

Elaboración propia.

Tabla 7.17

Inversión en infraestructura administrativa

\begin{tabular}{|l|r|}
\hline \multicolumn{1}{|c|}{ Concepto } & \multicolumn{1}{c|}{$\begin{array}{l}\text { Total } \\
(\mathrm{S} / .)\end{array}$} \\
\hline Comunicación e informática & 25,182 \\
\hline Mobiliario y equipamiento & 12,624 \\
\hline Impresora & 1,198 \\
\hline Total & $\mathbf{3 9 , 0 0 4}$ \\
\hline
\end{tabular}

Elaboración propia. 


\section{Inversión fija intangible}

Las inversiones en activos fijos intangibles son todas aquellas que se realizan sobre activos constituidos por los servicios o derechos adquiridos necesarios para la puesta en marcha del proyecto.

Los gastos pre operativos, ascienden a 50,278 soles En este rubro se consideran: estudio de mercado, adquisición de softwares como un pequeño ERP para gestionar los recursos de la empresa, implementación de página web y Microsoft office; así como licencia de funcionamiento y costo de trámites en la notaria para la formación de la empresa. Los detalles de los gastos en este rubro pueden ser vistos en la tabla 7.20

Tabla 7.18

Costo licencia Microsoft Office

\begin{tabular}{|c|c|c|}
\hline Costo por licencia (S/.) & Número de usuarios & Costo (S/.) \\
\hline 329 & 14 & 4,606 \\
\hline
\end{tabular}

Fuente. Saga Falabella, (2016)

Tabla 7.19

Licencia municipal de Lurigancho para el funcionamiento (comercial, industrial y/o servicios) establecimiento con área mayor a $500 \mathrm{~m}^{2}$

\begin{tabular}{|c|c|c|}
\hline Costo variable (S/.) & Margen de contribución (S/.) & Costo de una prestación (S/.) \\
\hline 88.95 & 3.22 & 92.18 \\
\hline
\end{tabular}

Fuente: Municipalidad de Lurigancho, (2016)

Tabla 7.20

Inversión fija intangible

\begin{tabular}{|l|c|}
\hline \multicolumn{1}{|c|}{ Concepto } & Monto (S/.) \\
\hline Estudio de mercado & 2,000 \\
\hline ERP & 34,500 \\
\hline Microsoft Office & 4,606 \\
\hline Página Web & 8,280 \\
\hline Licencia municipalidad & 92 \\
\hline Notaria & 800 \\
\hline Costo total & $\mathbf{5 0 , 2 7 8}$ \\
\hline
\end{tabular}

Elaboración propia. 
Tabla 7.21

Estimación del total de la inversión fija

\begin{tabular}{|c|c|}
\hline Inversión fija & Soles \\
\hline \multicolumn{2}{|l|}{ Inversión fija tangible } \\
\hline \multicolumn{2}{|l|}{ Infraestructura productiva } \\
\hline Maquinaria y equipo & $2,376,343$ \\
\hline \multicolumn{2}{|l|}{ Infraestructura administrativa } \\
\hline Muebles y equipos informáticos & 39,004 \\
\hline Total inversión fija tangible & $2,415,347$ \\
\hline \multicolumn{2}{|l|}{ Inversión fija intangible } \\
\hline Gastos Pre operativos & 50,278 \\
\hline Total de inversión fija & $2,465,625$ \\
\hline
\end{tabular}

Elaboración: Propia

El costo total en inversión fija es de 2, 465,625 soles

\subsubsection{Capital de trabajo}

El capital de trabajo consiste en los recursos que requiere la empresa para poder operar, también es conocido como activo corriente. Para que la fábrica hilandera de algodón nativo de color pueda empezar sus operaciones necesita dinero para cubrir las necesidades de insumos, materia prima, mano de obra, reposición de activos fijos, etc.

Para poder determinar el capital de trabajo se dividirá los costos y gastos totales entre el ciclo de caja. Ciclo de caja $=$ PPI + PPC - PPP

Por política de la empresa se establecerá el periodo promedio de pago de materias primas en 30 días; y el periodo promedio de cobro de producto terminado en 60 días. Para determinar el periodo promedio de inventario se calculara el tiempo que demora en procesar un fardo de algodón de $250 \mathrm{~kg}$. 
Tabla 7.22

Calculo del tiempo de producción de un fardo en el año 2016

\begin{tabular}{|c|l|c|c|c|c|c|c|}
\hline entrante $(\mathrm{kg})$ & \multicolumn{1}{|c|}{ proceso } & $\begin{array}{c}\text { tiempo } \\
\text { producción } \\
(\mathrm{kg} / \mathrm{h})\end{array}$ & $\begin{array}{c}\# \\
\text { Maquinas }\end{array}$ & $\begin{array}{c}\text { Tiempo } \\
(\text { horas })\end{array}$ & $\begin{array}{c}\% \\
\text { Merma }\end{array}$ & $\begin{array}{c}\text { Merma } \\
(\mathrm{kg})\end{array}$ & $\begin{array}{c}\text { Producto } \\
(\mathrm{kg})\end{array}$ \\
\hline 250 & Pre mezclado & 200 & & 1.25 & $0.5 \%$ & 1.25 & 248.75 \\
\hline 248.75 & Mezclado & 200 & 1 & 1.24 & $1.50 \%$ & 3.73 & 245.02 \\
\hline 245.02 & $\begin{array}{l}\text { Apertura y } \\
\text { limpieza }\end{array}$ & 800 & 1 & 0.31 & $1.50 \%$ & 3.68 & 241.34 \\
\hline 241.34 & Cardado & 100 & 1 & 2.41 & $2 \%$ & 4.83 & 236.52 \\
\hline 236.52 & $\begin{array}{l}\text { Regularizado de } \\
\text { cinta I }\end{array}$ & 96.55 & 1 & 2.45 & $1 \%$ & 2.37 & 234.15 \\
\hline 234.15 & $\begin{array}{l}\text { Regularizado de } \\
\text { cinta II }\end{array}$ & 96.55 & 1 & 2.43 & $1 \%$ & 2.34 & 231.81 \\
\hline 231.81 & Estirado & 152.93 & 1 & 1.52 & $1.50 \%$ & 3.48 & 228.33 \\
\hline 228.33 & Hilado & 14.37 & 3 & 5.30 & $2 \%$ & 4.57 & 223.77 \\
\hline 223.77 & Enconado & 51.84 & 1 & 4.32 & $2 \%$ & 4.48 & 219.29 \\
\hline 219.29 & Humidificado & 400 & 1 & 0.55 & $0 \%$ & 0.00 & 219.29 \\
\hline
\end{tabular}

Elaboración propia.

Debido a que la fábrica trabaja en el año 2019 en 2 turnos de 9 horas: es decir 18 horas día; por lo tanto el periodo promedio de inventario es de 2 días.

Ciclo de caja $=2+60-30=32$ días

El costo total operativo y administrativo que se calcularon en la sección 7.3.2 y 7.3.3 para el primer año del proyecto ascienden a 4, 238,102 y 592,708 soles respectivamente; por lo tanto, el costo total es de 4,610,010 soles.

Tabla 7.23

Costos y gastos del primer año del proyecto $(\mathrm{S} /$.

\begin{tabular}{|l|l|}
\hline & \multicolumn{1}{|c|}{2016} \\
\hline Costos totales & $4,238,102$ \\
\hline Gastos totales & 592,708 \\
\hline Total & $4,830,810$ \\
\hline
\end{tabular}

Elaboración propia. 
Finalmente, como se estableció previamente, el capital de trabajo es el dinero que se requiere para poder operar en el primer año del proyecto 2016 en el periodo del ciclo de caja el cual es 32 días.

Capital de trabajo $=4,830,810 / 360=13,419$ soles

Capital de trabajo $=13 ., 419 \times 32=429,405$ soles

Por lo tanto, el capital de trabajo asciende a 429,405 soles.

\subsection{Costos de producción}

\subsubsection{Costo de materias primas, insumos y otros materiales}

\section{I) Materiales directos}

\section{i) Materia prima}

Como se mencionó anteriormente el hilo que se desea elaborar está conformado por la mezcla del algodón nativo de color y el algodón Tangüis. El algodón nativo de color desmotado se comprará a un precio de 16 soles por kilo como se concluyó en la sección 2.6.3. Mientras que el algodón Tangüis se comprará a un precio promedio de los últimos 3 años el cual es de 2.02 dólares (6.96 soles). 
Se debe determinar el costo de la materia prima, proyectando la demanda para el proyecto

Tabla 7.24

Costo de materia prima

\begin{tabular}{|l|r|r|r|r|r|r|r|r|r|r|r|}
\hline & 2016 & 2017 & 2018 & 2019 & 2020 & 2021 & 2022 & 2023 & 2024 & 2025 \\
\hline Algodón nativo de color \\
\hline $\begin{array}{l}\text { Algodón nativo } \\
\text { requerido (kg) }\end{array}$ & 126,264 & 131,665 & 148,543 & 165,421 & 182,300 & 199,185 & 216,056 & 232,942 & 249,820 & 266,698 \\
\hline $\begin{array}{l}\text { Pago al crédito } \\
\text { último mes (S/.) }\end{array}$ & & 168,352 & 175,553 & 198,057 & 220,561 & 243,067 & 265,580 & 288,075 & 310,589 & 333,093 \\
\hline Pago anual (S/.) & $1,851,872$ & $1,931,087$ & $2,178,631$ & $2,426,175$ & $2,673,733$ & $2,921,380$ & $3,168,821$ & $3,416,483$ & $3,664,027$ & $3,911,571$ \\
\hline Crédito (S/.) & 168,352 & 175,553 & 198,057 & 220,561 & 243,067 & 265,580 & 288,075 & 310,589 & 333,093 & 355,597 \\
\hline $\begin{array}{l}\text { Costo algodón } \\
\text { nativo (S/.) }\end{array}$ & $1,851,872$ & $2,099,439$ & $2,354,184$ & $2,624,232$ & $2,894,295$ & $3,164,447$ & $3,434,401$ & $3,704,557$ & $3,974,616$ & $4,600,261$ \\
\hline
\end{tabular}

Algodón Tanguis

\begin{tabular}{|l|r|r|r|r|r|r|r|r|r|r|}
\hline $\begin{array}{l}\text { Algodón Tanguis } \\
\text { requerido (kg) }\end{array}$ & 74,155 & 77,327 & 87,240 & 97,152 & 107,065 & 116,982 & 126,890 & 136,807 & 146,720 & 156,632 \\
\hline $\begin{array}{l}\text { Pago al crédito } \\
\text { último mes (S/.) }\end{array}$ & & 42,994 & 44,834 & 50,581 & 56,328 & 62,075 & 67,825 & 73,570 & 79,320 & 85,067 \\
\hline Pago anual (S/.) & 472,939 & 493,169 & 556,391 & 619,607 & 682,829 & 746,077 & 809,267 & 872,515 & 935,737 & 998,953 \\
\hline Crédito (S/.) & 42,994 & 44,834 & 50,581 & 56,328 & 62,075 & 67,825 & 73,570 & 79,320 & 85,067 & 90,814 \\
\hline $\begin{array}{l}\text { Costo algodón } \\
\text { Tanguis (S/.) }\end{array}$ & 472,939 & 536,164 & 601,225 & 670,188 & 739,157 & 808,152 & 877,093 & 946,085 & $1,015,057$ & $1,174,834$ \\
\hline $\begin{array}{l}\text { Costo materia } \\
\text { prima (S/.) }\end{array}$ & $\mathbf{2 , 3 2 4 , 8 1 1}$ & $\mathbf{2 , 6 3 5 , 6 0 2}$ & $\mathbf{2 , 9 5 5 , 4 0 9}$ & $\mathbf{3 , 2 9 4 , 4 2 0}$ & $\mathbf{3 , 6 3 3 , 4 5 2}$ & $\mathbf{3 , 9 7 2 , 5 9 9}$ & $\mathbf{4 , 3 1 1 , 4 9 4}$ & $\mathbf{4 , 6 5 0 , 6 4 2}$ & $\mathbf{4 , 9 8 9 , 6 7 3}$ & $\mathbf{5 , 7 7 5 , 0 9 6}$ \\
\hline
\end{tabular}

Elaboración propia. 
ii) Insumos

Debido a que los conos, bolsas y etiquetas forman parte del producto final se consideran como material directo. Asimismo, los conos tienen una vida útil de 10 años.

Tabla 7.25

Costo de insumos (material directo)

\begin{tabular}{|l|c|c|c|c|c|c|c|c|c|c|}
\hline & 2016 & 2017 & 2018 & 2019 & 2020 & 2021 & 2022 & 2023 & 2024 & 2025 \\
\hline Conos (unid) & 1,000 & 0 & 2,000 & 0 & 0 & 0 & 0 & 0 & 0 & 0 \\
\hline Costo unid (S/.) & 3.45 & 3.45 & 3.45 & 3.45 & 3.45 & 3.45 & 3.45 & 3.45 & 3.45 & 3.45 \\
\hline Costo conos (S/.) & 3,450 & 0 & 6,900 & 0 & 0 & 0 & 0 & 0 & 0 & 0 \\
\hline Bolsas (unid) & 7,481 & 7,769 & 8,632 & 9,711 & 10,646 & 11,567 & 12,775 & 13,639 & 14,502 & 15,509 \\
\hline Costo unid (S/.) & 0.4 & 0.4 & 0.4 & 0.4 & 0.4 & 0.4 & 0.4 & 0.4 & 0.4 & 0.4 \\
\hline $\begin{array}{l}\text { Costo bolsas } \\
\text { (S/.) }\end{array}$ & 2,992 & 3,108 & 3,453 & 3,884 & 4,258 & 4,627 & 5,110 & 5,456 & 5,801 & 6,204 \\
\hline Etiquetas (unid) & 7,481 & 7,769 & 8,632 & 9,711 & 10,646 & 11,567 & 12,775 & 13,639 & 14,502 & 15,509 \\
\hline Costo unid (S/.) & 0.25 & 0.25 & 0.25 & 0.25 & 0.25 & 0.25 & 0.25 & 0.25 & 0.25 & 0.25 \\
\hline $\begin{array}{l}\text { Costo etiquetas } \\
\text { (S/.) }\end{array}$ & 1,870 & 1,942 & 2,158 & 2,428 & 2,662 & 2,892 & 3,194 & 3,410 & 3,626 & 3,877 \\
\hline Costo total & $\mathbf{8 , 3 1 3}$ & $\mathbf{5 , 0 5 0}$ & $\mathbf{1 2 , 5 1 1}$ & $\mathbf{6 , 3 1 2}$ & $\mathbf{6 , 9 2 0}$ & $\mathbf{7 , 5 1 9}$ & $\mathbf{8 , 3 0 4}$ & $\mathbf{8 , 8 6 5}$ & $\mathbf{9 , 4 2 6}$ & $\mathbf{1 0 , 0 8 1}$ \\
\hline
\end{tabular}

Elaboración propia. 


\section{II) Materiales indirectos}

Los materiales indirectos para el proceso de fabricación de hilos de algodón nativo de color están comprendidos por lubricantes y repuestos. De acuerdo a la información suministrada por representante en Perú de Sercometex (empresa que vende maquinaria de hilandera) el 8\% del costo total representa a los costos de mantenimiento (Lubricantes y repuestos). Por ello, teniendo el valor del costo de materia prima se puede calcular el valor del costo de mantenimiento; ya que, el costo de materia prima representa el $50 \%$ del costo total

\section{Tabla 7.26}

Benchmarking de costos en fábricas hilanderas

\begin{tabular}{|l|c|}
\hline \multicolumn{1}{|c|}{ Rubro } & Porcentaje del costo total \\
\hline Materia prima & $50 \%$ \\
\hline Mano de obra & $12 \%$ \\
\hline Energía & $16 \%$ \\
\hline Gastos administrativo & $10 \%$ \\
\hline $\begin{array}{l}\text { Mantenimiento (aceite y } \\
\text { repuestos) }\end{array}$ & $8 \%$ \\
\hline Gastos financieros & $4 \%$ \\
\hline Total & $100 \%$ \\
\hline
\end{tabular}

Fuente: Sercomatex, (2015) 
Tabla 7.27

Costo de lubricantes y repuestos

\begin{tabular}{|c|c|c|c|c|c|c|c|c|c|c|}
\hline & 2016 & 2017 & 2018 & 2019 & 2020 & 2021 & 2022 & 2023 & 2024 & 2025 \\
\hline $\begin{array}{l}\text { Costo materia prima } \\
(\mathrm{S} / .)\end{array}$ & $2,324,811$ & $2,635,602$ & $2,955,409$ & $3,294,420$ & $3,633,452$ & $3,972,599$ & $4,311,494$ & $4,650,642$ & $4,989,673$ & $5,775,096$ \\
\hline $\begin{array}{l}\text { Costo mantenimiento } \\
(\mathrm{S} / .)\end{array}$ & 371,970 & 421,696 & 472,865 & 527,107 & 581,352 & 635,616 & 689,839 & 744,103 & 798,348 & 924,015 \\
\hline
\end{tabular}

Elaboración propia.

\subsubsection{Costo de servicios (energía eléctrica, agua)}

\section{Costos generales de planta}

\section{1) Abastecimiento de energía eléctrica}

Para determinar el costo de energía eléctrica se debe tener los costos de la tarifa de energía eléctrica y la cantidad de energía en kW que es consumida por todas las maquinas. Debido a que se trata de una planta industrial, se analizará de acuerdo a la tarifa MT3 ya que, se requiere una potencia mayor a $90 \mathrm{~kW}$ por ello debe ser una tarifa de media tensión en vez de baja tensión. Asimismo, se utilizará la tarifa es MT3 debido a que es la más económica de acuerdo a la operación de la planta la cual va funcionar entre las 6 am a 11 pm. Por último como la fábrica está ubicada en Huachipa, la empresa distribuidora de electricidad en ese distrito es Luz del Sur. 
Tabla 7.28

Tarifa de electricidad MT3 (Luz del Sur)

\begin{tabular}{|l|c|c|}
\hline \multicolumn{1}{|c|}{ Concepto } & Unidad & Tarifa sin IGV \\
\hline Costo fijo mensual & S/./mes & 3.11 \\
\hline Cargo por energía activa en punta & ctm. S/./kW.h & 20.68 \\
\hline Cargo por energía activa fuera de punta & ctm. S/./kW.h & 17.32 \\
\hline Cargo en potencia activa de generación para usuarios & \multicolumn{2}{|l|}{42.84} \\
\hline Presentes en punta & S/./kW-mes & 29.19 \\
\hline Presentes fuera de punta & S/./kW-mes & \\
\hline Cargo por potencia activa de redes de distribución para usuarios \\
\hline Presentes en punta & $\mathrm{S} / . / \mathrm{kW}$-mes & 10.79 \\
\hline Presentes fuera de punta & $\mathrm{S} / . / \mathrm{kW}-\mathrm{mes}$ & 10.86 \\
\hline $\begin{array}{l}\text { Cargo por energía reactiva que exceda el 30\% } \\
\text { del total de la energía activa }\end{array}$ & ctm. S/./Var.h & 4.34 \\
\hline
\end{tabular}

Fuente: OSINERGMIN, (2016)

Elaboración propia

Hora punta: 18 horas -23 horas: 5 horas/día; Hora fuera de punta: Resto del día $=18$ horas

Tabla 7.29

Costo anual de energía eléctrica (S/,)

\begin{tabular}{|l|c|c|c|c|c|c|c|c|c|c|}
\hline & 2016 & 2017 & 2018 & 2019 & 2020 & 2021 & 2022 & 2023 & 2024 & 2025 \\
\hline Costo de energía & 383,71 & 389,98 & 408,86 & 432,28 & 510,57 & 530,37 & 556,03 & 629,89 & 648,21 \\
eléctrica (S/.) & 7 & 5 & 0 & 1 & 9 & 9 & 1 & $\begin{array}{c}669,57 \\
2\end{array}$ \\
\hline
\end{tabular}

Elaboración propia

\section{2) Abastecimiento de agua}

Para determinar el costo de agua se debe tener los costos de la tarifa de agua y la cantidad de agua en $\mathrm{m} 3$ que se consumen en la fábrica. La tarifa de agua en Sedapal por m3 se muestra en la tabla 7.30 
Tabla 7.30

Tarifas de agua

\begin{tabular}{|c|c|c|c|c|}
\hline \multirow{2}{*}{$\begin{array}{c}\text { Clase } \\
\text { categoría }\end{array}$} & Rango & \multicolumn{3}{|c|}{ Tarifa (S/m3) } \\
\cline { 2 - 5 } & $\mathrm{m} 3 / \mathrm{mes}$ & Agua potable & Alcantarillado & Total \\
\hline \multirow{2}{*}{ Industrial } & 0 a 1000 & 4.858 & 2.193 & 7.051 \\
\cline { 2 - 5 } & 1000 a más & 5.212 & 2.352 & 7.564 \\
\hline
\end{tabular}

Fuente: SEDAPAL S.A. (2016)

Elaboración propia

El servicio de agua es necesario para limpieza de las instalaciones de la planta y para el uso de los servicios higiénicos; ya que, los obreros al momento de terminar su jornada laboral se duchan. En verano el costo sube un poco ya que los obreros usan su hora de descanso para ducharse por el incesante calor que hay en la planta. Sin embargo, para el proceso productivo no es tan necesaria. El consumo mensual promedio es de $42 \mathrm{~m} 3$ al mes; por lo tanto, el consumo anual es de $504 \mathrm{~m} 3$ al año. Asimismo, también se considera el agua utilizada por el deshumidificador. 
Tabla 7.31

Costo de agua

\begin{tabular}{|c|c|c|c|c|c|}
\hline Año & $\begin{array}{c}\text { Agua requerida para } \\
\text { instalaciones de } \\
\text { planta }(\mathrm{m} 3)\end{array}$ & $\begin{array}{c}\text { Agua requerida para } \\
\text { el deshumidificador } \\
(\mathrm{m} 3)\end{array}$ & $\begin{array}{c}\text { Aguar requerida } \\
(\mathrm{m} 3)\end{array}$ & $\begin{array}{c}\text { Tarifa } \\
(\mathrm{S} / . / \mathrm{m} 3)\end{array}$ & Costo (S/.) \\
\hline 2016 & 504 & 65.925 & 569.9 & 7.051 & 4018.5 \\
\hline 2017 & 504 & 68.745 & 572.7 & 7.051 & 4038.4 \\
\hline 2018 & 504 & 77.558 & 581.6 & 7.051 & 4100.6 \\
\hline 2019 & 504 & 86.37 & 590.4 & 7.051 & 4162.7 \\
\hline 2020 & 504 & 95.183 & 599.2 & 7.051 & 4224.8 \\
\hline 2021 & 504 & 103.999 & 608.0 & 7.051 & 4287.0 \\
\hline 2022 & 504 & 112.808 & 616.8 & 7.051 & 4349.1 \\
\hline 2023 & 504 & 121.624 & 625.6 & 7.051 & 4411.3 \\
\hline 2024 & 504 & 130.436 & 634.4 & 7.051 & 4473.4 \\
\hline 2025 & 504 & 139.249 & 643.2 & 7.051 & 4535.5 \\
\hline
\end{tabular}

Elaboración propia.

\section{3) Alquiler de infraestructura de la planta}

Como se estableció previamente la infraestructura de la planta será alquilada y estará ubicada en Huachipa (Lurigancho). La planta contara con $2,000 \mathrm{~m}^{2}$ y su costo de alquiler se calculará en base al costo promedio mensual de $3.5 \$ / \mathrm{m}^{2}$ en Lurigancho del estudio de Colliers Internacional que se encuentra en la tabla 3.13. Por lo tanto el costo de alquiler es de 7,000 dólares mensuales; es decir, 84,000 dólares anuales. 


\section{4) Análisis de calidad de materia prima}

El análisis de la materia prima se tercerizará; ya que, el equipo para el análisis de las variables del algodón es muy costoso; por ello, se llevará a analizar 20 g/fardo de algodón nativo de color en el Senati. Las variables que se analizarán serán la finura del algodón (micronaire) y la longitud de fibra Asimismo, cabe recalcar que debido a la alta confiabilidad de los proveedores de algodón Tangüis no será necesario analizar las características de este algodón.

\section{Tabla 7.32}

Costo de análisis de materia prima

\begin{tabular}{|l|c|c|c|}
\hline Descripción de ensayos solicitados & Método & $\begin{array}{c}\text { Cantidad } \\
\text { (gr) }\end{array}$ & Costo (S/.) \\
\hline $\begin{array}{l}\text { Determinación de finura de fibra de } \\
\text { algodón - micronaire }\end{array}$ & ASTM D1448-11 & 200 & 75.90 \\
\hline $\begin{array}{l}\text { Determinación de longitud de fibra } \\
\text { de algodón - Classfiber }\end{array}$ & $\begin{array}{c}\text { ASTM D1447- } \\
\text { 07(2012)e1 }\end{array}$ & 200 & 75.90 \\
\hline Costo total & & $\mathbf{1 5 1 . 8 0}$ \\
\hline
\end{tabular}

Fuente: Senati, (2016) 
Tabla 7.33

Costo de anual de analizar la materia prima

\begin{tabular}{|l|c|c|c|c|c|c|c|c|c|c|}
\hline & 2016 & 2017 & 2018 & 2019 & 2020 & 2021 & 2022 & 2023 & 2024 & 2025 \\
\hline $\begin{array}{l}\text { Algodón Nativo } \\
\text { de color }\end{array}$ & $\begin{array}{c}126,26 \\
4\end{array}$ & $\begin{array}{c}131,66 \\
5\end{array}$ & $\begin{array}{c}148,54 \\
3\end{array}$ & $\begin{array}{c}165,42 \\
1\end{array}$ & $\begin{array}{c}182,30 \\
0\end{array}$ & $\begin{array}{c}199,18 \\
5\end{array}$ & $\begin{array}{c}216,05 \\
6\end{array}$ & $\begin{array}{c}232,94 \\
2\end{array}$ & $\begin{array}{c}249,82 \\
0\end{array}$ & $\begin{array}{c}266,69 \\
8\end{array}$ \\
\hline Fardos & 505 & 527 & 594 & 662 & 729 & 797 & 864 & 932 & 999 & 1,067 \\
\hline Muestra & 101 & 105 & 119 & 132 & 146 & 159 & 173 & 186 & 200 & 213 \\
\hline $\begin{array}{l}\text { Costo / muestra } \\
\text { (S/:) }\end{array}$ & 151 & 151 & 151 & 151 & 151 & 151 & 151 & 151 & 151 & 151 \\
\hline Costo total & $\mathbf{1 5 , 2 5 3}$ & $\mathbf{1 5 , 9 0 5}$ & $\mathbf{1 7 , 9 4 4}$ & $\mathbf{1 9 , 9 8 3}$ & $\mathbf{2 2 , 0 2 2}$ & $\mathbf{2 4 , 0 6 2}$ & $\mathbf{2 6 , 1 0 0}$ & $\mathbf{2 8 , 1 3 9}$ & $\mathbf{3 0 , 1 7 8}$ & $\mathbf{3 2 , 2 1 7}$ \\
\hline
\end{tabular}

Elaboración propia.

5) Seguro de la planta

Debido a los múltiples riesgos que pueden sufrir los activos de una planta es imprescindible, contar con un seguro que proteja la seguridad operativa y financiera de la planta con la finalidad de prevenir contingencias. Se contará con seguro multiriesgo, seguro contra robo y el seguro de responsabilidad civil. El seguro multiriesgo cubre los daños ocasionados, por incendios, explosiones, terrorismo, riesgo político, terremoto y riesgos de la naturaleza. El seguro de responsabilidad social cubre los daños sufridos por terceros, siempre que estos se produzcan con culpa o negligencia del asegurado; es decir, de la fábrica hilandera de algodón nativo de color. El costo del seguro se va a prorratear de acuerdo a las dimensiones de la planta que se usarán para producción y administración.

Tabla 7.34

Áreas de la planta

\begin{tabular}{|l|c|c|}
\hline Áreas de la planta & Área $(\mathrm{m} 2)$ & Porcentaje \\
\hline Área producción & 1250.52 & $64.2 \%$ \\
\hline Almacén MP & 306.18 & $15.7 \%$ \\
\hline Almacén PT & 172 & $8.8 \%$ \\
\hline \multicolumn{2}{|l|}{ Área productiva } & $88.7 \%$ \\
\hline $\begin{array}{l}\text { Área } \\
\text { administrativa }\end{array}$ & 219.50 & $11.3 \%$ \\
\hline Total área planta & $\mathbf{1 9 4 8 . 1}$ & $100.0 \%$ \\
\hline
\end{tabular}

Elaboración propia. 
Tabla 7.35

Costo anual de asegurar a la planta

\begin{tabular}{|l|c|c|c|c|c|c|c|}
\hline \multicolumn{1}{|c|}{ Tipo de seguro } & $\begin{array}{c}\text { Días de } \\
\text { cobertura }\end{array}$ & $\begin{array}{c}\text { Importe } \\
\text { asegurado }\end{array}$ & Prima & $\begin{array}{c}\text { Derecho } \\
\text { de } \\
\text { emisión }\end{array}$ & Interés & Total (\$) & Total (S/.) \\
\hline $\begin{array}{l}\text { Seguro de responsabilidad } \\
\text { social }\end{array}$ & 365 & $1,000,000$ & 1,750 & 53 & 0 & 1,803 & 6,219 \\
\hline Robo & 365 & 150,000 & 4,000 & 120 & 0 & 4,120 & 14,214 \\
\hline Seguro multiriesgo & 365 & $2,500,000$ & 55,685 & 1,671 & 0 & 7,289 & 25,146 \\
\hline Total & & & & & 45,578 \\
\hline Área productiva (88.7\%) & & & & & 40,428 \\
\hline Área administrativa (11.3\%)
\end{tabular}

Fuente: Rímac Seguros, (2016)

\section{5) Transporte de Materia prima}

El algodón nativo de color desmotado en Lambayeque se trasladará a Lima; por ello, se incurrirá en un costo por transportar este algodón; cabe recalcar, que el costo de traslado de Lambayeque hacia Lima es de 180 soles/tonelada. En cambio, en el caso del algodón Tangüis el proveedor llevará este algodón hacia la fábrica; por ello, no se incurrirá en el costo de transporte para este algodón

Tabla 7.36

Costo del traslado de algodón nativo desmotado desde Lambayeque hacia Lima

\begin{tabular}{|l|c|c|c|c|c|c|c|c|c|c|}
\hline & 2016 & 2017 & 2018 & 2019 & 2020 & 2021 & 2022 & 2023 & 2024 & 2025 \\
\hline $\begin{array}{l}\text { Algodón } \\
\text { nativo (kg) }\end{array}$ & 126,264 & 131,665 & 148,543 & 165,421 & 182,300 & 199,185 & 216,056 & 232,942 & 249,820 & 266,698 \\
\hline $\begin{array}{l}\text { Costo } \\
\text { transporte } \\
(\mathbf{S} / \text {, }\end{array}$ & $\mathbf{2 2 , 7 2 8}$ & $\mathbf{2 3 , 7 0 0}$ & $\mathbf{2 6 , 7 3 8}$ & $\mathbf{2 9 , 7 7 6}$ & $\mathbf{3 2 , 8 1 4}$ & $\mathbf{3 5 , 8 5 3}$ & $\mathbf{3 8 , 8 9 0}$ & $\mathbf{4 1 , 9 3 0}$ & $\mathbf{4 4 , 9 6 8}$ & $\mathbf{4 8 , 0 0 6}$ \\
\hline
\end{tabular}

Elaboración propia. 


\subsubsection{Costo de la mano de obra}

El costo de la mano de obra constituye uno de los principales ítems de los costos de operación del proyecto. La importancia relativa que tenga dentro de estos dependerá, entre otros aspectos, del grado de automatización del proceso productivo y de la especialización del personal requerido, de la situación del mercado laboral, las leyes laborales, del número de turnos requeridos, etc.

\subsubsection{Mano de obra directa}

La mano de obra directa está conformada por todos los trabajadores que intervienen en la producción de hilos de algodón nativo de color desde que entra en el proceso el algodón nativo de color y algodón Tangüis hasta que se tiene como resultado una bolsa con 12 conos de algodón de $2 \mathrm{~kg}$. Todos los trabajadores de la empresa estarán en planilla; por lo tanto, contarán con todos los beneficios sociales como compensación por tiempo de servicios (CTS), vacaciones, gratificaciones, asignación familiar; asimismo los trabajadores contarán con contribuciones sociales como Essalud, Senati y seguro complementario para trabajo en riesgo (SCTR).

\section{Cálculo del costo de horas extras}

El cálculo del costo de las horas extras se calculará con la base del sueldo bruto mensual. Se debe considerar que las 2 primeras horas extras tendrán un valor $1.25 \%$ el costo de la hora normal trabajada mientras que las 2 segundas horas tendrán un valor de $1.35 \%$ el costo de la hora normal trabajada. El sueldo bruto para todos los operarios es de 1,000 soles mensuales considerando que se trabaja 4.3 semanas/mes de lunes a sábado, considerando 8 horas de trabajo: por lo tanto el costo por hora es 4.8 soles/hora. Por lo tanto el costo de las 2 primeras horas extras es de 6.06 soles/hora y el costo de las 2 segundas horas extra es de 6.54 soles/hora. 


\section{Tabla 7.37}

Costo anual de mano de obra directa (S/.)

\begin{tabular}{|c|c|c|c|c|c|c|c|c|c|c|}
\hline & 2016 & 2017 & 2018 & 2019 & 2020 & 2021 & 2022 & 2023 & 2024 & 2025 \\
\hline $\begin{array}{l}\text { Costo de mano } \\
\text { de obra directa }\end{array}$ & 357,830 & 365,740 & 394,743 & 442,729 & 463,649 & 436,439 & 521,553 & 559,384 & 562,020 & 619,710 \\
\hline
\end{tabular}

Elaboración propia.

\subsubsection{Mano de obra indirecta}

En la fábrica de hilar algodón nativo de color la mano de obra indirecta está conformada por el jefe de planta, jefe de planeamiento los supervisores de planta, personal de mantenimiento, jefe de almacén e ayudante, personal del área de calidad. Para tener una adecuada remuneración para los trabajadores se tomó en cuenta el grado de dificultad de los servicios que brinda; y su grado de estudios y de conocimientos. En el cuadro 7.38 se muestra el costo anual de mano de obra indirecta.

Tabla 7.38

Costo anual de mano de obra indirecta (S/)

\begin{tabular}{|l|c|c|c|}
\hline \multicolumn{1}{|c|}{ Detalle } & $\begin{array}{c}\mathrm{N}^{\circ} \text { de } \\
\text { trabajadores }\end{array}$ & $\begin{array}{c}\text { Sueldo bruto } \\
\text { mensual }\end{array}$ & Total \\
\hline Jefe de planta & 1 & 3,800 & 63,705 \\
\hline $\begin{array}{l}\text { Jefe de } \\
\text { planeamiento }\end{array}$ & 1 & 2,000 & 33,564 \\
\hline Supervisor & 2 & 1,400 & 47,035 \\
\hline Mecánico de planta & 2 & 1,300 & 43,686 \\
\hline $\begin{array}{l}\text { Ayudante de } \\
\text { mecánico }\end{array}$ & 2 & 900 & 30,290 \\
\hline Electricista & 2 & 1300 & 43,686 \\
\hline $\begin{array}{l}\text { Jefe de control de } \\
\text { calidad }\end{array}$ & 1 & 2000 & 33,564 \\
\hline $\begin{array}{l}\text { Encargado del } \\
\text { laboratorio de } \\
\text { calidad }\end{array}$ & 2 & 1,000 & 33,639 \\
\hline Jefe de almacén & 1 & 1,800 & 30,215 \\
\hline $\begin{array}{l}\text { Asistente de } \\
\text { almacén }\end{array}$ & 2 & 1,000 & 33,639 \\
\hline
\end{tabular}

Elaboración propia. 


\subsection{Presupuesto de ingresos y egresos}

\subsubsection{Presupuesto de ingresos por ventas}

Para determinar los ingresos por ventas primero se determina la demanda anual proyectada para el proyecto de la planta hilandera de hilo de algodón nativo de color en los 10 primeros años del proyecto y se multiplica por el valor de venta que de 10 dólares/kg equivalente a 34.5 soles $/ \mathrm{kg}$. Asimismo, como se estableció previamente por política de la empresa el periodo promedio de cobro de producto terminado es de 60 días.

Tabla 7.39

Ingresos por ventas de hilo de algodón nativo de color (No incluye IGV)

\begin{tabular}{|l|c|c|c|c|c|c|c|c|c|c|}
\hline & 2016 & 2017 & 2018 & 2019 & 2020 & 2021 & 2022 & 2023 & 2024 & 2025 \\
\hline Hilo demandado (kg) & 159,820 & 183,320 & 206,820 & 230,320 & 253,820 & 277,330 & 300,820 & 324,330 & 347,830 & 371,330 \\
\hline $\begin{array}{l}\text { Cobro al crédito últimos dos } \\
\text { meses (S/.) }\end{array}$ & & $\mathbf{9 1 8 , 9 6 5}$ & $1,054,090$ & $\mathbf{1 , 1 8 9 , 2 1 5}$ & $\mathbf{1 , 3 2 4 , 3 4 0}$ & $\mathbf{1 , 4 5 9 , 4 6 5}$ & $\mathbf{1 , 5 9 4 , 6 4 8}$ & $1,729,715$ & $1,864,898$ & $2,000,023$ \\
\hline Cobro anual (S/.) & $\mathbf{4 , 5 9 4 , 8 2 5}$ & $\mathbf{5 , 2 7 0 , 4 5 0}$ & $\mathbf{5 , 9 4 6 , 0 7 5}$ & $\mathbf{6 , 6 2 1 , 7 0 0}$ & $\mathbf{7 , 2 9 7 , 3 2 5}$ & $\mathbf{7 , 9 7 3 , 2 3 8}$ & $\mathbf{8 , 6 4 8 , 5 7 5}$ & $\mathbf{9 , 3 2 4 , 4 8 8}$ & $10,000,113$ & $10,675,738$ \\
\hline Crédito (S/,) & 918,965 & $\mathbf{1 , 0 5 4 , 0 9 0}$ & $\mathbf{1 , 1 8 9 , 2 1 5}$ & $\mathbf{1 , 3 2 4 , 3 4 0}$ & $\mathbf{1 , 4 5 9 , 4 6 5}$ & $\mathbf{1 , 5 9 4 , 6 4 8}$ & $\mathbf{1 , 7 2 9 , 7 1 5}$ & $\mathbf{1 , 8 6 4 , 8 9 8}$ & $\mathbf{2 , 0 0 0 , 0 2 3}$ & $2,135,148$ \\
\hline Ingresos por ventas (S/.) & $\mathbf{4 , 5 9 4 , 8 2 5}$ & $\mathbf{6 , 1 8 9 , 4 1 5}$ & $\mathbf{7 , 0 0 0 , 1 6 5}$ & $\mathbf{7 , 8 1 0 , 9 1 5}$ & $\mathbf{8 , 6 2 1 , 6 6 5}$ & $\mathbf{9 , 4 3 2 , 7 0 3}$ & $\mathbf{1 0 , 2 4 3 , 2 2 3}$ & $\mathbf{1 1 , 0 5 4 , 2 0 3}$ & $\mathbf{1 1 , 8 6 5 , 0 1 0}$ & $\mathbf{1 4 , 8 1 0 , 9 0 8}$ \\
\hline
\end{tabular}

Elaboración propia.

\subsubsection{Presupuesto operativo de costos}

Para determinar el costo operativo se calculó previamente los costos de materia prima, insumo, mano de obra directa, indirecta y depreciación. En la tabla 7.41 se muestra la suma de todos estos costos

En primer lugar se calcula la depreciación de las maquinas. Para los cálculos se utiliza el método de la depreciación lineal y considerando que las máquinas tienen una vida útil de 5 años debido a que son máquinas de segunda. Se considerara que cada máquina y equipo se adquiere el año anterior a su operación debido a que estos deben de montarse antes de su funcionamiento. 
Tabla 7.40

Depreciación fabril de activos tangibles (S/.)

\begin{tabular}{|c|c|c|c|c|c|c|c|c|c|c|c|c|c|c|c|c|}
\hline Máquinas y equipos & Unidades & $\begin{array}{l}\text { Año } \\
\text { adquisición }\end{array}$ & Costo (S/.) & $\begin{array}{c}\text { Vida } \\
\text { útil } \\
\text { (años) }\end{array}$ & 2016 & 2017 & 2018 & 2019 & 2020 & 2021 & 2022 & 2023 & 2024 & 2025 & $\begin{array}{l}\text { Acumulado } \\
\text { (S/.) }\end{array}$ & $\begin{array}{l}\text { Valor en } \\
\text { libros(S/) }\end{array}$ \\
\hline Alimentador de mezcla & 1 & 2015 & 86,007 & 5 & 17,201 & 17,201 & 17,201 & 17,201 & 17,201 & 8 & 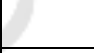 & & & & 86,007 & 0 \\
\hline Mezcladora & 1 & 2015 & 91,741 & 5 & 18,348 & 18,348 & 18,348 & 18,348 & 18,348 & & & & & & 91,741 & 0 \\
\hline Limpiador de mezcla & 3 & 2015 & 14,417 & 5 & 2,883 & 2,883 & 2,883 & 2,883 & 2,883 & & & & & & 14,417 & 0 \\
\hline Abridora & 2 & 2015 & 206,417 & 5 & 41,283 & 41,283 & 41,283 & 41,283 & 41,283 & & & & & & 206,417 & 0 \\
\hline Motor ventilador & 1 & 2015 & 3,795 & 5 & 759 & 759 & 759 & 759 & 759 & & & & 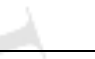 & & 3,795 & 0 \\
\hline Carda & 1 & 2015 & 203,995 & 5 & 40,799 & 40,799 & 40,799 & 40,799 & 40,799 & & & & & & 203,995 & 0 \\
\hline Manuar & 2 & 2015 & 173,670 & 5 & 34,734 & 34,734 & 34,734 & 34,734 & 34,734 & & & - & & & 173,670 & 0 \\
\hline Mechera & 1 & 2015 & 204,160 & 5 & 40,832 & 40,832 & 40,832 & 40,832 & 40,832 & & & & + & & 204,160 & 0 \\
\hline Continua & 3 & 2015 & 607,612 & 5 & 121,522 & 121,522 & 121,522 & 121,522 & 121,522 & & & & & & 607,612 & 0 \\
\hline Adaptación continua & 3 & 2015 & 36,000 & 5 & 7,200 & 7,200 & 7,200 & 7,200 & 7,200 & & & F & $\square$ & & 36,000 & 0 \\
\hline Conera & 1 & 2015 & 74,539 & 5 & 14,908 & 14,908 & 14,908 & 14,908 & 14,908 & & & & 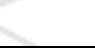 & & 74,539 & 0 \\
\hline Cámara humidificación & 1 & 2015 & 56,925 & 5 & 11,385 & 11,385 & 11,385 & 11,385 & 11,385 & & & n & 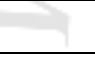 & & 56,925 & 0 \\
\hline Compresor & 1 & 2015 & 5,175 & 5 & 1,035 & 1,035 & 1,035 & 1,035 & 1,035 & & & A & & & 5,175 & 0 \\
\hline Ablandador de agua & 1 & 2015 & 2,415 & 5 & 483 & 483 & 483 & 483 & 483 & & & & . & & 2,415 & 0 \\
\hline $\begin{array}{l}\text { Transformador de media a } \\
\text { baja tensión }\end{array}$ & 1 & 2015 & 3,450 & 5 & 690 & 690 & 690 & 690 & 690 & & & & & & 3,450 & 0 \\
\hline Montacargas & 1 & 2015 & 21,735 & 5 & 4,347 & 4,347 & 4,347 & 4,347 & 4,347 & & & & & & 21,735 & 0 \\
\hline Continua & 1 & 2019 & 206,247 & 5 & & 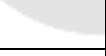 & + & & 41,249 & 41,249 & 41,249 & 41,249 & 41,249 & & 206,247 & 0 \\
\hline Adaptación continua & 1 & 2019 & 12,000 & 5 & & & & & 2,400 & 2,400 & 2,400 & 2,400 & 2,400 & & 12,000 & 0 \\
\hline
\end{tabular}




\begin{tabular}{|c|c|c|c|c|c|c|c|c|c|c|c|c|c|c|c|c|}
\hline Máquinas y equipos & Unidades & $\begin{array}{c}\text { Año } \\
\text { adquisición }\end{array}$ & Costo (S/.) & $\begin{array}{c}\text { Vida } \\
\text { útil } \\
\text { (años) }\end{array}$ & 2016 & 2017 & 2018 & 2019 & 2020 & 2021 & 2022 & 2023 & 2024 & 2025 & $\begin{array}{l}\text { Acumulado } \\
\text { (S/.) }\end{array}$ & $\begin{array}{l}\text { Valor en } \\
\text { libros(S/) }\end{array}$ \\
\hline Continua & 1 & 2022 & 206,247 & 5 & T- & 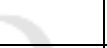 & A & $\mathrm{z}^{2}$ & & & & 41,249 & 41,249 & 41,249 & 123,748 & 82,499 \\
\hline Adaptación continua & 1 & 2022 & 12,000 & 5 & & & 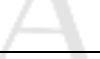 & 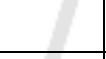 & & & & 2,400 & 2,400 & 2,400 & 7,200 & 4,800 \\
\hline Conera & 1 & 2022 & 74,539 & 5 & & 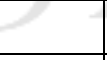 & 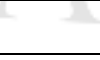 & -2 & 8 & & & 14,908 & 14,908 & 14,908 & 44,724 & 29,816 \\
\hline Nep Tester Uster & 1 & 2015 & 12,075 & 5 & 2,415 & 2,415 & 2,415 & 2,415 & 2,415 & & & & & & 12,075 & 0 \\
\hline $\begin{array}{l}\text { Equipo de regularmetria } \\
\text { Uster }\end{array}$ & 1 & 2015 & 115,920 & 5 & 23,184 & 23,184 & 23,184 & 23,184 & 23,184 & & & & & & 115,920 & 0 \\
\hline Torsiómetro eléctrico Zweigle & 1 & 2015 & 5,175 & 5 & 1,035 & 1,035 & 1,035 & 1,035 & 1,035 & & & $>$ & & & 5,175 & 0 \\
\hline Aspa eléctrico Mesdan & 1 & 2015 & 2,760 & 5 & 552 & 552 & 552 & 552 & 552 & & 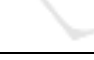 & & & & 2,760 & 0 \\
\hline Balanza electrónica ohaus & 1 & 2015 & 1,725 & 5 & 345 & 345 & 345 & 345 & 345 & & & & & & 1,725 & 0 \\
\hline Dinamómetro Uster & 1 & 2015 & 17,250 & 5 & 3,450 & 3,450 & 3,450 & 3,450 & 3,450 & & & $b$ & & & 17,250 & 0 \\
\hline Total & H & 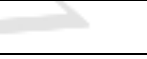 & $2,457,991$ & & 389,392 & 389,392 & 389,392 & 389,392 & 433,041 & 43,649 & 43,649 & 102,207 & 102,207 & 58,557 & $2,340,876$ & 117,114 \\
\hline
\end{tabular}

Elaboración propia.
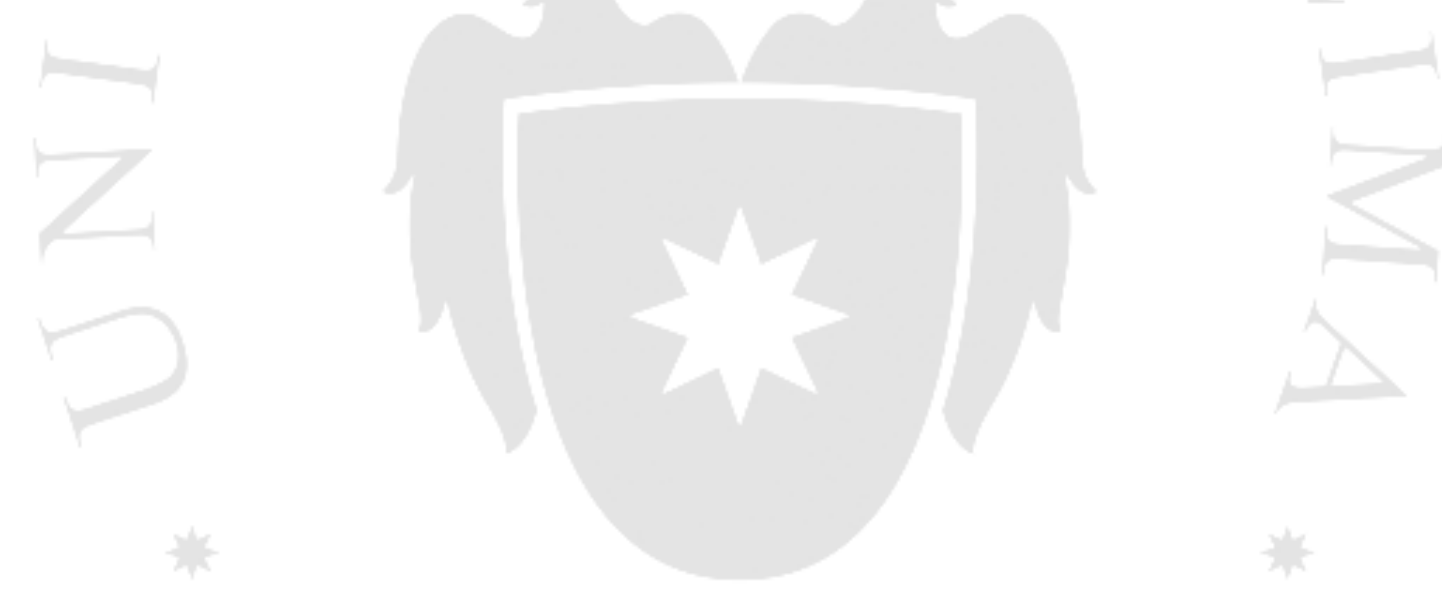
Tabla 7.41

Presupuesto operativo de costos (S/.)

\begin{tabular}{|c|c|c|c|c|c|c|c|c|c|c|}
\hline & 2016 & 2017 & 2018 & 2019 & 2020 & 2021 & 2022 & 2023 & 2024 & 2025 \\
\hline \multicolumn{11}{|l|}{ Costos directos } \\
\hline Mano de obra & 357,830 & 365,740 & 394,743 & 442,729 & 463,649 & 436,439 & 521,553 & 559,384 & 562,020 & 619,710 \\
\hline Materia prima & $2,324,811$ & $2,635,602$ & $2,955,409$ & $3,294,420$ & $3,633,452$ & $3,972,599$ & $4,311,494$ & $4,650,642$ & $4,989,673$ & $5,775,096$ \\
\hline insumos & 8,313 & 5,050 & 12,511 & 6,312 & 6,920 & 7,519 & 8,304 & 8,865 & 9,426 & 10,081 \\
\hline total costos directos & $2,690,953$ & $3,006,392$ & $3,362,662$ & $3,743,462$ & $4,104,021$ & $4,416,556$ & $4,841,350$ & $5,218,891$ & $5,561,120$ & $6,404,886$ \\
\hline \multicolumn{11}{|l|}{ Costos indirectos } \\
\hline Mano de obra indirecta & 393,025 & 393,025 & 393,025 & 393,025 & 393,025 & 393,025 & 393,025 & 393,025 & 393,025 & 393,025 \\
\hline alquiler de planta & 289,800 & 289,800 & 289,800 & 289,800 & 289,800 & 289,800 & 289,800 & 289,800 & 289,800 & 289,800 \\
\hline Análisis de calidad de MP & 15,253 & 15,905 & 17,944 & 19,983 & 22,022 & 24,062 & 26,100 & 28,139 & 30,178 & 32,217 \\
\hline Seguro de la planta & 40,428 & 40,428 & 40,428 & 40,428 & 40,428 & 40,428 & 40,428 & 40,428 & 40,428 & 40,428 \\
\hline Costo transporte materia prima & 22,728 & 23,700 & 26,738 & 29,776 & 32,814 & 35,853 & 38,890 & 41,930 & 44,968 & 48,006 \\
\hline $\begin{array}{l}\text { Costo transporte producto } \\
\text { terminado }\end{array}$ & 26,210 & 30,064 & 33,918 & 37,772 & 41,626 & 45,482 & 49,334 & 53,190 & 57,044 & 60,898 \\
\hline Agua & 4,019 & 4,038 & 4,101 & 4,163 & 4,225 & 4,287 & 4,349 & 4,411 & 4,473 & 4,536 \\
\hline Total costos indirectos & $1,547,149$ & $1,608,643$ & $1,687,680$ & $1,774,336$ & $1,915,871$ & $1,998,932$ & $2,087,796$ & $2,224,925$ & $2,306,474$ & $2,462,497$ \\
\hline \multicolumn{11}{|l|}{ Costos } \\
\hline Total costos & $4,238,102$ & $4,615,034$ & $5,050,342$ & $5,517,797$ & $6,019,892$ & $6,415,488$ & $6,929,147$ & $7,443,816$ & $7,867,594$ & $8,867,383$ \\
\hline
\end{tabular}

Elaboración propia. 


\subsubsection{Presupuesto operativo de gastos administrativos}

Los gastos administrativos están comprendidos por el pago de sueldos de personal administrativo, la depreciación de muebles y enseres de oficina, amortización de intangibles, vigilancia de la planta, seguro, servicio de contabilidad y asuntos legales. Por último, se considerará como gasto administrativo del primer año a la Implementación del Reglamento de Seguridad y Salud en el Trabajo (RSST).

Tabla 7.42

Gasto en personal administrativo (S/.)

\begin{tabular}{|c|c|c|c|c|c|c|c|c|c|c|c|}
\hline \multirow[b]{2}{*}{ Detalle } & \multirow{2}{*}{$\begin{array}{l}\mathrm{N}^{\circ} \text { de } \\
\text { trabajadores }\end{array}$} & \multirow{2}{*}{$\begin{array}{l}\text { Sueldo bruto } \\
\text { mensual }\end{array}$} & \multicolumn{4}{|c|}{ Beneficios laborales } & \multicolumn{4}{|c|}{ Contribuciones sociales } & \multirow[b]{2}{*}{ Total } \\
\hline & & & $\begin{array}{l}\text { Sueldo bruto } \\
\text { anual }\end{array}$ & Gratificación & Vacaciones & $\begin{array}{l}\text { Asignación } \\
\text { Familiar }\end{array}$ & CTS & ESSALUD & SENATI & SCTR & \\
\hline Gerente general & 1 & 4,500 & 49,500 & 9,000 & 4,500 & 75 & 5,250 & 5,670 & 405 & 1,026 & 75,426 \\
\hline Secretaria & 1 & 1,200 & 13,200 & 2,400 & 1,200 & 75 & 1,400 & 1,512 & 108 & 274 & 20,169 \\
\hline Jefe de administración y finanzas & 1 & 3,500 & 38,500 & 7,000 & 3,500 & 75 & 4,083 & 4,410 & 315 & 798 & 58,681 \\
\hline Asistente de administración y finanzas & 1 & 1,500 & 16,500 & 3,000 & 1,500 & 75 & 1,750 & 1,890 & 135 & 342 & 25,192 \\
\hline Jefe comercial & 1 & 3,500 & 38,500 & 7,000 & 3,500 & 75 & 4,083 & 4,410 & 315 & 798 & 58,681 \\
\hline Analista comercial & 2 & 1,500 & 16,500 & 3,000 & 1,500 & 75 & 1,750 & 1,890 & 135 & 342 & 50,384 \\
\hline Jefe de recursos humanos & 1 & 3,000 & 33,000 & 6,000 & 3,000 & 75 & 3,500 & 3,780 & 270 & 684 & 50,309 \\
\hline Asistente de recursos humanos & 1 & 1,300 & 14,300 & 2,600 & 1,300 & 75 & 1,517 & 1,638 & 117 & 296 & 21,843 \\
\hline $\begin{array}{l}\text { Jefe de seguridad, salud y medio } \\
\text { ambiente }\end{array}$ & 1 & 3,000 & 33,000 & 6,000 & 3,000 & 75 & 3,500 & 3,780 & 270 & 684 & 50,309 \\
\hline $\begin{array}{l}\text { Asistente de seguridad, salud y medio } \\
\text { ambiente }\end{array}$ & 1 & 1,300 & 14,300 & 2,600 & 1,300 & 75 & 1,517 & 1,638 & 117 & 296 & 21,843 \\
\hline Total & & & & & & & & & & & 432,837 \\
\hline
\end{tabular}

Elaboración propia. 
Tabla 7.43

Depreciación no fabril de activos tangibles (S/.)

\begin{tabular}{|c|c|c|c|c|c|c|c|c|c|c|c|c|c|c|}
\hline Concepto & Total (S/.) & $\begin{array}{l}\text { Vida util } \\
\text { (años) }\end{array}$ & 2016 & 2017 & 2018 & 2019 & 2020 & 2021 & 2022 & 2023 & 2024 & 2025 & Acumulado (S/.) & $\begin{array}{l}\text { Valor en libros } \\
\text { (S/.) }\end{array}$ \\
\hline Comunicación e informática & 25,182 & 3 & 8,394 & 8,394 & 8,394 & 0 & 0 & 0 & 0 & 0 & 0 & 0 & 25,182 & 0 \\
\hline Mobiliario y equipamiento & 12,624 & 3 & 4,208 & 4,208 & 4,208 & 0 & 0 & 0 & 0 & 0 & 0 & 0 & 12,624 & 0 \\
\hline Impresora & 1,198 & 3 & 399 & 399 & 399 & 0 & 0 & 0 & 0 & 0 & 0 & 0 & 1,198 & 0 \\
\hline Total & 39,004 & r & 13,001 & 13,001 & 13,001 & 0 & 0 & 0 & 0 & 0 & 0 & 0 & 39,004 & 0 \\
\hline
\end{tabular}

Elaboración propia.

Asimismo, se calcula la amortización de los activos intangibles: el estudio de mercado, ERP, implementación de página web, Microsoft Office y RSST cuya vida útil es de 4 años.

Tabla 7.44

Amortización de activos intangibles (S/.)

\begin{tabular}{|l|c|c|c|c|c|c|c|c|c|c|c|c|c|c|c|}
\hline \multicolumn{1}{|c|}{ Activo fijo intangible } & $\begin{array}{c}\text { Año de } \\
\text { adquisición }\end{array}$ & $\begin{array}{c}\text { Costo } \\
\text { (S/) }\end{array}$ & $\begin{array}{c}\text { Vida } \\
\text { útil } \\
\text { (años) }\end{array}$ & 2016 & 2017 & 2018 & 2019 & 2020 & 2021 & 2022 & 2023 & 2024 & 2025 & $\begin{array}{c}\text { Acumulado } \\
\text { (S/.) }\end{array}$ & $\begin{array}{c}\text { Valor en } \\
\text { libros (S/.) }\end{array}$ \\
\hline Estudio de mercado & 2015 & 2,000 & 4 & 500 & 500 & 500 & 500 & 0 & 0 & 0 & 0 & 0 & 0 & 2000 & 0 \\
\hline ERP & 2015 & 34,500 & 4 & 8625 & 8625 & 8625 & 8625 & 0 & 0 & 0 & 0 & 0 & 0 & 34500 & 0 \\
\hline Página web & 2015 & 8,280 & 4 & 2070 & 2070 & 2070 & 2070 & 0 & 0 & 0 & 0 & 0 & 0 & 8280 & 0 \\
\hline Microsoft Office & 2015 & 4,606 & 4 & 1152 & 1152 & 1152 & 1152 & 0 & 0 & 0 & 0 & 0 & 0 & 4606 & 0 \\
\hline & & 49,386 & & 12,347 & 12,347 & $\mathbf{1 2 , 3 4 7}$ & $\mathbf{1 2 , 3 4 7}$ & $\mathbf{0}$ & $\mathbf{0}$ & $\mathbf{0}$ & $\mathbf{0}$ & $\mathbf{0}$ & $\mathbf{0}$ & $\mathbf{4 9 3 8 6}$ & $\mathbf{0}$ \\
\hline
\end{tabular}

Elaboración propia. 


\section{Implementación del Reglamento de Seguridad y Salud en el Trabajo (RSST)}

El aseguramiento de la seguridad y salud de los trabajadores; es de vital importancia para la planta; ya que se desea evitar que sucedan accidentes laborales debido a que estos afectan a la integridad de los trabajadores y a la operatividad de la planta. Por ello se contratará los servicios de una empresa que realizara capacitaciones a los trabajadores se realizaran durante 4 meses con una frecuencia de 2 veces por semana. Este gasto es de 10,350 soles y sólo se realizará el primer año

\section{Vigilancia}

El servicio de vigilancia externa se brindará en dos turnos de 01 persona por turno, cada uno debe realizar un trabajo de 12 horas al día, este trabajo específico va a ser tercerizado a una empresa especialista en este rubro.

En el pago mensual que se realice a esta empresa está incluido el pago de todos los beneficios laborales de los trabajadores que ocupen el puesto. El costo mensual del servicio es de $\mathrm{S} / 5,500.00$ mensuales más IGV.

\section{Seguro del área administrativa}

Se contará con seguro multiriesgo, seguro contra robo y el seguro de responsabilidad civil, de acuerdo a lo calculado en la sección 7.2.2 el costo de asegurar el área administrativa es de 5,150 soles

\section{Servicios de contabilidad}

El servicio de contabilidad será entregado a una empresa externa, la cual estará a cargo de todos los aspectos referente a la contabilidad de la empresa. El costo mensual del servicio es de $\mathrm{S} / 3,500.00$ mensuales más IGV.

\section{Asuntos legales}

Se contratará lo servicios de una empresa en consultoría legal con el fin de obtener asesoramiento en las inspecciones del ministerio del trabajo, asesoría legal, consultas para elaboración del contrato, asesorías en la compra de activos. El gasto de este servicio es de 3450 soles mensuales. 


\section{Gastos de venta y distribución}

\section{$\underline{\text { Gastos de venta }}$}

Son los gastos para obtener y asegurar órdenes de pedido. Los gastos en los que se va a incurrir son propaganda y publicidad mediante avisos en revistas y páginas web del sector textil; y creación de una página web para la empresa y Facebook. Por último se participará en ferias textiles.

Se participará una vez al año en expo textil mediante el alquiler de un stand en el cual se exhibirá y dará a conocer a potenciales clientes todas las bondades del hilo de algodón nativo de color. El costo de un stand de $6 \mathrm{~m}^{2}$ es de 1,600 dólares más IGV.

Asimismo, la empresa tendrá una página web mediante la cual se ofrecerán los productos a potenciales clientes así como servirá para comunicarse con ellos. El costo de implementación de esta página se considerará como una inversión intangible; sin embargo, el costo del dominio es de 550 soles anuales y se implementarán 8 correos cuyo costo es de 200 dólares anuales.

\section{$\underline{\text { Gastos de distribución }}$}

Son los gastos que se incurren desde el momento que el producto terminado (bolsa de 12 conos) está listo en el almacén para ser llevado hacia la fábrica de los clientes.

\section{Transporte de Producto terminado}

Se tercerizará el transporte del producto terminado mediante una empresa que tiene camiones con capacidad de carga de 2 toneladas y cuyo costo de transporte es de 328 soles (sin IGV); por lo tanto, el costo de transporte por tonelada es de 164 soles. Este dato fue provisto por personal administrativo de la planta Atlantic. 


\section{Tabla 7.45}

Costo del transporte de producto terminado

\begin{tabular}{|l|c|c|c|c|c|c|c|c|c|c|}
\hline & 2016 & 2017 & 2018 & 2019 & 2020 & 2021 & 2022 & 2023 & 2024 & 2025 \\
\hline Hilo demandado $(\mathrm{kg})$ & 159,820 & 183,320 & 206,820 & 230,320 & 253,820 & 277,330 & 300,820 & 324,330 & 347,830 & 371,330 \\
\hline $\begin{array}{l}\text { Costo transporte } \\
\text { (S/.) }\end{array}$ & $\mathbf{2 6 , 2 1 0}$ & $\mathbf{3 0 , 0 6 4}$ & $\mathbf{3 3 , 9 1 8}$ & $\mathbf{3 7 , 7 7 2}$ & $\mathbf{4 1 , 6 2 6}$ & $\mathbf{4 5 , 4 8 2}$ & $\mathbf{4 9 , 3 3 4}$ & $\mathbf{5 3 , 1 9 0}$ & $\mathbf{5 7 , 0 4 4}$ & $\mathbf{6 0 , 8 9 8}$ \\
\hline
\end{tabular}

Elaboración propia.

Tabla 7.46

Presupuesto gastos administrativos

\begin{tabular}{|c|c|c|c|c|c|c|c|c|c|c|}
\hline & 2016 & 2017 & 2018 & 2019 & 2020 & 2021 & 2022 & 2023 & 2024 & 2025 \\
\hline \multicolumn{11}{|l|}{$\begin{array}{l}\text { Gastos } \\
\text { administrativos }\end{array}$} \\
\hline Sueldos & 432,837 & 432,837 & 432,837 & 432,837 & 432,837 & 432,837 & 432,837 & 432,837 & 432,837 & 432,837 \\
\hline RSST & 10,350 & & & & & & & & & \\
\hline Vigilancia & 66,000 & 66,000 & 66,000 & 66,000 & 66,000 & 66,000 & 66,000 & 66,000 & 66,000 & 66,000 \\
\hline Seguro & 5,150 & 5,150 & 5,150 & 5,150 & 5,150 & 5,150 & 5,150 & 5,150 & 5,150 & 5,150 \\
\hline Contabilidad & 42,000 & 42,000 & 42,000 & 42,000 & 42,000 & 42,000 & 42,000 & 42,000 & 42,000 & 42,000 \\
\hline Asesoría legal & 3,450 & 3,450 & 3,450 & 3,450 & 3,450 & 3,450 & 3,450 & 3,450 & 3,450 & 3,450 \\
\hline $\begin{array}{l}\text { Total Gasto } \\
\text { administrativo }\end{array}$ & 559,788 & 549,438 & 549,438 & 549,438 & 549,438 & 549,438 & 549,438 & 549,438 & 549,438 & 549,438 \\
\hline $\begin{array}{l}\text { Gastos de venta y } \\
\text { distribución }\end{array}$ & & & & & & & & 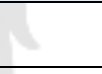 & & \\
\hline Página web & 1,190 & 1,190 & 1,190 & 1,190 & 1,190 & 1,190 & 1,190 & 1,190 & 1,190 & 1,190 \\
\hline $\begin{array}{l}\text { Participación en } \\
\text { ferias textiles }\end{array}$ & 5,520 & 5,520 & 5,520 & 5,520 & 5,520 & 5,520 & 5,520 & 5,520 & 5,520 & 5,520 \\
\hline Distribución & 26,210 & 30,064 & 33,918 & 37,772 & 41,626 & 45,482 & 49,334 & 53,190 & 57,044 & 60,898 \\
\hline $\begin{array}{l}\text { Total Gasto venta y } \\
\text { distribución }\end{array}$ & 32,920 & 36,774 & 40,628 & 44,482 & 48,336 & 52,192 & 56,044 & 59,900 & 63,754 & 67,608 \\
\hline Total Gastos & 592,708 & 586,212 & 590,066 & 593,920 & 597,774 & 601,630 & 605,482 & 609,338 & 613,192 & 617,046 \\
\hline
\end{tabular}

Elaboración propia. 


\section{Determinar costo fijo, costo variable y costo variable unitario}

Con los datos previamente calculados se procederá a calcular los costos fijos y variables para poder determinar en el capítulo 4 el punto de equilibro.

\section{Costo Fijo}

Tabla 7.47

Costo fijo (S/.)

\begin{tabular}{|c|c|c|c|c|c|c|c|c|c|c|}
\hline & 2016 & 2017 & 2018 & 2019 & 2020 & 2021 & 2022 & 2023 & 2024 & 2025 \\
\hline Costos & \multicolumn{10}{|c|}{ 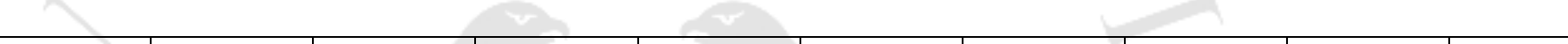 } \\
\hline Mano de obra indirecta & 393,025 & 393,025 & 393,025 & 393,025 & 393,025 & 393,025 & 393,025 & 393,025 & 393,025 & 393,025 \\
\hline alquiler de planta & 289,800 & 289,800 & 289,800 & 289,800 & 289,800 & 289,800 & 289,800 & 289,800 & 289,800 & 289,800 \\
\hline Seguro de la planta & 40,428 & 40,428 & 40,428 & 40,428 & 40,428 & 40,428 & 40,428 & 40,428 & 40,428 & 40,428 \\
\hline Agua & 4,019 & 4,038 & 4,101 & 4,163 & 4,225 & 4,287 & 4,349 & 4,411 & 4,473 & 4,536 \\
\hline Gastos & \multicolumn{5}{|l|}{$\square$} & \multicolumn{5}{|c|}{ 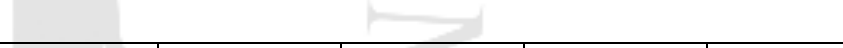 } \\
\hline Sueldos & 432,837 & 432,837 & 432,837 & 432,837 & 432,837 & 432,837 & 432,837 & 432,837 & 432,837 & 432,837 \\
\hline Vigilancia & 66,000 & 66,000 & 66,000 & 66,000 & 66,000 & 66,000 & 66,000 & 66,000 & 66,000 & 66,000 \\
\hline Seguro & 5,150 & 5,150 & 5,150 & 5,150 & 5,150 & 5,150 & 5,150 & 5,150 & 5,150 & 5,150 \\
\hline Contabilidad & 42,000 & 42,000 & 42,000 & 42,000 & 42,000 & 42,000 & 42,000 & 42,000 & 42,000 & 42,000 \\
\hline Asesoría legal & 3,450 & 3,450 & 3,450 & 3,450 & 3,450 & 3,450 & 3,450 & 3,450 & 3,450 & 3,450 \\
\hline Página web & 1,190 & 1,190 & 1,190 & 1,190 & 1,190 & 1,190 & 1,190 & 1,190 & 1,190 & 1,190 \\
\hline Participación en ferias textiles & 5,520 & 5,520 & 5,520 & 5,520 & 5,520 & 5,520 & 5,520 & 5,520 & 5,520 & 5,520 \\
\hline \multicolumn{11}{|l|}{ Depreciación y amortización } \\
\hline Depreciación Fabril & 389,392 & 389,392 & 389,392 & 389,392 & 433,041 & 43,649 & 43,649 & 102,207 & 102,207 & 58,557 \\
\hline Depreciación no fabril & 13,001 & 13,001 & 13,001 & 0 & 0 & 0 & 0 & 0 & 0 & 0 \\
\hline Amortización & 12,347 & 12,347 & 12,347 & 12,347 & 0 & 0 & 0 & 0 & 0 & 0 \\
\hline Total & $1,698,159$ & $1,698,179$ & $1,698,241$ & $1,685,302$ & $1,716,667$ & $1,327,337$ & $1,327,399$ & $1,386,019$ & $1,386,081$ & $1,342,494$ \\
\hline
\end{tabular}

Elaboración propia. 


\section{Costo Variable}

Tabla 7.48

Costo Variable (S/.)

\begin{tabular}{|c|c|c|c|c|c|c|c|c|c|c|}
\hline & 2016 & 2017 & 2018 & 2019 & 2020 & 2021 & 2022 & 2023 & 2024 & 2025 \\
\hline \multicolumn{11}{|l|}{ Costos } \\
\hline Mano de obra & 357,830 & 365,740 & 394,743 & 442,729 & 463,649 & 436,439 & 521,553 & 559,384 & 562,020 & 619,710 \\
\hline Materia prima & $2,324,811$ & $2,635,602$ & $2,955,409$ & $3,294,420$ & $3,633,452$ & $3,972,599$ & $4,311,494$ & $4,650,642$ & $4,989,673$ & $5,775,096$ \\
\hline insumos & 8,313 & 5,050 & 12,511 & 6,312 & 6,920 & 7,519 & 8,304 & 8,865 & 9,426 & 10,081 \\
\hline Lubricantes y repuestos & 371,970 & 421,696 & 472,865 & 527,107 & 581,352 & 635,616 & 689,839 & 744,103 & 798,348 & 924,015 \\
\hline Análisis de calidad de MP & 15,253 & 15,905 & 17,944 & 19,983 & 22,022 & 24,062 & 26,100 & 28,139 & 30,178 & 32,217 \\
\hline Costo transporte materia prima & 22,728 & 23,700 & 26,738 & 29,776 & 32,814 & 35,853 & 38,890 & 41,930 & 44,968 & 48,006 \\
\hline Costo transporte producto terminado & 26,210 & 30,064 & 33,918 & 37,772 & 41,626 & 45,482 & 49,334 & 53,190 & 57,044 & 60,898 \\
\hline Electricidad & 383,717 & 389,985 & 408,860 & 432,281 & 510,579 & 530,379 & 556,031 & 629,899 & 648,210 & 669,572 \\
\hline Gastos & \multicolumn{10}{|l|}{2} \\
\hline Distribución & 26,210 & 30,064 & 33,918 & 37,772 & 41,626 & 45,482 & 49,334 & 53,190 & 57,044 & 60,898 \\
\hline Total & $3,537,041$ & $3,917,807$ & $4,356,907$ & $4,828,154$ & $5,334,040$ & $5,733,430$ & $6,250,879$ & $6,769,342$ & $7,196,911$ & $8,200,493$ \\
\hline
\end{tabular}

Elaboración propia.

Tabla 7.49

Costo Variable unitario (S/.)

\begin{tabular}{|c|c|c|c|c|c|c|c|c|c|c|}
\hline & 2016 & 2017 & 2018 & 2019 & 2020 & 2021 & 2022 & 2023 & 2024 & 2025 \\
\hline Costo Variable (S/.) & $3,537,041$ & $3,917,807$ & $4,356,907$ & $4,828,154$ & $5,334,040$ & $5,733,430$ & $6,250,879$ & $6,769,342$ & $7,196,911$ & $8,200,493$ \\
\hline Producción (Kg) & 179,546 & 186,452 & 207,169 & 233,065 & 255,508 & 277,606 & 306,610 & 327,327 & 348,044 & 372,213 \\
\hline Costo variable unitario $(\mathrm{S} / . / \mathrm{kg})$ & 19.7 & 21.0 & 21.0 & 20.7 & 20.9 & 20.7 & 20.4 & 20.7 & 20.7 & 22.0 \\
\hline
\end{tabular}

Elaboración propia. 


\subsection{Flujo de fondos netos}

\subsubsection{Flujo de fondos económicos}

Tabla 7.50

Flujo de fondos económicos (S/.)

\begin{tabular}{|c|c|c|c|c|c|c|c|c|c|c|c|}
\hline & 2015 & 2016 & 2017 & 2018 & 2019 & 2020 & 2021 & 2022 & 2023 & 2024 & 2025 \\
\hline Ingresos & A & $4,594,825$ & $6,189,415$ & $7,000,165$ & $7,810,915$ & $8,621,665$ & $9,432,703$ & $10,243,223$ & $11,054,203$ & $11,865,010$ & $14,810,908$ \\
\hline Costos & & $4,238,102$ & $4,615,034$ & $5,050,342$ & $5,517,797$ & $6,019,892$ & $6,415,488$ & $6,929,147$ & $7,443,816$ & $7,867,594$ & $8,867,383$ \\
\hline Depreciación fabril & & 389,392 & 389,392 & 389,392 & 389,392 & 433,041 & 43,649 & 43,649 & 102,207 & 102,207 & 58,557 \\
\hline Utilidad bruta & & $-32,668$ & $1,184,989$ & $1,560,432$ & $1,903,726$ & $2,168,732$ & $2,973,565$ & $3,270,426$ & $3,508,180$ & $3,895,210$ & $5,884,967$ \\
\hline Gastos & & 592,708 & 586,212 & 590,066 & 593,920 & 597,774 & 601,630 & 605,482 & 609,338 & 613,192 & 617,046 \\
\hline Depreciación no fabril & 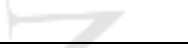 & 13,001 & 13,001 & 13,001 & 0 & 0 & 0 & 0 & 0 & 0 & 0 \\
\hline Amortización & & 12,347 & 12,347 & 12,347 & 12,347 & 0 & 0 & 0 & 0 & 0 & 0 \\
\hline Utilidad antes de impuestos & & $-650,725$ & 573,429 & 945,018 & $1,297,460$ & $1,570,958$ & $2,371,935$ & $2,664,944$ & $2,898,842$ & $3,282,018$ & $5,267,921$ \\
\hline Impuestos & & 0 & $-21,643$ & 264,605 & 363,289 & 439,868 & 664,142 & 746,184 & 811,676 & 918,965 & $1,475,018$ \\
\hline Utilidad después de impuestos & 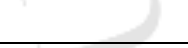 & $-650,725$ & 595,072 & 680,413 & 934,171 & $1,131,090$ & $1,707,793$ & $1,918,760$ & $2,087,166$ & $2,363,053$ & $3,792,903$ \\
\hline Depreciación fabril & & 389,392 & 389,392 & 389,392 & 389,392 & 433,041 & 43,649 & 43,649 & 102,207 & 102,207 & 58,557 \\
\hline Depreciación no fabril & & 13,001 & 13,001 & 13,001 & 0 & 0 & 0 & 0 & 0 & 0 & 0 \\
\hline Amortización & 34 & 12,347 & 12,347 & 12,347 & 12,347 & 0 & 0 & 0 & 0 & 0 & 0 \\
\hline Valor en libros & & & & & & & & & & & 117,114 \\
\hline Flujo de fondos operativos & & $-235,985$ & $1,009,811$ & $1,095,152$ & $1,335,909$ & $1,564,131$ & $1,751,443$ & $1,962,409$ & $2,189,373$ & $2,465,260$ & $3,968,575$ \\
\hline Inversiones & $-2,465,625$ & & & & & & +1 & & & & \\
\hline Recuperación capital de trabajo & & & & & & & 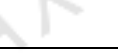 & & & & 429,405 \\
\hline Flujo de Caja Económico & $-2,465,625$ & $-235,985$ & $1,009,811$ & $1,095,152$ & $1,335,909$ & $1,564,131$ & $1,751,443$ & $1,962,409$ & $2,189,373$ & $2,465,260$ & $4,397,980$ \\
\hline
\end{tabular}

Elaboración propia. 


\subsubsection{Flujo de fondos financiero}

El financiamiento se hará por medio de bancos entre los cuales elegirá entre BCP, BBVA y Scotiabank por ser de primer orden. Los préstamos comerciales se encuentran dentro del segmento de la Banca de Negocios, Banca Empresa y banca Corporativa. En la mayoría de bancos se financia una oportunidad de negocio considerando los flujos actuales de la empresa, esto quiere decir, que la cuota del crédito a solicitar debe de estar cubierto con las utilidades presentes; no se consideran los ingresos proyectados por realización del proyecto. Los porcentajes de financiación van a depender de muchos factores, tales como: experiencia de la empresa, viabilidad del proyecto, tiempo de retorno de la inversión, , tiempo de duración de la deuda (a mayor plazo, mayor riesgo). Se maneja el concepto riesgo compartido; ya que, algunos bancos no van a financiar el 100\% de la inversión; por el contrario exigen al cliente un aporte que puede variar. Por otro lado, hay bancos que son mucho más agresivos comercialmente y financian hasta el $100 \%$ del total de la inversión, pero todo dependerá de los factores antes mencionados, teniendo como principal punto el plazo del crédito. Existen dos productos convenientes para la financiación del activo: préstamo comercial de mediano plazo y préstamos a través de un leasing de importación y leasing (activos extranjeros) y leasing (activos nacionales).

\section{Alternativa 1: Préstamo comercial}

En este caso el banco requiere una garantía hipotecaria (local, terreno, vivienda de los dueños) que cobertura en al menos el 120\% del monto del crédito, el plazo máximo es de 96 meses y de forma exponencial 120 meses. Una vez aprobado el crédito, el banco desembolsa al cliente y este con el dinero en su cuenta corriente compra el activo. La ventaja es que el activo está a nombre del cliente.

\section{Alternativa 2: Leasing}

En este caso, el cliente para gozar de los beneficios tributarios, tiene que encontrarse en el Régimen General de la Tercera Categoría en SUNAT, puesto que el crédito fiscal y la depreciación acelerada al que se acoge impactan positivamente en el impuesto a la renta que se realiza de forma anual. Adicional a los beneficios tributarios, la ventaja del leasing es que el banco es quien adquiere el activo y lo alquila al cliente, dándole a éste la posibilidad de compra del activo, al finalizar el 
crédito. En ese momento el cliente opta por comprarlo o no; en algunos casos el cliente opta por no comprar y prefiere que el banco le financie un nuevo activo.

En el caso de Leasing de Importación el cliente necesita lo siguiente:

Valor del bien indicando Incoterm (CIF, FOB, Ex work) y forma de pago y condiciones (carta de crédito, transferencia al exterior o mixto)

Proforma del bien

Indicar número aproximado de embarques, así como la fecha aproximada de entrega

Seguro de transporte internacional en el caso el incoterm no sea CIF o CIP

\section{Forma de financiamiento escogida: Leasing}

Se optará por la alternativa de Leasing debido a que para poder obtener un préstamo comercial se debe contar con una hipoteca cuyo valor es el $120 \%$ del préstamo lo cual no se tiene, en cambio con el leasing las maquinarias son las que respaldan el préstamo; ya que, el banco es su dueño. Asimismo por medio de la depreciación acelerada se puede obtener un mejor flujo de caja financiero los primeros años. Por último, la tasa de interés del BCP en leasing es de $7.5 \%$ la cual resulta muy conveniente al ser mucho menor que el costo de oportunidad del inversionista que es de $11.56 \%$.

Se utilizará un Leasing de importación y el costo de los activos nacionales lo asumirán los inversionistas de la planta hilandera de algodón nativo de color. La modalidad de pago será en cuotas constantes con periodo de gracia total de un año.

\section{Inversión activos importados}

En este caso se calculará el valor presente de las maquinarias de hilatura importada considerando un costo de oportunidad del inversionista del $11.56 \%$. 


\section{Tabla 7.51}

Costo de activos importados

\begin{tabular}{|l|l|l|l|}
\hline & 2015 & 2019 & 2022 \\
\hline Máquinas & $1,770,318$ & 218,247 & 292,786 \\
\hline
\end{tabular}

Elaboración propia.

Por lo tanto, el valor presente de los activos importados asciende a 2, 201,202 soles.

\section{Inversión activos nacionales}

Dentro de los activos tangibles e intangibles nacionales se encuentran, maquinarias, equipos de calidad, activos no fabriles e intangibles como estudio de mercado, ERP, softwares de tecnología de la información, licencia municipal y notaria.

Tabla 7.52

Costo de activos nacionales

\begin{tabular}{|l|c|}
\hline & 2015 \\
\hline Maquinaria & 56,925 \\
\hline Equipos & 11,040 \\
\hline Equipos calidad & 142,830 \\
\hline activos no & \\
fabriles & 39,004 \\
\hline Intangibles & 50,278 \\
\hline Total & 300,077 \\
\hline
\end{tabular}

Elaboración propia.

\section{Tasa de interés}

De acuerdo a la página web de la SBS (Superintendencia de banca, seguros y AFP) para medianas empresa cuyo préstamo es mayor a 360 días, la tasa de interés promedio anual es de $10.72 \%$ 
Tabla 7.53

Tasa de interés anual para préstamos a medianas empresas por periodos mayores a 360 días

\begin{tabular}{|l|c|c|c|c|c|c|c|c|}
\hline & Continental & BCP & Financiero & BIF & Scotiabank & Interbank & Santander & Promedio \\
\hline $\begin{array}{l}\text { Tasa de } \\
\text { interés Anual }\end{array}$ & $10.06 \%$ & $9.31 \%$ & $13.18 \%$ & $10.43 \%$ & $9.32 \%$ & $11.77 \%$ & $10.99 \%$ & $\mathbf{1 0 . 7 2 \%}$ \\
\hline
\end{tabular}

Fuentes: SBS, (2016)

Como se calculó previamente el monto del crédito mediante Leasing asciende a 2, 201,202 soles, la depreciación acelerada según ley es de 2 años según La Ley de Arrendamiento Financiero aprobada por el Decreto Legislativo $\mathrm{N}^{\circ} 299$. Además, la tasa de interés es de $10.72 \%$ anual en cuotas anuales durante 5 años con un año de periodo de gracia parcial. Al finalizar el leasing se optará por comprar los activos a un valor equivalente al 1\% del crédito.

\section{Tabla 7.54}

Servicio a la Deuda

\begin{tabular}{|c|r|r|r|c|}
\hline año & principal & amortización & interés & cuota \\
\hline 0 & $2,201,202$ & & & \\
\hline 1 & $2,201,202$ & & 235,969 & 235,969 \\
\hline 2 & $2,201,202$ & 469,299 & 235,969 & 705,268 \\
\hline 3 & $1,731,902$ & 519,608 & 185,660 & 705,268 \\
\hline 4 & $1,212,294$ & 575,310 & 129,958 & 705,268 \\
\hline 5 & 636,984 & 636,984 & 68,285 & 705,268 \\
\hline
\end{tabular}

Elaboración propia.

\section{Adquisición de los activos luego del leasing}

Luego del periodo del Leasing se optará por adquirir los activos a un valor equivalente al $1 \%$ de su costo. Luego se calculará el valor presente con el costo de oportunidad del inversionista equivalente a $11.56 \%$ 


\section{Tabla 7.55}

Compra del bien luego del Leasing

\begin{tabular}{|l|c|c|c|c|c|c|c|}
\hline & 2015 & 2016 & 2017 & 2018 & 2019 & 2020 & 2021 \\
\hline & & & & & & & 22,012 \\
\hline Valor presente & 19,731 & & & & & & \\
\hline
\end{tabular}

Elaboración propia.

\section{Depreciación acerada (activos importados)}

Tabla 7.56

Depreciación activos importados (S/.)

\begin{tabular}{|c|c|c|}
\hline Activos importados & 2016 & 2017 \\
\hline $2,201,202$ & $1,100,601$ & $1,100,601$ \\
\hline
\end{tabular}

Elaboración propia.

\section{Depreciación Lineal (activos nacionales)}

Tabla 7.57

Depreciación activos fabriles nacionales (S/.)

\begin{tabular}{|l|c|c|r|r|r|r|r|r|c|}
\hline & Inversión & $\begin{array}{c}\text { Año } \\
\text { adquisición }\end{array}$ & 2016 & 2017 & 2018 & 2019 & 2020 & $\begin{array}{c}\text { Acumulado } \\
\text { Valor en } \\
\text { libros }\end{array}$ \\
\hline Maquinaria & 56,925 & 2015 & 11,385 & 11,385 & 11,385 & 11,385 & 11,385 & 56,925 & 0 \\
\hline Equipos & 11,040 & 2015 & 2,208 & 2,208 & 2,208 & 2,208 & 2,208 & 11,040 & 0 \\
\hline Total & & & 13,593 & 13,593 & 13,593 & 13,593 & 13,593 & & \\
\hline
\end{tabular}

Elaboración propia. 
Tabla 7.58

Flujo de caja financiero

\begin{tabular}{|c|c|c|c|c|c|c|c|c|c|c|c|}
\hline & 2015 & 2016 & 2017 & 2018 & 2019 & 2020 & 2021 & 2022 & 2023 & 2024 & 2025 \\
\hline Ingresos & & $4,594,825$ & $6,189,415$ & $7,000,165$ & $7,810,915$ & $8,621,665$ & $9,432,703$ & \#\#\#\#\#\#\#\# & $11,054,203$ & $11,865,010$ & $14,810,908$ \\
\hline Costos & & $4,238,102$ & $4,615,034$ & $5,050,342$ & $5,517,797$ & $6,019,892$ & $6,415,488$ & $6,929,147$ & $7,443,816$ & $7,867,594$ & $8,867,383$ \\
\hline Depreciación fabril importaciones & & $1,100,601$ & $1,100,601$ & & & & - & & & & \\
\hline Depreciación fabril nacional & & 13,593 & 13,593 & 13,593 & 13,593 & 13,593 & & 2 & & & \\
\hline Utilidad Bruta & & $-757,471$ & 460,187 & $1,936,230$ & $2,279,525$ & $2,588,180$ & $3,017,214$ & $3,314,076$ & $3,610,386$ & $3,997,416$ & $5,943,524$ \\
\hline Gastos & & 592,708 & 586,212 & 590,066 & 593,920 & 597,774 & 601,630 & 605,482 & 609,338 & 613,192 & 617,046 \\
\hline Depreciación no fabril & & 13,001 & 13,001 & 13,001 & 0 & 0 & 0 & 0 & 0 & 0 & 0 \\
\hline Amortización & & 12,347 & 12,347 & 12,347 & 12,347 & 0 & 0 & 0 & 0 & 0 & 0 \\
\hline Gastos financieros & & 235,969 & 235,969 & 185,660 & 129,958 & 68,285 & 0 & 0 & 0 & 0 & 0 \\
\hline Utilidad antes de impuestos & & $-1,611,496$ & $-387,342$ & $1,135,156$ & $1,543,300$ & $1,922,121$ & $2,415,585$ & $2,708,594$ & $3,001,048$ & $3,384,225$ & $5,326,478$ \\
\hline Impuestos & & 0 & 0 & 0 & 190,293 & 538,194 & 676,364 & 758,406 & 840,294 & 947,583 & $1,491,414$ \\
\hline Utilidad después de impuestos & & $-1,611,496$ & $-387,342$ & $1,135,156$ & $1,353,007$ & $1,383,927$ & $1,739,221$ & $1,950,187$ & $2,160,755$ & $2,436,642$ & $3,835,064$ \\
\hline Depreciación fabril importaciones & & $1,100,601$ & $1,100,601$ & 0 & 0 & 0 & 0 & 0 & _ & 0 & 0 \\
\hline Depreciación fabril nacional & & 13,593 & 13,593 & 13,593 & 13,593 & 13,593 & 0 & 0 & 0 & 0 & 0 \\
\hline Depreciación no fabril & & 13,001 & 13,001 & 13,001 & 0 & 0 & 0 & 0 & 0 & 0 & 0 \\
\hline Amortización & (5) & 12,347 & 12,347 & 12,347 & 12,347 & 0 & 0 & 0 & 0 & 0 & 0 \\
\hline Valor en libros & & & & & & f & & & & & 0 \\
\hline Flujo de fondos operativos & & $-471,954$ & 752,200 & $1,174,097$ & $1,378,946$ & $1,397,520$ & $1,739,221$ & $1,950,187$ & $2,160,755$ & $2,436,642$ & $3,835,064$ \\
\hline Inversiones & $-2,501,279$ & & & & & & & 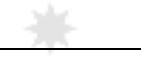 & & & \\
\hline compra activos luego del leasing & $-19,731$ & & & & & & & & & & \\
\hline Recuperación capital de trabajo & & & & & & & & & & & 429,405 \\
\hline Deuda & $2,201,202$ & & & & & & & & & & \\
\hline Amortización & & 0 & 469,299 & 519,608 & 575,310 & 636,984 & & & & & \\
\hline Flujo de caja financiero & $-319,808$ & $-471,954$ & 282,900 & 654,489 & 803,636 & 760,537 & $1,739,221$ & $1,950,187$ & $2,160,755$ & $2,436,642$ & $4,264,470$ \\
\hline
\end{tabular}

Elaboración propia. 


\section{Calculo del WAAC (Costo promedio ponderado de Capital)}

Se procederá a calcular el WAAC de acuerdo a los siguientes datos establecidos:

Deuda financiera: 2, 201,202 soles

Capital aportado por el inversionista: 300,077 soles

Costo de oportunidad del inversionista: $11.56 \%$

Tasa de interés: $10.72 \%$

Impuestos: $28 \%$

$\mathrm{WAAC}=11.56 \% \mathrm{X}(300,077 / 2,501,279)+11.56 \% \mathrm{X}(1-28 \%) \mathrm{X}(2,201,202 / 2,501,279)$

$\mathrm{WAAC}=8.18 \%$ 


\section{CAPÍTULO VIII: EVALUACIÓN ECONÓMICA Y FINANCIERA DEL PROYECTO}

\subsection{Evaluación económica}

Tabla 8.1

Evaluación económica

\begin{tabular}{|l|c|c|c|c|c|c|c|c|c|c|c|}
\hline & 2015 & 2016 & 2017 & 2018 & 2019 & 2020 & 2021 & 2022 & 2023 & 2024 & 2025 \\
\hline Flujo de caja económico (SI.) & $-2,465,625$ & $-235,985$ & $1,009,811$ & $1,095,152$ & $1,335,909$ & $1,564,131$ & $1,751,443$ & $1,962,409$ & $2,189,373$ & $2,465,260$ & $4,397,980$ \\
\hline
\end{tabular}

Elaboración propia.

El costo de oportunidad de los accionistas es de $11.56 \%$

$$
\mathrm{B} / \mathrm{C}=8,283,766 / 2,465,625
$$

VAN 5, 818,141 soles

$$
\mathrm{B} / \mathrm{C}=3.36 \text { soles }
$$

$\mathrm{TIR}=37 \%$

Tabla 8.2

Periodo de recupero flujo de caja económico

\begin{tabular}{|l|c|c|c|c|c|c|}
\hline & \multicolumn{1}{|c|}{2015} & \multicolumn{1}{|c|}{2016} & 2017 & \multicolumn{1}{|c|}{2018} & \multicolumn{1}{|c|}{2019} & 2020 \\
\hline Valor presente & $-2,465,625$ & $-211,532$ & 811,378 & 788,767 & 862,468 & 905,171 \\
\hline Acumulado & $-2,465,625$ & $-2,677,157$ & $-1,865,779$ & $-1,077,012$ & $-214,544$ & 690,627 \\
\hline
\end{tabular}

Elaboración propia 
Tabla 8.3

Interpolación para determinar el periodo de recupero del flujo de caja económico

\begin{tabular}{|c|r|}
\hline 2020 & $-214,544$ \\
\hline$X$ & 0 \\
\hline 2021 & 690,627 \\
\hline
\end{tabular}

Elaboración propia.

$X=2,020.237$. El periodo de recupero es de 4 años con 2 meses y 26 días.

\subsection{Evaluación financiera}

Tabla 8.4

Evaluación financiera

\begin{tabular}{|c|c|c|c|c|c|c|c|c|c|c|c|}
\hline & 2015 & 2016 & 2017 & 2018 & 2019 & 2020 & 2021 & 2022 & 2023 & 2024 & 2025 \\
\hline Flujo de caja financiero & $-319,808$ & $-471,954$ & 282,900 & 654,489 & 803,636 & 760,537 & $1,739,221$ & $1,950,187$ & $2,160,755$ & $2,436,642$ & $4,264,470$ \\
\hline
\end{tabular}

Elaboración propia.

WAAC: $8.18 \%$

$\mathrm{VAN}=7,608,344$ soles

$\mathrm{TIR}=68 \%$

$\mathrm{B} / \mathrm{C}=7,928,152 / 2,521,010$

$\mathrm{B} / \mathrm{C}=3.14$ soles 


\section{Tabla 8.5}

Periodo de recupero flujo de caja financiero

\begin{tabular}{|l|c|c|c|c|c|}
\hline & \multicolumn{1}{|c|}{2015} & \multicolumn{1}{c|}{2016} & \multicolumn{1}{c|}{2017} & \multicolumn{1}{c|}{2018} & \multicolumn{1}{c|}{2019} \\
\hline Valor presente & $-319,808$ & $-423,049$ & 227,309 & 471,386 & 518,830 \\
\hline Acumulado & $-319,808$ & $-742,858$ & $-515,549$ & $-44,163$ & 474,668 \\
\hline
\end{tabular}

Elaboración propia.

Tabla 8.6

\begin{tabular}{|c|r|}
\hline 2019 & $-44,163$ \\
\hline$X$ & 0 \\
\hline 2020 & 474,668 \\
\hline
\end{tabular}

Interpolación para determinar el periodo de recupero del flujo de caja económico Elaboración propia.

$X=2019.09$ El periodo de recupero es de 3 años con 1 mes y 2 días

\subsection{Análisis de los resultados económicos y financieros del proyecto}

\subsubsection{Evaluación económica}

Como el VAN es 5, 818,141 soles el cual es positivo; por lo tanto, es un buen indicio de que es conveniente invertir en este proyecto

Como el TIR es 37\%; por lo tanto, es mayor que el costo de oportunidad de los accionistas $(11.56 \%)$; por lo tanto, es un indicador que es conveniente invertir en el proyecto

El análisis beneficio-costo es 3.36 soles por lo cual por cada sol que se invierta se ganará 2.36 soles por tal motivo conviene invertir en el proyecto.

El periodo de recupero es de 4 años y 2 meses; por lo tanto, es un buen indicador; ya que, se recupera la inversión en un corto tiempo. 


\subsubsection{Evaluación financiera}

Como el VAN es 7, 608,344 soles el cual es positivo; por lo tanto, es un buen indicio de que es conveniente invertir en este proyecto

Como el TIR es $68 \%$ por lo tanto, es mayor que el costo de oportunidad de los accionistas $(11.56 \%)$; por lo tanto, es un indicador que es conveniente invertir en el proyecto

El análisis beneficio-costo es 3.14 soles por lo cual por cada sol que se invierta se ganara 2.14 soles por tal motivo conviene invertir en el proyecto.

El periodo de recupero es de 3 años y un mes; por lo tanto, es un buen indicador; ya que, se recupera la inversión en un corto tiempo.

\subsubsection{Evaluación}

Al evaluar el flujo de caja económico y financiero con sus respectivos indicadores se llega a la conclusión de que conviene la evaluación financiera debido a que el VAN, TIR son más rentables

que la evaluación económica; por lo tanto, conviene pedir un préstamo al banco. Asimismo el periodo de recupero financiero es menor que el periodo de recupero económico lo cual es un indicador de que conviene optar por el flujo financiero.

\subsection{Análisis de sensibilidad del proyecto}

Para poder determinar la rentabilidad del proyecto se debe hacer un análisis de sensibilidad en base a un posible cambio en una variable del proyecto. En el caso de este proyecto se hará este análisis en base al costo de materia prima. 


\section{Caso: El costo del algodón nativo de color aumenta a 20 soles/kg de algodón desmotado.}

Tabla 8.7

Costo de materia prima considerando aumento del costo de algodón nativo a 20 soles $/ / \mathrm{kg}$

\begin{tabular}{|c|c|c|c|c|c|c|c|c|c|c|}
\hline & 2016 & 2017 & 2018 & 2019 & 2020 & 2021 & 2022 & 2023 & 2024 & 2025 \\
\hline \multicolumn{11}{|l|}{ Algodón nativo de color } \\
\hline $\begin{array}{l}\text { Algodón nativo requerido } \\
(\mathrm{kg})\end{array}$ & 126,264 & 131,665 & 148,543 & 165,421 & 182,300 & 199,185 & 216,056 & 232,942 & 249,820 & 266,698 \\
\hline $\begin{array}{l}\text { Pago al crédito último mes } \\
(\mathrm{S} / .)\end{array}$ & & 210,440 & 219,442 & 247,572 & 275,702 & 303,833 & 331,975 & 360,093 & 388,237 & 416,367 \\
\hline Pago anual (S/.) & $2,314,840$ & $2,413,858$ & $2,723,288$ & $3,032,718$ & $3,342,167$ & $3,651,725$ & $3,961,027$ & $4,270,603$ & $4,580,033$ & $4,889,463$ \\
\hline Crédito (S/.) & 210,440 & 219,442 & 247,572 & 275,702 & 303,833 & 331,975 & 360,093 & 388,237 & 416,367 & 444,497 \\
\hline Costo algodón nativo (S/.) & $2,314,840$ & $2,624,298$ & $2,942,730$ & $3,280,290$ & $3,617,868$ & $3,955,558$ & $4,293,002$ & $4,630,697$ & $4,968,270$ & $5,750,327$ \\
\hline \multicolumn{11}{|l|}{ Algodón Tanguis } \\
\hline $\begin{array}{l}\text { Algodón nativo requerido } \\
(\mathrm{kg})\end{array}$ & 74,155 & 77,327 & 87,240 & 97,152 & 107,065 & 116,982 & 126,890 & 136,807 & 146,720 & 156,632 \\
\hline $\begin{array}{l}\text { Pago al crédito último mes } \\
(\mathrm{S} / .)\end{array}$ & & 42,994 & 44,834 & 50,581 & 56,328 & 62,075 & 67,825 & 73,570 & 79,320 & 85,067 \\
\hline Pago anual $(\mathrm{S} /)$. & 472,939 & 493,169 & 556,391 & 619,607 & 682,829 & 746,077 & 809,267 & 872,515 & 935,737 & 998,953 \\
\hline Crédito (S/.) & 42,994 & 44,834 & 50,581 & 56,328 & 62,075 & 67,825 & 73,570 & 79,320 & 85,067 & 90,814 \\
\hline $\begin{array}{l}\text { Costo algodón Tanguis } \\
(\mathrm{S} / .)\end{array}$ & 472,939 & 536,164 & 601,225 & 670,188 & 739,157 & 808,152 & 877,093 & 946,085 & $1,015,057$ & $1,174,834$ \\
\hline Costo materia prima (S/.) & $2,787,779$ & $3,160,462$ & $3,543,955$ & $3,950,478$ & $4,357,026$ & $4,763,711$ & $5,170,094$ & $5,576,782$ & $5,983,327$ & $6,925,161$ \\
\hline
\end{tabular}

Elaboración propia. 
Tabla 8.8

Costo de mantenimiento considerando aumento del costo de algodón nativo a 20 soles//kg

\begin{tabular}{|l|c|c|c|c|c|c|c|c|c|c|}
\hline & 2016 & 2017 & 2018 & 2019 & 2020 & 2021 & 2022 & 2023 & 2024 & 2025 \\
\hline Costo materia prima (S/.) & $2,787,779$ & $3,160,462$ & $3,543,955$ & $3,950,478$ & $4,357,026$ & $4,763,711$ & $5,170,094$ & $5,576,782$ & $5,983,327$ & $6,925,161$ \\
\hline Costo mantenimiento (S/.) & $\mathbf{4 4 6 , 0 4 5}$ & $\mathbf{5 0 5 , 6 7 4}$ & $\mathbf{5 6 7 , 0 3 3}$ & $\mathbf{6 3 2 , 0 7 7}$ & $\mathbf{6 9 7 , 1 2 4}$ & $\mathbf{7 6 2 , 1 9 4}$ & $\mathbf{8 2 7 , 2 1 5}$ & $\mathbf{8 9 2 , 2 8 5}$ & $\mathbf{9 5 7 , 3 3 2}$ & $\mathbf{1 , 1 0 8 , 0 2 6}$ \\
\hline
\end{tabular}
Elaboración propia.

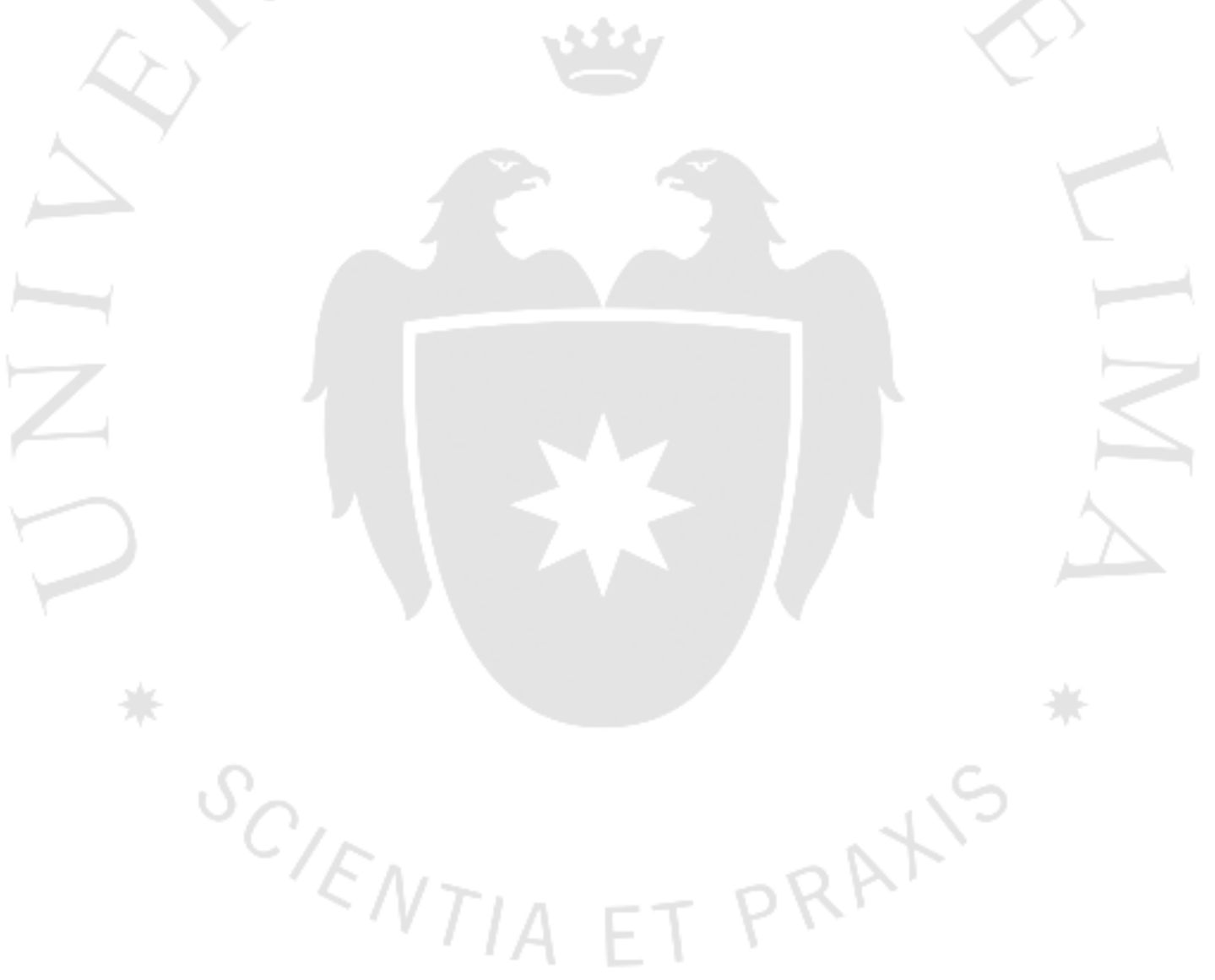


Tabla 8.9

Presupuesto operativo de costos considerando aumento del costo de algodón nativo a 20 soles $/ \mathrm{kg}$

\begin{tabular}{|c|c|c|c|c|c|c|c|c|c|c|}
\hline & 2016 & 2017 & 2018 & 2019 & 2020 & 2021 & 2022 & 2023 & 2024 & 2025 \\
\hline \multicolumn{11}{|l|}{ Costos directos } \\
\hline Mano de obra & 357,830 & 365,740 & 394,743 & 442,729 & 463,649 & 436,439 & 521,553 & 559,384 & 562,020 & 619,710 \\
\hline Materia prima & $2,787,779$ & $3,160,462$ & $3,543,955$ & $3,950,478$ & $4,357,026$ & $4,763,711$ & $5,170,094$ & $5,576,782$ & $5,983,327$ & $6,925,161$ \\
\hline insumos & 8,313 & 5,050 & 12,511 & 6,312 & 6,920 & 7,519 & 8,304 & 8,865 & 9,426 & 10,081 \\
\hline total costos directos & $3,153,921$ & $3,531,251$ & $3,951,208$ & $4,399,520$ & $4,827,594$ & $5,207,668$ & $5,699,951$ & $6,145,031$ & $6,554,774$ & $7,554,952$ \\
\hline \multicolumn{11}{|l|}{ Costos indirectos } \\
\hline Lubricantes y repuestos & 446,045 & 505,674 & 567,033 & 632,077 & 697,124 & 762,194 & 827,215 & 892,285 & 957,332 & $1,108,026$ \\
\hline Mano de obra indirecta & 393,025 & 393,025 & 393,025 & 393,025 & 393,025 & 393,025 & 393,025 & 393,025 & 393,025 & 393,025 \\
\hline alquiler de planta & 289,800 & 289,800 & 289,800 & 289,800 & 289,800 & 289,800 & 289,800 & 289,800 & 289,800 & 289,800 \\
\hline Análisis de calidad de MP & 15,253 & 15,905 & 17,944 & 19,983 & 22,022 & 24,062 & 26,100 & 28,139 & 30,178 & 32,217 \\
\hline Seguro de la planta & 40,428 & 40,428 & 40,428 & 40,428 & 40,428 & 40,428 & 40,428 & 40,428 & 40,428 & 40,428 \\
\hline Costo transporte materia prima & 22,728 & 23,700 & 26,738 & 29,776 & 32,814 & 35,853 & 38,890 & 41,930 & 44,968 & 48,006 \\
\hline Costo transporte producto terminado & 26,210 & 30,064 & 33,918 & 37,772 & 41,626 & 45,482 & 49,334 & 53,190 & 57,044 & 60,898 \\
\hline Electricidad & 383,717 & 389,985 & 408,860 & 432,281 & 510,579 & 530,379 & 556,031 & 629,899 & 648,210 & 669,572 \\
\hline Agua & 4,019 & 4,038 & 4,101 & 4,163 & 4,225 & 4,287 & 4,349 & 4,411 & 4,473 & 4,536 \\
\hline Total costos indirectos & $1,621,224$ & $1,692,620$ & $1,781,847$ & $1,879,305$ & $2,031,643$ & $2,125,510$ & $2,225,173$ & $2,373,107$ & $2,465,459$ & $2,646,507$ \\
\hline \multicolumn{11}{|l|}{ Costos } \\
\hline Total costos & $4,775,145$ & $5,223,871$ & $5,733,055$ & $6,278,824$ & $6,859,237$ & $7,333,178$ & $7,925,123$ & $8,518,138$ & $9,020,232$ & $10,201,459$ \\
\hline
\end{tabular}

Elaboración propia 


\section{Flujo Económico}

\section{$\mathrm{COK}=11.56 \%$}

Tabla 8.10

Calculo Flujo de fondos económico para el análisis de sensibilidad

\begin{tabular}{|c|c|c|c|c|c|c|c|c|c|c|c|}
\hline & 2015 & 2016 & 2017 & 2018 & 2019 & 2020 & 2021 & 2022 & 2023 & 2024 & 2025 \\
\hline Ingresos & $\angle$ & $4,594,825$ & $6,189,415$ & $7,000,165$ & $7,810,915$ & $8,621,665$ & $9,432,703$ & $10,243,223$ & $11,054,203$ & $11,865,010$ & $14,810,908$ \\
\hline Costos & & $4,775,145$ & $5,223,871$ & $5,733,055$ & $6,278,824$ & $6,859,237$ & $7,333,178$ & $7,925,123$ & $8,518,138$ & $9,020,232$ & $10,201,459$ \\
\hline Depreciación fabril & A & 389,392 & 389,392 & 389,392 & 389,392 & 433,041 & 43,649 & 43,649 & 102,207 & 102,207 & 58,557 \\
\hline Utilidad bruta & $\underline{1}$ & $-569,711$ & 576,152 & 877,718 & $1,142,699$ & $1,329,387$ & $2,055,876$ & $2,274,450$ & $2,433,858$ & $2,742,571$ & $4,550,891$ \\
\hline Gastos & & 592,708 & 586,212 & 590,066 & 593,920 & 597,774 & 601,630 & 605,482 & 609,338 & 613,192 & 617,046 \\
\hline Depreciación no fabril & & 13,001 & 13,001 & 13,001 & 0 & 0 & 0 & 0 & 0 & 0 & 0 \\
\hline Amortización & & 12,347 & 12,347 & 12,347 & 12,347 & 0 & 0 & 0 & 0 & 0 & 0 \\
\hline $\begin{array}{l}\text { Utilidad antes de } \\
\text { impuestos }\end{array}$ & 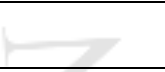 & $-1,187,767$ & $-35,408$ & 262,304 & 536,432 & 731,613 & $1,454,246$ & $1,668,968$ & $1,824,520$ & $2,129,379$ & $3,933,845$ \\
\hline Impuestos & & 0 & 0 & 0 & $-118,843$ & 204,852 & 407,189 & 467,311 & 510,866 & 596,226 & $1,101,477$ \\
\hline $\begin{array}{l}\text { Utilidad después de } \\
\text { impuestos }\end{array}$ & & $-1,187,767$ & $-35,408$ & 262,304 & 655,275 & 526,761 & $1,047,057$ & $1,201,657$ & $1,313,654$ & $1,533,153$ & $2,832,369$ \\
\hline Depreciación fabril & & 389,392 & 389,392 & 389,392 & 389,392 & 433,041 & 43,649 & 43,649 & 102,207 & 102,207 & 58,557 \\
\hline Depreciación no fabril & & 13,001 & 13,001 & 13,001 & 0 & 0 & 0 & 0 & 0 & 0 & 0 \\
\hline Amortización & 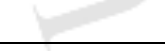 & 12,347 & 12,347 & 12,347 & 12,347 & 0 & 0 & 0 & 0 & 0 & 0 \\
\hline Valor en libros & & & & & & & & & & & 117,114 \\
\hline $\begin{array}{l}\text { Flujo de fondos } \\
\text { operativos }\end{array}$ & & $-773,028$ & 379,331 & 677,044 & $1,057,013$ & 959,802 & $1,090,706$ & $1,245,306$ & $1,415,861$ & $1,635,360$ & $3,008,040$ \\
\hline Inversiones & $-2,465,625$ & & & & -2 & & & $\sqrt{x}+2+2$ & & & \\
\hline $\begin{array}{l}\text { Recuperación capital } \\
\text { de trabajo }\end{array}$ & & & & & & & & & & & 429,405 \\
\hline $\begin{array}{l}\text { Flujo de Caja } \\
\text { Economico }\end{array}$ & $-2,465,625$ & $-773,028$ & 379,331 & 677,044 & $1,057,013$ & 959,802 & $1,090,706$ & $1,245,306$ & $1,415,861$ & $1,635,360$ & $3,437,446$ \\
\hline
\end{tabular}


Elaboración propia

VAN: $2,368,898$ soles

TIR: $22 \%$

$\mathrm{B} / \mathrm{C}==4,834,522 / 2,465,625=1.96$ soles

Tabla 8.11

Periodo de recupero del flujo económico de acuerdo al análisis de sensibilidad

\begin{tabular}{|l|c|c|c|c|c|c|c|c|}
\hline & 2015 & 2016 & 2017 & 2018 & 2019 & 2020 & 2021 & 2022 \\
\hline Valor presente & $-2,465,625$ & $-692,926$ & 304,791 & 487,631 & 682,412 & 555,442 & 565,792 & 579,051 \\
\hline Acumulado & $-2,465,625$ & $3,158,551$ & $2,853,760$ & $2,366,129$ & $1,683,718$ & $1,128,275$ & $-562,483$ & 16,568 \\
\hline
\end{tabular}

Elaboración propia.

El periodo de recupero es de 6 años 11 meses y 19 días

\section{Comparación entre el VAN del proyecto y el VAN del análisis de sensibilidad del caso 1}

VAN proyecto: $5,818,141$ soles

VAN análisis de sensibilidad: 2, 368,898 oles

Variación del VAN: $(5,818,141$-2, 368,898) / / 5, 818,141

Variación del VAN: $59.28 \%$ 


\section{CAPÍTULO IX: EVALUACIÓN SOCIAL DEL PROYECTO}

\subsection{Identificación de las zonas y comunidades de influencia del proyecto}

Para la identificación del área de influencia del proyecto, se tomará en consideración los impactos ambientales y sociales que afectarán potencialmente al territorio involucrado a lo largo del desarrollo del proceso.

\subsection{1 Área de influencia directa.}

Huachipa en Lurigancho lugar donde se llevará a cabo el proyecto es una zona donde la lotización se viene desarrollándose de forma exitosa desde el 2012. Este parque industrial se encuentra ubicado cerca al puente Huachipa y abarca una extensión de casi 500 hectáreas divididas en tres etapas de desarrollo. Asimismo, Huachipa cuenta con las previsiones de zonificación y habilitación, así como obras de infraestructura de luz y agua. Cabe recalcar, que también se considerarían como área de influencia directa del proyecto a las zonas donde se extrae la materia prima como Lambayeque (algodón nativo de color) y Chincha (Algodón Tangüis). Asimismo, se debe tener en cuenta, el trayecto de los camiones que traen la materia prima; ya que estos producen emisiones como $\mathrm{CO}_{2}, \mathrm{CO}$ y $\mathrm{NO}_{x}$

\subsection{2 Área de influencia indirecta}

Se considera como área de influencia indirecta del proyecto a la ciudad de Lima y su población; ya que, las emisiones y residuos sólidos que se podría generar en la planta contaminarían a la ciudad; ya que, dentro de esta se encuentra Huachipa. 


\subsection{Impacto en la zona de influencia del proyecto}

En el capítulo 5 se identificó, evaluó y se propuso medidas preventivas y correctivas potenciales a los impactos ambientales que se producirían por la operación de la planta. Por lo tanto, los principales impactos ambientales son los siguientes:

- Emisión de fibra volátil la cual afectaría a la salud de los trabajadores y contaminaría el aire.

- Ruido y vibración que afectarían a la salud de los trabajadores

- Residuos sólidos como fibra de algodón y merma los cuales contaminarían el suelo.

- Residuos líquidos como aceites que se utilizan en el mantenimiento de las maquinarias, con potencial contaminación en el suelo y agua.

- Se controlará que los efluentes de la cámara de humidificación estén dentro de los límites máximos permisibles. Las variables que se controlarán son PH, oxígeno disuelto, aceites y grasas; y metales.

Asimismo tanto en el transporte de materia prima como producto terminado los camiones que los transportarán emitirán $\mathrm{CO}, \mathrm{CO}_{2}$ y $\mathrm{NOx}$; por ello, las empresas que realicen este transporte deberán tener sus vehículos en buenas condiciones usando como combustible el gas natural para minimizar las emisiones

\subsection{Impacto social del proyecto}

Este proyecto busca contribuir al desarrollo de las comunidades que se dedican a la siembra del algodón nativo de color como en la región Lambayeque, Piura y San Martin; ya que, estas comunidades serán los proveedores de la materia prima que se adquirirá; por lo tanto, se verán beneficiados económicamente; ya que, tanto las cantidades como el precio de algodón nativo a los cuales se les comprará activaran su economía.

Asimismo, se apoyará a los campesinos a aumentar la productividad de su siembra mediante programas de capacitación y apoyo a la investigación sobre el cultivo de este algodón. 
La industrialización del algodón nativo de color es una alternativa adecuada para minimizar la contaminación ambiental promoviendo el desarrollo sostenible; ya que, en el proceso de teñido se utilizan varias sustancias químicas y colorantes que contaminan el medio ambiente. Asimismo, la elaboración de prendas con hilo de algodón nativo de color propicia a que las personas alérgicas o de piel sensible a los tintes químicos puedan utilizar estas prendas de vestir.. 


\section{CONCLUSIONES}

- La instalación de una planta de hilos de calidad a partir del algodón nativo de color es factible, debido a que existe un mercado interesado en hilos cuyo color es natural y además, mediante innovaciones se pudo procesar este hilo; por lo tanto, es tecnológicamente viable. Asimismo, es económicamente viable; ya que, al ser de color natural le da un valor agregado al hilo. Por último es socialmente viable ya que contribuirá con el desarrollo de las comunidades que se dedican a la siembra de este tipo de algodón; y es ambientalmente viable; ya que, las prendas de vestir que se elaboren con este hilo no requerirán ser teñidas lo cual evitaría la contaminación ambiental producida por el proceso de teñido

- Mediante el estudio de mercado se pudo evidenciar que hay varias empresas textiles interesadas en comprar el hilo de algodón nativo; ya que este posee la bondad de tener colores naturales lo cual favorece a disminuir la contaminación ambiental del proceso de teñido así como el hecho de ser un producto ecológico genera mucho interés de las empresas.

- Se determinó que las principales fábricas textiles dedicadas a la elaboración de telas y prendas de vestir de exportación están interesadas en comprar hilo de algodón nativo de color. Estas fábricas podrían incrementar la compra de hilo de algodón nativo de acuerdo a los requerimientos de sus clientes.

- Se identificó un alto poder de negociación de los proveedores; ya que, el precio del kilo de algodón nativo de color es elevado con respecto a los precios de otros algodón; ya que, su producción es baja; sin embargo si es que se presenta una alta demanda de este algodón los campesinos se verán motivados a producir en mayor cantidad y se podría negociar un mejor precio. 
- Se identificó a Lima como lugar de localización de la planta; ya que, está cerca de las industrias textiles que se encuentran en dicha ciudad. Asimismo, Lima se encuentra cerca de las plantaciones de algodón Tangüis que están en Chincha los cuales representan el 33\% de la materia prima.

- Se identificó a Huachipa situado en el distrito de Lurigancho como ubicación de la planta; ya que, el costo promedio de alquiler por metro cuadrado es más económico; asimismo, los potenciales clientes (fábricas textiles) se encuentran ubicados en el cono este de Lima.

- Como se pudo evaluar en el capítulo 4, la capacidad máxima está limitada por el mercado, el cual requiere de la producción de 817,70 toneladas de hilo por año, ya que tanto la tecnología como los recursos productivos no restringen la capacidad a un menor nivel. Por otro lado, la cantidad mínima necesaria de producción para no incurrir en pérdidas será de 89.9 toneladas de hilo por año.

- Elaborar hilo de algodón nativo de color de alta calidad es indispensable para introducir el producto al merco; por ello, se deben hacer análisis de las distintas variables del hilo como torsión, titulo, regularidad e elongación con el fin de asegurar la calidad del mismo.

- En el capítulo 5 se identificó todas las tecnologías existentes para poder procesar hilo y se seleccionó la tecnología idónea para procesar hilo a partir de algodón nativo de color y a su vez se propuso mezclarlo con algodón Tangüis para facilitar su proceso.

- Se demostró que mediante un acondicionamiento de la máquina para hilar se puede obtener un hilo de calidad a partir del algodón nativo de color el cual posee características difíciles de tratar como fibra corta y baja resistencia a la torsión; ya que, al proporcionarle a esta máquina un sistema de transmisión de velocidades idóneo se puede trabajar con el algodón nativo.

- La máquina de hilar en la que se adaptó un sistema de velocidades adecuado para obtener hilo con título 10 a $40 \mathrm{Ne}$ a partir de una mecha de $0.80 \mathrm{Ne}$ ganó el Concurso Nacional de Invenciones en el área Utilitarios en el año 2015; por lo tanto, se pudo demostrar que se puede obtener hilo de calidad a partir del algodón nativo de color. Mediante un diseño adecuado de las distintas partes de la máquina en cuanto al tamaño, diseño y forma de las 
distintas partes de esta se puede obtener un sistema adecuado para poder hilar el algodón nativo.

- Se concluyó que al usar un algodón cuyo color es natural se reduce significantemente la contaminación ambiental; ya que, el principal contaminante en la industria textil se genera en proceso del teñido.

- Se concluyó que mediante el programa de mantenimiento preventivo que se implementó en el capítulo 5, se podía tener una alta disponibilidad de la maquinaria de hilatura.

- Debido a la elevada velocidad con las que trabajan las maquinarias de hilatura se debe tomar todas las medidas preventivas con el fin de disminuir los accidentes laborales, implementando guardas en las maquinarias, suministrando equipos de protección personal a los trabajadores y mediante la matriz IPER se pueden evitar los accidentes.

- Es conveniente tener el área de producción cerca a los almacenes de materia prima y producto terminado con el objetivo de tener un buen flujo de materiales así como tanto el área administrativa como el comedor deben estar alejados de esta área; ya que debido a que en el área de producción se trabaja con motores de alta potencia se genera mucho calor y por el mismo proceso de hilatura se genera mucha merma y pelusa.

- Para poder elaborar un hilo de calidad se debe mantener el ambiente a una temperatura de $32^{\circ} \mathrm{C}$; ya que, si se presenta una temperatura mayor; el algodón se deshidrataría y se volvería más débil lo cual causaría rompimiento en cambio si se presenta una menor temperatura la mecha no se puede estirar y se deforma.

- El hilo luego de ser procesado debe pasar por una cámara de humidificación con el objetivo de aumentar el nivel de humedad al $8 \%$ de tal forma que se aumente la resistencia de este.

- El principal costo que se incurre en el proyecto es en la adquisición de maquinaria de hilar que a pesar de ser de segunda en buenas condiciones representa un alto costo.

- En cuanto a los costos variables la materia prima, mano de obra y energía eléctrica en ese orden son los más representativos. 
- El valor de venta del hilo de algodón nativo de color (10 dólares $/ \mathrm{kg}$ ) es mayor que los algodones convencionales debido a su valor ambiental e histórico; por ello, los ingresos por este producto son elevados.

- Al evaluar el flujo de caja económico y financiero con sus respectivos indicadores se llega a la conclusión de que conviene la evaluación financiera debido a que el VAN, TIR son más rentables que la evaluación económica; por lo tanto, conviene pedir un préstamo al banco. Asimismo el periodo de recupero financiero es menor que el periodo de recupero económico lo cual es un indicador de que conviene optar por el flujo financiero

- La materia prima es el costo más significativo; ya que, el valor de venta del algodón nativo es mucho más elevado que los demás algodones; por ello, en el análisis de sensibilidad se vio que esta variable es la que más afecta al VAN del proyecto.

- El proyecto contribuirá al desarrollo de las comunidades que se dedican a la siembra de este algodón; ya que, el producir algodón nativo es más rentable que producir otro producto; ya que, el precio de este es mayor. 


\section{RECOMENDACIONES}

- Para el análisis de la demanda para el proyecto es hacer un buen estudio de mercado para poder determinar la demanda para el proyecto; es decir, la cantidad de hilo que están dispuestas a comprar las fábricas de telas.

- Se debe identificar los proveedores de materias primas, principalmente algodón nativo de color. Asimismo identificar las regiones donde se produce y su rendimiento por hectárea.

- El uso de algodón nativo promueve el desarrollo sostenible ya que, al usar este algodón de cuy color es natural se evita el proceso de teñido que genera contaminación en el agua.

- Se debe identificar la tecnología idónea para poder producir un hilo de alta calidad.

- Se debe tomar todas las medidas preventivas para no contaminar el medio ambiente.

- Se debe establecer procesos óptimos con el objetivo de aumentar la productividad.

- Se debe realizar un buen estudio de disposición de planta con el objetivo de optimizar el flujo de material en proceso y tener un buen orden en la planta para poder procesar idóneamente el producto final.

- Se debe tener un alto nivel de estándares en seguridad industrial; ya que, las máquinas de hilatura son peligrosas debido a sus altas velocidades. Por ello, se debe tener un plan de capacitación y sensibilización a los trabajadores para el uso adecuado de estas máquinas así como suministrarles equipos de capacitación personal

- Como se demostró en el capítulo 7, mediante un leasing para la adquisición de las maquinarias se obtiene una mejor rentabilidad del proyecto

- Mediante la evaluación económica y financiera se debe evaluar los indicadores financieros VAN, TIR y beneficio-costo para determinar si es viable el proyecto antes de invertir. 


\section{REFERENCIAS}

- Cortijo, D. y Cancio, R. (2012).'Innovación tecnológica para recuperar el algodón natío de color”. Revista de ingeniería Industrial año XIV, N³0. Lima: Universidad de Lima, Fondo Editorial

- Vásquez P. y Pérez S P. (2011). Revalorando Algodón Nativo: fibra de calidad para la industria un cultivo ancestral. Perú: Caritas

- Díaz, G. B., Jarufe, Z. B., Noriega, A. M. T., (2007). Disposición de planta. Lima: Universidad de Lima, Fondo editorial.

- Fincyt. (2014). “Con apoyo de Fincyt realizarán montaje de planta desmotadora de algodón nativo de color". Recuperado de:

http://www.fincyt.gob.pe/site/noticias/728-con-apoyo-del-fincyt-realizaran-montaje-deplanta-desmotadora-del-algodon-nativo

- Diario Perú 21. (2015). Expectativas económicas revelen menos crecimiento y más inflación, según encuesta del BCR. Recuperado de:

http://peru21.pe/economia/expectativas-economicas-revelan-menos-crecimiento-y-masinflacion-segun-encuesta-bcr-2226981

- El Economista. (2015). Las cuentas del 2016 se apoyan en 1 euro a 1.10 dólares y el Brent en 68.8 dólares. Recuperado de:

http://www.eleconomista.es/economia/noticias/6918133/08/15/El-Gobierno-elabora-lascuentas-de-2016-sobre-la-prevision-del-euro-en-110-dolares-y-el-Brent-en-688dolares.html

- Sunat. (2016). Tratamiento arancelario por subpartida nacional (Recuperado de: http://www.aduanet.gob.pe/itarancel/arancelS01Alias

- Bankrate. (2016). Treasury securities. Recuperado de: http:/www.bankrate.com/rates/interest-rates/treasury.aspx 
- BCRP. (2016). Tasas de interés internacionales. Recuperado de: https://estadisticas.bcrp.gob.pe/estadisticas/series/diarias/tasas-de-interes-internacionales

- SBS. (2016). Tasa de interés promedio del sistema bancario. Recuperado de: $<$ http://www.sbs.gob.pe/app/pp/EstadisticasSAEEPortal/Paginas/TIActivaTipoCreditoE mpresa.aspx?tip $=\mathrm{B}>$

- Hialpesa. (2015). Rango de título para prendas de vestir. Recuperado de: http://www.hialpesa.com/

- Hialpesa. (2015). Precio histórico de algodón Tangüis y Pima. Recuperado de: http://www.hialpesa.com/

- Hialpesa. (2015). Costo de equipos de medición de calidad para el proceso de hilatura. Recuperado de: http://www.hialpesa.com/

- Marzolli. (2015). Cotización de maquinarias para el proceso de hilatura. Recuperado de: http://www.marzoli.it/it/camozzigroup/textile-machinery/marzoli/home

- Senati, (2016). Análisis de calidad de hilo de algodón nativo de color. Recuperado de: http://www.senati.edu.pe/web/

- Senati, (2016). Análisis de calidad de algodón nativo de color. Recuperado de: http://www.senati.edu.pe/web/

- Ministerio de la Producción. (2015). Demanda de algodón nativo de color. Recuperado de: http://www.produce.gob.pe/

- Ministerio de la Producción. (2015). Concentración geográfica de las empresas del subsector de fabricación hilados y tejidos. Recuperado de: http://www.produce.gob.pe/

- Ministerio de Agricultura y Riego. (2015). Producción de algodón Tangüis por región en toneladas. Recuperado de: http://www.minagri.gob.pe

- Ministerio de Transportes y Comunicaciones. (2015). Distancia entre regiones. Recuperado de: http://www.mtc.gob.pe/ 
- Ministerio de Transportes y Comunicaciones. (2012). Red vial por sistemas de carreteras. Recuperado de: http://www.mtc.gob.pe/

- Trans Molina. (2015). Costo del flete de producto terminado desde cada alternativa de localización hacia Lima. Recuperado de: http://trans-molina.com/

- Veritrade, (2015). Importación y exportación de algodón. Recuperado de: http://www.veritrade.info/index.aspx

- Ipsos Apoyo. (2015). Perfil del adulto joven (21 a 35 años). Recuperado de: http://www.ipsos.pe/

- Mercadeo y Opinión. (2015). Estudio de demanda de hilo de algodón nativo en la Gran Lima. Recuperado de: http://www.mercadeoyopinion.com/

- Frank \& Ricky. (2016). Características del algodón Tangüis. Recuperado de: http://www.frankyandricky.com/

- Gobierno Regional de Lambayeque. (2015). Área de producción, comercialización y artesanía del algodón nativo de color. Recuperado de: http://www.regionlambayeque.gob.pe

- Osinergmin, (2015). Tarifas de electricidad. Recuperado de: http://www.osinergmin.gob.pe/

- Sedapal. (2015). Tarifas de agua. Recuperado de: http://www.sedapal.com.pe/

- Epsel, (2015). Tarifas de agua. Recuperado de: http://www.epsel.com.pe/Presentacion/Default.aspx

- Emapa. (2015). Tarifas de agua. Recuperado de: http://www.emapasanmartin.com/

- Colliers. (2012). Reporte de investigación y pronostico. Recuperado de: http://www.colliers.com/es-pe/peru

- Atlas Copco. (2016). Cotización de compresor de aire. Recuperado de: $\mathrm{http}: / / \mathrm{www} \cdot a t$ lascopco.com.pe/pees/

- Ecofil. (2016). Cotización de ablandador de agua. Recuperado de: http://www.ecofil.com.ve/ 
- OLX. (2016). Transformador trifásico de media a baja tensión. Recuperado de: https://www.olx.com.pe/

- SUNAT. (2016). Medidas impositivas para maquinarias de hilar. Recuperado de: http://www.sunat.gob.pe/

- DHL. (2016). Cotización de importación desde Italia de maquinaria de hilar. Recuperado de: http://www.dhl.com.pe/es.html

- Sercomatex. (2016). Costo de bienes complementarios del proceso de hilatura. Recuperado de: http://www.sercomatex.com/es/

- Sercomatex. (2016). Benchmarking de costos en fábricas hilanderas. Recuperado de: http://www.sercomatex.com/es/

- Saga Falabella. (2016). Costo de equipos informáticos. Recuperado de: http://www.falabella.com.pe/falabella-pe/

- Sodimac (2016). Costo de inmobiliario de oficina. Recuperado de: http://www.sodimac.com.pe/

- Rímac Seguros. (2014). Costo de aseguramiento de fábrica hilandera. Recuperado de: http://www.rimac.com.pe/

- Municipalidad de Lurigancho (2016). Licencia municipal de funcionamiento. Recuperado de: http://www.munichosica.gob.pe/ 


\section{BIBLIOGRAFÍA}

- Servicio Nacional de Adiestramiento en Trabajo Industrial (2007). Manual de aprendizaje para mecánico textil en hilandería "Materiales textiles". Lima: SENATI, Fondo Editorial.

- Servicio Nacional de Adiestramiento en Trabajo Industrial (2006). Manual de aprendizaje para mecánico textil en hilandería "Regulaciones de la continua de anillos de FC y FL tercera parte".Lima: SENATI, Fondo Editorial.

- Hollen, N; Saddler, J. y Langford, A (1992). Introducción a los textiles, Méjico: Grupo Noriega Editores.

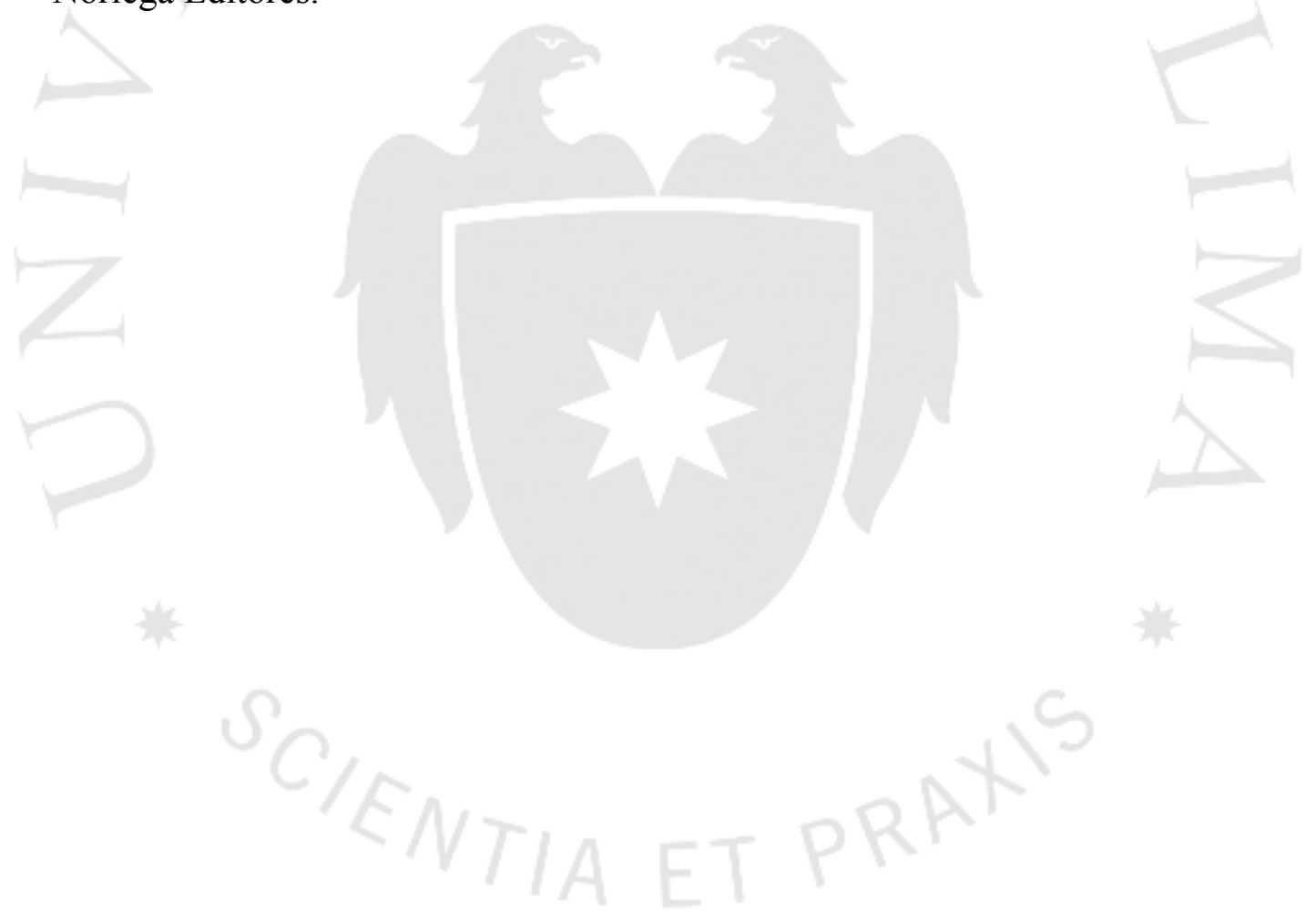




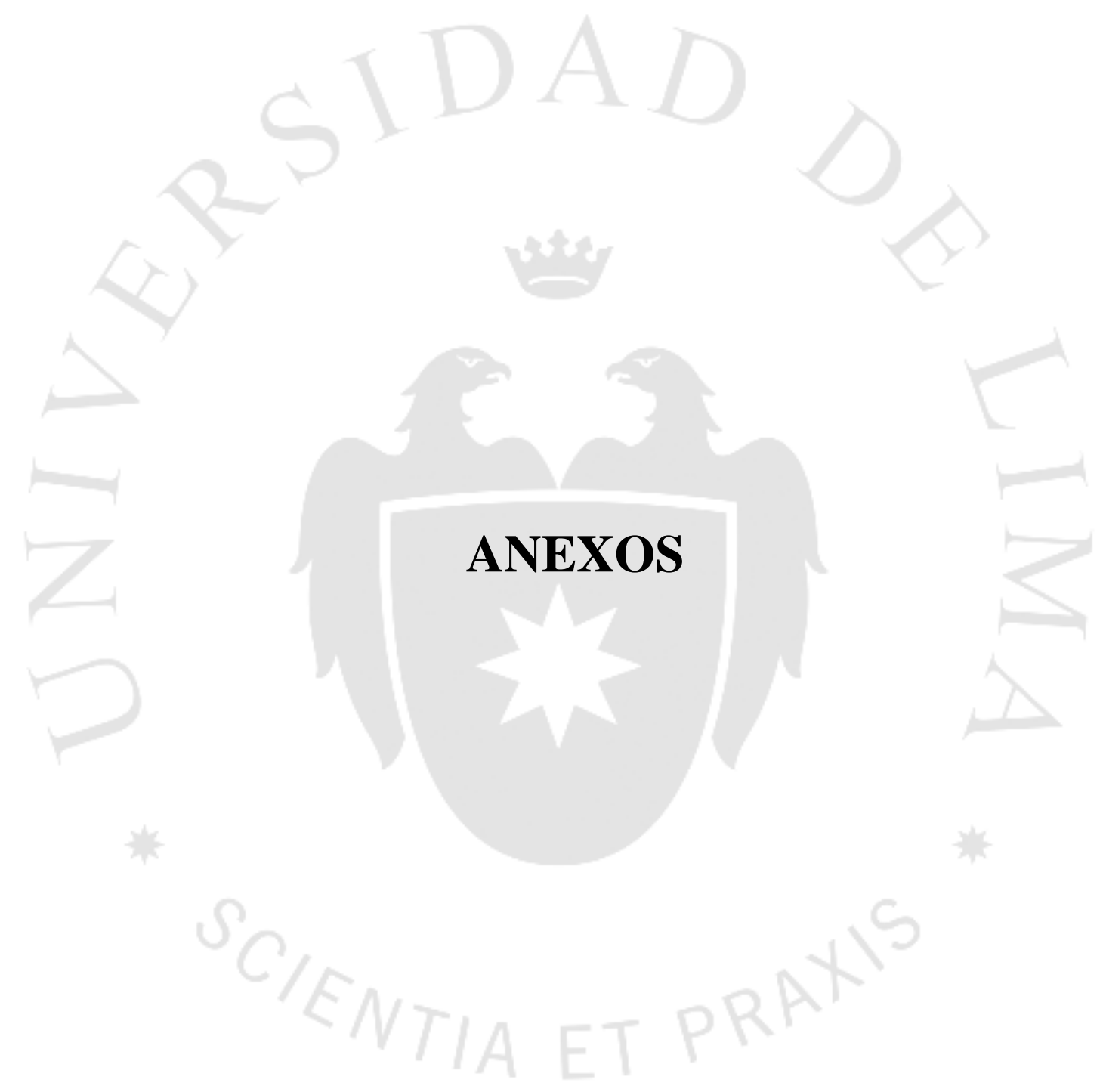




\section{ANEXO 1: Estudio de mercado de la demanda de hilo de algodón nativo de color}

MERCADEO \& OPINIÓN S.A.

Las Begonias 656 Of.08, San Isidro Telef. 421-7694

Buenos días/tardes, soy representante de la Cía. MERCADEO \& OPINIÓN S.A. empresa especializada en estudios de mercado, y estamos entrevistando a principales expresas textiles de Lima sobre el uso de hilados de algodón para la confección de prendas de calidad premium. La información que nos proporcione será tratada con absoluta confidencialidad. Le ruego me conceda unos minutos de su tiempo para hacerle unas preguntas, GRACIAS.

(ENT: MOSTRAR CARTA DE PRESENTACION. PEDIR DEVOLUCION). PEDIR POR GERENTE DE PRODUCCION/ DE OPERACIONES/DE CALIDAD Y/O PERSONA DE LA EMPRESA QUE DECIDE LA COMPRA/USO DE HILADOS.

1. Qué tipos de hilo de algodón acostumbran comprar para utilizar en la confección de sus prendas de vestir de calidad premium y/o para exportación? (SEGÚN RESPUESTA : Por qué?)

$\begin{array}{lll}\text { - } & \text { Pima (1) } & 1 \\ \text { - } & \text { Tanguis } & 2 \\ \text { - } & \text { Nativo teñido } & 3 \\ \text { - } & \text { Nativo de color natural } & 4 \\ \text { - } & \text { Otros_ } & 5\end{array}$

2. (SEGÚN TIPOS QUE USAN/COMPRAN EN P. 1)Quienes son sus actuales proveedores de este tipo de hilado?

3. (SEGÚN TIPO DE HILADO QUE COMPRAN) Con qué frecuencia adquieren este tipo de hilo?

4. (SEGÚN FRECUENCIA DE COMPRA) Y dígame, en promedio, cuántos kilos compra al año?

5. (SEGÚN TIPOS DE HILO QUE USAN/COMPRAN) Y en promedio, cuánto paga por un kilo de este tipo de hilo?

6. (SEGÚN TIPOS DE HILO QUE USAN/COMPRAN) En qué presentación, en cuanto a número de conos y $\mathrm{kg}$ por cono le ofrecen el producto?

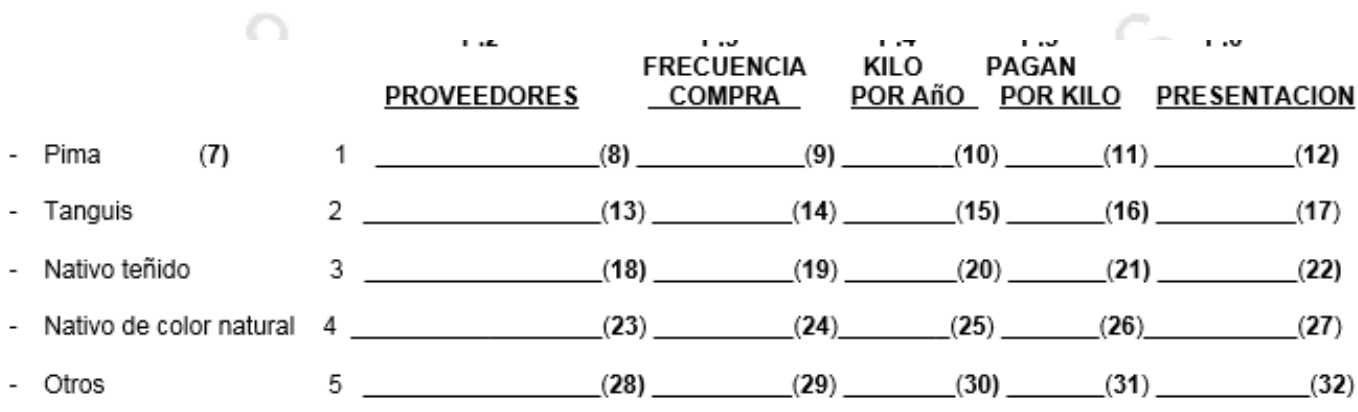


7. Compraría Ud. hilo elaborado con algodón nativo de color para usar en sus confecciones de calidad premium y/o de exportación? (SEGÚN RESPUESTA: Por qué?

Si (33) 1

No 2

8. (SI RESPONDIO SI EN P.8) En una escala de 10 puntos donde 1 es "Decididamente no compraría" y 10 es "Decididamente compraría", cuál número de la escala expresa su intención futura de compra de hilo elaborado con algodón nativo de color?

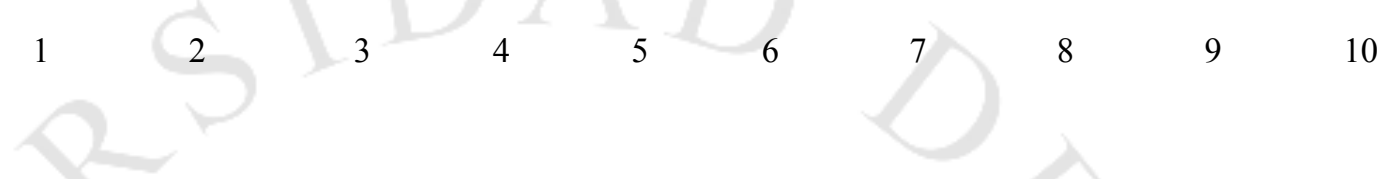

9. Ahora, le voy a mostrar el concepto de un hilo elaborado con algodón nativo de color natural, quisiera que por favor lo lea detenidamente. Qué opinión le merece?

10. Que fortalezas/aspectos positivos le encuentra frente a otros hilados de algodón?

11. Y, cuáles debilidades le encuentra?

12. Si vinieran a ofrecerle este producto para la confección de sus prendas premium y/o de exportación, cuál sería su intención futura de compra? (SEGÜN RESPUESTA: Por qué?)(MOSTRAR TARJETA I)

- Decididamente compraría

- Probablemente compraría

- No sabe si compraría o no

- Probablemente no compraría

- Decididamente no compraría

(40) 1

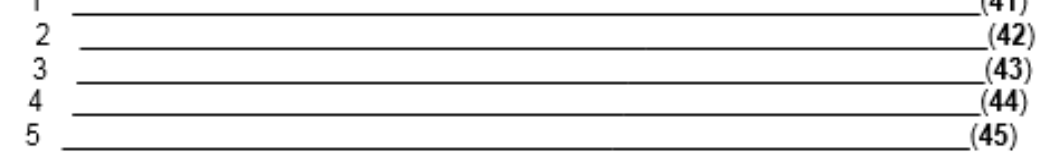

13. Con qué frecuencia compraría este hilo elaborado con algodón nativo de color natural?

14. Y dígame, en promedio, cuántos kilos compraría al año? 
15. Y en promedio, cuánto pagaría por un kilo de este hilo de algodón nativo de color natural?

\begin{tabular}{lcc}
$\begin{array}{c}\text { P.13 } \\
\begin{array}{l}\text { FRECUENCIA } \\
\text { COMPRA }\end{array}\end{array}$ & $\begin{array}{c}\text { P.14 } \\
\text { KILOS } \\
\text { POR Año }\end{array}$ & $\begin{array}{c}\text { P.15 } \\
\text { PAGAN } \\
\end{array}$ \\
\hline
\end{tabular}

16. Compraría este hilo elaborado con algodón nativo de color natural si le dijera que su precio estará entre 17 y 19 dólares por kilo?

- $\quad \mathrm{Si} 1(\mathbf{4 9 )}$

- No 2 - Hasta cuánto estaría dispuesto a pagar por un kg. de algodón nativo de color natural?

$\mathrm{U} / \mathrm{S} \$$ (50)

17. Finalmente, que comentarios y sugerencias haría a este nuevo producto?

MUCHAS GRACIAS POR SU AMABLE COLABORACIÓN ;

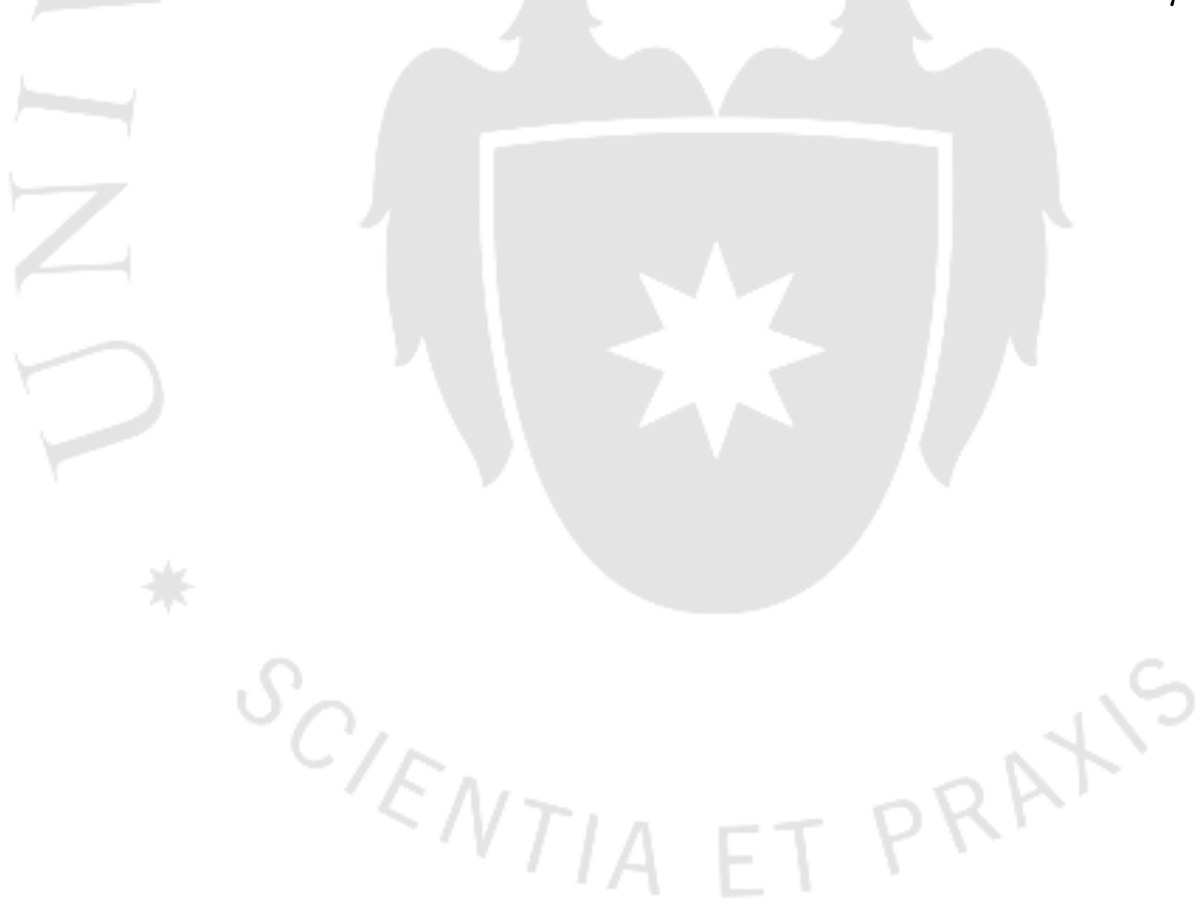




\section{DATOS DE CONTROL}

EMPRESA

TELEFONO

DIRECCIÓN DISTRITO:

PERSONA ENTREVISTADA:

CARGO:

\begin{tabular}{|c|c|c|c|}
\hline ENTREVISTADOR & SUPERVISOR & EDITOR & CODIFICADOR \\
\hline & & & \\
\hline
\end{tabular}

FECHA :

HORA DE INICIO:

HORA DE TERMINO: 


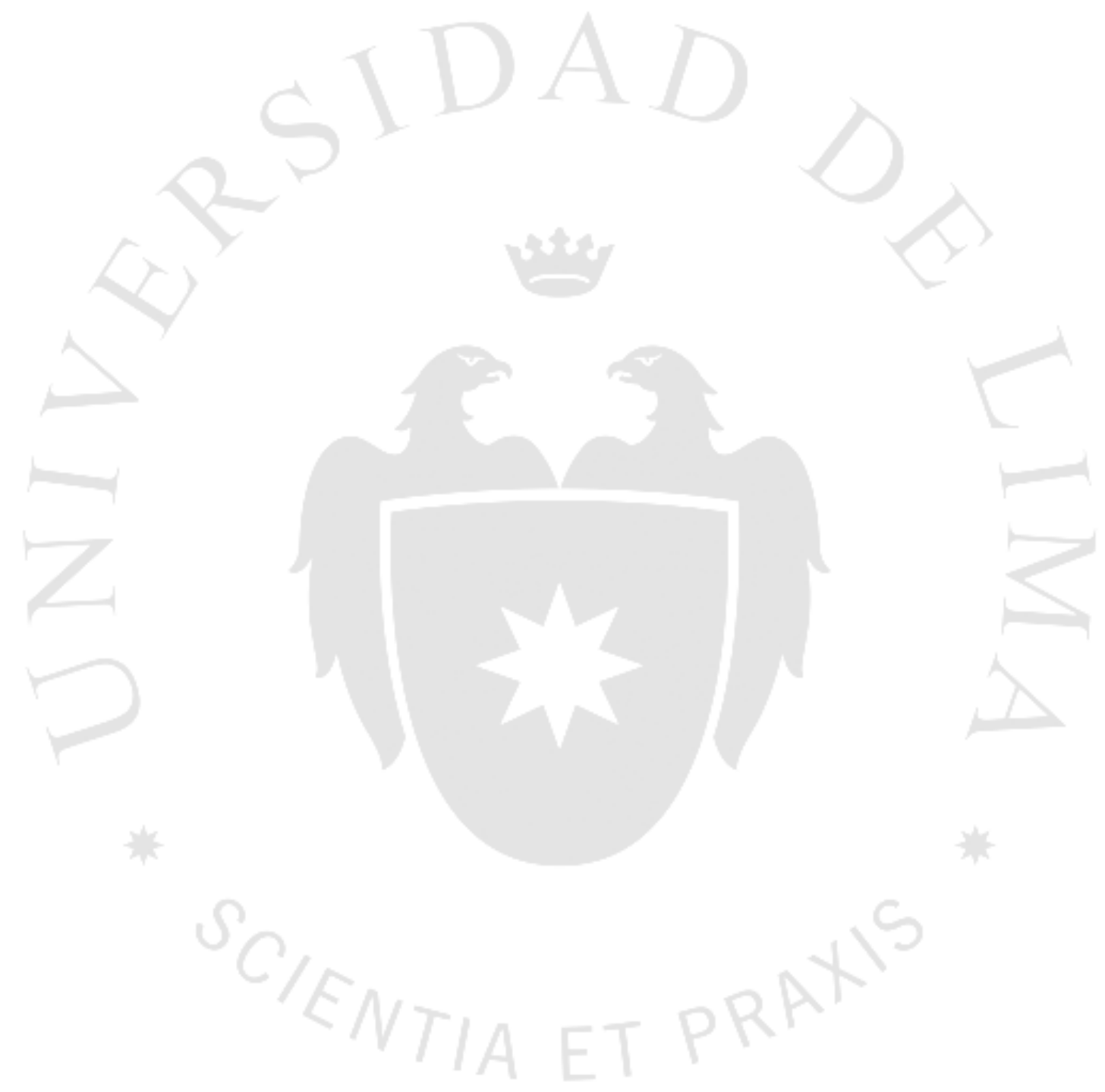

